\author{
Instituto de Física de São Carlos \\ Instituto de Química de São Carlos \\ Escola de Engenharia de São Carlos
}

Rachel Passos de Oliveira Santos

Compósitos baseados em PET reciclado, fibras de sisal e plasticizantes oriundos de fontes renováveis: estudo do processamento e propriedades destes materiais

São Carlos

2012 


\section{Compósitos baseados em PET reciclado, fibras de sisal e plasticizantes oriundos de fontes renováveis: estudo do processamento e propriedades destes materiais}

Rachel Passos de Oliveira Santos

Dissertação apresentada à Escola de Engenharia de São Carlos, da Universidade de São Paulo, como parte dos requisitos para obtenção do Título de Mestre em Ciências, Programa Ciência e Engenharia de Materiais.

Área de Concentração: Desenvolvimento, Caracterização e Aplicação de Materiais.

Orientadora: Profa. Dra. Elisabete Frollini

São Carlos

2012 
Ficha catalográfica preparada pela Seção de Tratamento da Informação do Serviço de Biblioteca - EESC/USP

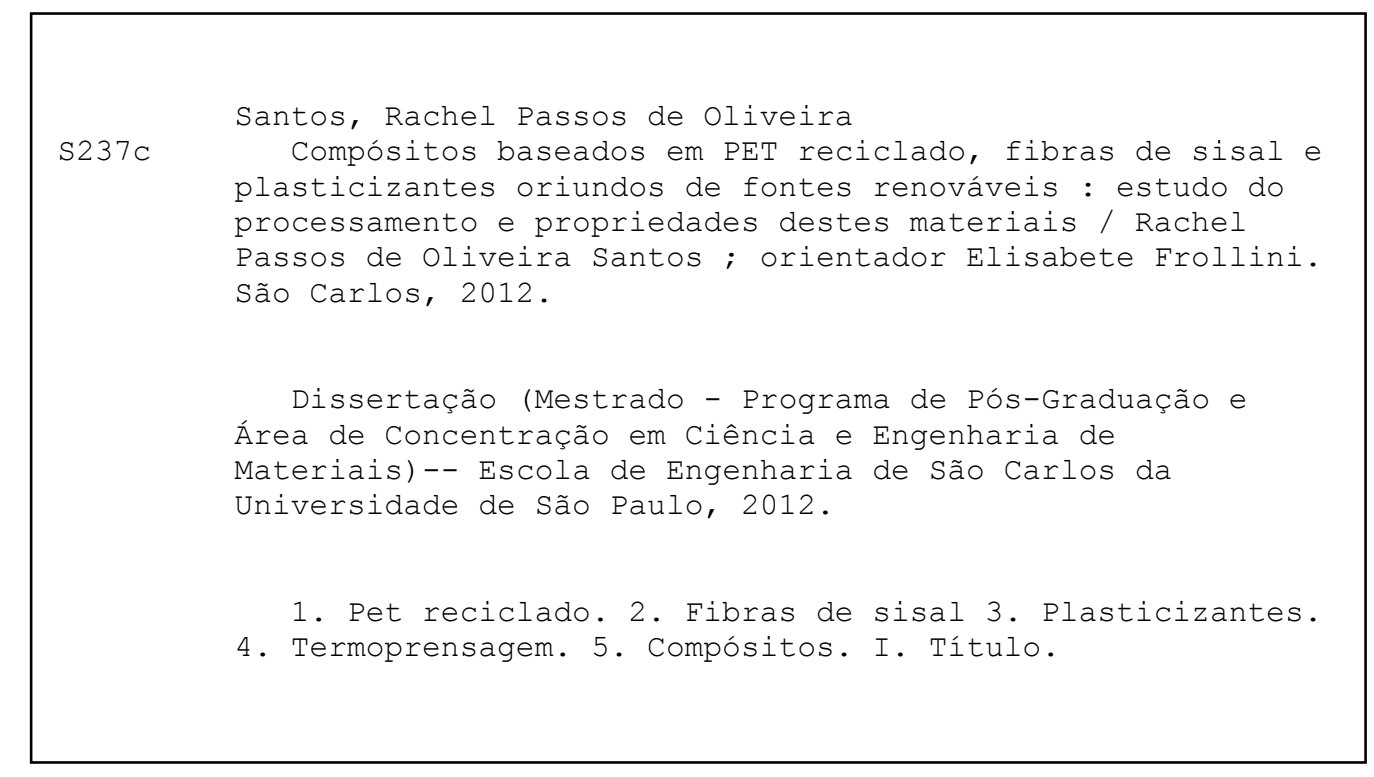



“É muito melhor arriscar coisas grandiosas, alcançar triunfos e glórias, mesmo expondo-se a derrota, do que formar fila com os pobres de espírito que nem gozam muito nem sofrem muito, porque vivem nessa penumbra cinzenta que não conhece vitória nem derrota."

(Theodore Roosevelt) 
Aos meus heróis, meu avô José Manoel (in memoriam) e minha mãe Maria Lisette, pelos exemplos de força e perseverança, incentivo, por sempre acreditarem em mim, e, sobretudo, por todo o amor e apoio incondicionais.

Amo muito vocês. 


\section{Agradecimentos}

Primeiramente a Deus, por simplesmente tudo;

À minha orientadora Professora Dra. Elisabete Frollini, pela orientação, dedicação, paciência, contribuição na minha formação pessoal/profissional e oportunidade de desenvolver este trabalho;

Ao Professor Dr. Adhemar Ruvolo-Filho pelos ensinamentos na graduação e colaboração na realização deste trabalho;

Ao meu pai Hamilton e a minha irmã Carolina, pelo carinho e incentivo em todos os momentos e por estarem sempre comigo, não importando a distância. Amo muito vocês;

Ao Bruno, por ser meu melhor amigo, acompanhar meu trabalho e estar sempre comigo me auxiliando e incentivando. Enfim, por todos os momentos inesquecíveis que passamos juntos desde o início do meu mestrado;

À minha amiga, sempre presente, Nízia Sophia;

Aos professores Dra. Gelse Mazzoni Campos, Dr. Massami Yonashiro e Dr. Edward Ralph Dockal, pelo grande incentivo para o início na pós-graduação;

Ao Fernando, companheiro de laboratório, de linha de pesquisa e amigo, por todo o auxílio e amizade, fundamentais para a realização deste trabalho;

À Daniele, também companheira de linha de pesquisa, por todo auxílio sem o qual não seria possível a realização de grande parte das análises deste trabalho;

Aos demais companheiros de laboratório e amigos: Aline, Bianca, Cristina, Elaine, Érika e Talita. Muito obrigado pela acolhida e amizade ao longo deste trabalho;

Aos novos companheiros de laboratório Joice, Daiana e Mário;

Ao Professor Dr. Sérgio Paulo Campana Filho e aos demais amigos do Grupo de Físico-Química Orgânica: Anderson, Adriana, Daniella, Jorge, Lílian, Sara, Tonimar e Virgínia;

Ao técnico Luiz, pela atenção, paciência e realização das análises térmicas;

À técnica do grupo, Márcia Zambon;

Meu agradecimento especial ao Elvio da Oficina Eletrônica e aos funcionários da Oficina Mecânica: Ednelson, Milton, Alex e Toninho pelos consertos emergenciais do molde, auxílio na desmoldagem dos compósitos e confecção dos corpos de prova; 
Aos demais funcionários do Instituto de Química de São Carlos, presentes na Central de Análises Químicas, Biblioteca Professor Dr. Johannes Rüdiger Lechat, Setor Financeiro, Oficina de vidro, dentre outros setores. Muito obrigado pelos diversos serviços prestados;

Ao Instituto de Química de São Carlos e Programa Interunidades em Ciência e Engenharia de Materiais, pelo apoio institucional e infraestrutura;

Ao Departamento de Química (DQ) e Departamento de Engenharia de Materiais (DEMA) da UFSCar, pela infraestrutura proporcionada para a realização de grande parte deste trabalho;

Ao Daniel e ao Fábio, da UFSCar, pela grande ajuda prestada.

Ao Gruppo M\&G, Scandiflex, Inbra e Petroflex pelo gentil fornecimento dos materiais;

A CAPES, pela bolsa concedida e ao CNPq e FAPESP, pelo suporte financeiro. 


\section{SUMÁRIO}

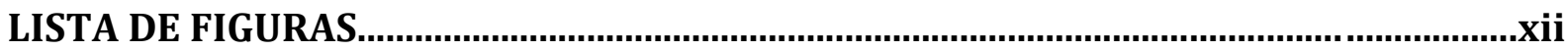

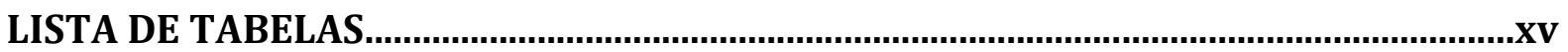

LISTA DE ABREVIATURAS E SIGLAS...........................................................................

RESUMO............................................................................................................Xviii

ABSTRACT

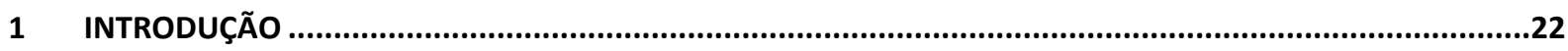

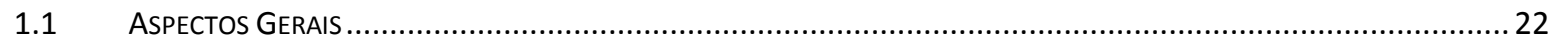

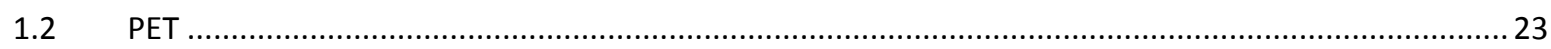

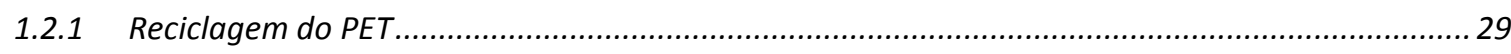

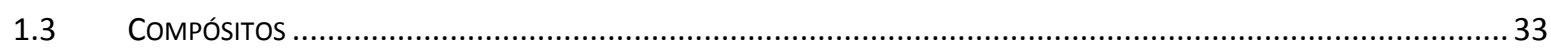

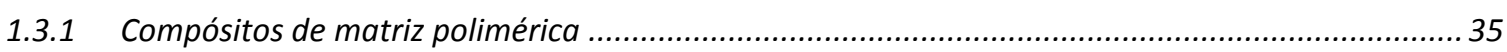

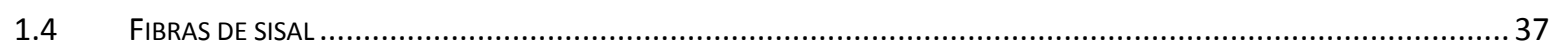

1.4.1 Fibras de sisal como material de reforço em compósitos poliméricos.............................................40

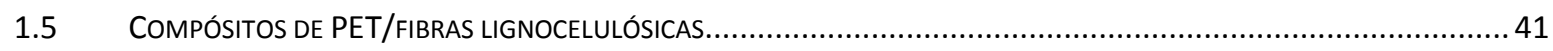

1.6 DIFICULDADES DE PROCESSAMENTO DE COMPÓSITOS DE PET/FIBRAS LIGNOCELULÓSICAS ......................................42

1.7 USO DE PLASTICIZANTES NO PROCESSAMENTO DE MATERIAIS COMPÓSITOS.......................................................44

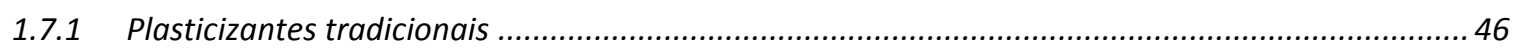

1.7.2 Plasticizantes oriundos de fontes renováveis/naturais e que possam atuar também como

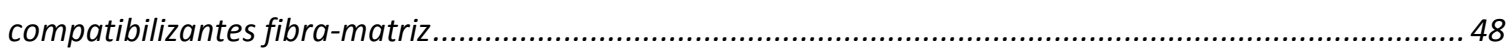

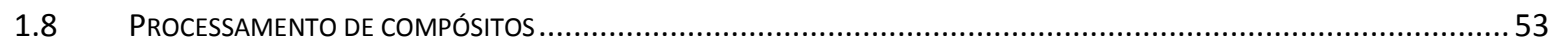

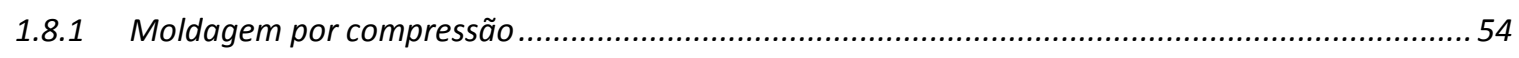

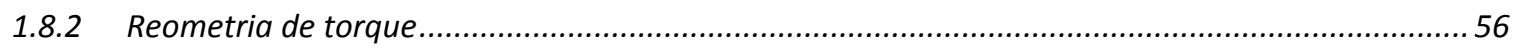

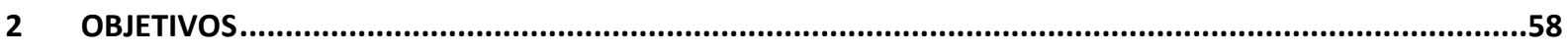

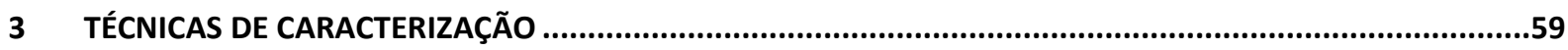

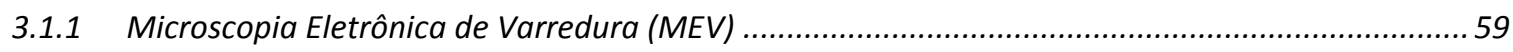

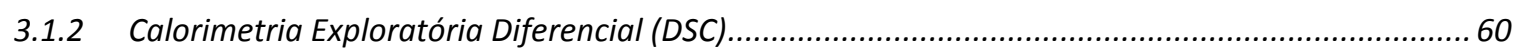

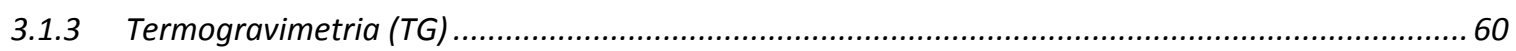

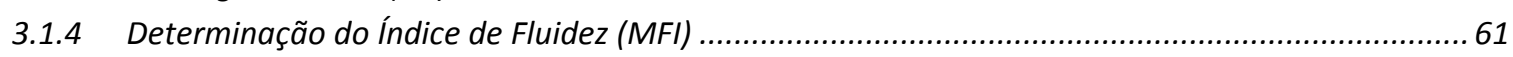

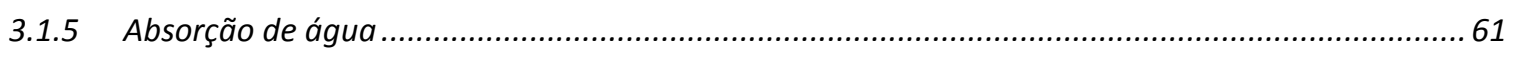

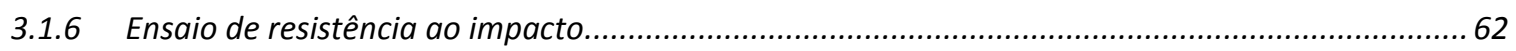

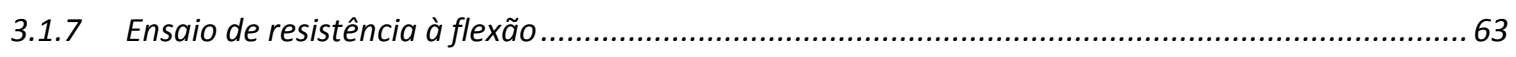

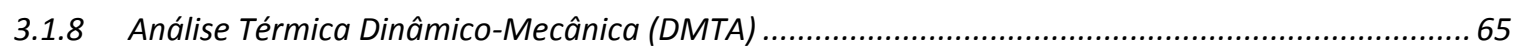

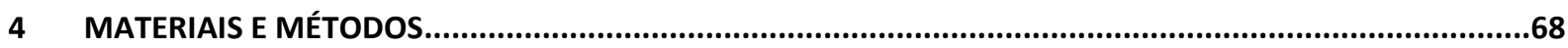

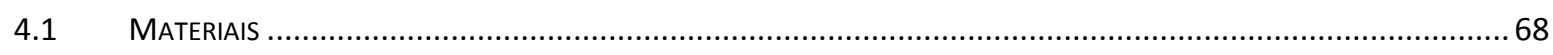

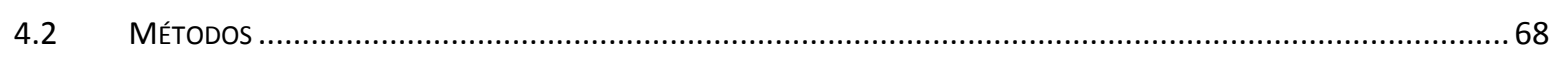

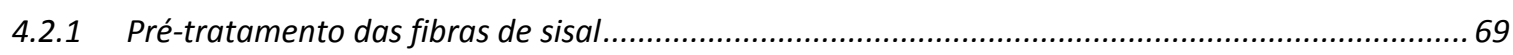

4.2.2 Preparação da placa controle de PET reciclado e dos compósitos de PET reciclado reforçados com

fibras de sisal por moldagem por compressão ............................................................................................69

4.2.2.1 Preparação da placa controle de PET reciclado (CTRPET) ….................................................................69

4.2.2.2 Desenvolvimento do ciclo de temperaturas para moldagem por compressão dos compósitos..............71 
4.2.2.3 Mistura do agente de reforço com os plasticizantes........................................................................77

4.2.2.4 Moldagem por compressão dos compósitos de PET reciclado/fibras de sisal/plasticizante(s) ................77

4.2.3 Preparação da mistura de PET reciclado/20\% glicerol/20\% OM e dos compósitos de matriz de PET reciclado reforçados com fibras de sisal por reometria de torque .............................................................8 81

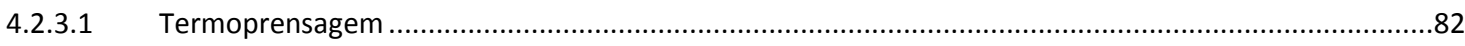

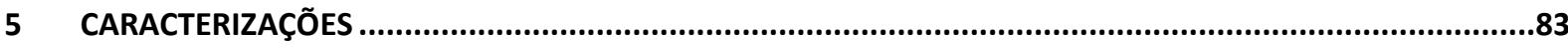

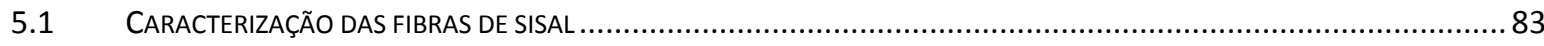

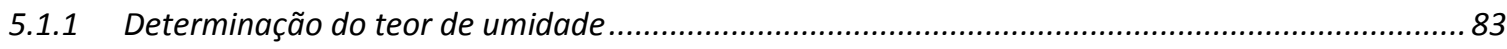

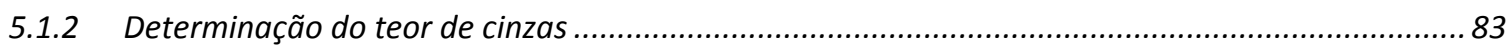

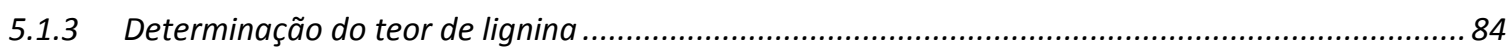

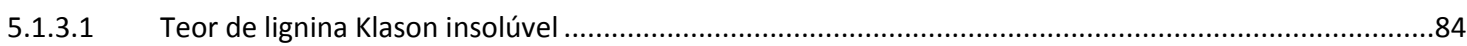

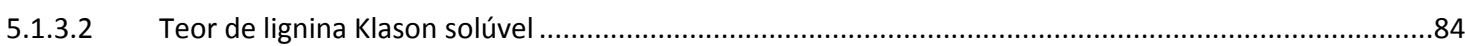

5.1.4 Determinação do teor de holocelulose (celulose e hemicelulose) ..................................................85

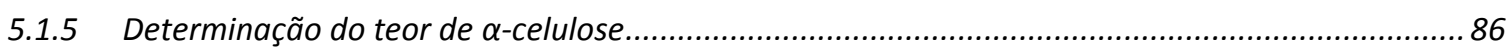

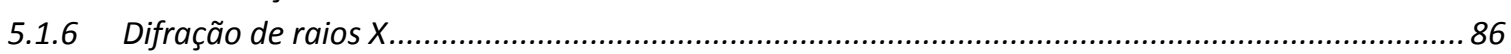

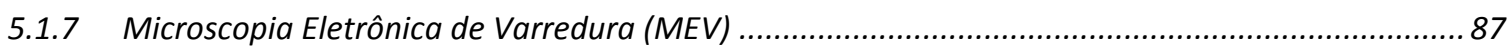

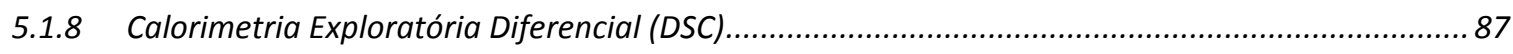

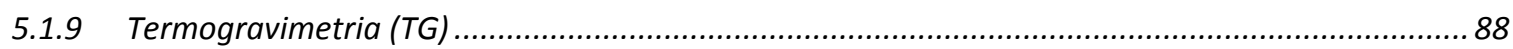

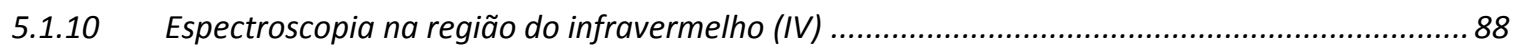

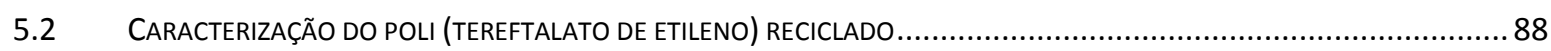

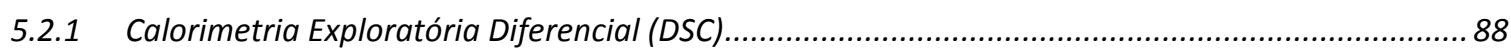

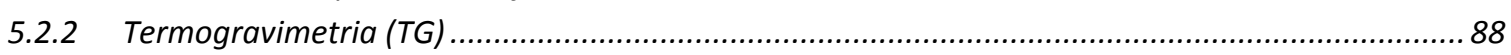

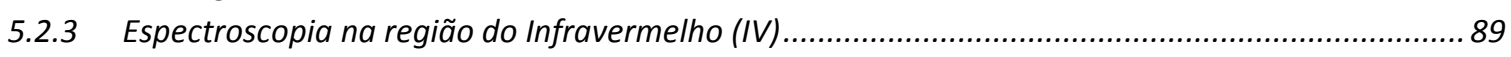

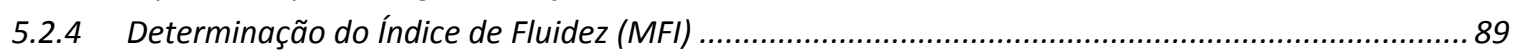

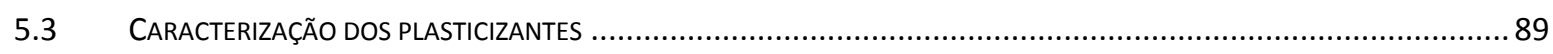

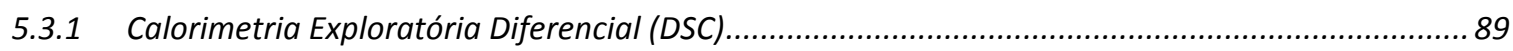

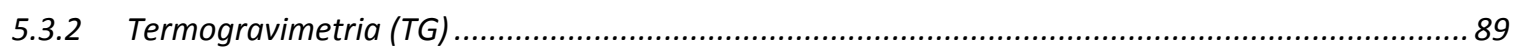

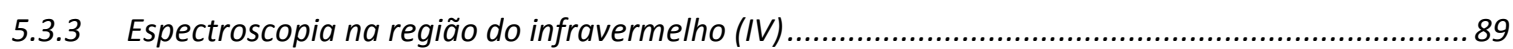

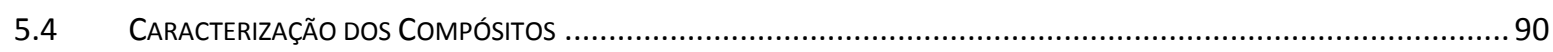

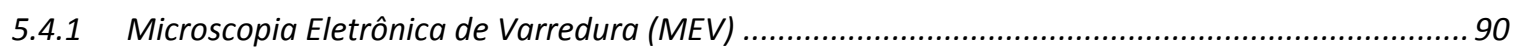

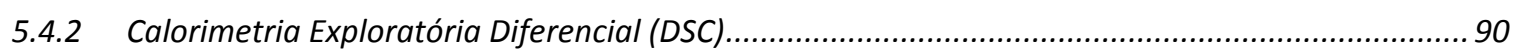

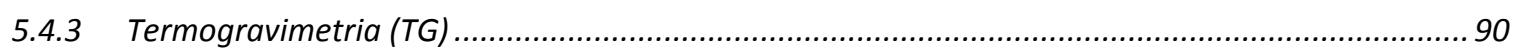

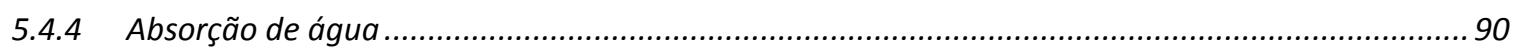

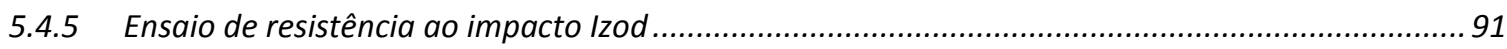

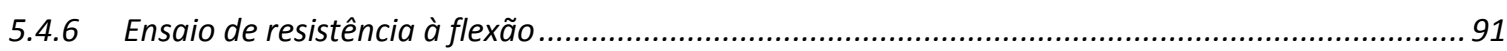

5.4.7 Análise Térmica Dinâmico-Mecânica (DMTA) ........................................................................... 91

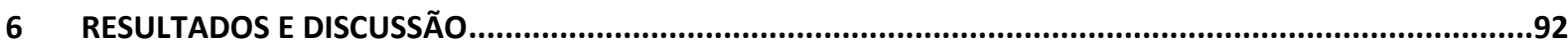

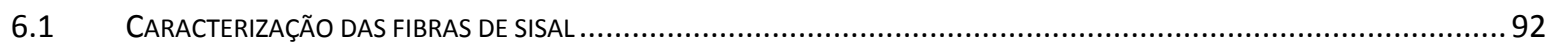

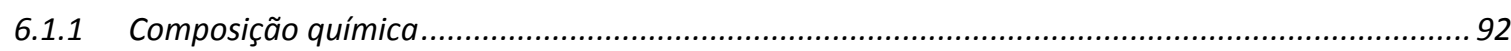

6.1.2 Determinação do Índice de Cristalinidade por Difração de raios X ........................................... 93

6.1.3 Microscopia Eletrônica de Varredura (MEV) ............................................................................... 94

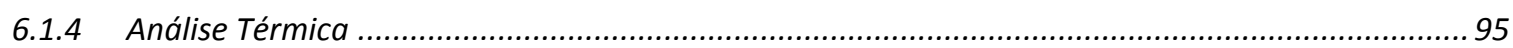

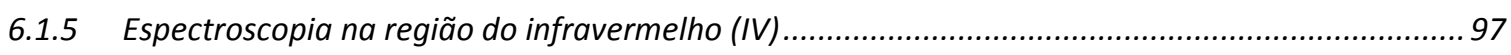

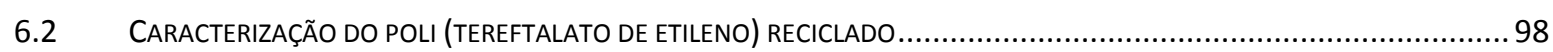

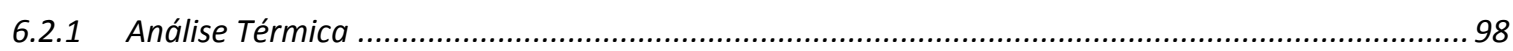

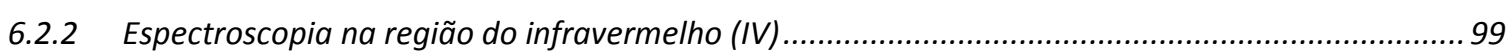

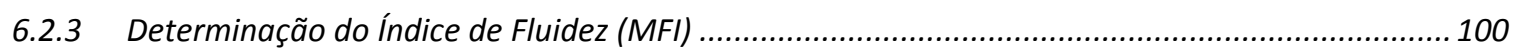

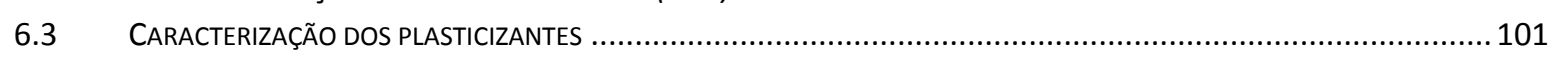




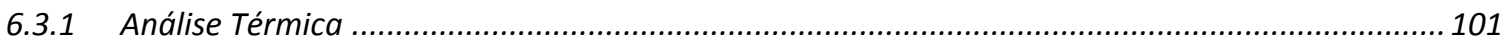

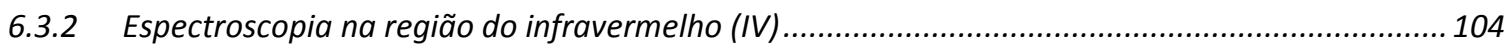

6.4 PREPARAÇÃO DOS COMPÓSITOS DE PET RECICLADO REFORÇADOS COM FIBRAS DE SISAL POR MOLDAGEM POR COMPRESSÃO .....

6.4.1 Desenvolvimento do ciclo de temperaturas para a moldagem por compressão dos compósitos. 107 6.5 PREPARAÇÃo dOS COMPÓSITOS DE PET RECICLADO REFORÇADOS COM FIBRAS DE SISAL POR REOMETRIA DE TORQUE E

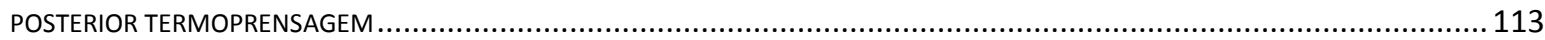

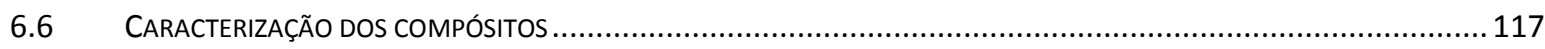

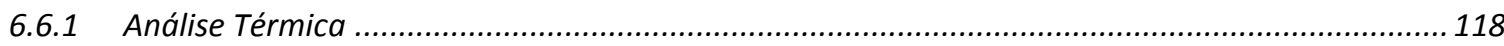

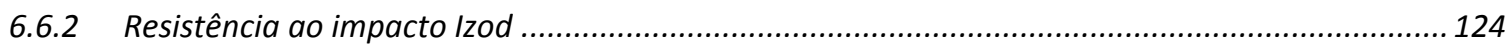

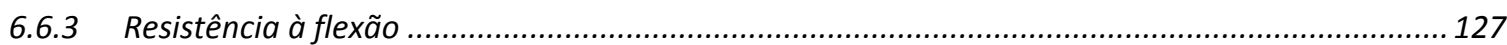

6.6.4 Análise Térmica Dinâmico-Mecânica (DMTA) ........................................................................... 131

6.6.5 Microscopia Eletrônica de varredura (MEV) ........................................................................ 134

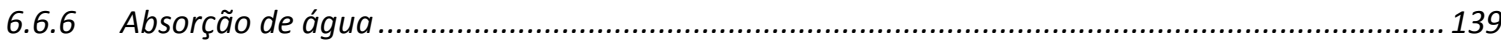

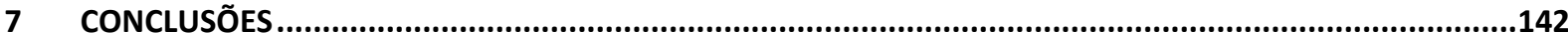

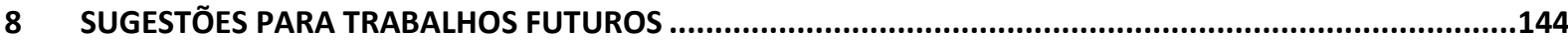

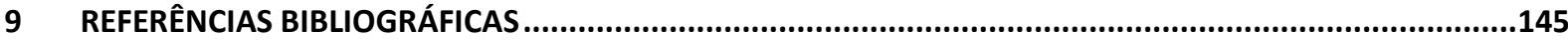




\section{LISTA DE FIGURAS}

Figura 1. Fórmula estrutural do PET.

Figura 2. Hidrólise do PET com a formação de grupos carboxílicos e hidroxílicos terminais. ..........................25

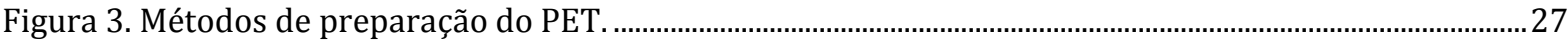

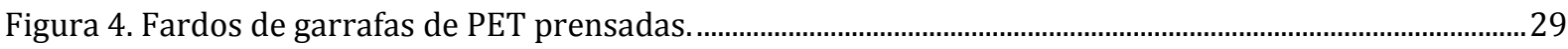

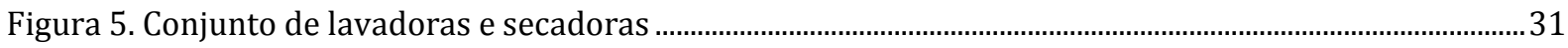

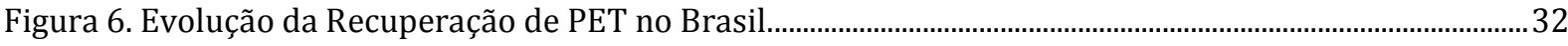

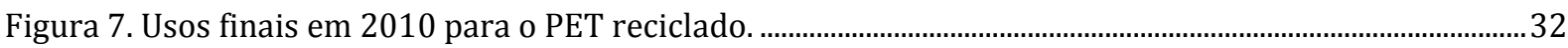

Figura 8. Sistema de classificação de compósitos com relação ao agente de reforço ...........................................34

Figura 9. Sistema de classificação de compósitos com relação à matriz..................................................................34

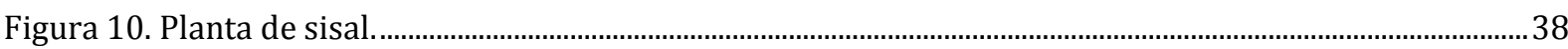

Figura 11. Imagem da fibra de sisal (a) e seus principais constituintes: (b) principais componentes da

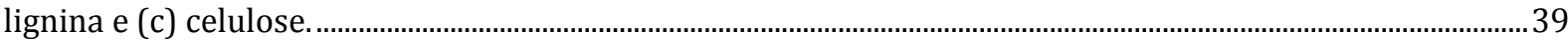

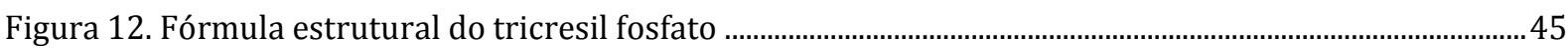

Figura 13. Fórmula estrutural geral de éster de ácido adípico. ........................................................................... 46

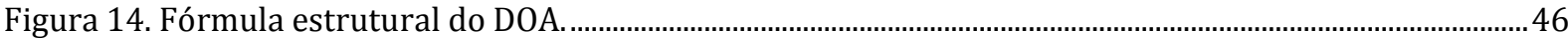

Figura 15. Fórmula estrutural geral de éster do ácido ftálico.........................................................................47

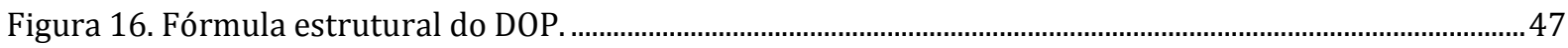

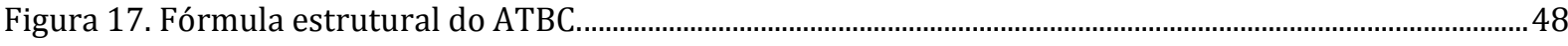

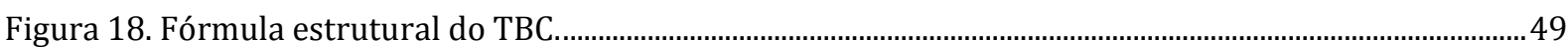

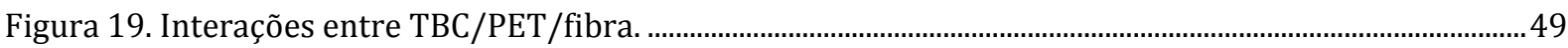

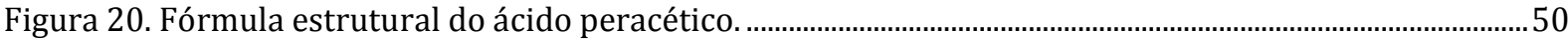

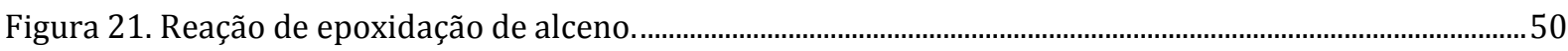

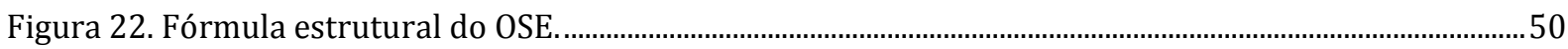

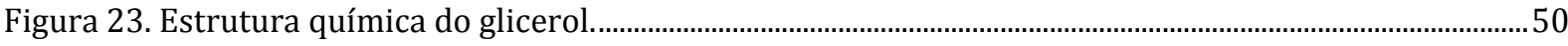

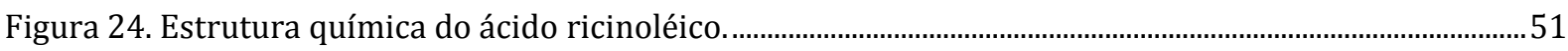

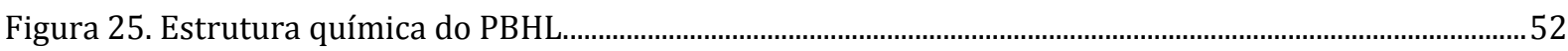

Figura 26. Misturador interno acoplado ao reômetro de torque Haake..............................................................57

Figura 27. Esquema de movimento de um pêndulo simples utilizado nos ensaios de resistência mecânica ao impacto

Figura 28. Esquema representativo de um ensaio de flexão em três pontos.....................................................64

Figura 29. Molde metálico utilizado no preparo dos compósitos .............................................................................69

Figura 30. Representação do sistema utilizado para a moldagem por compressão.............................................70

Figura 31. Representação esquemática do processo de preparação dos compósitos. .........................................78

Figura 32. Diagrama esquemático mostrando os diferentes plasticizantes usados (na forma isolada ou

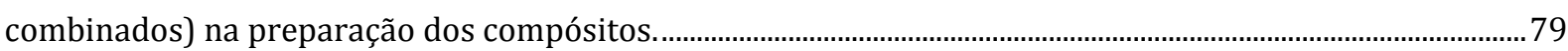

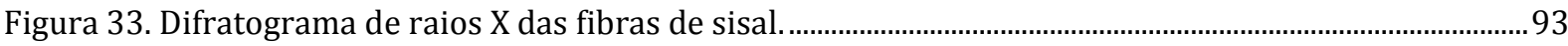


Figura 34. Micrografias das fibras de sisal: (a) e (b) superfície ampliada; (c) e (d) corte transversal ampliado.

Figura 35. Curvas (a) DSC e (b) TG e dTG para a fibra de sisal (fluxo de $\mathrm{N}_{2}$ de $50 \mathrm{~mL} \mathrm{~min}^{-1}$, razão de aquecimento de $10^{\circ} \mathrm{C} \mathrm{min}^{-1}$ ).

Figura 36. Espectro na região do infravermelho para a fibra de sisal.

Figura 37. Curvas (a) DSC para as amostras de PET reciclado sem tratamento térmico e pós-tratamento térmico e (b) TG e dTG para a amostra de PET reciclado sem tratamento térmico (fluxo de $\mathrm{N}_{2}$ de $50 \mathrm{~mL}$ $\min ^{-1}$, razão de aquecimento de $10^{\circ} \mathrm{C}$ min $^{-1}$ ).

Figura 38. Espectro na região do infravermelho a) para o PET reciclado e b) ampliado na região de 1500$1900 \mathrm{~cm}^{-1}$

Figura 39. Curvas DSC para os plasticizantes (a) PBHL, (b) TBC, (c) OSE, (d) OM, (e) Glicerol e (f) ATBC (fluxo de $\mathrm{N}_{2}$ de $50 \mathrm{~mL} \mathrm{~min}^{-1}$, razão de aquecimento de $10{ }^{\circ} \mathrm{C} \mathrm{min}^{-1}$ ).

Figura 40. Curvas TG e dTG para os plasticizantes (a) TBC, (b) PBHL, (c) OSE, (d) OM, (e) Glicerol e (f) ATBC (fluxo de $\mathrm{N}_{2}$ de $50 \mathrm{~mL} \mathrm{~min}^{-1}$, razão de aquecimento de $10{ }^{\circ} \mathrm{C} \mathrm{min}^{-1}$ ).

Figura 41. Espectro na região do infravermelho dos plasticizantes (a) PBHL, (b) OSE, (c) OM, (d) Glicerol, (e) TBC e (f) ATBC.

Figura 42. Fotografia ampliada da placa de compósito obtida utilizando-se o ciclo de temperaturas no 1 (Experimental)

Figura 43. Fotografia ampliada da placa de PET reciclado/PBHL obtida utilizando-se o ciclo de temperaturas n $\mathrm{n}^{\circ} 4$ (Experimental)

Figura 44. Fotografia ampliada da placa de PET reciclado/glicerol/fibra de sisal obtida utilizando-se o ciclo de temperaturas $n^{\circ} 8$ (Experimental)

Figura 45. Fotografia ampliada da placa de PET reciclado/glicerol/fibra de sisal (CG) obtida utilizando-se o ciclo de temperaturas $\mathrm{n}^{\circ} 10$ (Experimental)

Figura 46. Curva de processamento da mistura PET reciclado/fibras de sisal a $260{ }^{\circ} \mathrm{C}$.

Figura 47. Fotografia ampliada da placa do compósito PET reciclado/fibras de sisal obtida por termoprensagem a $260{ }^{\circ} \mathrm{C}(\mathrm{CH})$

Figura 48. Curvas de processamento das misturas PET reciclado/fibras de sisal/glicerol/OM e PET reciclado/glicerol/OM.

Figura 49. Curvas DSC da placa controle de PET reciclado (CTRPET) e dos compósitos CT, CGT, CGTM, CGTS, CAT, CGTP, CGMP, CG e CGM obtidos por moldagem por compressão

Figura 50. Curvas DSC do PET reciclado, da placa controle de PET/glicerol/OM (CTRH) e do compósito PET reciclado/fibras de sisal/glicerol/OM (CHGM) obtidos por reometria de torque e posterior termoprensagem (fluxo de $\mathrm{N}_{2}$ de $50 \mathrm{~mL} \mathrm{~min}^{-1}$, razão de aquecimento de $10{ }^{\circ} \mathrm{C} \mathrm{min}-1$ ).

Figura 51. Curvas dTG da placa controle de PET reciclado (CTRPET) e dos compósitos CGTP, CGMP, CG, CGM, CT, CGT, CGTM, CGTS e CAT obtidos por moldagem por compressão

Figura 52. Curvas dTG do PET reciclado, da placa controle de PET/glicerol/OM (CTRH) e do compósito PET reciclado/fibras de sisal/glicerol/OM (CHGM) obtidos por reometria de torque e posterior termoprensagem (fluxo de $\mathrm{N}_{2}$ de $50 \mathrm{~mL} \mathrm{~min}^{-1}$, razão de aquecimento de $10{ }^{\circ} \mathrm{C} \mathrm{min}^{-1}$ ). 
Figura 53. Resistência ao impacto Izod da placa controle de PET reciclado (CTRPET), dos compósitos CT, CGT, CGTM, CGTS, CAT, CGTP, CGMP, CGM e CG obtidos por moldagem por compressão e do compósito CHGM obtido por reometria de torque e posterior termoprensagem.

Figura 54. Deformação na ruptura da placa controle de PET reciclado (CTRPET), dos compósitos CT, CGT, CGTM, CGTS, CAT, CGTP, CGMP, CG e CGM obtidos por moldagem por compressão e do compósito CHGM obtido por reometria de torque e posterior termoprensagem

Figura 55. Módulos de flexão da placa controle de PET reciclado (CTRPET), dos compósitos CT, CGT, CGTM, CGTS, CAT, CGTP, CGMP, CG e CGM obtidos por moldagem por compressão e do compósito CHGM obtido por reometria de torque e posterior termoprensagem

Figura 56. Resistência à flexão da placa controle de PET reciclado (CTRPET), dos compósitos CT, CGT, CGTM, CGTS, CAT, CGTP, CGMP, CG, CGM obtidos por moldagem por compressão e do compósito CHGM obtido por reometria de torque e posterior termoprensagem

Figura 57. Módulo de armazenamento $\left(30^{\circ} \mathrm{C}\right)$ da placa controle de PET reciclado (CTRPET), dos compósitos CT, CGT, CGTM, CGTS, CAT, CGTP, CGMP, CG, CGM obtidos por moldagem por compressão, e do compósito $\mathrm{CHGM}$ obtido por reometria de torque e posterior termoprensagem.

Figura 58. Temperatura de transição vítrea ( $\mathrm{T}_{\mathrm{g}}$ ) da placa controle de PET reciclado (CTRPET), dos compósitos CT, CGT, CGTM, CGTS, CAT, CGTP, CGMP, CG, CGM obtidos por moldagem por compressão e do compósito CHGM obtido por reometria de torque e posterior termoprensagem. 133

Figura 59. Micrografia da superfície fraturada da placa controle de PET reciclado (CTRPET) obtida por moldagem por compressão. 134

Figura 60. Micrografias das superfícies de fratura dos compósitos obtidos por moldagem por compressão: (a) PET reciclado/fibras de sisal/TBC (CT); (b) e (c) PET reciclado/fibras de sisal/glicerol/TBC (CGT); (d) PET reciclado/fibras de sisal/glicerol/TBC/OM (CGTM); (e) PET reciclado/fibras de sisal/glicerol/TBC/OSE (CGTS); (f) PET reciclado/fibras de sisal/ATBC (CAT)

Figura 61. Micrografias das superfícies de fratura dos compósitos obtidos por moldagem por compressão:

(a) PET reciclado/fibras de sisal/glicerol/TBC/PBHL (CGTP); (b) PET reciclado/fibras de sisal/glicerol/OM/PBHL (CGMP).

Figura 62. Micrografias das superfícies de fratura dos compósitos obtidos por moldagem por compressão:

(a) PET reciclado/fibras de sisal/glicerol (CG); (b) PET reciclado/fibras de sisal/glicerol/OM (CGM). ....137 Figura 63. Micrografias das superfícies de fratura dos compósitos obtidos por reometria de torque e posterior termoprensagem: (a) PET reciclado/fibras de sisal (CH); (b), (c) e (d) PET reciclado/fibras de sisal/glicerol/OM (CHGM).

Figura 64. Absorção de água, após $1 \mathrm{~h}$ de imersão (temperatura ambiente), da placa controle de PET reciclado (CTRPET) e dos compósitos CT, CGT, CGTM, CGTS, CAT, CGTP, CGMP, CG, CGM obtidos por moldagem por compressão. 


\section{LISTA DE TABELAS}

Tabela 1. Teor de componentes químicos majoritários das fibras de sisal.

Tabela 2. Principais absorções observadas no espectro na região do infravermelho da fibra de sisal e seus respectivos modos vibracionais.

Tabela 3. Compósitos preparados por moldagem por compressão, usando 40\% de plasticizantes e 15\% de fibras de sisal $-3 \mathrm{~cm}$ (\% em massa). 


\section{LISTA DE ABREVIATURAS E SIGLAS}

ABIPET - Associação Brasileira da Indústria do PET

ATBC - Acetil tributil citrato

BHET - Tereftalato de bis (2-hidroxietileno)

CAT - PET reciclado/fibras de sisal/ATBC processado por moldagem por compressão

CG - PET reciclado/fibras de sisal/glicerol processado por moldagem por compressão

CGM - PET reciclado/fibras de sisal/glicerol/OM processado por moldagem por compressão

CGMP - PET reciclado/fibras de sisal/glicerol/OM/PBHL processado por moldagem por compressão

CGT - PET reciclado/fibras de sisal/glicerol/TBC processado por moldagem por compressão

CGTM - PET reciclado/fibras de sisal/glicerol/TBC/OM processado por moldagem por compressão

CGTP - PET reciclado/fibras de sisal/glicerol/TBC/PBHL processado por moldagem por compressão

CGTS - PET reciclado/fibras de sisal/glicerol/TBC/OSE processado por moldagem por compressão

CH - PET reciclado/fibras de sisal processado por reometria de torque e posterior termoprensagem

CHGM - PET reciclado/fibras de sisal/glicerol/OM processado por reometria de torque e posterior termoprensagem

CT - PET reciclado/fibras de sisal/TBC processado por moldagem por compressão

CTRH - PET reciclado/glicerol/OM processado por reometria de torque e posterior termoprensagem

CTRPET - Placa controle de PET reciclado processada por moldagem por compressão

DMA/DMTA - Análise Dinâmico-Mecânica/Análise Térmica Dinâmico-Mecânica

DMT - Éster tereftalato de dimetileno

DOA - Di octil adipato

DOP - Ftalato de di-2-etil hexila

DSC - Calorimetria Exploratória Diferencial

E' - Módulo de armazenamento

E" - Módulo de perda

EBGMA - Etileno/n-butil acrilato/glicidil metacrilato

EG - Etileno glicol

EMA - etileno-metil acrilato

$\mathbf{I}_{\mathbf{c}}$ - Índice de Cristalinidade

IV - Espectroscopia na região do infravermelho

MEV - Microscopia Eletrônica de Varredura

MFI - Índice de Fluidez

OM - Óleo de mamona

OSE - Óleo de soja epoxidado

PBHL - Polibutadieno hidroxilado

PE - Polietileno

PELBD - Polietileno linear de baixa densidade

PET - Poli (tereftalato de etileno) 
PP - Polipropileno

PVC - Poli (cloreto de vinila)

SSP - Reação de polimerização no estado sólido (solid state polimerization)

TBC - Tributil citrato

$\mathbf{T}_{\mathbf{g}}$ - Temperatura de transição vítrea

TG - Termogravimetria

$\mathbf{T}_{\mathbf{m}}$ - Temperatura de fusão cristalina

$\mathbf{T}_{\mathbf{p}}$ - Temperatura máxima de decomposição

TPA - Ácido tereftálico 


\section{RESUMO}

É crescente o interesse e a necessidade de substituição de materiais preparados a partir de matéria-prima obtida de fontes fósseis, por materiais oriundos de fontes renováveis, como os compósitos poliméricos reforçados com fibras naturais. Adicionalmente, é acelerada a geração de descarte de embalagens plásticas no país, comparativamente à reciclagem de materiais. Neste contexto, o presente trabalho consistiu na busca pelo desenvolvimento de processos de preparação de compósitos baseados em poli (tereftalato de etileno) reciclado (PET reciclado) e fibras de sisal. As fibras de sisal foram caracterizadas segundo o teor de componentes químicos majoritários, difração de raios X, microscopia eletrônica de varredura (MEV), análise térmica (calorimetria exploratória diferencial (DSC) e termogravimetria (TG)) e espectroscopia na região do infravermelho (IV). O PET reciclado foi caracterizado por DSC, TG, IV e determinação do índice de fluidez. Inicialmente, compósitos de PET reciclado/fibras de sisal foram processados via reometria de torque, com posterior termoprensagem, à temperatura de $260{ }^{\circ} \mathrm{C}$, porém foi observada a decomposição térmica das fibras, ou seja, o recobrimento pela matriz não retardou a decomposição das fibras. Consequentemente, visando uma diminuição da temperatura de fusão do PET reciclado $\left(\sim 265^{\circ} \mathrm{C}\right)$, a fim de evitar a decomposição térmica das fibras durante o processamento, os plasticizantes acetil tributil citrato (ATBC), tributil citrato (TBC), glicerol, óleo de mamona (OM) e óleo de soja epoxidado (OSE) foram acrescentados às formulações dos compósitos. Adicionalmente, polibutadieno hidroxilado líquido (PBHL) foi acrescentado à formulação do material, visando avaliar sua ação como agente compatibilizante/de acoplamento na interface fibra-matriz. Destaca-se que estes plasticizantes foram escolhidos por serem oriundos de fontes renováveis, assim como por possuírem grupos nas respectivas estruturas com afinidade tanto por grupos presentes nos componentes da fibra como na matriz. Desta forma a possível ação dos mesmos como compatibilizantes também foi considerada. Os plasticizantes foram caracterizados por DSC, TG e IV. A exploração de parâmetros de processamento, usando plasticizantes, foi feita misturando os componentes usando pás rotativas, seguido de moldagem por compressão. A composição da mistura e parâmetros de processamento, que levaram ao melhor conjunto de resultados, foi considerada para processamento via reometria de torque/termoprensagem. Os compósitos foram caracterizados por MEV, 
DSC, TG, absorção de água, e com relação às suas propriedades mecânicas por análise térmica dinâmico-mecânica (DMTA), e ensaios de resistência ao impacto e à flexão. Analisando-se os resultados obtidos, observa-se que, com relação aos diferentes processamentos dos compósitos, a moldagem por compressão foi mais adequada para a preparação dos compósitos de PET reciclado/fibras de sisal, principalmente em relação ao superior desempenho mecânico apresentado por estes materiais, em comparação aos compósitos processados por reometria de torque e posterior termoprensagem. O PET reciclado não reforçado, dentre as propriedades mecânicas apresentadas, não apresentou boa resistência ao impacto, assim como os compósitos preparados a partir dele, ou seja, a propriedade do PET reciclado foi predominante nos compósitos. No entanto, o uso de plasticizantes viabilizou não só o processamento dos compósitos à menor temperatura, assim como aumentou a molhabilidade da fibra pelo polímero, por diminuir a viscosidade da mistura. Ainda, no geral, as micrografias das superfícies de fratura dos compósitos demonstraram uma boa adesão na interface fibra-matriz, indicando atuação dos plasticizantes também como compatibilizantes entre fibra e matriz. Destaca-se que, no geral, os resultados de resistência à flexão e DMTA apontaram no sentido de que a presença das fibras e plasticizantes levaram a materiais menos rígidos e mais flexíveis. Dentre os compósitos, pode-se considerar que a mistura PET reciclado/fibras de sisal/glicerol/ TBC apresentou o melhor desempenho mecânico, que levou, no geral, ao melhor resultado de resistência ao impacto, boa resistência à flexão e deformação na ruptura. O compósito de PET reciclado/fibras de sisal, contendo em sua composição somente o plasticizante TBC, também apresentou um bom desempenho frente aos demais compósitos, com o melhor resultado de resistência à flexão, maior módulo de armazenamento e baixo teor de água absorvida. Assim, como pretendido, viabilizou-se o preparo de compósitos de PET reciclado/fibras de sisal, com a adição de diferentes tipos e misturas de plasticizantes, avaliando-se não somente a influência destes, assim como parâmetros de processo, uso de diferentes tipos de processamento e propriedades finais dos materiais gerados. 


\begin{abstract}
There is an increasing interest and need for the replacement of materials prepared from raw material obtained from fossil sources by those from renewable sources, such as polymeric composites reinforced with natural fibers. Additionally, the generation of plastic packaging disposal is accelerated in the country compared to materials recycling. In this context, the focus of this investigation was on the search for developing processes for the preparation of composites based on recycled poly (ethylene terephthalate) (recycled PET) and sisal fibers. The sisal fibers were characterized according to the content of major chemical components by X-ray diffraction, scanning electron microscopy (SEM), thermal analysis (differential scanning calorimetry (DSC) and thermogravimetry (TG)) and by infrared spectroscopy (IR). The recycled PET was characterized by DSC, TG, IV and melt index determination. Initially, composites of recycled PET/sisal fibers were processed in a Haake torque rheometer with subsequent thermopressing, at $260^{\circ} \mathrm{C}$, but this method proved to be inefficient, since fiber decomposition was observed, i.e., the decomposition of the fibers was not delayed by the matrix coating. Consequently, by aiming at obtaining a decrease of the melting temperature of the recycled PET ( 265 oC) in order to avoid thermal decomposition of the fibers during processing, the plasticizers, acetyl tributyl citrate (ATBC), tributyl citrate (TBC), glycerol, castor oil (CO) and epoxidized soybean oil (OSE) were added to the formulations of the composites. In addition, hydroxylated liquid polybutadiene (PBHL) was added to the formulation of the material to evaluate its action as a compatibilizer/coupling agent in the fiber-matrix interface. It is emphasized that these plasticizers were chosen because they come from renewable sources, as well as having groups in the respective structures with affinity for both groups present in components of the fiber and the matrix. Thus the possible action of plasticizers as compatibilizers was also considered. The plasticizers were characterized by DSC, TG and IV. The exploitation of processing parameters using plasticizers was made by mixing the components using shovels, followed by compression molding. The composition of the mixture and the processing parameters, which led to the best set of results, were considered for processing via torque rheometry/thermopressing. The composites were characterized by SEM, DSC, TG, water absorption, and regarding their mechanical properties, by dynamic mechanical thermal analysis (DMTA) and impact and flexural
\end{abstract}


strength. Analyzing the results, it is observed that when it comes to different processes of composites, compression molding was the most suitable for the preparation of the composites of recycled PET/sisal fibers, especially in relation to the superior mechanical performance presented by these materials compared to composites processed by torque rheometry and subsequent thermopressing. The non-reinforced recycled PET, among the mechanical properties shown, did not show a good impact strength, nor did the composites prepared from it, i.e., the property of recycled PET in the composites was predominant. However, not only did the use of plasticizers allow the processing of the composites at a lower temperature, but also it increased the wettability of the polymerfiber by reducing the viscosity of the mixture. Still, in general, the SEM images of fractured surfaces of the composites showed a good adhesion between fiber-matrices, indicating activity of plasticizers and also compatibilizers between fiber and matrix. It is noteworthy that, in general, the results of flexural strength and DMTA pointed out that the presence of plasticizers led to less rigid and more flexible materials. Among the composites, it can be assumed that the mixture recycled PET/sisal fibers/glycerol/TBC presented the best mechanical performance, which in general led to the best result of impact strength, good flexural strength and fracture strain. The composite of recycled $\mathrm{PET} /$ sisal fibers in its composition, containing only the TBC plasticizer, also performed well compared to other composites, with the best result of flexural strength, higher storage modulus and low moisture absorption. Thus, as desired, the preparation of composites based on recycled PET / sisal fibers with the addition of different types and mixtures of plasticizers was enabled, evaluating not only their influence but also process parameters, the use of different types of processing and the final properties of the generated materials. 


\section{Introdução}

\subsection{Aspectos Gerais}

Durante o seu desenvolvimento intelectual, o homem vem agregando conhecimento sobre os mais diversos tipos de materiais. 0 primeiro material utilizado pelo homem foi a pedra, passando pela madeira, couro, fibras vegetais, cerâmica, vidro, metais e, mais recentemente, os polímeros. Na atual era da civilização, existe uma gama enorme de materiais utilizados para as mais diversas finalidades, sendo possível classificar este período de tempo como a Era dos Materiais (CHAWLA, 1998; HERAKOVICH, 1998).

Atualmente, as necessidades da sociedade moderna clamam por um crescente e contínuo desenvolvimento de novos materiais. Em tempos de aquecimento global e diminuição das reservas de combustíveis fósseis, a conversão de biomassa em materiais que sejam úteis ao homem possui considerável valor econômico e ambiental (WO0L; SUN, 2005).

Assim, compósitos poliméricos reforçados com fibras lignocelulósicas constituem uma classe de materiais em contínua expansão, a qual busca por novas tecnologias, novas combinações de polímeros e fibras, e novas técnicas de processamento que permitam a exploração da versatilidade e características únicas que possuem estes materiais (FROLLINI, 2002). A substituição de materiais tradicionais, cujos processamentos despendem elevado consumo energético, por materiais oriundos de fontes renováveis/naturais, tem despertado grande atenção e ganhado cada vez mais notoriedade. Os materiais naturais, como as fibras lignocelulósicas, tem importância não só pela economia energética gerada em seus processamentos, mas também por serem de origem renovável e, normalmente, serem biodegradáveis, neutros com relação às emissões de $\mathrm{CO}_{2}$, que por sua vez tem grande impacto no efeito estufa atmosférico e, portanto, no aquecimento global (MONTEIRO et al., 2009). O uso de materiais biocompósitos surge, então, como uma das soluções a estes complexos problemas ambientais.

Outro problema enfrentado pela sociedade moderna é a geração de lixo urbano que, de acordo com a Abrelpe (Associação Brasileira de Empresas de Limpeza Pública e 
Resíduos Especiais), em 2010, cresceu seis vezes mais do que a população brasileira. Em relação à reciclagem, o estudo mostra tendência de crescimento, mas em ritmo menor ao da geração de lixo. ${ }^{1}$ Neste contexto, a produção de poli (tereftalato de etileno) (PET) corresponde a 9\% (em massa) do total de polímeros produzidos no Brasil, porém, representa uma média de 20\% (em massa) dentre os polímeros presentes no resíduo sólido urbano (RSU). Isto se deve ao fato de polímeros como o polipropileno (PP) e poli (cloreto de vinila) (PVC) serem utilizados como matéria-prima para a fabricação de produtos de longa vida útil pelas indústrias de bens de consumo e construção civil, contudo, o PET é utilizado em produtos de curta vida útil, como embalagens, por exemplo (ROMÃO; SPINACÉ; DE PAOLI, 2009).

Portanto, faz-se necessário o desenvolvimento de pesquisas que levem a materiais preparados a partir de PET reciclado, gerando consequentemente produtos finais com elevado valor agregado, como os compósitos.

Assim, visando à valorização das fibras lignocelulósicas e reciclagem do PET, neste estudo, a fibra de sisal foi utilizada como agente de reforço em compósitos de matriz polimérica de PET reciclado.

\subsection{PET}

Em 1930 Wallace H. Carothers sintetizou o primeiro poliéster linear a partir de monômeros a base de trimetileno glicol e do ácido dicarboxílico hexadecametileno. Assim, originou-se a primeira fibra sintética. Entretanto, a baixa temperatura de fusão e baixa estabilidade hidrolítica da fibra comprometiam a qualidade do produto final (PAUL; GOODMAN; KROSCHWITZ, 1985). Somente em 1941, o poli (tereftalato de etileno) (PET), conhecido durante muitos anos somente sob a forma de fibra e chamado, inicialmente, de "poliéster", foi primeiramente sintetizado por dois químicos britânicos, J. T. Dickson e J. W. Whinfield (EHRIG, 1992).

Nos anos 50, época de transição entre o período de guerras da primeira metade do século XX e o período das revoluções comportamentais e tecnológicas da segunda metade, a produção de PET foi principalmente dirigida para aplicações na indústria têxtil, impulsionada pela empresa DuPont. Nos anos subsequentes, houve grande

\footnotetext{
1 Disponível em http://planetasustentavel.abril.com.br/noticia/lixo/producao-destinacao-residuos-solidos-brasilpanorama-2010-abrelpe-625938.shtml, acesso em 23/03/12.
} 
desenvolvimento tecnológico na fabricação e posterior aplicação deste polímero, para os fins mais variados. Nos anos 60, o filme de PET biorientado (produzido por biorientação de uma fina película do polímero em pelo menos duas etapas, em direções opostas) (BARRY; PELLEREAU, 1993) foi utilizado, com grande aceitação, como material de embalagem para acondicionamento de alimentos. Em 1962, a Goodyear utilizou o PET na confecção de pneus. ${ }^{2}$

Em 1973, através dos processos de conformação de injeção e sopro com biorientação desenvolvidos pela DuPont, o PET foi introduzido em aplicações como garrafas, as quais começaram a ser comercializadas em 1977 nos Estados Unidos, revolucionando o mercado de embalagens e notadamente o de bebidas carbonatadas. Entretanto, o PET grau garrafa tornou-se disponível no Brasil apenas em 1989 (ISOLDI, 2003).

O PET é um dos materiais, sob a forma de filmes, lâminas, revestimentos e garrafas, de maior sucesso nas últimas décadas, com crescente aplicabilidade devido às peculiares características que possui e que lhe conferem grande versatilidade.

Pertencente à família dos poliésteres, o PET é um polímero que possui, em sua cadeia, anéis benzênicos e grupos ésteres (R-CO-O-R'). A cadeia alifática (aberta e não cíclica), juntamente com o oxigênio presente na cadeia principal de sua estrutura química (Figura 1), são responsáveis por conferir flexibilidade ao PET à temperaturas acima de sua transição vítrea. Entretanto, o grupo benzênico presente na estrutura do PET confere rigidez, além de elevada estabilidade hidrolítica à cadeia polimérica (PAUL; GOODMAN; KROSCHWITZ, 1985; ISOLDI, 2003; ROMÃO; SPINACÉ; DE PAOLI, 2009)

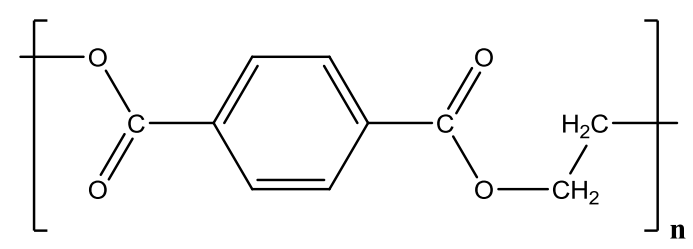

Figura 1. Fórmula estrutural do PET.

O PET possui massa molar ponderal média variável, que pode assumir valores desde $45.000 \mathrm{~g} \mathrm{~mol}^{-1}$, quando o PET é utilizado para a confecção de garrafas, até valores próximos a $15.000 \mathrm{~g} \mathrm{~mol}^{-1}$, quando este é destinado para a fabricação de fibras. A densidade do PET pode assumir valores em torno de 1,38 $\mathrm{g} \mathrm{cm}^{-3}$ (ALVES et al., 1998).

\footnotetext{
2 Disponível em http://www.abipet.com.br, acesso em 23/03/12.
} 
Variando-se as condições do processo de cristalização do PET, uma extensa faixa de porcentagens de cristalinidade pode ser alcançada, desde 50\% até 95\% de cristalinidade máxima, sob condições muito específicas. Esta extensa faixa de porcentagens de cristalinidade torna possível a obtenção de variações significantes nas propriedades mecânicas do PET (ISOLDI, 2003).

Com temperaturas de transição vítrea $\left(\mathrm{T}_{\mathrm{g}}\right)$ de aproximadamente $75{ }^{\circ} \mathrm{C}$ e de fusão cristalina $\left(\mathrm{T}_{\mathrm{m}}\right)$ em torno de $265{ }^{\circ} \mathrm{C}$, o PET possui razoável manutenção de suas propriedades mecânicas a altas temperaturas.

Diferentemente de outros poliésteres, o PET é resistente ao ataque de ácidos, bases e água. Este fato deve-se à presença de anéis aromáticos neste polímero e ao empacotamento de suas cadeias poliméricas, o que dificulta o acesso dos reagentes. No entanto, em temperaturas acima da $\mathrm{T}_{\mathrm{g}}$ do polímero (acima de aproximadamente $75{ }^{\circ} \mathrm{C}$ ), a reação de hidrólise do PET é acentuada. Em temperaturas na faixa de 100-120 드, com a presença de $100 \%$ de umidade relativa, a hidrólise do PET é aproximadamente 10 mil vezes mais rápida que sua degradação térmica e 5 mil vezes mais rápida que a oxidação em ar (BARBOZA, 2003). Launay, Thominette e Verdu (1994) concluíram que a reação de hidrólise é autocatalítica, devido à formação de ácidos carboxílicos (grupos carboxílicos terminais), sendo dependente do grau de cristalinidade e hidrofilicidade do polímero. As regiões cristalinas do polímero atuam como uma espécie de barreira, pois reduzem a permeação de umidade e a difusão do oxigênio. Para o PET, a hidrólise é considerada um processo de cisão simples, formando moléculas de baixa massa molar com grupos carboxílicos ou hidroxílicos em suas extremidades (Figura 2). Assim, o PET possui boa resistência química a ácidos e bases, como mencionado anteriormente, embora possa sofrer hidrólise na presença de água, sendo que a hidrólise exerce uma influência muito maior na degradação do PET frente à degradação oxidativa ou térmica (SPINACÉ, 2000).

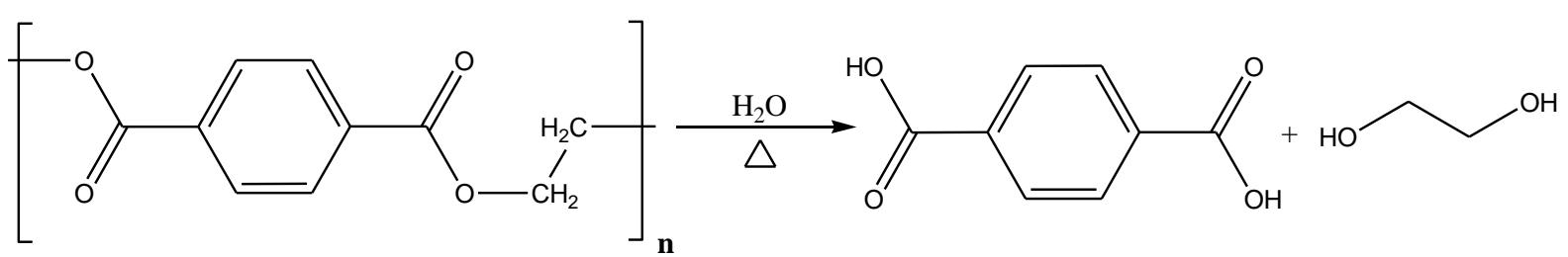

Figura 2. Hidrólise do PET com a formação de grupos carboxílicos e hidroxílicos terminais. 
Importante destacar que a transparência no estado não cristalino, aliada à sua propriedade de baixa permeabilidade a gases (principalmente $\mathrm{O}_{2}$ e $\mathrm{CO}_{2}$ ), tornaram o PET muito importante no desenvolvimento da indústria de embalagens, principalmente de garrafas para refrigerantes (BILLMEYER JR., 1995)

Assim, as propriedades apresentadas pelo PET o tornaram um importante substituto de materiais convencionais como o vidro, o PVC, as latas de aço e alumínio, dentre outros materiais (ISOLDI, 2003). Atualmente, o PET é um dos termoplásticos mais produzidos no mundo, alcançando em 2010, somente no Brasil, uma produção em torno de 550 kton. $^{3}$

Com relação à sua obtenção, o PET é um poliéster saturado formado pela reação de condensação reversível entre o ácido tereftálico (TPA), ou o éster tereftalato de dimetileno (DMT), com o etileno glicol (EG). A polimerização ocorre por aquecimento dos reagentes na presença de um catalisador de antimônio (usualmente o trióxido de antimônio), com remoção de água ou metanol (MANO, 1991).

Dependendo do processo escolhido, pode-se ter a esterificação direta do TPA com EG (Figura 3-a) ou a transesterificação do DMT com EG (Figura 3-b).

${ }^{3}$ Disponível em http://www.abipet.com.br/UserFiles/File/Site\%201.pdf, acesso em 23/03/12. 


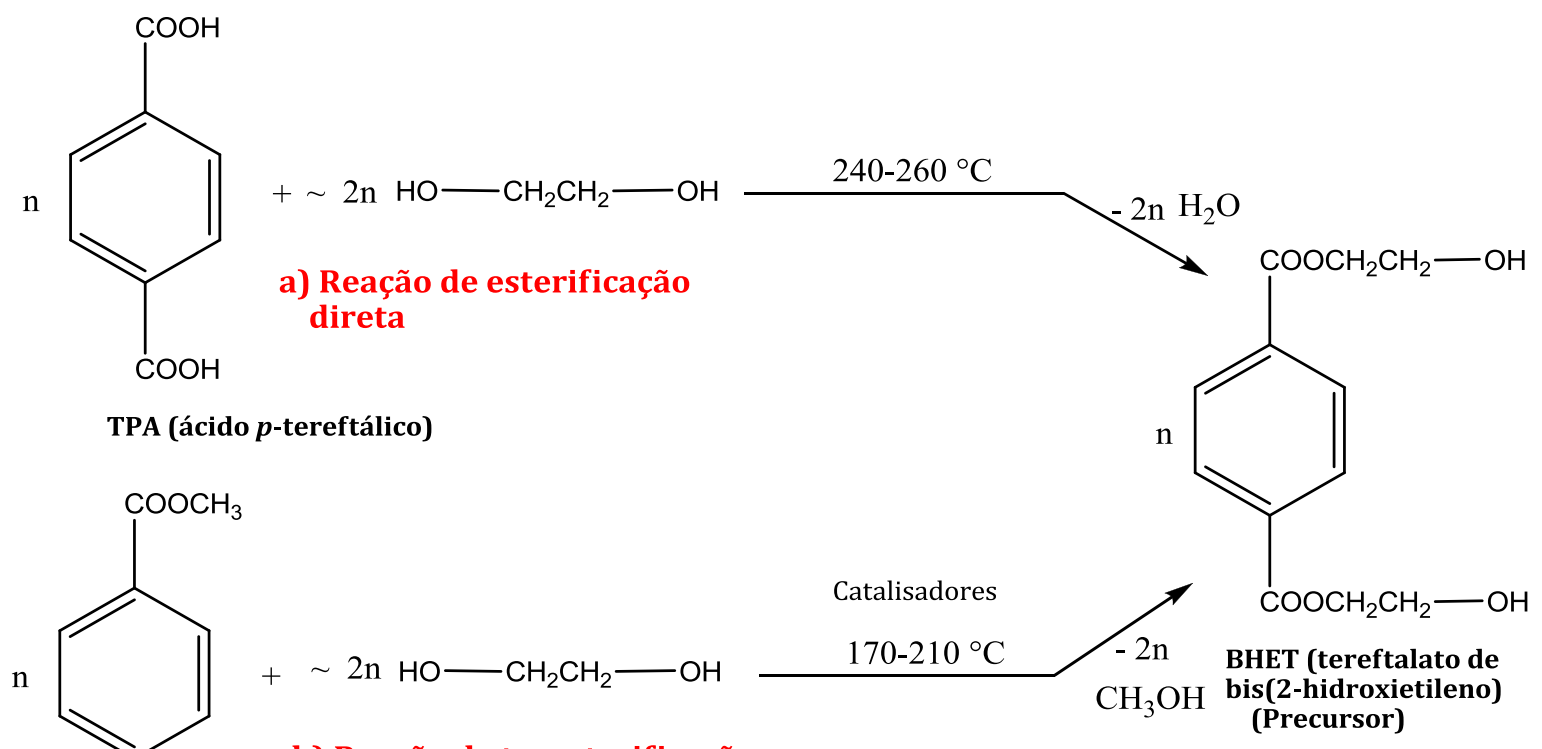

b) Reação de transterificação

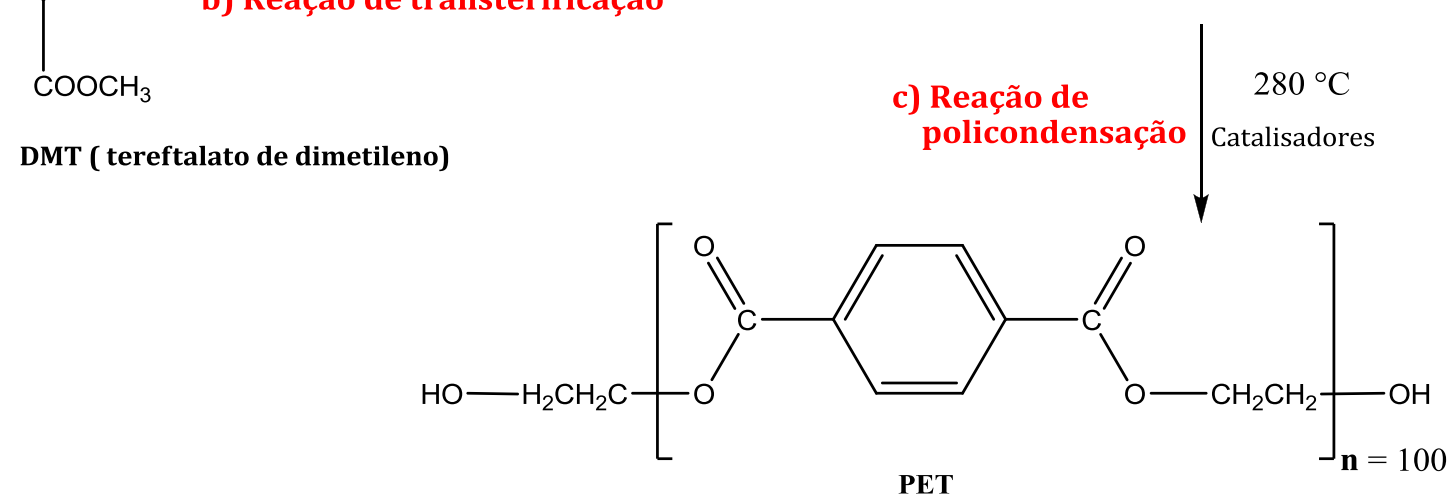

Figura 3. Métodos de preparação do PET (ROMÃO; SPINACÉ; DE PAOLI, 2009).

Assim, a reação inicia com a síntese do precursor tereftalato de bis (2hidroxietileno), BHET, que pode ser produzido por duas rotas distintas: a) esterificação direta; e b) transesterificação.

A reação de esterificação direta é o processo que vem sendo utilizado preferencialmente para a produção industrial do PET, devido ao desenvolvimento de um método de purificação do monômero TPA (PERNICONE et al., 1998; ROMÃO; SPINACÉ; DE PAOLI, 2009). Como exemplo, a empresa do Grupo Mossi \& Ghisolfi (M\&G) produz o PET exclusivamente a partir do processo de esterificação direta. ${ }^{4} \mathrm{~A}$ esterificação direta é uma reação heterogênea e autocatalítica (os grupos carboxílicos terminais oriundos do ácido TPA autocatalisam a reação), dispensando a adição de catalisadores, Figura 3-a. A razão molar do TPA : EG e a faixa de temperatura reacional usadas são 1:1,5-3 e $240-260{ }^{\circ} \mathrm{C}$, respectivamente. A utilização de uma menor razão entre os monômeros (TPA/EG) e uma maior temperatura, é imprescindível para

\footnotetext{
${ }^{4}$ Disponível em http://www.gruppomg.com.br/home.asp, acesso em 23/03/12.
} 
alcançar uma excelente solubilidade do monômero TPA em EG (RAVINDRANATH; MASHELKAR, 1986; YANG et al., 1996; ROMÃO; SPINACÉ; DE PAOLI, 2009).

No processo de transesterificação, o reator é carregado com DMT:EG (razão molar $=1: 2,1-2,3$ ) e catalisadores em uma temperatura entre $170-210{ }^{\circ} \mathrm{C}$. Durante a reação, coleta-se o metanol liberado em um receptor, o que permite estimar a extensão da reação, Figura 3-b. Quando é cessada a destilação do metanol, considera-se o fim da reação com a obtenção do precursor BHET.

Após sua síntese na etapa de pré-polimerização, o BHET é aquecido a $280{ }^{\circ} \mathrm{C}$ na policondensação, Figura 3-c. Durante o aquecimento, a pressão interna do reator é reduzida para valores abaixo de $1,3 \times 10^{2} \mathrm{~Pa}$ e, consequentemente, o grau de polimerização é elevado para aproximadamente 100. 0 tempo reacional total das duas etapas preliminares pode variar de 5 a 10 h, obtendo-se o EG como um subproduto (CHEGOLYA; SHEVCHENKO; MIKHAILOV, 1979; ROMÃO; SPINACÉ; DE PAOLI, 2009). Para aplicações como fibras têxteis, as quais não são submetidas a elevadas solicitações mecânicas, essas duas etapas de síntese (pré-polimerização e policondensação) são suficientes (RAVINDRANATH; MASHELKAR, 1986).

$\mathrm{Na}$ policondensação se obtém polímeros com massa molar média aproximadamente de $33.000 \mathrm{~g} \mathrm{~mol}^{-1}$, devido à redução da taxa de reação pelo aumento da viscosidade do material e dificuldade de difusão do EG.

A reação de polimerização no estado sólido (solid state polimerization, SSP) é utilizada para a produção de PET com elevada massa molar média ( $>30.000 \mathrm{~g} \mathrm{~mol}^{-1}$ ), que pode ser aplicado, por exemplo, em embalagens para bebidas carbonatadas. Esta reação é realizada a uma temperatura intermediária, entre a temperatura de transição vítrea e a temperatura de fusão do PET $\left(220-230{ }^{\circ} \mathrm{C}\right.$, por um período de $10-30 \mathrm{~h}$ ). Através da reação SSP é possível aumentar o grau de cristalinidade do material em um intervalo curto de tempo, sob alto vácuo, ou através de um sistema de atmosfera inerte sob agitação, evitando assim o processo de sinterização (partículas começam a aderir umas às outras). Quando isso acontece, os flakes grudam nas paredes do reator e podem danificá-lo (PO et al., 1996; DUH, 2001; 2002). 


\subsubsection{Reciclagem do PET}

A reciclagem de polímeros pode ser classificada em quatro categorias distintas: primária, secundária, terciária e quaternária. As reciclagens primária e secundária são conhecidas como reciclagem mecânica e o que diferencia uma da outra é que, na primária, são usados polímeros pré-consumo e na secundária, polímeros pós-consumo. A reciclagem terciária é chamada de química e a quaternária de energética. No Brasil, segundo a Associação Brasileira da Indústria do PET (ABIPET), a principal reciclagem praticada, a mesma que gerou o material utilizado no presente trabalho, é a mecânica. 0 PET é considerado o segundo material mais reciclado no país, superado apenas pelo alumínio (DOS SANTOS, 2008; ROMÃO; SPINACÉ; DE PAOLI, 2009).

A reciclagem mecânica do PET pós-consumo inicia com a coleta das garrafas de refrigerantes descartadas pela sociedade. Nesta fase, os catadores recolhem manualmente as garrafas encontradas no meio ambiente, em aterros sanitários, lixões, ou unidades municipais de coleta seletiva. Após esta etapa, tampas, rótulos, dentre outros materiais são retirados das garrafas, o que leva a uma perda de aproximadamente 18\% (em massa) do material recolhido (WELLE, 2011). As garrafas são então separadas por cor e prensadas, originando fardos com peso médio de $80 \mathrm{~kg}$ e volume de 0,5 $\mathrm{m}^{3}$. A prensagem e enfardamento (Figura 4) viabilizam o acondicionamento e a comercialização do material (DOS SANTOS, 2008).

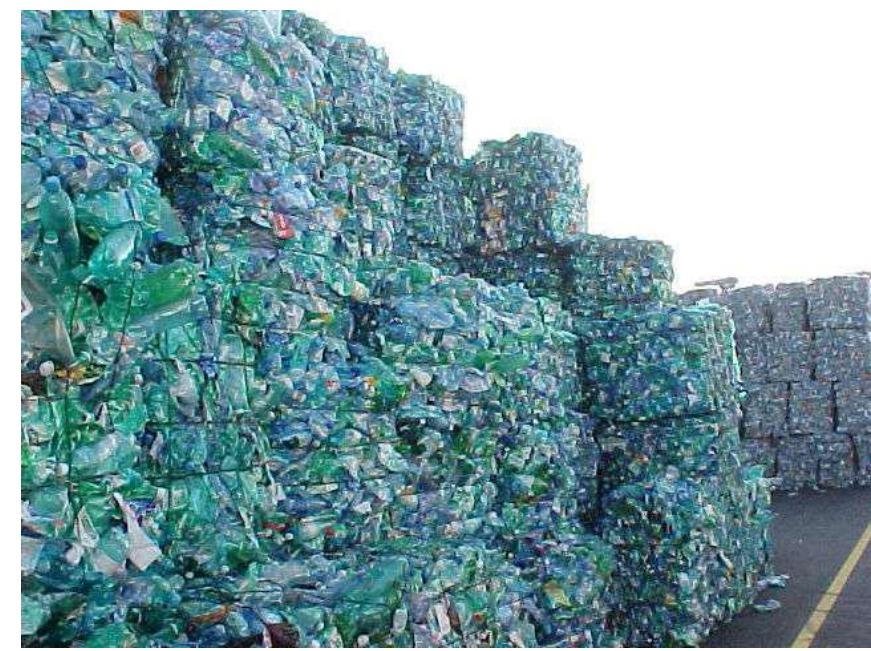

Figura 4. Fardos de garrafas de PET prensadas. ${ }^{5}$

Para que o material adquira valor comercial agregado é importante que esteja com a menor contaminação possível, pois a presença de contaminantes como o vidro,

\footnotetext{
${ }^{5}$ Disponível em http://www.abipet.com.br, acesso em 23/03/12.
} 
papel, metais ou outros polímeros como o poli (cloreto de vinila) (PVC), polietileno (PE), polipropileno (PP), dentre outros, provoca a desvalorização do material enfardado ou, até mesmo, pode inviabilizar sua comercialização. Destaca-se o PVC, cuja degradação térmica pode promover a geração de ácidos que provocam a hidrólise e consequente degradação do PET, mesmo em concentrações da ordem de 400 ppm (DOS SANTOS, 2008).

O PET enfardado é então enviado para centenas de empresas recicladoras que revisam a sucata com o auxílio de uma esteira transportadora equipada com um detector de metais. As contaminações visíveis são removidas manualmente, por peneira estática ou vibratória, dentre outros dispositivos. Na etapa seguinte, as garrafas são moídas em moinhos de facas rotativas originando o PET moído, denominado flocos ou flakes, com granulometria em torno de 9,5 mm (DOS SANTOS, 2008).

Os flocos moídos são transportados pneumaticamente para as lavadoras na presença de água e produtos químicos de limpeza como a soda cáustica, em concentrações de 2-3\%, por exemplo. As lavadoras são máquinas que possuem pás rotativas presas ao eixo central e apoiadas por mancais, girando na velocidade de 1200 rotações por minuto, e assim promovendo grande atrito e movimentação dos flakes. 0 eixo da máquina é envolto por uma chapa metálica perfurada, que mantém o material no processo, e permite a passagem de soluções de limpeza e da sujeira extraída dos flocos para fora do sistema (DOS SANTOS, 2008; WELLE, 2011).

Um tanque de decantação, abastecido com água, recebe o material pré-lavado, onde os flakes de PET descem para o fundo do tanque, separando-se do PE e PP (materiais que compõem, no geral, as tampas das garrafas PET), que flutuam na superfície da água, sendo continuamente removidos do processo através de um fluxo que transborda por um dreno, localizado na parte superior do tanque. Em seguida, os flakes de PET lavados são encaminhados para as centrífugas de secagem (DOS SANTOS, 2008; WELLE, 2011).

Através de centrífugas rotativas idênticas às lavadoras, porém, sem adição de água ou soluções de limpeza, a umidade superficial do polímero é reduzida por centrifugação. Um transportador pneumático conduz o PET limpo e seco para silos de armazenagem, que permitem a embalagem do polímero em grandes sacos, já em condições de comercialização, ou destinados a outros processos complementares (DOS 
SANTOS, 2008). Na Figura 5 é mostrado um conjunto típico de lavadoras e secadoras utilizadas na reciclagem mecânica do PET.

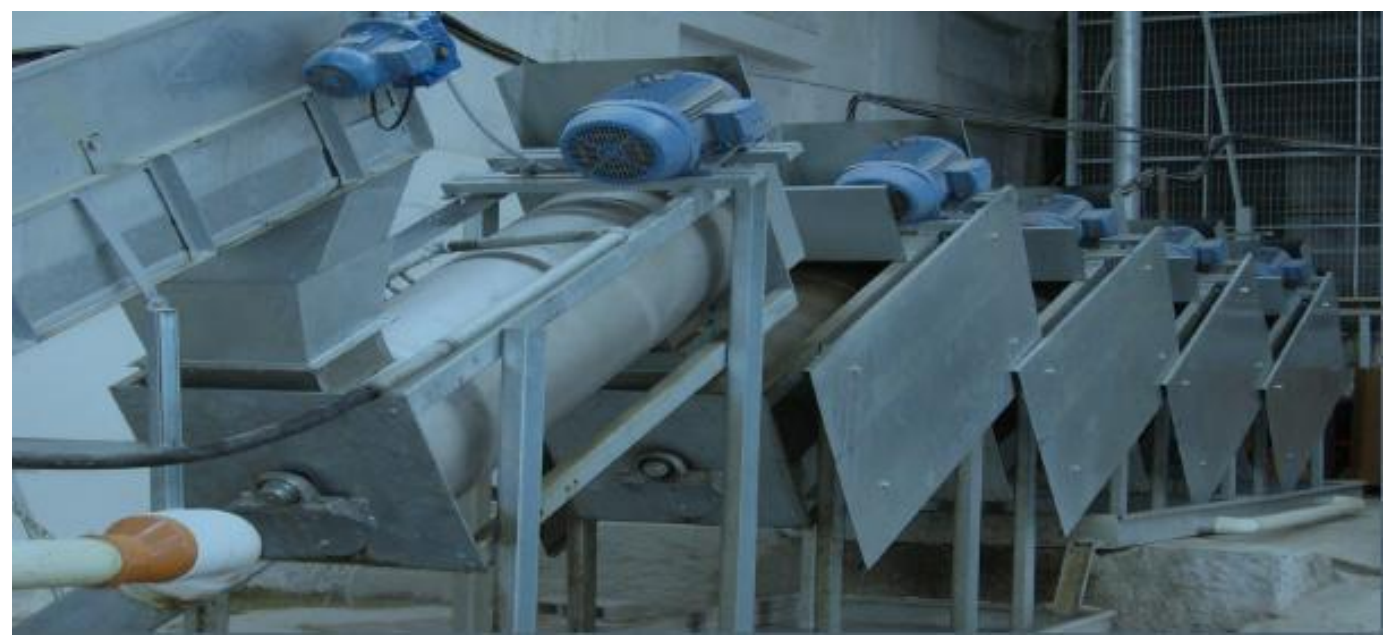

Figura 5. Conjunto de lavadoras e secadoras (DOS SANTOS, 2008)

No que tange à energia consumida nos processos de reciclagem, estima-se que, em média, é consumido apenas 30\% da energia que seria utilizada na produção da resina virgem (MANCINI; BEZERRA; ZANIN, 1998).

Em 2007, o Brasil revalorizou mais da metade do PET consumido nacionalmente, posicionando-se como o segundo maior reciclador de PET do planeta, à frente da média européia com 40\%, e dos Estados Unidos, com 23,5\%, sendo superado apenas pelo Japão, que reaproveitou $66,3 \%$ do polímero consumido. ${ }^{6}$ A posição mundial brasileira manteve-se em $2010^{7}$.

A indústria de reciclagem de polímeros no Brasil é constituída por cerca de 490 empresas recicladoras, $80 \%$ delas concentradas na região Sudeste, com faturamento de R\$ 1,22 bilhão/ano, gerando 11.500 empregos diretos (ROMÃO; SPINACÉ; DE PAOLI, 2009). De acordo com o sétimo censo da reciclagem do PET no Brasil, realizado pela ABIPET, o Brasil, em 2010, recuperou 55,8\% de PET pós-consumo, dado que representa um total de 282 ktons do polímero (Figura 6). Assim, o país posicionou-se mundialmente, como já citado anteriormente, como o segundo maior reciclador de PET.7 A Figura 6 representa o aumento da reciclagem de PET a partir de 2004, até 2010.

\footnotetext{
${ }^{6}$ Disponível em http://www.plasticomoderno.com.br/revista/pm409/noticias/noticias07.html, acesso em 23/03/12.

${ }^{7}$ Disponível em http://www.agenda21 comperj.com.br/noticias/reciclagem-de-garrafas-pet-aumenta-no-brasil, acesso em 23/03/12.
} 


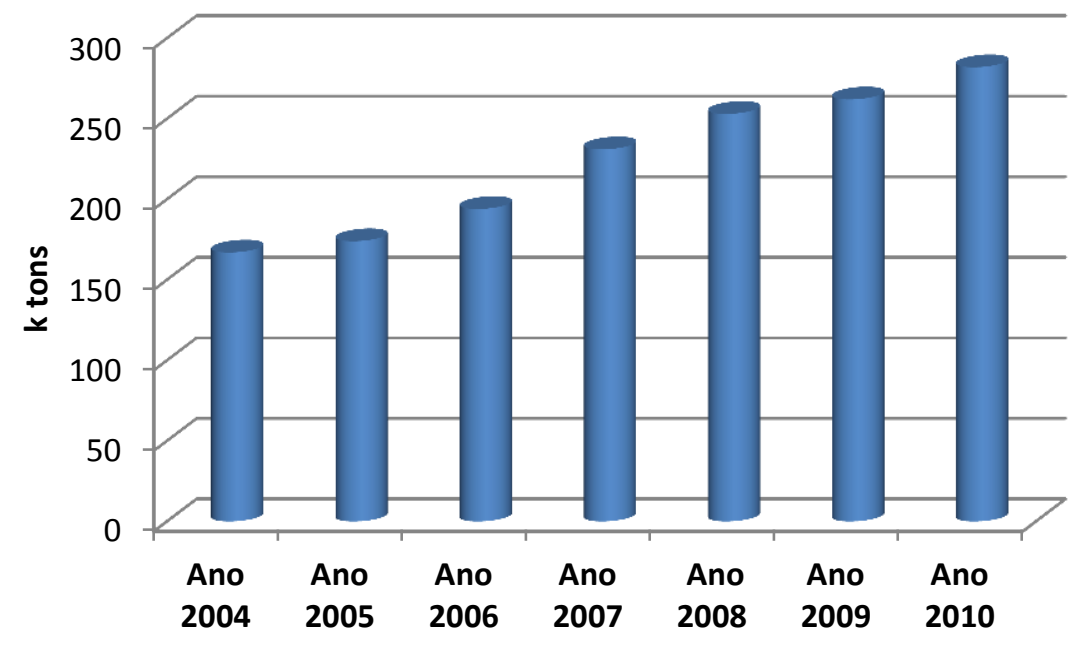

Figura 6. Evolução da Recuperação de PET no Brasil.8

Ainda, de acordo com o sétimo censo da reciclagem do PET no Brasil, em 2010, $60 \%$ do PET reciclado comercializado foi sob a forma de flakes, e destinado principalmente para fins têxteis, notadamente para a fabricação de não tecidos, como mantas de TNT, por exemplo (Figura 7).

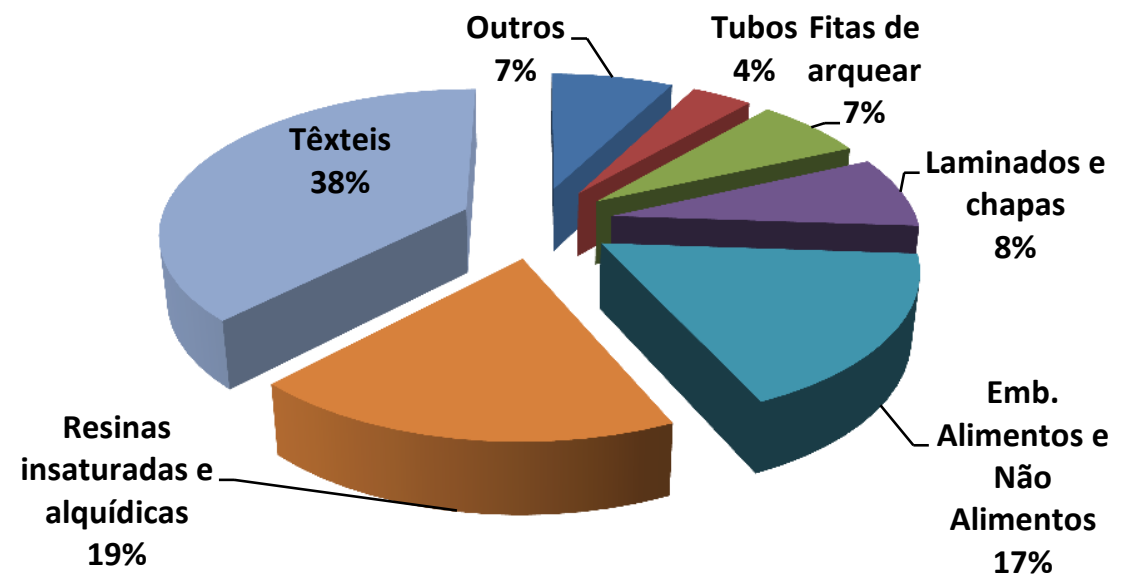

Figura 7. Usos finais em 2010 para o PET reciclado. 8

A reciclagem mecânica, apesar de vantajosa frente à reciclagem química, devido ao seu baixo custo, pode restringir as aplicações do PET reciclado, pela possibilidade de deterioração da resina durante o processo. Ainda, os flakes de garrafas PET não encontram aplicação em produtos de elevado valor comercial (NAKATANI; HIRAO, 2011). Portanto, no Brasil, ainda não foi encontrada uma aplicação mais nobre para o

${ }^{8}$ Disponível em http://www.abipet.com.br, acesso em 23/03/12. 
PET reciclado, que apresente propriedades de engenharia e preço de commodity (ROMÃO; SPINACÉ; DE PAOLI, 2009).

\section{No presente trabalho, PET reciclado mecanicamente foi utilizado.}

\subsection{Compósitos}

Os compósitos representam um caso de particular importância na classe dos materiais de engenharia, correspondendo a materiais heterogêneos, com pelo menos duas fases distintas. Uma das fases é descontínua, denominada reforço, responsável por fornecer a principal resistência ao esforço. A outra fase é contínua, chamada de matriz, correspondendo ao meio de transferência desse esforço (MANO, 1991; HERAKOVICH, 1998).

Portanto, as propriedades dos compósitos são fortemente influenciadas pelas propriedades dos seus constituintes, pelas suas distribuições e pela interação existente entre eles. A finalidade da combinação entre reforço e matriz é a promoção de características específicas para o material resultante, de acordo com a aplicação desejada (HERAKOVICH, 1998; PAIVA; FROLLINI, 2002).

Os compósitos podem ser projetados de forma a se obter excelentes combinações de resistência ao impacto, tenacidade, densidade, dureza, condução elétrica, resistência a altas temperaturas e corrosão (MANO, 1991; HERAKOVICH, 1998).

Os primeiros compósitos produzidos surgiram após o abandono das cavernas pelos homens, quando da necessidade de construírem suas moradias. Inicialmente, esta necessidade foi suprida pela enorme quantidade disponível de madeira e pedras. Entretanto, a escassez destes materiais em algumas regiões fez com que o homem passasse a utilizar o barro para a produção de tijolos. Estes tijolos eram muito quebradiços, fator consideravelmente melhorado pela introdução de palhas de arroz ou milho como materiais de reforço ao barro (matriz), com a obtenção de materiais mais resistentes e duráveis (GIACOMINI, 2003).

Pode-se considerar que, no futuro, as aplicações dos compósitos serão limitadas exclusivamente pela criatividade individual e pelos interesses das sociedades em explorar a área (TRINDADE et al., 2005).

Os compósitos podem ser classificados de acordo com a forma física e a distribuição do material utilizado como agente de reforço em duas classes distintas: 
particulados (reforçados com partículas) e fibrosos (reforçados por fibras longas ou curtas). No entanto, devido ao desenvolvimento desta classe de materiais, este sistema de classificação torna-se incompleto. Um esquema de classificação mais elaborado foi desenvolvido para os compósitos (Figura 8) (MATTHEWS; RAWLINGS, 1994).

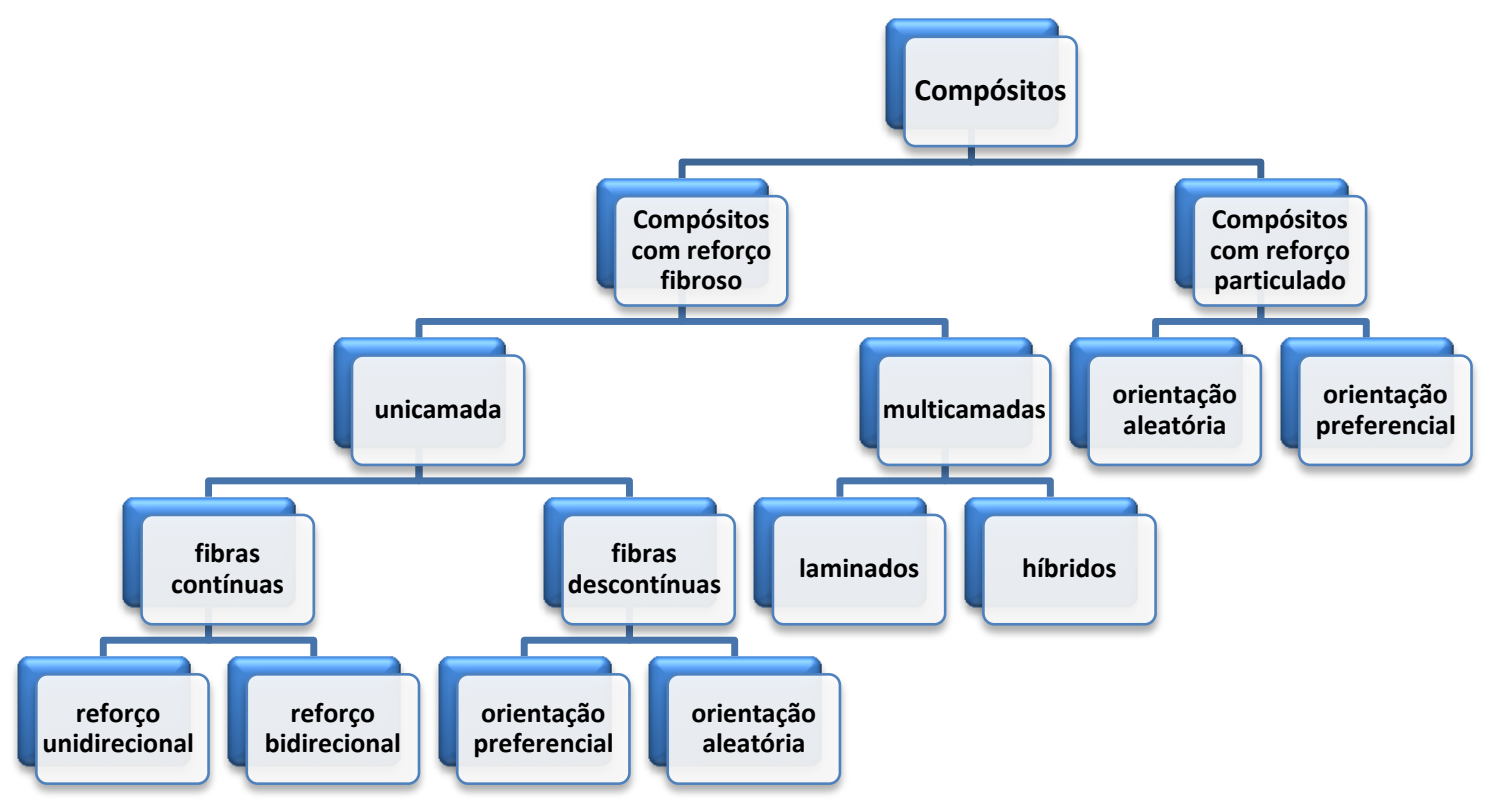

Figura 8. Sistema de classificação de compósitos com relação ao agente de reforço (MATTHEWS; RAWLINGS, 1994).

Há uma grande diversidade de materiais que podem ser empregados como matriz no preparo de compósitos. Estes materiais utilizados como matrizes podem ser classificados de acordo com o esquema representado na Figura 9 (MATTHEWS; RAWLINGS, 1994).

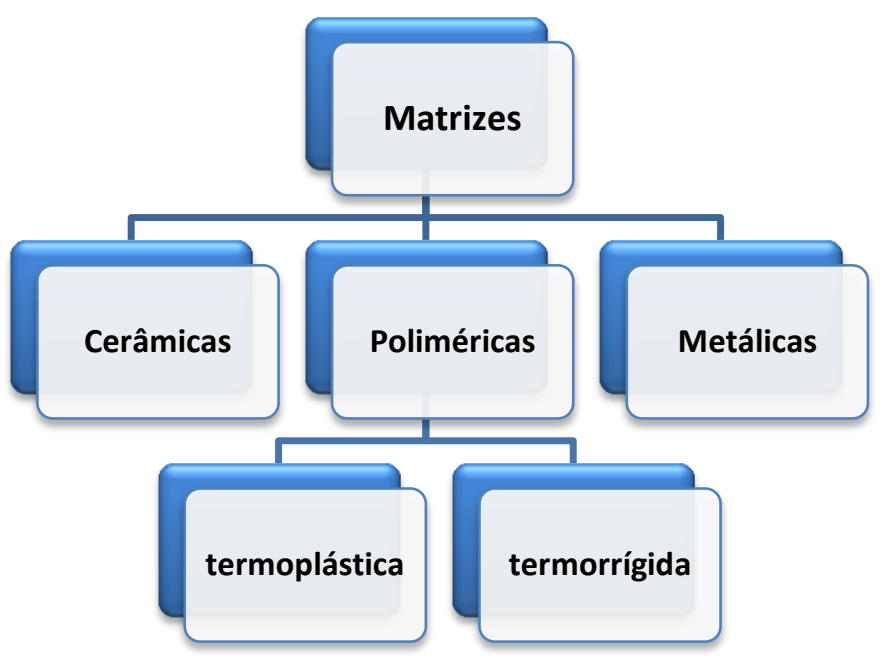

Figura 9. Sistema de classificação de compósitos com relação à matriz (MATTHEWS; RAWLINGS, 1994). 
No presente trabalho, foram preparados compósitos de matriz polimérica termoplástica, reforçados por fibras descontínuas, com distribuição aleatória.

\subsubsection{Compósitos de matriz polimérica}

Materiais poliméricos são considerados indispensáveis à vida moderna, no entanto, devido ao contínuo desenvolvimento de novas tecnologias, torna-se cada vez mais difícil encontrar um polímero que possua todas as características necessárias para uma determinada aplicação, seja devido às propriedades mecânicas, formas de obtenção ou custo. Assim, os polímeros são cada vez mais utilizados como matrizes no desenvolvimento de compósitos. Devido às vantagens dos polímeros em relação aos demais materiais, como as cerâmicas e os metais, na facilidade de processamento, baixo custo e elevada, e ao mesmo tempo versátil, aplicabilidade, os compósitos com matrizes poliméricas desenvolveram-se rapidamente e logo foram aceitos tanto pelas indústrias como pelo mercado consumidor (RAMIRES, 2010). Compósitos com matrizes poliméricas possuem diversas aplicações, desde a indústria automotiva, naval e aeroespacial, passando por aplicações militares, dentre outras (SURESH; SENTHIL KUMAR, 2011).

Esta diversidade de aplicações deve-se ao extenso número de combinações possíveis quando se mistura um material de reforço em matrizes poliméricas. Portanto, compósitos de matriz polimérica podem ser entendidos como a combinação de dois ou mais materiais, por exemplo, um reforço ou carga envolvido por uma matriz polimérica, com propriedades superiores a de seus constituintes (ALAM et al., 2011).

PET reciclado foi usado no presente trabalho para preparar compósitos de matriz polimérica termoplástica.

Quando fibras são utilizadas como material de reforço em materiais poliméricos, o compósito obtido pode apresentar grandes mudanças em suas propriedades, como melhoria nas propriedades mecânicas, aumento da resistência à flexão, módulo de elasticidade, dentre outras (RATNA PRASAD; MOHANA RAO, 2011). Os compósitos reforçados com materiais fibrosos normalmente são preparados a partir de fibras de alto módulo de elasticidade e resistência mecânica, embutidas ou ligadas na matriz com interfaces distintas entre elas (fronteira). Em geral, as fibras são os principais membros de solicitação mecânica, enquanto as vizinhanças da matriz as mantêm na localização e 
direção desejadas, agindo como um transportador médio de carga e protegendo as fibras de danos ambientais, decorrentes, por exemplo, de altas temperaturas e umidade (FROLLINI, 2002).

Plásticos reforçados com fibras naturais começaram a ser preparados em 1908, com fibras de celulose como material de reforço em compósitos fenólicos, mais tarde, uréia e melamina também foram utilizadas (JOHN; THOMAS, 2008). Com a obtenção de compósitos de matriz polimérica reforçada com fibras de vidro, esta classe de materiais atingiu o status de commodity (mercadoria), sendo as fibras de vidro utilizadas em 95\% dos compósitos termoplásticos e termorrígidos (MOHANTY; MISRA; DRZAL, 2005; JOHN; THOMAS, 2008).

Apesar de inúmeras vantagens, fibras como as de vidro apresentam inconvenientes quanto ao seu manuseio e processamento, e também podem causar problemas de saúde aos trabalhadores, como irritações na pele e no sistema respiratório durante seu manuseio. Ainda, estas fibras são abrasivas, produzindo desgaste nos equipamentos durante o processamento. Estes dois fatores são os principais responsáveis pelo relativo elevado custo de produção destas fibras, visto que são necessários consideráveis investimentos em acessórios, treinamentos de segurança e freqüente manutenção dos equipamentos usados. Entretanto, o principal problema a ser considerado na aplicação destas fibras sintéticas corresponde ao negativo impacto ambiental, pois as fibras apresentam baixa velocidade de degradação no meio ambiente e são produzidas a partir de matérias-primas oriundas de fontes não renováveis (MEGIATTO, 2006).

Assim, considera-se de extrema importância a necessidade do desenvolvimento e comercialização de materiais que possuam constituintes de origem natural (biobased composites, biocompósitos), com impacto positivo do ponto de vista ambiental, devido à redução da dependência de materiais provenientes de fontes fósseis, e também do ponto de vista econômico (JOSHI et al., 2004). É importante salientar que o termo biocompósito pode ser aplicado a materiais em que uma ou mais fases tem origem biológica (FOWLER; HUGHES; ELIAS, 2006). A partir dessa definição, biocompósitos podem ser aqueles preparados a partir de fibras naturais, em matrizes poliméricas oriundas de fontes renováveis ou não, recicláveis ou não (CAÑIGUERAL et al., 2009). Quando a fibra e a matriz possuem origem biológica (matriz baseada em biopolímeros), 
os biocompósitos são geralmente chamados de "green composites" (compósitos verdes) (MOHANTY; MISRA; DRZAL, 2005).

Neste contexto, os polímeros e as fibras naturais têm suscitado grande interesse nos últimos anos. Estes materiais podem ser obtidos a partir de fontes renováveis, são biodegradáveis, apresentam baixo custo, possuem baixa densidade específica, sendo, portanto, excelentes candidatos para substituir os tradicionais polímeros e fibras sintéticas (DONMEZ ÇAVDAR; KALAYCIOGLU; MENGELOGLU, 2011). Além disso, devido à sua baixa densidade, as fibras naturais podem reduzir a massa do compósito, fator importante para aplicações na indústria automobilística, construção civil, dentre outras (CORRADINI et al., 2009).

O Brasil, país de vocação agrícola, possui um dos maiores potenciais em biomassa do mundo, além da maior extensão territorial com possibilidade de cultivo. A exploração sistemática destes recursos, visando o desenvolvimento sustentável e aplicações diversificadas daquelas já consideradas atualmente, pode representar uma fonte alternativa de emprego no setor agrícola, além de providenciar uma solução para a poluição do meio ambiente, e encontrar novas aplicações para a matéria-prima excedente (FROLLINI, 2002).

Estudos envolvendo fibras naturais como as de sisal, bagaço de cana de açúcar, curauá, seda, folha de abacaxi, juta, dentre outras, em substituição às tradicionais fibras sintéticas, como fibras de vidro e carbono, em aplicações como agentes de reforço em matrizes poliméricas, têm crescido muito nos últimos anos (DE CASTRO, 2010; ALAM et al., 2011; DA SILVA, 2011; DEVI; BHAGAWAN; THOMAS, 2011; LIMA; MONTEIRO; SATYANARAYANA, 2011; NHLAPO; LUYT, 2012). Dentre a vasta gama de fibras lignocelulósicas existente, o sisal corresponde a uma das mais utilizadas, devido às suas excelentes propriedades (CAMPOS et al., 2011).

\subsection{Fibras de sisal}

O sisal (Figura 10) pertence à classe das monocotiledôneas, família Agavaceae, subfamília Agavoidea, gênero Agave, espécie Agave sisalana. A designação Agave provém do grego agavos que significa admirável, magnífico; e sisalana significa rigidez (PAIVA; FROLLINI, 2002). Trata-se de uma planta de elevada complexidade morfofisiológica que apresenta sistema radicular fibroso e em forma de tufo. Possui dois tipos de raízes 
designadas por transportadoras e alimentadoras, sendo as primeiras responsáveis pela fixação da planta ao solo. Não tem caule, e as folhas são destituídas de pecíolos (espécie de haste delgada através da qual as folhas ligam-se ao caule), podendo chegar a quase dois metros de comprimento. Existem duas espécies no gênero Agave, de importância econômica: A. Sisalana, que tem a Bahia como maior produtor mundial, e a $A$. fourcroydes, explorada no México sob a denominação de henequém e cuja fibra é utilizada para a fabricação de fios e cordas. $^{9}$

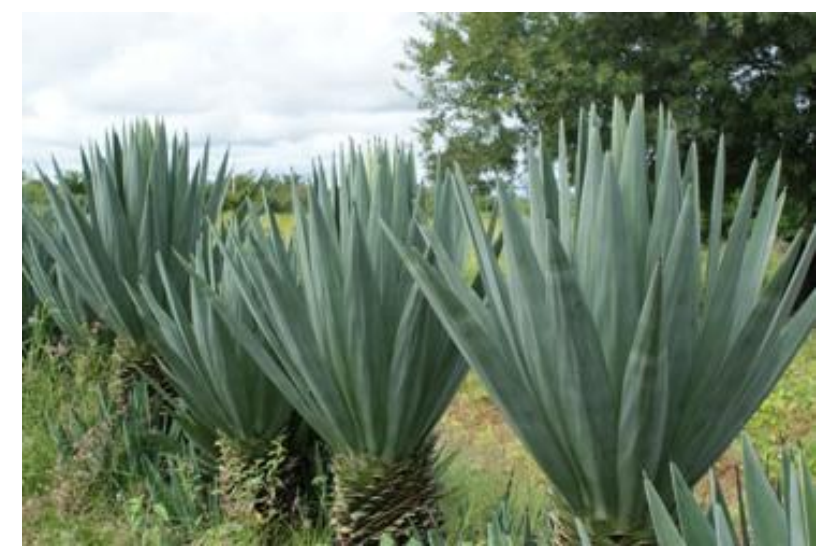

Figura 10. Planta de sisal. ${ }^{10}$

O sisal é uma das principais fibras duras (fibra vegetal fiável com elevada resiliência e resistência mecânica) produzida no mundo, correspondendo a aproximadamente $70 \%$ da produção comercial de todas as fibras desse tipo. A fibra do sisal, beneficiada ou industrializada, rende cerca de 80 milhões de dólares em divisas para o Brasil, além de gerar mais de meio milhão de empregos na sua cadeia de serviços, que começa com as atividades de manutenção das lavouras, colheita, desfibramento e beneficiamento da fibra e termina com a industrialização e a confecção de artesanato. 0 Brasil é o maior produtor e exportador de fibras e manufaturados de sisal do mundo, com 58\% da produção e 70\% da exportação no ano de 2010. A Bahia é responsável por 96\% da produção de fibra nacional, seguida por Pernambuco, Paraíba, Rio Grande do Norte e Ceará. A produtividade média de sisal, no estado da Bahia, em 2010, após alguns investimentos, chegou a $1.200 \mathrm{~kg} / \mathrm{ha}$, indicando um crescimento, em relação a 2009, que alcançou $1.033 \mathrm{~kg} /$ ha. Os principais importadores da fibra de sisal produzida no país são os Estados Unidos, China, México e Portugal. ${ }^{9}$

\footnotetext{
${ }^{9}$ Disponível em http://www.brazilianfibres.com.br/?page_id=17\&lang=pt, acesso em 24/03/12.

10 Disponível em http://www.agronews.blog.br/noticia/sisal-tem-dia-de-campo-sobre-producao-integrada/28, acesso em 24/03/12.
} 
No Brasil, a agaveicultura se concentra em áreas de pequenos produtores, com predomínio do trabalho familiar. A cultura é de fundamental importância na economia nordestina, pois torna produtivas regiões semi-áridas. Estas regiões apresentam escassas alternativas econômicas e baixo Índice de Desenvolvimento Humano (IDH), sendo a cultura sisaleira fator de sobrevivência devido ao emprego de grande volume de mão de obra, contribuindo para a fixação do homem no campo.

A fibra de sisal é uma das fibras naturais mais amplamente utilizadas, devido à facilidade de cultivo e seu curto tempo de renovação, visto que as fibras são colhidas geralmente a cada nove meses. Estas possuem também diversas aplicações tais como na fabricação de cordas principalmente para a marinha, tapetes, redes de pesca e artesanatos em geral (AKRAM KHAN et al., 2011).

Em média, cada folha de sisal fornece, em peso, 4\% de fibras descontínuas, 0,75\% de cutículas, 8\% de matéria seca e o restante, 87,25\% de água (NABI SAHEB; JOG, 1999; LI; MAI; YE, 2000; JACOB; THOMAS; VARUGHESE, 2004).

Do ponto de vista anatômico, as fibras extraídas do sisal se inserem no grupo de fibras denominadas estruturais, cuja função é dar sustentação e rigidez às folhas (LI; MAI; YE, 2000). As fibras lignocelulósicas, como as fibras de sisal (Figura 11-a), são constituídas por uma matriz não cristalina de hemicelulose e lignina (Figura 11-b) reforçada por microfibrilas de celulose (Figura 11-c) em toda a sua extensão. Estes constituintes são os principais responsáveis pelas propriedades físicas das fibras (DA SILVA, 2011). Além desses constituintes, as fibras são compostas por pectina, ceras e outras substâncias de caráter hidrofílico (GEORGOPOULOS et al., 2005).

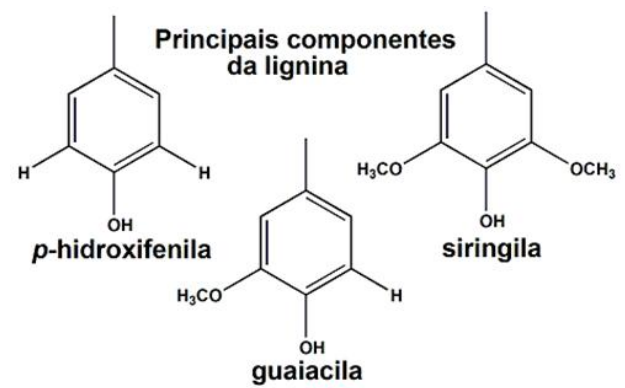

(b)

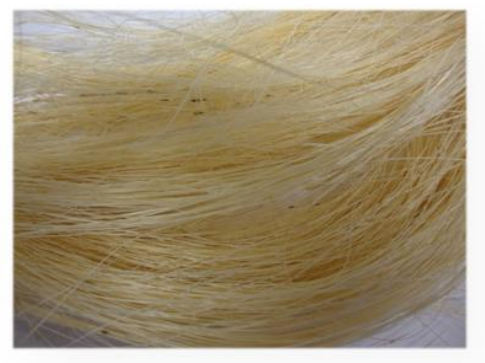

(a)

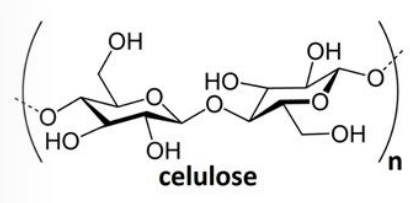

(c)

Figura 11. Imagem da fibra de sisal (a) e seus principais constituintes: (b) principais componentes da lignina e (c) celulose.

As fibras lignocelulósicas possuem algumas limitações quanto ao seu uso, pois são passíveis de degradação térmica quando processadas em elevadas temperaturas. As 
análises térmicas de Calorimetria Exploratória Diferencial (DSC) e Termogravimetria (TG) mostraram que quatro distintos processos térmicos ocorrem com a fibra sob aquecimento a temperaturas de $37-490^{\circ} \mathrm{C}$. 0 primeiro processo ocorre na faixa de temperaturas de 37-105 ${ }^{\circ}$ C. Neste processo ocorre somente à desidratação da fibra, a decomposição inicia acima de $200{ }^{\circ} \mathrm{C}$. 0 segundo processo de decomposição térmica sofrido pela fibra é a decomposição da hemicelulose, seguido da decomposição da celulose, principal constituinte da fibra. Neste processo, a celulose sofre desidratação e despolimerização, com a formação de produtos voláteis. Em temperaturas superiores a $380{ }^{\circ} \mathrm{C}$ ocorre a decomposição da lignina com a completa perda da estrutura nativa da fibra (SAIKIA, 2008; DE OLIVEIRA, 2010; MARTIN et al., 2010; RAMIRES, 2010).

Visando a valorização da fibra de sisal, pois como já mencionado o país é o maior produtor mundial, porém com cerca de $87 \%$ da produção interna exportada, esta fibra foi usada no presente estudo.

\subsubsection{Fibras de sisal como material de reforço em compósitos poliméricos}

Nos últimos anos houve um aumento considerável na demanda por compósitos reforçados por fibras naturais, como as fibras de sisal, por exemplo. Na literatura são relatados compósitos preparados com fibras de sisal como agente de reforço das mais diversas matrizes, tais como borracha natural (JACOB; THOMAS; VARUGHESE, 2004), lignosulfonato-formaldeído (DE OLIVEIRA, 2010), termorrígido fenólico (DA SILVA, 2011), blenda amido termoplástico/policaprolactona (TPS/PCL) (CAMPOS et al., 2011), dentre outros materiais. Estes compósitos encontram aplicações desde as indústrias de embalagens, automobilísticas, construção civil, até as indústrias aeronáuticas (HUQ et al., 2011).

A combinação de compósitos poliméricos com fibras de sisal se destaca por apresentar bom desempenho mecânico quanto à alta resistência ao impacto, assim como boas propriedades de resistência à tração axial e à flexão. Como exemplo, Rosário et al. (2011) estudaram as propriedades mecânicas de compósitos de polipropileno (PP) virgem e reciclado reforçados com fibras de sisal. Neste estudo, os autores verificaram que os compósitos reforçados com 30\% em massa de fibras de sisal apresentaram melhor desempenho em relação à matriz reciclada sem fibra, no que se refere à 
resistência à tração, módulo de Young e especialmente resistência ao impacto (com um aumento de $140 \%)$.

Apesar do potencial das fibras de sisal para utilização como reforço em compósitos poliméricos, sua aplicação ainda não é tão efetiva quanto à de fibras sintéticas, e o seu uso ainda requer estudos que indiquem, por exemplo, as matrizes mais adequadas para serem usadas (MEGIATTO, 2006).

Além da heterogeneidade na estrutura e composição química, as fibras de sisal também apresentam restrições quanto às condições de processamento. 0 tratamento térmico, normalmente imposto às fibras durante a etapa de preparação dos compósitos, pode provocar mudanças físicas e químicas. A decomposição térmica das fibras causa deterioração das suas propriedades mecânicas, comprometendo o desempenho mecânico do compósito final obtido (GEORGOPOULOS et al., 2005).

Dentre as desvantagens das fibras lignocelulósicas, como as de sisal, talvez a principal corresponda à sua natureza hidrofílica. Por apresentarem alto teor de polissacarídeos (hemicelulose e celulose), e, portanto, grupos hidroxila, as fibras de sisal (e outras fibras naturais) possuem alta higroscopicidade, em relação às fibras sintéticas. Estas fibras também possuem em sua superfície impurezas como ceras naturais, que podem levar a fraca adesão interfacial fibra-matriz dos compósitos. Este caráter hidrofílico tem limitado a sua aplicação como agente de reforço, principalmente em matrizes poliméricas hidrofóbicas, devido à falta de compatibilidade entre os componentes do compósito (AKRAM KHAN et al., 2011). Tratamentos com a finalidade de modificação da superfície das fibras, como o uso de soluções alcalinas de $\mathrm{NaOH}$ em concentrações de até 10\%, tem sido considerados (FAULSTICH DE PAIVA; FROLLINI, 2006).

Os compósitos preparados no presente trabalho corresponderam a matriz polimérica termoplástica de PET reciclado reforçado por fibras curtas de sisal, distribuídas aleatoriamente na matriz.

\subsection{Compósitos de PET/fibras lignocelulósicas}

Para que a reciclagem do PET no país atinja 100\%, é considerado que é preciso envolver todos os elos da cadeia: o consumidor, os trabalhadores na coleta seletiva e na separação dos materiais, sistema de logística reversa (área da logística que trata, 
genericamente, do fluxo físico de produtos, embalagens, dentre outros materiais, desde o ponto de consumo até ao local de origem), assim como o desenvolvimento de um parque industrial adequado. Pode-se acrescentar a estes fatores a necessidade de desenvolvimento de pesquisas que levem a materiais, preparados a partir de PET reciclado, com valor agregado, como podem se tornar os compósitos de PET reforçados com fibras lignocelulósicas. ${ }^{11}$

O PET é um termoplástico de baixo custo e elevado desempenho (HUQ et al., 2011). É amplamente utilizado como material de embalagens, fibras e garrafas devido a características como rigidez, dureza, resistência à abrasão, resistência química a solventes e isolamento elétrico. No entanto, possui devido a sua estrutura química relevante sensibilidade ao entalhe, fragilidade e elevado ponto de fusão, comparativamente a poliolefinas como o PP e o PE (BARKOULA et al., 2008; RAHMAN et al., 2008).

O uso de fibras naturais como materiais de reforço em compósitos de matriz de PET apresenta um grande potencial na melhora do desempenho mecânico e aplicação tecnológica destes materiais, devido a características das fibras como baixo custo, biodegradabilidade e elevada força específica. Huq et al. (2010) estudaram as propriedades mecânicas de compósitos de PET reforçados por fibras de juta. Neste estudo, os autores verificaram que compósitos de PET reforçados com 50\% em massa de fibras de juta apresentaram valores superiores de resistência à tração, impacto e flexão, quando comparados com os valores apresentados pelo PET. Outros estudos envolvendo fibras naturais como as de linho, bagaço de cana de açúcar e fibras de algodão também têm sido relatados (CORRADINI et al., 2009; NIU et al., 2010; ZOU; REDDY; YANG, 2011).

\subsection{Dificuldades de processamento de compósitos de PET/fibras lignocelulósicas}

Uma limitação encontrada no processamento de compósitos de PET/fibras lignocelulósicas corresponde à limitada estabilidade térmica das fibras, que são passíveis de decomposição térmica se processadas a elevadas temperaturas, conforme já

11 Disponível em http://www.revistasustentabilidade.com.br/reciclagem, acesso em 24/03/12. 
mencionado. A temperatura de fusão do PET é de aproximadamente $265^{\circ} \mathrm{C}$, ou seja, uma temperatura que compromete a estabilidade da fibra. Assim, quando é observado que o polímero não é suficiente para recobrir e retardar a decomposição das fibras, faz-se necessária a adição de plasticizantes para diminuição da temperatura de fusão do PET e melhoria da processabilidade dos compósitos. Zou, Reddy e Yang (2011) estudaram o efeito da adição dos plasticizantes glicerol e 2-fenil fenol (em concentrações de até 10\% em massa) no preparo de compósitos de PET reforçados com fibras de algodão. Em seu estudo verificaram que, com a adição dos plasticizantes, a temperatura de fusão do PET diminuiu para $241{ }^{\circ} \mathrm{C}$, de acordo com as curvas obtidas através da análise de calorimetria exploratória diferencial (DSC). Com a adição dos plasticizantes, os autores também verificaram um aumento na resistência à flexão e tração dos compósitos, assim como uma diminuição na resistência ao impacto destes.

Devido à predominância da natureza hidrofílica das fibras lignocelulósicas e de regiões hidrofóbicas do PET, os compósitos podem apresentar fraca interação fibramatriz. Como possível solução para este problema, agentes de compatibilização podem ser adicionados às formulações dos compósitos para o aumento da compatibilidade entre as fibras naturais e a matriz termoplástica, melhorando o desempenho mecânico dos compósitos (XUE et al., 2007).

Corradini et al. (2009) em seu estudo consideraram a adição dos copolímeros etileno/n-butil acrilato/glicidil metacrilato (EBGMA) e etileno-metil acrilato (EMA) como agentes de acoplamento em compósitos de PET reciclado/fibras de bagaço de cana de açúcar. De acordo com os autores, ambos os agentes compatibilizantes aumentaram a adesão das fibras de bagaço de cana/PET reciclado. O EBGMA foi mais eficiente como compatibilizante, de acordo com as medidas reométricas de torque e análise térmica dinâmico-mecânica (DMTA) dos compósitos.

Em seu estudo, Huq et al. (2010) consideraram a incorporação de polietileno linear de baixa densidade (PELBD) em compósitos de PET reciclado reforçados com fibras de juta. Os autores verificaram que a blenda formada de PET/PELBD em compósitos reforçados com fibras de juta melhorou a processabilidade e a elongação na ruptura quando comparados com compósitos de PET/fibras de juta.

No presente trabalho, se buscou o uso de plasticizantes que também pudessem atuar como agentes de compatibilização entre fibras lignocelulósicas e PET reciclado. 


\subsection{Uso de plasticizantes no processamento de materiais compósitos}

Inventores anônimos foram os primeiros, nas suas respectivas áreas geográficas, a usar a água como o primeiro plasticizante. A cerâmica foi provavelmente o primeiro produto que foi produzido com o uso de um plasticizante. A pintura é também outro exemplo de aplicação em tempos remotos de plasticizantes (SEARS; DARBY, 1982).

Ao antigo Egito é creditado o uso inicial de plasticizantes para preservar a pele de humanos e animais. Estes foram utilizados no processo de mumificação, em que o corpo era seco e, como a pele seca era muito frágil, uma mistura de óleo de cedro, cera, natrão (mineral composto por carbonato de sódio hidratado) e goma era esfregada na pele para suavizá-la e evitar rachaduras (SEARS; DARBY, 1982). Todos estes exemplos mostram que desde tempos remotos os desenvolvimentos tecnológicos foram ditados por necessidades de processamento e transformação de materiais.

Numerosas definições de plasticizante estão em uso, resumindo-se, pode-se definí-lo como sendo um material de baixa massa molar, adicionado a materiais poliméricos tais como tintas, plásticos ou adesivos. ${ }^{12}$

Um dos fatores externos que mais altera os valores das temperaturas de transição vítrea $\left(\mathrm{T}_{\mathrm{g}}\right)$ e de fusão $\left(\mathrm{T}_{\mathrm{m}}\right)$ é a presença de plasticizantes na forma líquida, ou sólidos de baixa massa molar, intencionalmente adicionados ou naturalmente absorvidos pelo polímero. Estas moléculas, geralmente pequenas, alojam-se entre as cadeias poliméricas, afastando-as umas das outras. Este afastamento reduz a intensidade da atração intermolecular, aumentando a mobilidade de segmentos de cadeias, ou seja, "lubrificando" as cadeias do polímero. Esta "lubrificação" molecular reduz o nível energético necessário para dar a mobilidade às ligações de segmentos da cadeia, ou seja, diminui as barreiras energéticas para rotação em torno de ligações, consequentemente, reduzindo a temperatura de transição vítrea do polímero.

Plasticizantes podem ser adicionados à formulação de um polímero, reduzindo a dureza do produto comparativamente ao estado inicial, alterando fortemente seu comportamento mecânico. Crespo et al. (2007) estudaram o efeito da adição de diferentes concentrações do plasticizante de nome comercial Hexamoll DINCH da BASF

12 Disponível em http://lpcr.iqm.unicamp.br/arquivos/dplasticizanteslubrificantes.pdf, acesso em 24/03/12. 
Ltda. em compósitos de PVC/casca de arroz. De acordo com os autores, a resistência à tração dos compósitos diminuiu linearmente com o aumento da concentração de plasticizante. Houve também uma diminuição na rigidez dos compósitos com o aumento da concentração de plasticizante.

Wong, Shanks e Hodzic (2003) estudaram o efeito dos plasticizantes tri etil citrato (TEC), tributil citrato (TBC) e glicerol tri acetato (GTA) em compósitos de ácido poliláctico reforçados com fibras de linho. Os resultados mostraram que as transições térmicas dos compósitos foram afetadas com a adição dos plasticizantes, principalmente a temperatura de transição vítrea, que diminuiu consideravelmente devido a presença destes.

Na presença de plasticizantes normalmente ocorre um aumento da mobilidade de segmentos, que pode induzir a cristalização. Um maior poder de solvatação do plasticizante pode afetar a fase cristalina ou interferir na cristalização (CANEVAROLO JR., 2006). Por outro lado, plasticizantes também podem retardar a formação de estruturas cristalinas, pois interferem no crescimento dos esferulitos, uma vez que estão presentes nas superfícies das lamelas cristalinas (WYPYCH, 2003).

A localização exata do plasticizante é freqüentemente avaliada para melhor compreensão da estrutura dos polímeros plasticizados. No PVC plasticizado, as moléculas de plasticizante foram encontrados na região não-cristalina, mas também estão presentes nas regiões interlamelares, interfibrilares e interesferulíticas (CANEVAROLO JR., 2006).

No PVC, esferulitos que crescem na presença de tricresil fosfato (Figura 12) são mais espessos e menos birrefringentes (formação de dupla refração apresentada por certos cristais intimamente ligada com a velocidade e direção de propagação da luz) (CANEVAROLO JR., 2006).<smiles>Cc1cccc(OP(=O)(Oc2cccc(C)c2)Oc2ccccc2C)c1</smiles>

Figura 12. Fórmula estrutural do tricresil fosfato 
Destaca-se o crescente uso de plasticizantes no processamento de compósitos poliméricos reforçados com fibras lignocelulósicas tais como glicerol e uréia em compósitos de álcool polivinílico reforçado com bagaço de laranja e maça, 3metacriloxipropil-trimetoxisilano em compósitos de resina de poliéster ortoftálico insaturado reforçado com fibras de sisal, glicerol em compósitos de amido reforçado com fibras de banana e bagaço de cana, dentre outros(CHIELLINI et al., 2001; FONSECA et al., 2004; GUIMARÃES et al., 2010).

\subsubsection{Plasticizantes tradicionais}

Os Adipatos são plasticizantes industriais ditos "tradicionais", sendo derivados dos ésteres de ácido adípico (Figura 13).

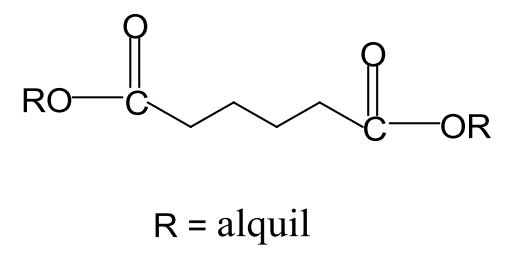

Figura 13. Fórmula estrutural geral de éster de ácido adípico.

São especialmente indicados quando se deseja a manutenção da flexibilidade de produtos em baixas temperaturas, como o Vinnolit S4099 (resina de PVC de alta massa molar média).13 0 plasticizante mais conhecido desta família é o di octil adipato (DOA) (Figura 14).

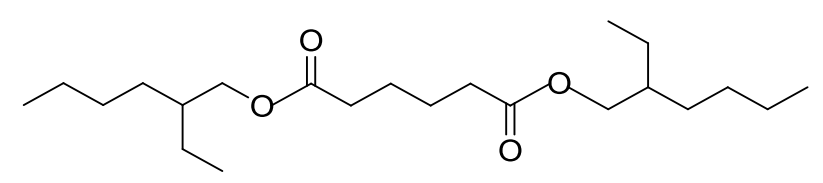

Figura 14. Fórmula estrutural do DOA.

O DOA, entre outras aplicações, é utilizado em filmes flexíveis de PVC para embalagens e revestimentos de fios e cabos. ${ }^{14}$

Outra tradicional classe de plasticizantes corresponde aos ftalatos, ésteres do ácido ftálico, de fórmula estrutural de acordo com a Figura 15.

\footnotetext{
13 Disponível em http://www.vinylarena.com.br/files/artigos_tecnicos/S-PVC_Valor_K99-Vinnolit_S4099.pdf, acesso em 24/03/12.

14 Disponível em http://www.braskem.com.br/upload/portal_braskem/pt/produtos_e_servicos/boletins/P asticizantes.pdf, acesso em 24/03/12.
} 
<smiles></smiles>

Figura 15. Fórmula estrutural geral de éster do ácido ftálico.

Estes ésteres constituem a classe de plasticizantes mais usada para combinações com resinas vinílicas. Estes plasticizantes são largamente empregados em função de seu baixo custo e das boas propriedades no produto acabado. Desta classe o ftalato de di-2etil hexila (DOP), Figura 16, é o mais utilizado e pode ser aplicado na maioria das formulações do PVC.<smiles>CCOC(=O)c1ccccc1C(=O)OCC</smiles>

Figura 16. Fórmula estrutural do DOP.

O DOP é utilizado em embalagens, calçados, tubos e perfis, dentre outras aplicações. Este representa mais de $50 \%$ do total de plasticizantes produzidos no mundo. ${ }^{15}$

Como resultado da utilização generalizada dos ftalatos, estes são comumente detectados no ar, água, solos e até mesmo em tecidos humanos (FROMME et al., 2002; FERNANDEZ; IKONOMOU; BUCHANAN, 2007; ZENG et al., 2009; SIMMCHEN; VENTURA; SEGURA, 2012).

Alguns ftalatos apresentam restrições de uso para determinadas aplicações, já que estudos em roedores demonstraram potencial carcinogênico e mutagênico nestes (HEUDORF; MERSCH-SUNDERMANN; ANGERER, 2007). Para o IARC (International Agency for Research on Cancer), órgão científico ligado à OMS (Organização Mundial da Saúde), o DOP é, desde 2000, classificado como "substância que não pode ser considerada como carcinogênica nos seres humanos". Apesar de tal recomendação é crescente a restrição do uso desta substância como plasticizante para polímeros e elastômeros no mundo todo. ${ }^{16}$ 


\subsubsection{Plasticizantes oriundos de fontes renováveis/naturais e que possam atuar também como compatibilizantes fibra-matriz}

Krauskopf e Godwin (1999) abordaram em seu estudo alternativas aos plasticizantes à base de ftalatos para uso com polímeros polares, com ênfase ao PVC. Os plasticizantes ftálicos apresentam expressivo histórico frente às diversas aplicações para os setores hospitalar, farmacêutico e alimentício. Alguns destes setores têm adotado medidas cautelosas na busca de alternativas aos plasticizantes ftálicos, que têm sido muito questionados nos últimos anos (MADALENO et al., 2009a). Assim, é crescente a busca por novos plasticizantes naturais, oriundos de fontes renováveis.

Embora seu emprego seja mais restrito devido aos custos mais elevados de produção, os citratos, conhecidos como ésteres do ácido cítrico, atuam como plasticizantes de grande aceitação na área médica, por exemplo, pois são considerados produtos sem riscos à saúde humana.

O plasticizante mais conhecido desta família é o acetil tributil citrato (ATBC) (Figura 17) que tem na Europa aplicações na área médica, sendo também utilizado em filmes transparentes de PVC para embalagens e em filmes de cloreto de polivinilideno (PVDC). ${ }^{17}$

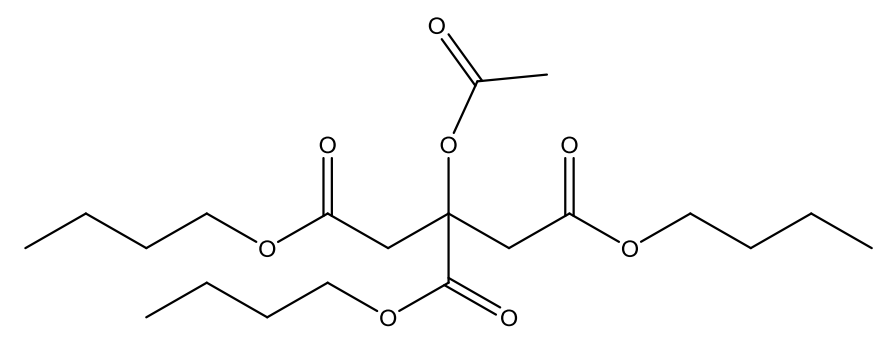

Figura 17. Fórmula estrutural do ATBC.

Não se pode deixar de considerar o crescente uso do tributil citrato (TBC) (Figura 18) como plasticizante em compósitos poliméricos termoplásticos reforçados com fibras lignocelulósicas (WONG; SHANKS; HODZIC, 2003; OUAJAI; SHANKS, 2009).

17 Disponível em http://www.plastico.com.br/reportagem.php?rrid=717\&rppagina=5, acesso em 24/03/12. 


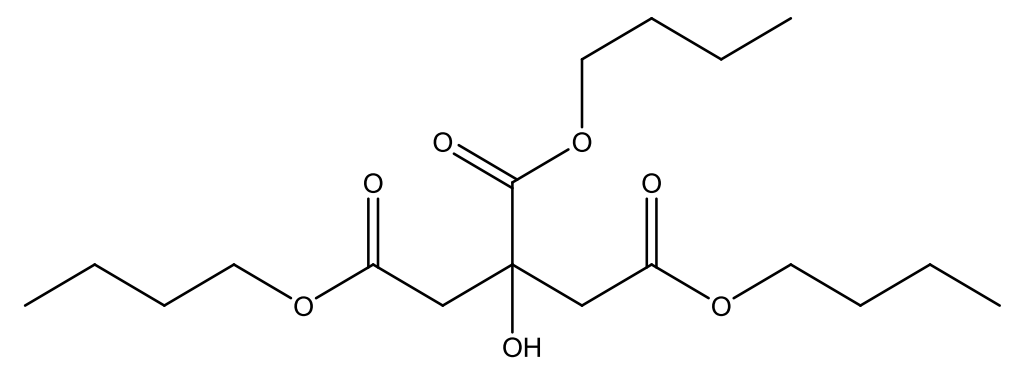

Figura 18. Fórmula estrutural do TBC.

Estes ésteres, derivados do ácido cítrico, vêm substituindo os ftalatos, principalmente o DOP, por serem considerados, como já citado, produtos naturais e com propriedades antioxidantes, sendo que o ácido cítrico desempenha importante papel no metabolismo de quase todos os seres vivos. ${ }^{18}$

Destaca-se que, no presente trabalho, os plasticizantes TBC, ATBC, dentre outros plasticizantes, foram escolhidos como plasticizantes por também poderem atuar como compatibilizantes fibra-matriz devido às possíveis interações intermoleculares com a matriz de PET reciclado e as fibras de sisal. A Figura 19 mostra algumas destas interações entre o TBC/PET/fibras.

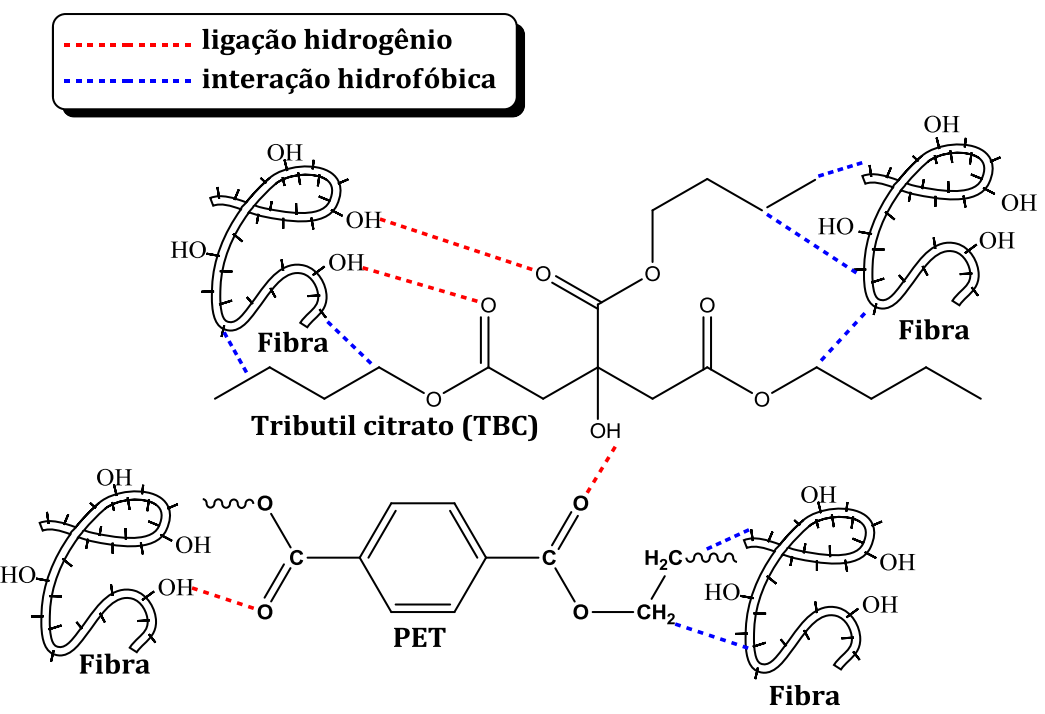

Figura 19. Interações entre TBC/PET/fibra.

Outros tipos mais conhecidos de plasticizantes obtidos de fontes naturais são produzidos pela epoxidação de óleos vegetais, sendo que esta reação emprega, em geral, peróxido de hidrogênio ou ácido peracético (Figura 20).

\footnotetext{
18 Disponível em http://www.braskem.com.br/upload/portal_braskem/pt/produtos_e_servicos/boletins/Plasticizantes.pdf, acesso em 24/03/12.
} 
<smiles>CC(=O)OO</smiles>

Figura 20. Fórmula estrutural do ácido peracético.

A classe constituída pelos óleos vegetais epoxidados é a dos epóxidos, e a reação de epoxidação de alceno com o uso de peróxido de hidrogênio é mostrada na Figura 21.

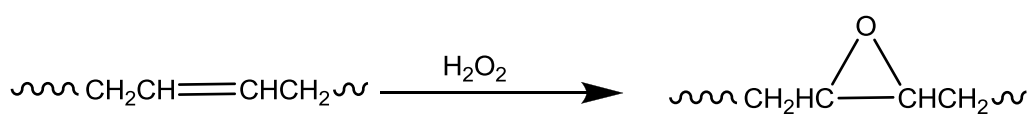

Figura 21. Reação de epoxidação de alceno.

Como exemplo, tem-se o óleo de soja epoxidado (OSE) (Figura 22), que pode ser utilizado em PVC em concentrações de até 10\% em massa, com vantagens de baixo custo, baixa toxicidade e também devido às suas características de sinergia com os estabilizantes térmicos para o PVC, além de sua baixa migração. ${ }^{19}$

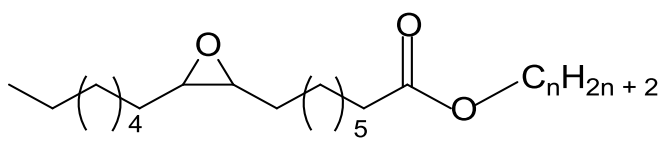

Figura 22. Fórmula estrutural do OSE.

Este mesmo processo pode ser empregado para outras fontes de ácidos graxos, por exemplo, os demais óleos vegetais insaturados e até as gorduras de origem animal. Madaleno et al. (2009b), em seu estudo, desenvolveram a epoxidação do éster do óleo de milho com a obtenção de um plasticizante que poderá apresentar grande interesse comercial e técnico ao mercado do PVC. Para o desenvolvimento foi usado o óleo extraído do germe do milho e refinado industrialmente.

O glicerol (Figura 23) é outro plasticizante de origem natural largamente empregado no processamento de materiais poliméricos como o álcool polivinílico, blendas de poliestireno/amido termoplástico, dentre outros (SCHLEMMER; SALES; RESCK, 2010; MOHSIN; HOSSIN; HAIK, 2011).<smiles>OCC(O)CO</smiles>

Figura 23. Estrutura química do glicerol. 
A obtenção do glicerol em sua forma pura pode ocorrer como subproduto do processo de produção do biodiesel (a partir da transesterificação de óleos vegetais com alcoóis como o metanol ou etanol). Neste processo, além da produção de mistura de monoésteres metílicos ou etílicos (biodiesel), também é produzido o glicerol como coproduto. Para cada $90 \mathrm{~m}^{3}$ de biodiesel produzido pela reação de transesterificação de óleos vegetais, são gerados, aproximadamente, $10 \mathrm{~m}^{3}$ de glicerol. No Brasil, as previsões para 2013 são de um excedente de 150 mil toneladas/ano de glicerol. 0 aumento da produção de biodiesel só poderá ser viabilizado economicamente se forem encontradas novas aplicações e mercado para o glicerol produzido, buscando uma maior agregação de valor à cadeia produtiva (FOLLMANN, 2009). Assim, faz-se necessário o desenvolvimento de aplicações alternativas para o glicerol (GUIMARÃES et al., 2010), como seu uso como plasticizante em compósitos poliméricos reforçados por fibras lignocelulósicas, por exemplo (GUIMARÃES et al., 2010; ZOU; REDDY; YANG, 2011).

0 óleo de mamona (OM) é um líquido viscoso obtido por um processo de prensagem das sementes da planta Ricinus communis, e constitui outra substância que pode atuar como plasticizante biodegradável (TAKANO et al., 2007). Este plasticizante é constituído principalmente por cerca de 89,5\% de ácido ricinoléico (Figura 24). 0 grupo hidroxila confere ao óleo de mamona a propriedade de álcool, além disso, este é estável em diversas condições de pressão e temperatura, atóxico, dentre outras características (COSTA et al., 2004).

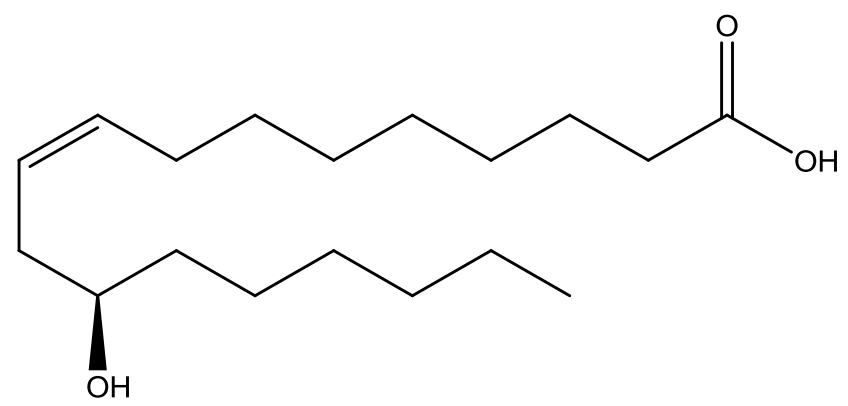

Figura 24. Estrutura química do ácido ricinoléico.

O óleo de mamona pode ser utilizado em aplicações tais como na fabricação de tintas, corantes, desinfetantes, germicidas além de nylon e outros materiais poliméricos (TAKANO et al., 2007). Os efeitos de ácidos graxos derivados de óleos vegetais sobre a vulcanização, propriedades dinâmico-mecânicas e resistência à fadiga em composições de borracha natural (SMRL) e de borracha natural epoxidada (ENR 25 e ENR 50) foram estudados por Ismail, Jaffri e Rozman (2001). 
Foram utilizados no presente trabalho os plasticizantes oriundos de fontes renováveis ATBC, TBC, glicerol, OSE e óleo de mamona no preparo dos compósitos de PET reciclado/fibras de sisal.

Os plasticizantes também podem ser utilizados como compatibilizantes/agentes de acoplamento fibra/matriz em compósitos poliméricos reforçados com fibras lignocelulósicas, conforme já mencionado. A natureza hidrofílica das fibras vegetais resulta em baixa umectação e adsorção de grande parte dos polímeros hidrofóbicos em sua superfície, resultando em fraca adesão interfacial fibra/matriz (DE CARVALHO; CAVALCANTI, 2006). Assim, ao não se utilizar um agente compatibilizante, pode-se obter propriedades mecânicas não satisfatórias no produto final (compósito) (LAI et al., 2002; HABIBI et al., 2008).

Agentes de acoplamento são geralmente utilizados para modificação da interface fibra/matriz nos compósitos poliméricos reforçados com fibras lignocelulósicas. Estes agentes aumentam a dispersão da fibra pela matriz assim como possibilitam uma maior adesão fibra/matriz, permitindo que a matriz transfira a carga recebida para o reforço, durante uma solicitação mecânica, de forma eficiente (LUSINCHI et al., 2001; ZDRAZILOVA et al., 2003).

Os elastômeros são materiais que podem ser utilizados como agentes de acoplamento e tenacificação em compósitos de matriz polimérica. Quando uma tensão é aplicada ao material, as partículas elastoméricas dispersas podem concentrar ou absorver essa tensão, provocando uma alteração do estado de tensão da fase matricial e uma deformação plástica, melhorando assim a resistência ao impacto do material. A introdução de uma pequena quantidade de borracha líquida, como polibutadieno hidroxilado (PBHL) (Figura 25) como segunda fase à matriz, portanto, pode aumentar a resistência à fratura destes materiais. Quando a trinca atinge a região do elastômero, este se deforma com facilidade, dissipando a tensão localizada na ponta da trinca por toda a superfície da partícula elastomérica, impedindo a propagação da falha (MEGIATTO; RAMIRES; FROLLINI, 2010).

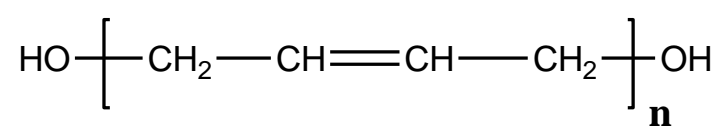

Figura 25. Estrutura química do PBHL. 
De Castro, Ruvolo-Filho e Frollini (2011) estudaram o efeito da adição de PBHL e óleo de mamona em compósitos de biopolietileno reforçados com fibras de curauá. Este estudo teve como objetivo a redução da propagação de trincas durante o ensaio de impacto dos compósitos. Verificou-se também a atuação como agentes de acoplamento do PBHL e do óleo de mamona, uma vez que o PBHL e o óleo de mamona possuem cadeias hidrocarbônicas com afinidades com o biopolietileno, e grupos hidroxilas com afinidades com os grupos polares presentes nas fibras lignocelulósicas. Neste estudo foi possível concluir também que a adição de PBHL e óleo de mamona levaram a uma melhor adesão e distribuição das fibras na matriz termoplástica. Assim, houve uma melhora nas propriedades mecânicas destes compósitos, particularmente na resistência ao impacto (DE CASTRO; RUVOLO-FILHO; FROLLINI, 2011). A adição de PBHL a polímeros como o PET pode ainda levar a uma ação como plasticizante.

No presente trabalho, buscou-se além da diminuição da temperatura de fusão do PET reciclado, uma alternativa às mudanças estruturais no polímero (como a graftização de anidrido maleico em PP), usadas para aumentar a compatibilidade polímero-fibra lignocelulósica. Estas mudanças podem significar um aumento nos custos do processamento, bem como às modificações químicas na superfície da fibra, o que normalmente melhora as interações fibra-matriz, porém, no geral, piora as propriedades mecânicas da fibra (o meio reacional pode deteriorar a fibra). Assim, neste estudo, plasticizantes de origem natural foram empregados como compatibilizantes fibra-matriz devido à presença de grupos polares nestes aditivos, tornando-os capazes de estabelecer interações tanto com as fibras de sisal quanto com a matriz de PET reciclado.

Polibutadieno hidroxilado (PBHL), óleo de mamona (OM) e óleo de soja epoxidado (OSE) foram utilizados neste trabalho, visando ação como agentes compatibilizantes e também como plasticizantes do PET reciclado.

\subsection{Processamento de compósitos}

Os polímeros passam por uma ou mais fases de processamento para atingir seu formato final. Durante o processamento, estão sujeitos a variações de temperatura, ao esforço de cisalhamento e a exposição ao oxigênio. 0 tempo e o grau de aplicação de cada um destes efeitos são dependentes do método de processamento ao qual o material 
é submetido. De modo geral, o processamento de termoplásticos é classificado como: termoformagem, moldagem por compressão, calandragem, extrusão, extrusão e sopro, injeção, injeção seguida de sopro e rotomoldagem (DE PAOLI, 2008).

Existe ampla variedade de equipamentos de mistura que podem ser utilizados na preparação de compósitos celulósicos termoplásticos, tais como misturadores internos e as extrusoras de rosca simples ou dupla (DOS SANTOS, 2006).

Durante o processamento, a umidade das fibras lignocelulósicas, devido a sua natureza hidrofílica, é um fator crítico para o processamento dos compósitos. 0 elevado teor de umidade das fibras pode afetar o processamento dos compósitos, levando a produtos porosos e comprometendo suas propriedades mecânicas. Assim, deve-se remover a umidade das fibras, por um processo de secagem em estufa, por exemplo (DOS SANTOS, 2006).

A temperatura é um dos fatores mais importantes no processamento de compósitos termoplásticos. A distribuição de calor durante o processamento pode afetar desde a qualidade até a microestrutura do produto final. Em temperaturas acima de 160 ${ }^{\circ} \mathrm{C}$ e na presença de oxigênio, as fibras lignocelulósicas podem sofrer termo-oxidação levando ao escurecimento e, em temperaturas acima de $230{ }^{\circ} \mathrm{C}$, a decomposição das mesmas, com consequente perda de suas propriedades (IANNACE; ALI; NICOLAIS, 2001).

Compósitos reforçados com fibras naturais podem ser processados fazendo uso das mesmas tecnologias de processamento empregadas para os termoplásticos. Para que se consiga uma boa dispersão da fibra na matriz, são necessários dispositivos como rotores acoplados à câmara de mistura, dentre outros, que possibilitem uma mistura efetiva dos mesmos. No entanto, as altas tensões de cisalhamento que ocorrem durante a mistura em uma câmara misturadora de um reômetro de torque, por exemplo, podem resultar na quebra das fibras (IANNACE; ALI; NICOLAIS, 2001).

\subsubsection{Moldagem por compressão}

A técnica de processamento por moldagem por compressão é relativamente simples e de baixo custo (CHILDS, 1990; AHMED; ALEXANDROU, 1992). O material é inserido dentro da cavidade apresentada por uma das metades do molde. Após, as duas metades do molde são fechadas para aquecimento da resina. Pressão é aplicada ao 
molde através de uma prensa hidráulica, fazendo com que as duas metades do molde deslizem até se encontrarem e a resina flua, adaptando-se à forma do molde. Depois que o molde foi preenchido e o ciclo de processamento do material finalizado, este é resfriado e a peça final é ejetada do molde (CHILDS, 1990).

Há variações na moldagem por compressão de compósitos termoplásticos em relação aos termorrígidos. A principal é a de que não há a cura do material termoplástico. Além disso, como os polímeros termoplásticos são mais viscosos que os pré-polímeros que originam os termorrígidos, necessita-se de uma pressão maior que a utilizada para os termorrígidos, para que o material possa fluir na cavidade do molde (HARPER; PUGH, 1990). As temperaturas de moldagem para materiais termorrígidos estão na faixa de $135-160{ }^{\circ} \mathrm{C}$, enquanto que no processamento de materiais termoplásticos as temperaturas de processamento utilizadas devem estar acima da temperatura de fusão do polímero (CHILDS, 1990; HARPER; PUGH, 1990).

De Sousa et al. (2004) estudaram a influência da pressão de moldagem no comportamento mecânico de compósitos de poliéster ortoftálico com 2\% (em massa) de etil-metil-cetona reforçados com fibras de bagaço de cana. Neste estudo foi possível verificar que os compósitos submetidos aos maiores valores de pressão de moldagem apresentaram significativa melhoria na resistência à flexão, devido a mudanças em suas microestruturas e consequente melhoria no desempenho mecânico.

A técnica de moldagem por compressão tem sido utilizada há décadas e foi adotada por um longo tempo como método padrão para a moldagem de resinas fenólicas e outros materiais termorrígidos. Esta técnica foi parcialmente substituída pela de moldagem por injeção, devido a facilidades de manuseio dos materiais e automação. No entanto, a técnica de moldagem por compressão oferece grandes vantagens no processamento de materiais compósitos quando comparada com a técnica de moldagem por injeção. Durante a moldagem por compressão, o material sofre pequena quantidade de deformação, não havendo regiões de estresse muito alto, contrário do que ocorre em um cilindro contendo uma rosca transportadora, componentes utilizados na moldagem por injeção. Além disso, não há nenhum cilindro através do qual as fibras devem entrar no molde. Assim, as fibras não são danificadas pelo fluxo durante o enchimento do molde, o que possibilita também o uso de fibras longas como agentes de reforço e em maior quantidade nas composições dos materiais compósitos. Outra vantagem da moldagem por compressão é que esta se trata de uma técnica de excelente 
reprodutibilidade e alta produtibilidade. Ainda, a mistura da resina com as fibras antes da compressão permite um bom controle da mistura do produto final (CHEN; CHEN; CHENG, 1998; ADVANI; SOZER, 2003).

As principais desvantagens do uso da técnica de moldagem por compressão são um elevado investimento inicial em moldes e termoprensas, dentre outros fatores (ADVANI; SOZER, 2003).

As peças preparadas por moldagem por compressão são geralmente utilizadas nas indústrias automotivas, por exemplo, em painéis de veículos (LEE; FOLGAR; TUCKER, 1984; KOTSIKOS; GIBSON, 1998). Os componentes moldados por compressão também são utilizados na indústria aeronáutica em substituição às peças de alumínio, em painéis de controle, componentes das asas, dentre outras partes (CHILDS, 1990).

A técnica de moldagem por compressão foi usada no presente trabalho, no processamento dos compósitos de PET reciclado reforçado por fibras de sisal.

\subsubsection{Reometria de torque}

Outra técnica utilizada no processamento de compósitos é a reometria de torque, a qual faz uso do reômetro de torque Haake (Figura 26). 0 reômetro de torque é um equipamento que reproduz, em menor escala, as geometrias dos equipamentos utilizados industrialmente no processamento de polímeros (BRETAS; D'AVILLA, 2000). Este reômetro, por sua vez, é acoplado a uma câmara misturadora, na qual são inseridos dois rotores. Os rotores giram a uma velocidade constante, estipulada previamente pelo usuário, e o torque necessário para manter essa velocidade é medido. As medidas podem ser feitas isotermicamente ou sob uma rampa de temperatura (VALADARES, 2005). Assim, na câmara misturadora ocorre a mistura do polímero no estado fundido com a fibra natural, com o monitoramento do torque e da temperatura com o tempo. Ao longo de cada processamento, curvas de torque e de temperatura em função do tempo de mistura são registradas, com a finalidade de se avaliar o comportamento de fluxo da mistura. A área sob as curvas de torque podem ser relacionadas à energia absorvida pelo material durante o processamento, assim como o torque medido está relacionado à viscosidade do material durante o processamento, ou seja, corresponde à resistência do material ao fluxo (BRETAS; D'AVILLA, 2000). A vantagem deste tipo de processamento 
de compósitos é a de ser o mesmo utilizado para materiais termoplásticos não reforçados (ANUAR et al., 2007).

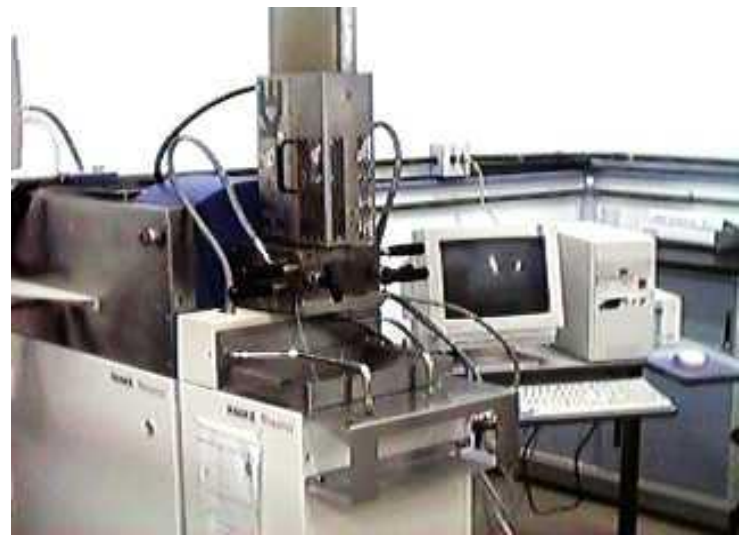

Figura 26. Misturador interno acoplado ao reômetro de torque Haake. ${ }^{20}$

A reometria de torque é, portanto, muito útil para estudar as propriedades de materiais poliméricos, tais como a temperatura e viscosidade de processamento, estabilidade do polímero fundido, temperatura de reticulação (no caso de termorrígidos), dentre outras. Trata-se de um método de processamento vantajoso, pois fornece respostas imediatas, com volume menor de amostra quando comparado com o processamento em extrusora (BRETAS; D'AVILLA, 2000). Não se pode deixar de considerar também o alto poder cisalhante que o reômetro de torque possui em comparação a outros tipos de processamento, como por exemplo, a moldagem por compressão (VALADARES, 2005).

Neste trabalho, a reometria de torque também foi considerada no processamento de compósitos, usando-se um misturador interno acoplado a um reômetro de torque Haake. 


\section{Objetivos}

O objetivo deste trabalho consistiu no desenvolvimento de processos de preparação de compósitos baseados em poli (tereftalato de etileno) reciclado e fibras de sisal.

Visando uma diminuição da temperatura de fusão do PET reciclado $\left(\sim 265^{\circ} \mathrm{C}\right)$, a fim de evitar a decomposição da fibra durante o processamento, plasticizantes como o acetil tributil citrato (ATBC), tributil citrato (TBC), glicerol, óleo de mamona (OM) e óleo de soja epoxidado (OSE) foram acrescentados às formulações dos compósitos. Estes plasticizantes foram escolhidos por serem oriundos de fontes renováveis, assim como por possuírem grupos nas respectivas estruturas com afinidade com grupos presentes em ambos, fibra e matriz, ou seja, buscando também ação como compatibilizantes. Adicionalmente, polibutadieno hidroxilado líquido (PBHL) foi acrescentado à formulação do material, visando avaliar sua ação como agente compatibilizante/de acoplamento na interface fibra-matriz.

Desta forma, materiais baseados principalmente em matérias-primas provenientes de fontes naturais, assim como em material reciclado, foram preparados visando à valorização de materiais gerados em importantes setores econômicos brasileiros: agricultura (fibras de sisal) e indústria de reciclagem (PET reciclado). 


\section{Técnicas de Caracterização}

\subsubsection{Microscopia Eletrônica de Varredura (MEV)}

A Microscopia Eletrônica de Varredura (MEV) é uma técnica utilizada para o estudo da estrutura fina e da morfologia de materiais. 0 microscópio eletrônico utiliza elétrons para a formação das imagens, com melhor resolução do que as imagens apresentadas por um microscópio óptico (DEDAVID; GOMES; MACHADO, 2007).

Através do microscópio eletrônico de varredura podem-se obter imagens das amostras com elevada profundidade de foco em que diferentes relevos da superfície da amostra são mostrados simultaneamente em foco. As imagens obtidas, por serem tridimensionais (resultado direto da grande profundidade de campo), são de mais fácil interpretação, além da já mencionada alta resolução, que propicia a obtenção de imagens com elevada nitidez de detalhes (CANEVAROLO JR., 2007; DEDAVID; GOMES; MACHADO, 2007).

Nesta técnica as amostras são preparadas de forma relativamente simples e fácil. Materiais não condutores, como as fibras lignocelulósicas e a maioria dos polímeros, requerem, em geral, apenas revestimentos condutivos ou a utilização de baixa voltagem de aceleração do feixe. A espessura da amostra também não é um aspecto crítico, o principal interesse de uso desta técnica é geralmente a avaliação da topografia da amostra (CANEVAROLO JR., 2007).

Inicialmente a montagem da amostra é feita sobre suportes metálicos, com a utilização de fitas dupla-face de carbono, cobre, dentre outras. É comum também o uso de colas condutoras de prata ou carbono para a fixação do material, que podem proporcionar também uma melhora na condutividade do mesmo (DEDAVID; GOMES; MACHADO, 2007). Após, a amostra é recoberta por uma fina película condutora para evitar o acúmulo de carga negativa, no caso da mesma ser de natureza isolante. A camada de metal deve ser suficientemente contínua e fina para não mascarar e interferir na avaliação da topografia da superfície, no entanto, deve conduzir de forma adequada o excesso de carga negativa. Para esta finalidade, a evaporação do metal e a metalização por sputtering são as técnicas mais comuns. Os metais mais utilizados nos revestimentos são o ouro, liga ouro-paládio, platina, alumínio e carbono (CANEVAROLO JR., 2007). 


\subsubsection{Calorimetria Exploratória Diferencial (DSC)}

Neste tipo de análise térmica é avaliada a variação de entalpia que ocorre entre a amostra e a referência durante o processo de aquecimento/resfriamento que os materiais são submetidos, através de uma programação controlada de temperatura (HEMMINGER; SARGE, 1994).

As transições que geram modificações em curvas DSC são as transições de primeira e de segunda ordem. As transições de primeira ordem apresentam variação de entalpia que pode ser endotérmica ou exotérmica, o que origina a formação de picos. Como exemplo, em polímeros, pode ocorrer os eventos endotérmicos de fusão, perdas de massa da amostra (vaporização de água, aditivos ou produtos voláteis de reação ou decomposição), dessorção e reações de redução. Outros eventos exotérmicos que podem ser observados nos polímeros são a cristalização, reações de polimerização, oxidação, degradação oxidativa, adsorção, dentre outros. As transições de segunda ordem são caracterizadas pela variação da capacidade calorífica, contudo, não há a variação de entalpia. Estas transições não geram picos nas curvas DSC e apresentam-se como um deslocamento da linha base em forma de "S", como exemplo, a transição vítrea de polímeros termoplásticos (CANEVAROLO JR., 2007).

A Calorimetria Exploratória Diferencial apresenta vantagens tais como o uso de quantidade reduzida de amostra, rapidez, obtenção de informações necessárias para a determinação dos parâmetros cinéticos de uma reação, por exemplo, dentre outros benefícios (HERRMANN; ENGEL; EISENREICH, 1992).

\subsubsection{Termogravimetria (TG)}

A termogravimetria (TG) é uma das técnicas de análise térmica em que as variações de massa da amostra (ganho ou perda) são monitoradas em função da temperatura e/ou tempo, enquanto a substância é submetida a um programa controlado de temperatura, sob uma atmosfera específica (WENDLANDT, 1985; HAINES, 1995). Através desta técnica podem-se conhecer as alterações que o aquecimento pode provocar na massa das substâncias, permitindo estabelecer a faixa de temperatura em que elas mantêm composição química definida e constante, a temperatura em que 
começam a se decompor, acompanhar o andamento de reações de desidratação, oxidação, decomposição, dentre outros fatores (CANEVAROLO JR., 2007).

A termogravimetria pode ser utilizada para verificação de propriedades das fibras de sisal tais como a umidade residual, temperatura de decomposição das fibras, dentre outras. A temperatura de início da decomposição térmica das fibras define o intervalo de temperatura que poderá ser considerado no processamento dos compósitos, além de definir a temperatura máxima para aplicação destes.

\subsubsection{Determinação do Índice de Fluidez (MFI)}

O Índice de Fluidez (MFI) é uma importante técnica de caracterização reológica para a análise da viscosidade no estado fundido de polímeros. Além da facilidade de operação, boa reprodutibilidade dos resultados e baixo custo, através desta técnica é possível se obter uma boa noção da viscosidade do polímero fundido, indicando qual a técnica de processamento mais adequada para o mesmo. Assim, o MFI é considerado um parâmetro crítico no processamento de polímeros. Apesar de largamente empregado, o MFI não permite uma visão detalhada do comportamento de diferentes frações de um polímero, apenas fornece uma visão do comportamento médio global deste (CÁCERES; CANEVAROLO JR., 2006).

\subsubsection{Absorção de água}

Em geral, os compósitos apresentam melhor desempenho quando expostos a intempéries do que os materiais tradicionais de construção (SCUDAMORE; CANTWELL, 2002). No entanto, em compósitos poliméricos reforçados por fibras lignocelulósicas, a alta higroscopicidade apresentada pelas fibras pode ter efeitos indesejáveis sobre as propriedades mecânicas e estabilidade dimensional destes materiais. Assim, a absorção de água é um importante parâmetro na determinação do tipo de aplicação destes materiais (KUSHWAHA; KUMAR, 2009; SEKI et al., 2012).

A absorção de água em um material compósito ocorre principalmente por três mecanismos: 1) difusão das moléculas de água para dentro dos "vazios" entre as cadeias poliméricas; 2) transporte por capilaridade das moléculas de água para as lacunas e interstícios da interface fibra-matriz devido à baixa molhabilidade e incompleta 
impregnação da fibra pela matriz e 3) transporte de moléculas de água através de microfissuras presentes na matriz, provenientes de defeitos durante o processamento dos compósitos. Entretanto, o efeito global de absorção de água pelas fibras naturais é principalmente atribuído ao mecanismo de difusão das moléculas de água (KUSHWAHA; KUMAR, 2009; SEKI et al., 2012).

\subsubsection{Ensaio de resistência ao impacto}

A resistência ao impacto é uma propriedade muito requisitada na especificação do comportamento mecânico de polímeros, quando utilizados em aplicações estruturais. Assim, a tenacidade ao impacto, usualmente conhecida como resistência ao impacto, pode ser definida como a habilidade de um material absorver energia sem que sofra ruptura quando uma força máxima é aplicada repentinamente, como em um ensaio sob impacto (CANEVAROLO JR., 2007).

Os ensaios mecânicos sob impacto podem ser realizados através de máquinas contendo martelos acoplados a pêndulos (Figura 27) ou em queda livre (CANEVAROLO JR., 2007). Os ensaios de impacto utilizando pêndulos podem ser divididos em ensaios Izod e Charpy. Em ambos os tipos de ensaio, o corpo de prova possui o formato de uma barra com seção reta quadrada, e pode ou não ser entalhado (CALLISTER JR., 2002). As diferenças principais destes tipos de ensaio de impacto são as dimensões dos corpos de prova, a base de fixação e o tipo de pêndulo. Em um ensaio do tipo Izod, o corpo de prova é posicionado na forma vertical em relação à base do equipamento e o entalhe é posicionado no lado no qual o martelo atingirá o corpo de prova, diferentemente do que ocorre em um ensaio do tipo Charpy. Neste ensaio, o corpo de prova é posicionado horizontalmente em relação à base do equipamento e o entalhe deve estar voltado para a face contrária do corpo de prova que será atingida pelo martelo (CANEVAROLO JR., 2007). 


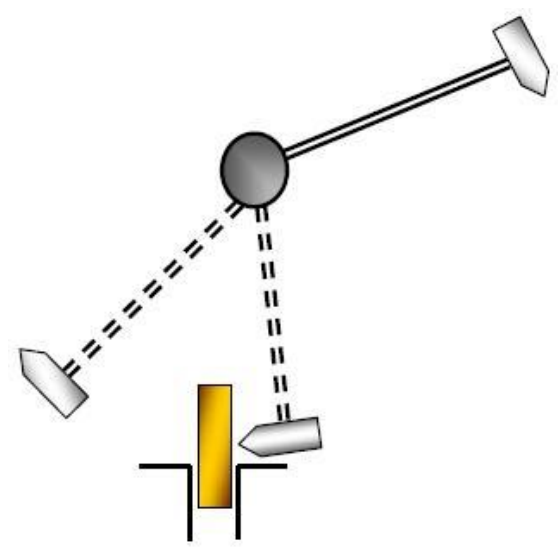

Figura 27. Esquema de movimento de um pêndulo simples utilizado nos ensaios de resistência mecânica ao impacto (MEGIATTO, 2006).

Destaca-se que, no presente trabalho, foram realizados ensaios de impacto do tipo Izod, os quais se destinam à avaliação de corpos de prova sob esforço de flexão mediante impacto, assim como à avaliação da fragilidade ou tenacidade dentro dos limites das condições de ensaio. Esta propriedade é considerada uma das mais importantes para os compósitos, tendo em vista a aplicação dos mesmos (CHAWLA, 1998).

A determinação da resistência ao impacto de materiais poliméricos e compósitos, como os compósitos poliméricos reforçados por fibras naturais, pode ser afetada por diversos parâmetros, tais como: a velocidade de solicitação sob impacto, sensibilidade ao entalhe do material, temperatura, orientação molecular, tipos de processamento, grau de cristalinidade, espessura do corpo de prova, nível de adesão interfacial, no caso de compósitos, entre o polímero e as fibras, dentre outros fatores (CANEVAROLO JR., 2007; COUTINHO et al., 2007). Para melhorar a adesão interfacial, um agente compatibilizante pode ser adicionado à mistura polímero/fibras (COUTINHO et al., 2007).

\subsubsection{Ensaio de resistência à flexão}

A resistência à flexão pode ser definida como a capacidade de um material resistir à deformação sob a aplicação de uma carga. Os ensaios de resistência à flexão podem ser realizados utilizando o carregamento em um sistema com três ou quatro pontos, sendo o carregamento em um sistema com três pontos (Figura 28) o mais comumente utilizado (NORMA ASTM D790 - 02). 
Figura 28. Esquema representativo de um ensaio de flexão em três pontos (DE OLIVEIRA, 2010).

Nos ensaios de flexão em três pontos o corpo de prova é uma barra de seção cruzada retangular que é ajustado em dois apoios fixados em uma travessa fixa. 0 carregamento neste tipo de ensaio é realizado por meio de um terceiro apoio (travessa móvel) que está posicionado a uma distância média entre os apoios fixados ao suporte (travessa fixa) (CANEVAROLO JR., 2007).

Em geral, a distância de separação dos apoios deve ser ajustada de forma que sua razão com a profundidade do corpo de prova (L/d) seja igual a 16 (CANEVAROLO JR., 2007).

Nestes ensaios o corpo de prova é defletido até que ocorra sua ruptura na superfície oposta ao carregamento, ou até o alcance da máxima deformação, que é de $5 \%$. Assim, para um ensaio de flexão em três pontos a deflexão na qual a máxima deformação permitida (5\%) irá ocorrer pode ser calculada através da Equação 1:

$$
\mathrm{D}=\frac{\mathrm{rL}^{2}}{6 \mathrm{~d}}
$$

Sendo:

$\mathrm{D}$ = deflexão no ponto médio entre os apoios

$\mathrm{r}=$ deformação, $0,05 \mathrm{~mm} / \mathrm{mm}$

$\mathrm{L}=$ distância entre os apoios

$\mathrm{d}$ = profundidade do corpo de prova

Para os materiais que não rompem ou não falham na superfície oposta ao carregamento dentro de um limite máximo de 5,0\% de deformação, a resistência à flexão deve ser calculada utilizando o método de quatro pontos. Os dois métodos de 
ensaios de flexão diferem quanto à localização do momento da carga máxima e na tensão de tração máxima axial na superfície oposta ao carregamento. Em um ensaio de três pontos a tensão de tração máxima axial ocorre debaixo do ponto de carregamento, contrário do que ocorre em um ensaio de quatro pontos em que essa ocorre na área entre os dois pontos de carregamento (CANEVAROLO JR., 2007).

Na aplicação dos ensaios de flexão em três pontos dois procedimentos podem ser utilizados:

- $A$ é aplicado nos materiais que rompem em deflexões comparativamente pequenas e deve ser utilizado para medidas de propriedades sob flexão, como o módulo sob flexão.

- $B$ é aplicado para os materiais que suportam grandes deflexões durante o teste e deve ser utilizado somente para medidas de resistência à flexão (CANEVAROLO JR., 2007).

Normalmente, os dados obtidos em um ensaio de resistência à flexão são muitas vezes utilizados para selecionar os materiais para o preparo de peças que irão suportar elevadas cargas. 0 módulo de flexão é usado como indicativo da rigidez de um material quando flexionado. Uma vez que as propriedades de muitos materiais (especialmente os termoplásticos) podem variar dependendo da temperatura ambiente, faz-se necessário realizar testes em ambientes com temperatura controlada, simulando as condições do uso pretendido (DE CASTRO, 2010).

\subsubsection{Análise Térmica Dinâmico-Mecânica (DMTA)}

A análise dinâmico-mecânica (DMA) ou análise térmica dinâmico-mecânica (DMTA) tem como principais objetivos correlacionar as propriedades macroscópicas, tais como as propriedades mecânicas, às relaxações moleculares associadas a mudanças conformacionais e a deformações microscópicas que podem ser geradas a partir de rearranjos moleculares (WUNDERLICH, 1997). Assim, esta análise tem sido amplamente utilizada para a caracterização dos polímeros através da detecção dos processos de relaxação macroscópicos e moleculares. Esta técnica também é muito utilizada por apresentar uma grande sensibilidade, quando comparada às técnicas convencionais de análise térmica (CANEVAROLO JR., 2007). 
Essa técnica fornece informações a respeito do módulo elástico (E'), do módulo de dissipação viscosa (E") e do amortecimento mecânico ou atrito interno ( $\left.\tan \delta=E^{\prime \prime} / E^{\prime}\right)$ de um material, quando sujeito a uma solicitação dinâmica. Através dessas variáveis, pode-se correlacionar várias propriedades mecânicas tais como a tenacidade, resistência ao impacto, dentre outras (CANEVAROLO JR., 2007).

Por meio da técnica de DMTA é possível a obtenção de informações sobre transições termodinâmicas de primeira ordem, como a fusão e a cristalização em condições de aquecimento, bem como transições termodinâmicas de pseudo segunda ordem, como a transição vítrea e das relaxações secundárias associadas às fases cristalina e não cristalina (MURAYAMA, 1988).

A análise de DMTA também fornece informações a respeito do comportamento viscoelástico do sistema, que é desmembrado em duas componentes: a contribuição elástica e a viscosa (CANEVAROLO JR., 2007).

O módulo oriundo da componente tensão resposta em fase com a deformação, E', é denominado módulo de armazenamento, e o módulo oriundo da componente de tensão resposta $90^{\circ}$ fora de fase com a deformação, E”, é chamado módulo de perda. A razão entre os valores de módulo de perda (E") e módulo de armazenamento (E') define a grandeza denominada tangente de perda, $\tan \delta$.

A tangente de perda, que também pode ser chamada de fricção interna ou amortecimento, é definida como sendo a razão entre a energia dissipada por ciclo e a energia potencial máxima armazenada durante o ciclo. Portanto, materiais mais rígidos apresentarão valores de $\tan \delta$ menores, e materiais mais flexíveis apresentarão valores de $\tan \delta$ maiores. Em um ensaio de DMTA, as grandezas E', E” e $\tan \delta$ são dadas em função da temperatura ou da freqüência (LUCAS; SOARES; MONTEIRO, 2001).

Os métodos dinâmico-mecânicos são muito sensíveis às transformações que ocorrem em nível molecular, sendo capazes de detectar movimentos discretos como as relaxações secundárias (LUCAS; SOARES; MONTEIRO, 2001). Nos compósitos, as interações matriz-fibra podem influir significativamente nas relaxações das cadeias presentes na interface fibra-matriz, fato que pode ser detectado por um deslocamento nas curvas de E" e tan $\delta$, quando comparadas às amostras controle, sem fibras.

As transições que ocorrem nas macromoléculas podem ser divididas em transições que ocorrem na fase cristalina e as que ocorrem na fase não cristalina. As relaxações primárias são descritas pela letra $\alpha$, assim, a transição relacionada à 
temperatura de transição vítrea, que é a relaxação acentuada da fase não cristalina, é representada por $\alpha_{a}$. Esta transição é resultante dos movimentos moleculares, que envolvem os segmentos da cadeia polimérica principal (HUTCHINSON, 1997). Já a transição relacionada à temperatura de fusão cristalina, que é a relaxação acentuada na fase cristalina, é representada por $\alpha_{c}$. Relaxações secundárias que ocorrem abaixo de $\alpha_{c} \mathrm{e}$ acima de $\alpha_{\mathrm{a}}$ estão relacionadas com a parte cristalina e são representadas por $\alpha_{\text {c.. }}^{\prime}$ As transições que ocorrem abaixo de $\alpha_{\mathrm{a}}$ estão relacionadas com a parte não cristalina do material e são representadas pelas letras $\beta_{\alpha}, \gamma_{\alpha}, \delta_{\alpha}$, dentre outras, da mais alta para a mais baixa temperatura. Estas transições são facilmente observadas pelos picos detectados nas curvas de E” ou tan $\delta$ (LUCAS; SOARES; MONTEIRO, 2001). 


\section{Materiais e Métodos}

Faz-se importante salientar que este trabalho foi desenvolvido em colaboração com o Professor Dr. Adhemar Colla Ruvolo-Filho, atualmente professor colaborador vinculado ao Departamento de Engenharia de Materiais (DEMA) da Universidade Federal de São Carlos-UFSCar (São Carlos, SP).

\subsection{Materiais}

O PET reciclado sob a forma de flakes foi gentilmente cedido pela empresa do Gruppo Mossi \& Ghisolfi (M\&G), São Paulo, SP.

As fibras de sisal utilizadas neste trabalho foram adquiridas na forma de fios da empresa Sisal Sul Indústria e Comércio Ltda., São Paulo, SP.

Os plasticizantes TBC E ATBC, cujos nomes comerciais são SCANDINOL SP-21 e SCANDINOL SP-22 respectivamente, foram gentilmente cedidos pela empresa Scandiflex S/A, São Paulo, SP.

O plasticizante OSE, de nome comercial DRAPEX 6.8, foi gentilmente cedido pela empresa INBRA Indústrias Químicas Ltda., São Paulo, SP.

$\mathrm{O}$ polibutadieno hidroxilado líquido (PBHL), nome comercial Liquiflex $\mathrm{H}$, foi gentilmente cedido pela empresa Petroflex Ind. Com., Rio de Janeiro, RJ.

O óleo de mamona (OM) utilizado neste trabalho foi obtido através da empresa A. Azevedo Indústria e Comércio de Óleos Ltda., São Paulo, SP.

\subsection{Métodos}

Na preparação da placa controle de PET reciclado e de todos os compósitos obtidos por moldagem por compressão e reometria de torque, o PET reciclado e as fibras de sisal (pós-tratamento descrito no item 4.2.1) foram utilizados após prévia secagem em estufa de circulação de ar por no mínimo $4 \mathrm{~h}$, respectivamente às temperaturas de $160{ }^{\circ} \mathrm{C}$ e $105^{\circ} \mathrm{C}$. 


\subsubsection{Pré-tratamento das fibras de sisal}

As fibras de sisal foram extraídas em um sistema de refluxo, utilizando-se uma mistura de cicloexano/etanol (Synth) (1:1, v:v) por um período de $10 \mathrm{~min}$, sendo então lavadas com água, a temperatura ambiente, e secas em estufa de circulação de ar a $105{ }^{\circ} \mathrm{C}$, até massa constante. Este pré-tratamento teve como objetivo a eliminação de extrativos orgânicos e também impurezas inorgânicas presentes nas fibras. Estes extrativos correspondem a ceras, constituídas principalmente por moléculas apolares as quais podem prejudicar as interações fibra-matriz nos compósitos.

\subsubsection{Preparação da placa controle de PET reciclado e dos compósitos de PET reciclado reforçados com fibras de sisal por moldagem por compressão}

\subsubsection{Preparação da placa controle de PET reciclado (CTRPET)}

Obteve-se o PET reciclado sob a forma de pó através da moagem criogênica em um micromoinho de rotor vertical com facas móveis e fixas da Marconi, modelo MA048. Assim, o PET reciclado em pó foi vertido em um molde portátil, com capacidade para aproximadamente $350 \mathrm{~g}$, constituído por duas placas nas quais resistências elétricas foram embutidas (Figura 29). 0 molde metálico utilizado com dimensões de (30,2 x $14,1 \times 0,47 \mathrm{~cm}$ ) (c x l x e) foi previamente encapado com folhas delgadas de teflon.

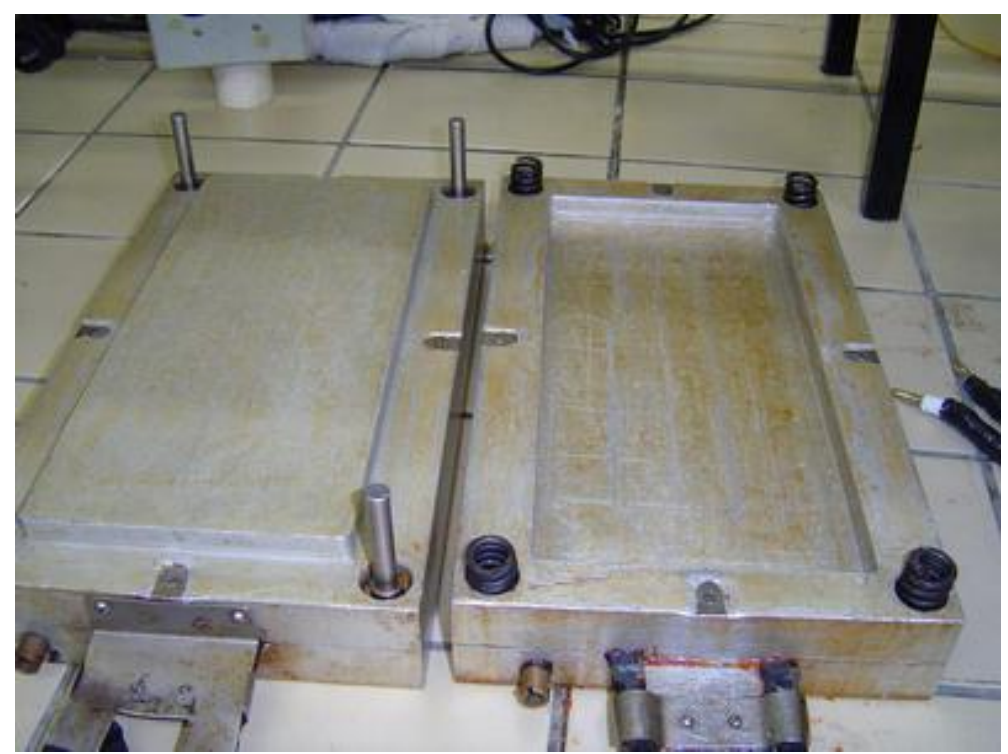

Figura 29. Molde metálico utilizado no preparo dos compósitos (RAMIRES, 2010). 
Após, o PET reciclado foi moldado por compressão e aquecimento com o uso de uma prensa hidráulica sob pressão constante de 38,08 $\mathrm{Kgf} \mathrm{cm}^{-2}$, de acordo com a Figura 30.

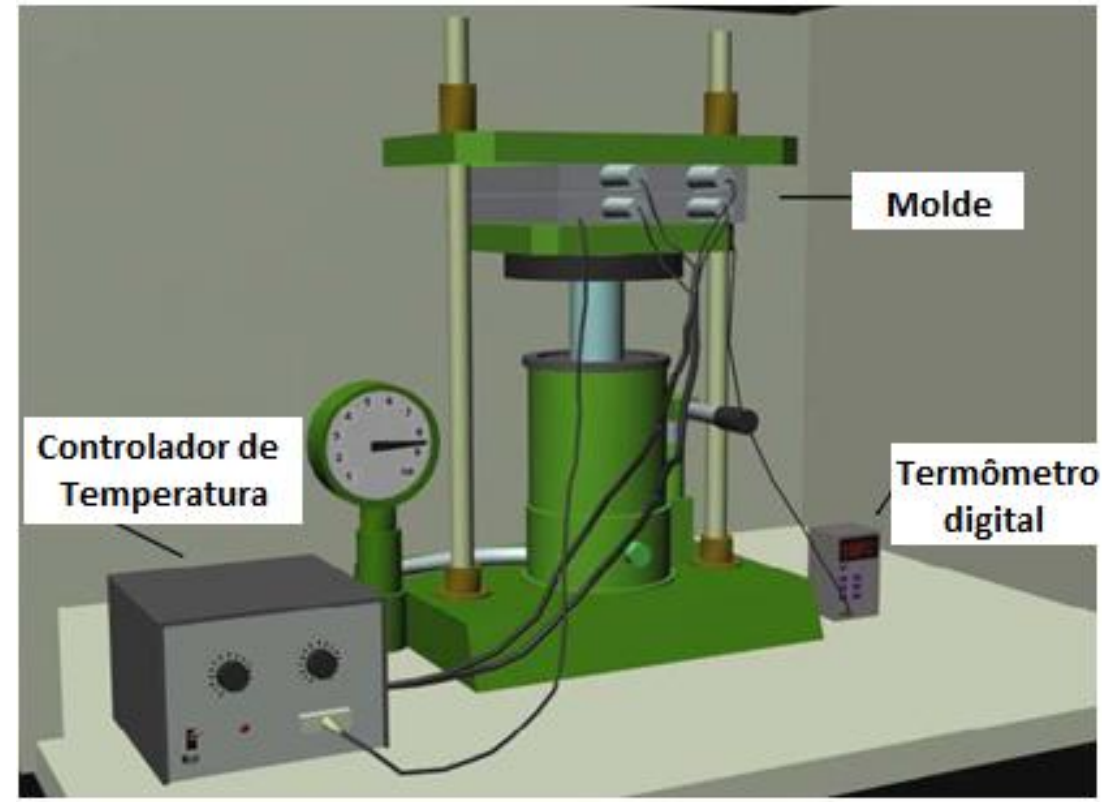

Figura 30. Representação do sistema utilizado para a moldagem por compressão (RAMIRES, 2010).

Durante o processamento adotou-se o ciclo de temperaturas no 1 , determinado experimentalmente, com duração total, incluindo as rampas de aquecimento, de $3 \mathrm{~h} 20$ $\min$.

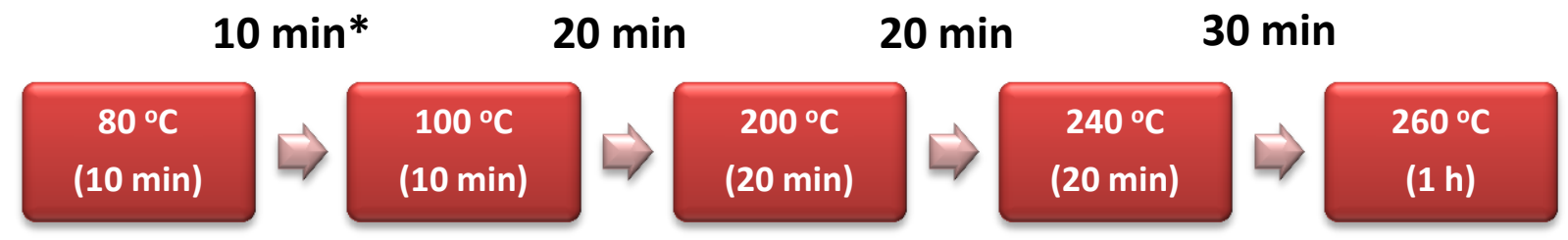

* intervalo de tempo das rampas de aquecimento.

Ciclo de temperaturas $\mathrm{n}^{\circ} 1$ (Experimental).

Após o término do ciclo, deixou-se o molde resfriar até atingir a temperatura ambiente, mantendo-se a pressão constante de 38,08 $\mathrm{Kgf} \mathrm{cm}^{-2}$. Em seguida, desmoldouse o PET reciclado sob a forma de placa (CTRPET). 


\subsubsection{Desenvolvimento do ciclo de temperaturas para moldagem por compressão dos compósitos}

Neste trabalho, as condições ótimas para a preparação dos compósitos foram determinadas após vários testes, nos quais variados parâmetros, como o ciclo de temperaturas para a moldagem por compressão dos compósitos, utilização de PET reciclado sob a forma de flakes ou em pó, tipos de plasticizantes utilizados e modo de impregnação das fibras com os plasticizantes, foram considerados.

Inicialmente, considerou-se para o preparo dos compósitos uma proporção de 15\% (em massa) de fibras de sisal (3 cm de comprimento), misturadas manualmente com 85\% de PET reciclado em flakes. A porcentagem e o comprimento das fibras escolhidos devem-se ao fato de que estes levaram a materiais, processados por moldagem por compressão, com melhores resultados de propriedades mecânicas, em estudos anteriormente realizados no mesmo grupo de pesquisa, no qual o presente trabalho se insere (Paiva, 2001; Da Silva, 2011). Em seguida, a mistura foi colocada em um molde metálico (o mesmo anteriormente utilizado no preparo da placa de PET reciclado e previamente revestido com folhas delgadas de teflon) seguindo a moldagem por compressão sob as mesmas condições (ciclo de temperaturas no 1 (Experimental)) anteriormente utilizadas e descritas no item 4.2.2.1 para o preparo da placa de PET reciclado. 0 compósito obtido ao final do processamento apresentava trincas em sua estrutura e poros, provavelmente devido à decomposição térmica das fibras de sisal e consequente saída de voláteis.

Após os testes experimentais em que se utilizou os ciclos de temperaturas no 2, 3, 4, 5 e 6, sem êxito, em um outro teste, preparou-se uma placa de PET reciclado com 20\% de glicerol, previamente misturados manualmente, por moldagem por compressão (ciclo de temperaturas no 7 (Experimental)) à pressão constante de 38,08 $\mathrm{Kgf} \mathrm{cm}^{-2}$. Esta placa foi triturada criogenicamente e misturada também de maneira manual com $15 \%$ (em massa) de fibras de sisal, sendo a mistura novamente vertida no molde metálico revestido com folhas delgadas de teflon. Após o processamento (ciclo de temperaturas no 8 (Experimental)) sob pressão constante de 38,08 $\mathrm{Kgf} \mathrm{cm}^{-2}$, o compósito obtido apresentava distribuição heterogênea das fibras na matriz e visível decomposição térmica das fibras. 
Outro teste foi realizado utilizando o ciclo de temperaturas $\mathbf{n}^{\mathbf{0}} \mathbf{9}$, visando a determinação das condições ideais para o processamento dos compósitos, na busca da fusão do PET reciclado em temperatura inferior à temperatura em que inicia a decomposição térmica das fibras, porém novamente não se obteve êxito.

Encontradas as condições ótimas de processamento (ciclo de temperaturas no 10), os compósitos reforçados com fibras de sisal foram preparados segundo estas condições pré-determinadas e com a utilização de um misturador mecânico (descrito no item 4.2.2.3) para prévia mistura das fibras de sisal com os plasticizantes. 
- Ciclo de temperaturas no $1 \rightarrow$ PET reciclado (flakes) (Tempo $\rightarrow 3$ h 20 min) (15\% de FIBRA DE SISAL)

\begin{tabular}{|c|c|c|c|c|c|c|c|c|c|c|}
\hline & $\min *$ & & $\min$ & & $\min$ & & $\min$ & & & \\
\hline $\begin{array}{c}80^{\circ} \mathrm{C} \\
(10 \mathrm{~min})\end{array}$ & $\Rightarrow$ & $\begin{array}{c}100{ }^{\circ} \mathrm{C} \\
(10 \mathrm{~min})\end{array}$ & $\Rightarrow$ & $\begin{array}{c}200^{\circ} \mathrm{C} \\
(20 \mathrm{~min})\end{array}$ & $\Rightarrow$ & $\begin{array}{c}240{ }^{\circ} \mathrm{C} \\
(20 \mathrm{~min})\end{array}$ & $\Rightarrow$ & $\begin{array}{c}260^{\circ} \mathrm{C} \\
(1 \mathrm{~h})\end{array}$ & $\Rightarrow$ & $\begin{array}{l}\text { Decomposição } \\
\text { das fibras de } \\
\text { sisal }\end{array}$ \\
\hline
\end{tabular}

- Ciclo de temperaturas no $\mathbf{2} \rightarrow$ PET reciclado (flakes) $+20 \%$ de PBHL (Tempo $\rightarrow 3$ h) (Sem Agente de Reforço)

$100^{\circ} \mathrm{C}$
$(40 \mathrm{~min})$

- Ciclo de temperaturas $\mathbf{n}^{\circ} \mathbf{3} \rightarrow$ PET reciclado (flakes) + 20\% de PBHL (Tempo $\rightarrow \mathbf{6}$ h 10 min) (Sem Agente de Reforço)

$10 \mathrm{~min}$

$10 \mathrm{~min}$

$20 \mathrm{~min}$

$20 \mathrm{~min}$

$\Rightarrow \begin{gathered}100^{\circ} \mathrm{C} \\ (20 \mathrm{~min})\end{gathered} \Rightarrow \begin{gathered}150{ }^{\circ} \mathrm{C} \\ (20 \mathrm{~min})\end{gathered} \Rightarrow \begin{gathered}20{ }^{\circ} \mathrm{C} \\ (1 \mathrm{~h})\end{gathered} \Rightarrow \begin{gathered}210^{\circ} \mathrm{C} \\ (1 \mathrm{~h} 30 \mathrm{~min})\end{gathered} \Rightarrow \begin{gathered}220^{\circ} \mathrm{C} \\ (2 \mathrm{~h})\end{gathered} \Rightarrow \begin{gathered}\text { Não houve } \\ \text { fusão do PET } \\ \text { reciclado }\end{gathered}$

*intervalo de tempo das rampas de aquecimento. 
- Ciclo de temperaturas no $4 \rightarrow$ PET reciclado (flakes) $+20 \%$ de PBHL (Tempo $\rightarrow 6$ h 40min) (Sem Agente de Reforço)

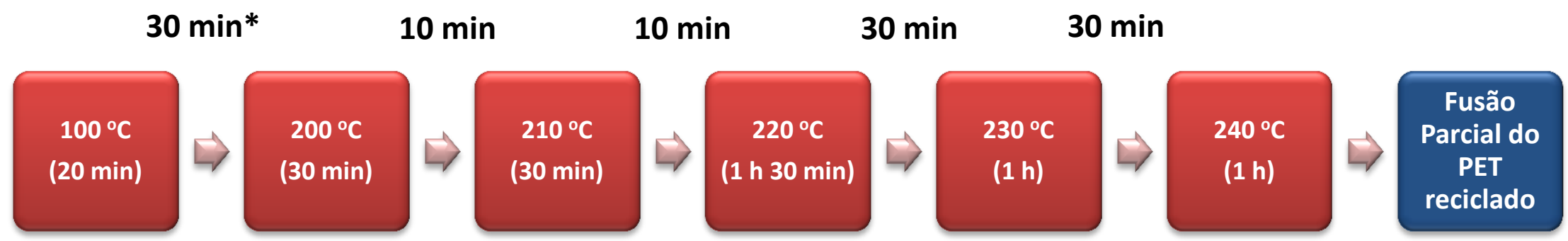

- Ciclo de temperaturas no $5 \rightarrow$ PET reciclado (flakes) $+20 \%$ de PBHL (Tempo $\rightarrow \mathbf{7}$ h) (Sem Agente de Reforço)

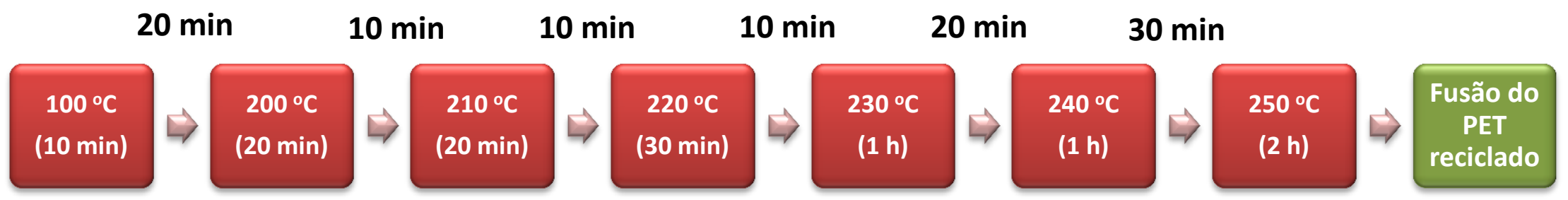

- Ciclo de temperaturas $n^{\circ} 6 \rightarrow$ PET reciclado (pó) $+20 \%$ de glicerol (Tempo $\rightarrow 2$ h50 min) (Sem Agente de Reforço)

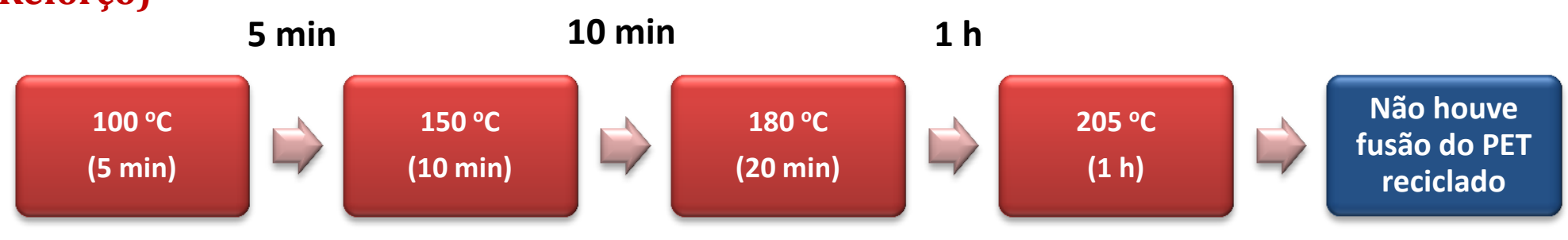

*intervalo de tempo das rampas de aquecimento. 
- Ciclo de temperaturas no $7 \rightarrow$ PET reciclado (pó) $+20 \%$ de glicerol (Tempo $\rightarrow \mathbf{1}$ h $\mathbf{4 0}$ min) (Sem Agente de Reforço)

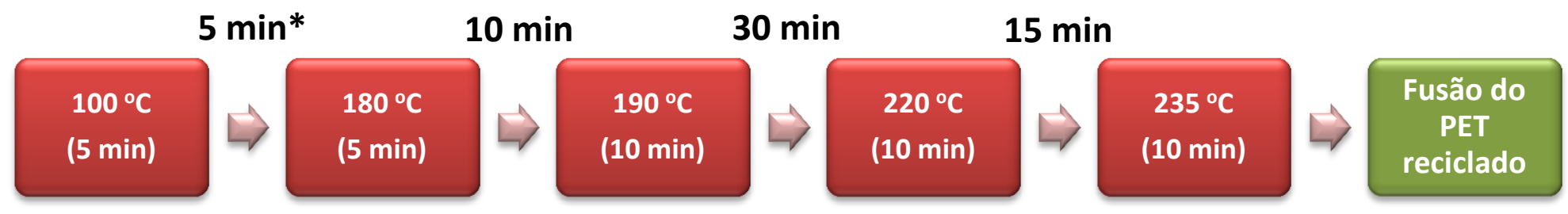

- Ciclo de temperaturas no $8 \rightarrow$ PET reciclado (pó) + 20\% de glicerol (Tempo $\rightarrow 1$ h 40 min) (15\% de FIBRA DE SISAL)

$100^{\circ} \mathrm{C}$
$(5 \mathrm{~min})$$\rightarrow \begin{gathered}180^{\circ} \mathrm{C} \\ (5 \mathrm{~min})\end{gathered} \rightarrow \begin{gathered}190^{\circ} \mathrm{C} \\ (10 \mathrm{~min})\end{gathered} \rightarrow \begin{gathered}220^{\circ} \mathrm{C} \\ (10 \mathrm{~min})\end{gathered} \rightarrow \begin{gathered}235^{\circ} \mathrm{C} \\ (10 \mathrm{~min})\end{gathered}$

- Ciclo de temperaturas no $9 \rightarrow$ PET reciclado (pó) $+40 \%$ de glicerol (Tempo $\rightarrow \mathbf{4 h ~} 15$ min) (Sem Agente de Reforço)

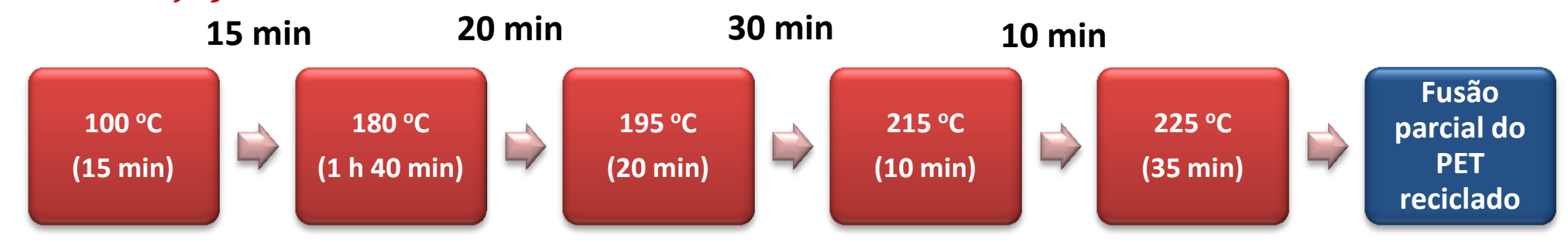

*intervalo de tempo das rampas de aquecimento. 
Ciclo de temperaturas no $\mathbf{1 0} \rightarrow$ PET reciclado (pó) $+40 \%$ de glicerol (Tempo $\rightarrow \mathbf{5}$ h $\mathbf{5 5} \mathbf{~ m i n})(\mathbf{1 5 \%}$ de FIBRA DE SISAL)

(15 min* 150 min min

*intervalo de tempo das rampas de aquecimento.

Condição ótima de processamento: Placa homogênea, observando a fusão do PET reciclado, com boa impregnação fibra-matriz e não decomposição térmica das fibras de sisal 


\subsubsection{Mistura do agente de reforço com os plasticizantes}

Para a moldagem dos compósitos na presença de plasticizantes, inicialmente, o agente de reforço (fibras de sisal com $3 \mathrm{~cm}$ de comprimento) foi misturado aos plasticizantes. Com o auxílio de um misturador mecânico (Empresa JVJ, Pardinho, SP), desenvolvido especialmente visando à mistura e consequente impregnação fibra/polímero e/ou fibra/plasticizante, as fibras foram acondicionadas e misturadas, juntamente à metade da quantidade total proposta do(s) plasticizante(s) de interesse, por um tempo de $3 \mathrm{~min}$, com velocidade de $30 \mathrm{rpm}$.

Após esse tempo, as fibras contendo plasticizante(s) foram misturadas manualmente ao PET reciclado em pó contendo a outra metade da quantidade total proposta de plasticizante(s) (previamente misturado(s) também de forma manual). A mistura então foi vertida no molde metálico devidamente encapado com folhas delgadas de teflon. Estas etapas tiveram como objetivo buscar uma distribuição homogênea do plasticizante entre PET reciclado e fibras, a fim de viabilizar a ação também como agente de compatibilização fibra-matriz.

\subsubsection{Moldagem por compressão dos compósitos de PET reciclado/fibras de sisal/plasticizante(s)}

Os compósitos foram moldados por compressão e aquecimento sob pressão constante de 38,08 $\mathrm{Kgf}_{\mathrm{cm}}^{-2}$, de acordo o esquema da Figura 31. 


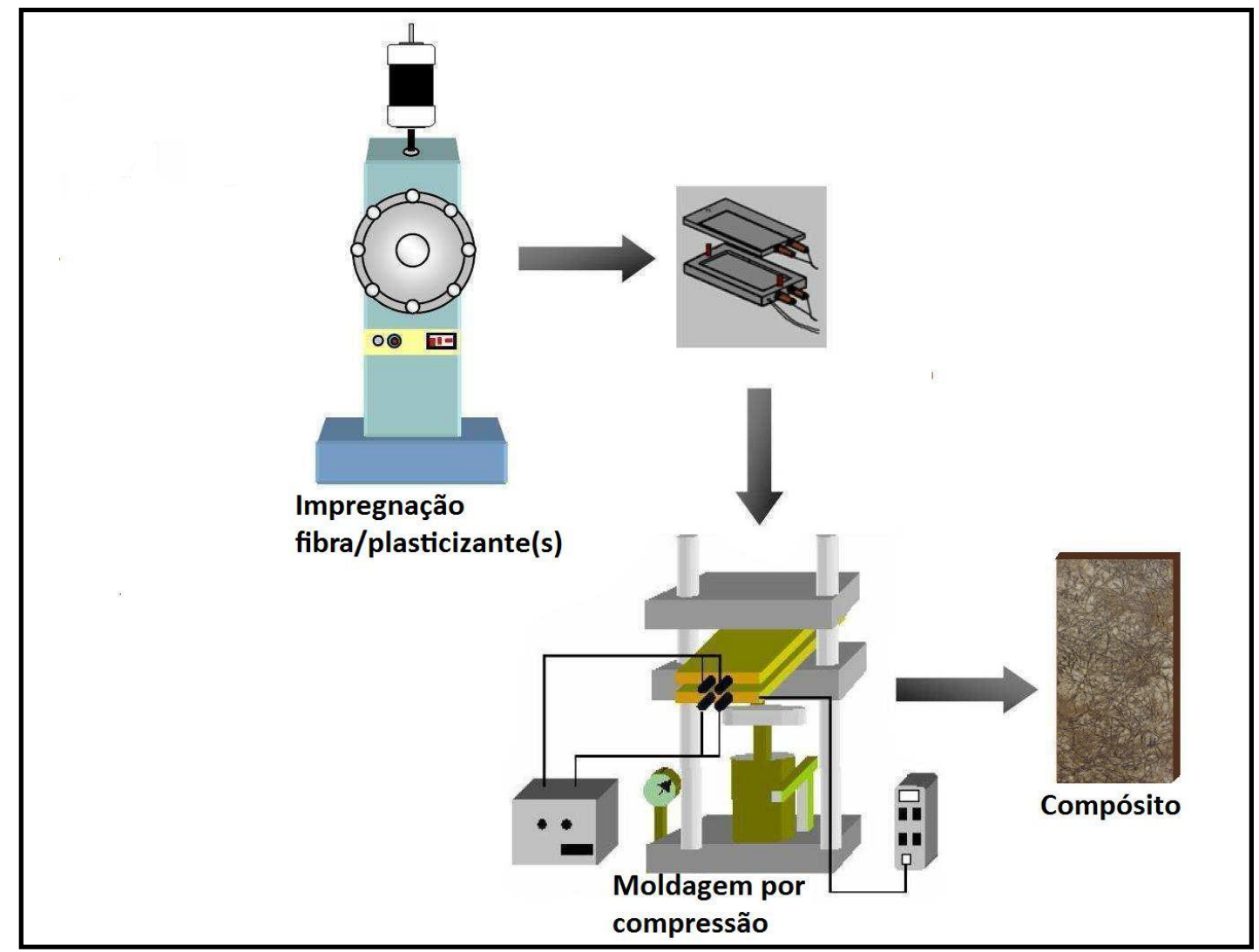

Figura 31. Representação esquemática do processo de preparação dos compósitos (adaptado de MEGIATTO (2006)).

Durante o preparo dos compósitos adotou-se o ciclo de temperaturas no 10 , com duração total, incluindo as rampas de aquecimento, de 5 h 55 min.

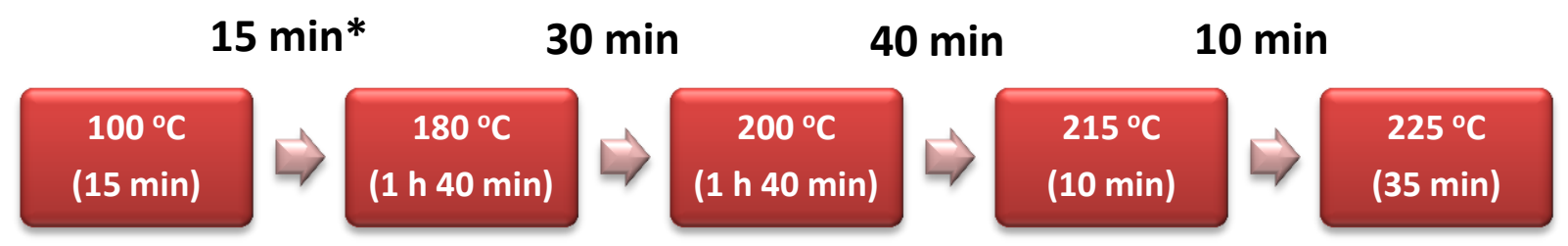

*intervalo de tempo das rampas de aquecimento.

Ciclo de temperaturas no 10 (Experimental).

Após o término do ciclo, deixou-se o molde resfriar até atingir a temperatura ambiente, mantendo-se a pressão constante. Em seguida, ocorreu a desmoldagem dos compósitos, com diferentes composições, esquematizadas na Figura 32, sob a forma de placas. 


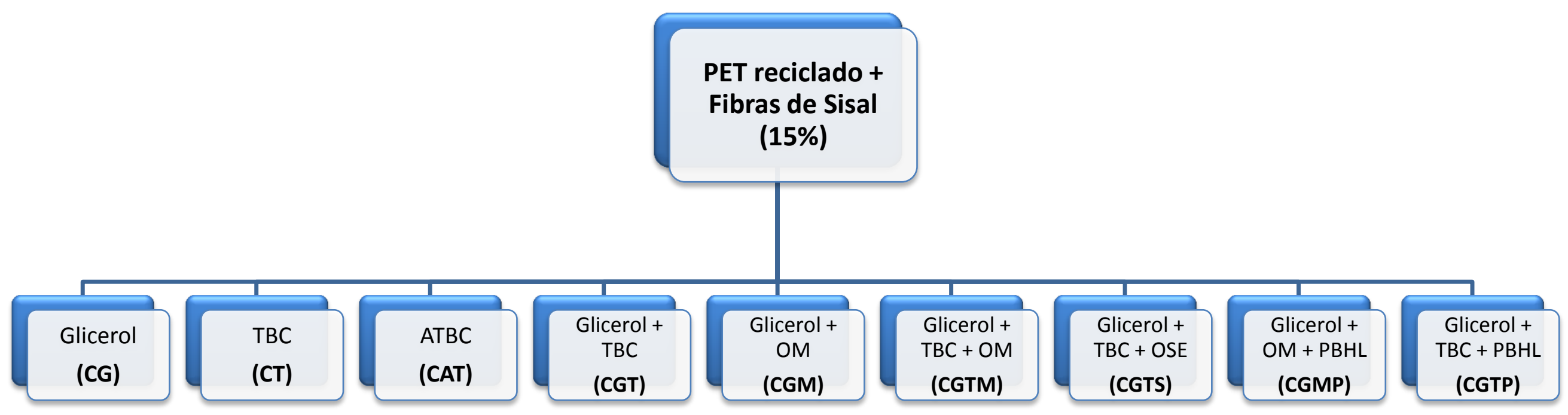

Figura 32. Diagrama esquemático mostrando os diferentes plasticizantes usados (na forma isolada ou combinados) na preparação dos compósitos. 
As diversas composições dos compósitos foram preparadas a partir de uma proporção fixa de 15\% (em massa) de fibras de sisal (3 cm de comprimento) misturadas com 85\% de PET reciclado com a adição de diferentes tipos e misturas de plasticizantes.

Os compósitos CG, CT e CAT foram preparados com a adição de 40\% (em massa) dos plasticizantes glicerol, TBC e ATBC, respectivamente, com relação à massa de PET reciclado utilizada. As porcentagens de plasticizantes informadas correspondem a valores nominais, pois durante o processamento podem ocorrer perdas, principalmente por volatilização, a temperaturas mais altas.

$\mathrm{Na}$ formulação dos compósitos CGT e CGM que continham misturas, respectivamente, dos plasticizantes glicerol com TBC e glicerol com $\mathrm{OM}$, adicionou-se $20 \%$ (em massa) de cada um dos plasticizantes também com relação à massa de PET reciclado utilizada.

Nos compósitos CGTM e CGTS preparados a partir de misturas, respectivamente, de glicerol, TBC e OM, e glicerol, TBC e OSE, os plasticizantes glicerol e TBC foram adicionados cada qual na proporção de $20 \%$ (em massa) em relação à massa de PET reciclado usada. Os plasticizantes OM e OSE foram adicionados cada qual na proporção de $10 \%$ (em massa) em relação à massa total de PET reciclado e dos outros plasticizantes usados.

Os compósitos CGMP e CGTP foram preparados a partir de misturas dos plasticizantes, respectivamente, glicerol, OM e PBHL, e glicerol, TBC e PBHL. Os plasticizantes glicerol e OM foram adicionados na formulação do compósito CGMP cada qual na proporção de 20\% (em massa) em relação à massa de PET reciclado, assim como foram adicionados na formulação do compósito CGTP os plasticizantes glicerol e TBC. O PBHL foi adicionado no preparo dos compósitos na proporção de $15 \%$ (em massa) com relação à massa total de PET reciclado e dos outros plasticizantes adicionados. Destaca-se que, no presente estudo, a quantidade elevada de plasticizantes adicionados em comparação ao que se encontra na literatura para o preparo de compósitos poliméricos reforçados com fibras lignocelulósicas, deve-se a perdas de parte destes aditivos por volatilização durante o processamento dos materiais. 


\subsubsection{Preparação da mistura de PET reciclado/20\% glicerol/20\% OM e dos compósitos de matriz de PET reciclado reforçados com fibras de sisal por reometria de torque}

Inicialmente, 15\% (em massa) de fibras de sisal (5 mm de comprimento) misturadas com $85 \%$ de PET reciclado em flakes foram processados em um reômetro de torque Haake com câmara de mistura Rheomix 3000p com capacidade para $45 \mathrm{~g}$ (disponível no Departamento de Engenharia de Materiais - DEMA da Universidade Federal de São Carlos - UFSCar, São Carlos, SP) a $260^{\circ} \mathrm{C}$ e $60 \mathrm{rpm}$, por um período de 6 min. Posteriormente, o material obtido foi reservado para a realização da termoprensagem.

Devido à ocorrência de decomposição térmica das fibras de sisal no processamento anterior por reometria de torque, o PET reciclado em pó, ao invés de flakes, foi inicialmente misturado com 20\% (em massa) de glicerol, em relação à massa do polímero, e levado ao reômetro de torque Haake, utilizado anteriormente, a $225{ }^{\circ} \mathrm{C}$ e $60 \mathrm{rpm}$. Após 3 min de processamento, e consequente fusão do PET reciclado, foi adicionado 15\% (em massa) de fibras de sisal (5 mm de comprimento) misturadas com $20 \%$ de OM, ambas as porcentagens em relação à massa do polímero, por mais 2 min. Ao final do processamento, o material obtido foi cortado com o auxílio de uma guilhotina em pequenos pedaços e pulverizado criogenicamente com o auxílio de um moinho universal da marca IKA, modelo M20 (disponível no Departamento de Engenharia de Materiais - DEMA da Universidade Federal de São Carlos - UFSCar, São Carlos, SP). Após, este foi reservado para posterior termoprensagem. Destaca-se que, o comprimento das fibras escolhido, inferior a $1 \mathrm{~cm}$, deve-se ao fato de que este levou a materiais, processados por reometria de torque, com melhores resultados de propriedades mecânicas, em estudos anteriormente desenvolvidos no mesmo grupo de pesquisa, no qual o presente trabalho se insere (De Castro, 2010).

A mistura de PET reciclado contendo frações de $20 \%$ de glicerol e $20 \%$ de OM foi processada em um reômetro de torque Haake, o mesmo utilizado anteriormente, a $225{ }^{\circ} \mathrm{C}$ e $60 \mathrm{rpm}$, por um período de $5 \mathrm{~min}$. Em seguida, o material também foi pulverizado criogenicamente e reservado para posterior termoprensagem. 


\subsubsection{Termoprensagem}

Aproximadamente $52 \mathrm{~g}$ do compósito (CH) obtido a partir de 15\% de fibras de sisal misturadas com 85\% de PET reciclado em flakes, obtido através do procedimento do item 4.2.3, foram colocados entre duas placas de aço inox, sob a forma de um "sanduíche", entre duas películas de teflon. Sobre as duas películas de teflon foi colocada uma moldura de alumínio, para a garantia da regularidade da espessura final desejada da placa do compósito. Após, o conjunto foi levado a uma termoprensa hidráulica, previamente aquecida a $260^{\circ} \mathrm{C}$, por $3 \mathrm{~min}$, sendo então submetido às cargas de 0,5 ton, 1 ton e 2 ton por mais $1 \mathrm{~min}$. $\mathrm{O}$ conjunto foi resfriado até $60{ }^{\circ} \mathrm{C}$ sob carga constante de 2 ton. Em seguida, esse foi retirado da termoprensa e deixou-se resfriar até a temperatura ambiente, obteve-se então o compósito sob a forma de placa (CH).

As misturas de PET reciclado/20\% glicerol/20\% OM/15\% fibras de sisal (CHGM) e de PET reciclado/20\% glicerol/20\% OM (CTRH), preparadas de acordo com o item 4.2.3, foram termoprensadas conforme o procedimento descrito anteriormente, porém à temperatura de $225^{\circ} \mathrm{C}$. 


\section{Caracterizações}

\subsection{Caracterização das fibras de sisal}

\subsubsection{Determinação do teor de umidade}

Esta determinação foi realizada de acordo com a norma ABNT (NBR 9656), em triplicata. Em pesa-filtros previamente tarados, pesou-se $1,0 \mathrm{~g}$ de amostra $\left(\mathrm{m}_{1}\right)$. As amostras foram secas em estufa com circulação de ar a $105{ }^{\circ} \mathrm{C}$ por $4 \mathrm{~h}$. Após, as amostras foram transferidas para um dessecador e em seguida foram pesadas até massa constante. 0 teor de umidade foi calculado pela Equação 2:

$$
\% \text { Umidade }=\frac{\mathrm{m}_{1}-\mathrm{m}_{2}}{\mathrm{~m}_{1}} \times 100
$$

Sendo:
$\mathrm{m}_{1}=$ massa
(g) inicial da amostra
$\mathrm{m}_{2}=$ massa $(\mathrm{g})$ da amostra seca

\subsubsection{Determinação do teor de cinzas}

Esta determinação foi realizada segundo a norma TAPPI T211, em triplicata. Em cadinhos de porcelana refratária previamente tarados a $900{ }^{\circ} \mathrm{C}$, foram adicionadas amostras de 1,0 g de fibra seca e moída. Os cadinhos foram então levados ao bico de Bunsen até combustão lenta da amostra. Em seguida, os cadinhos foram levados a mufla, a temperatura de $900{ }^{\circ} \mathrm{C}$, por $4 \mathrm{~h}$. Após este período, as amostras calcinadas foram colocadas em um dessecador contendo sílica para resfriamento e, em seguida, pesadas até massa constante. 0 teor de cinzas foi calculado pela Equação 3:

$$
\% \text { Cinzas }=\frac{\mathrm{m}_{1}}{\mathrm{~m}_{2}} \times 100
$$


Sendo:

$\mathrm{m}_{1}=$ massa $(\mathrm{g})$ de cinzas

$\mathrm{m}_{2}=$ massa $(\mathrm{g})$ da amostra seca

\subsubsection{Determinação do teor de lignina}

Este método fundamenta-se na hidrólise ácida dos polissacarídeos e consequente separação e determinação gravimétrica da lignina insolúvel em ácido sulfúrico (72\%) (FENGEL; WEGENER, 1989).

\subsubsection{Teor de lignina Klason insolúvel}

Esta análise foi realizada em triplicata. Pesou-se 1,0 $\mathrm{g}$ de amostra de fibra previamente seca em estufa. A amostra foi colocada em um erlenmeyer de $250 \mathrm{~mL}$ com 15,0 mL de ácido sulfúrico 72\%. Deixou-se a amostra em agitação mecânica constante por $2 \mathrm{~h}$ a temperatura ambiente. Em seguida, a amostra foi transferida para um balão de 1,0 L adicionando-se 560,0 $\mathrm{mL}$ de água destilada, seguido de refluxo por $4 \mathrm{~h}$. Após, filtrou-se a lignina insolúvel obtida em funil de vidro sinterizado (previamente tarado) lavando-se várias vezes com água destilada. A lignina insolúvel foi seca em estufa a 105 ${ }^{\circ} \mathrm{C}$ até massa constante.

\subsubsection{Teor de lignina Klason solúvel}

O filtrado obtido da lignina Klason insolúvel foi analisado por espectroscopia na região de ultravioleta (UV), sendo determinadas as absorbâncias nos comprimentos de onda de 280 e 215 nm como descrito na norma TAPPI T13 m-54 (FENGEL; WEGENER, 1989). As concentrações de lignina em $\mathrm{g} \mathrm{L}^{-1}$ nas amostras diluídas foram calculadas através da Equação 4:

$$
\mathrm{C}\left(\mathrm{g} \mathrm{L}^{-1}\right)=\frac{4,53 x\left(\mathrm{~A}_{215}\right)-\mathrm{A}_{280}}{300}
$$

Sendo:

$\mathrm{C}\left(\mathrm{g} \mathrm{L}^{-1}\right)$ = concentração em g L-1 de lignina Klason solúvel nas amostras diluídas $\mathrm{A}_{215}$ = valor da absorbância a $215 \mathrm{~nm}$ 
$\mathrm{A}_{280}=$ valor da absorbância a $280 \mathrm{~nm}$

Através da soma dos resultados obtidos em 5.1.3.1 e em 5.1.3.2 quantificou-se a concentração total de lignina das amostras.

\subsubsection{Determinação do teor de holocelulose (celulose e hemicelulose)}

0 teor de holocelulose, que corresponde à soma dos teores de celulose e hemicelulose, foi determinado (em triplicata) de acordo com o método descrito na norma TAPPI T19-54, adaptado para as fibras lignocelulósicas (RAZERA, 2006). Em um erlenmeyer de 1,0 L foi adicionado 3,0 g de amostra seca e moída de fibra, 250,0 mL de água destilada, 1,0 $\mathrm{mL}$ de ácido acético glacial e 2,5 g de clorito de sódio. Fechou-se o recipiente com outro erlenmeyer de $250 \mathrm{~mL}$ invertido sobre o primeiro, sendo o conjunto colocado em um banho termostatizado a $70 \pm 2{ }^{\circ} \mathrm{C}$.

A mistura foi mantida sob agitação constante e, após $1 \mathrm{~h}$, foram adicionados mais 1,0 mL de ácido acético glacial e 2,5 g de clorito de sódio. Esta etapa foi repetida mais uma vez e, ao final de $3 \mathrm{~h}$, a mistura foi resfriada abaixo de $10^{\circ} \mathrm{C}$ e em seguida filtrada em um funil de vidro sinterizado, previamente tarado. A holocelulose (sobrenadante) foi lavada com água destilada até pH idêntico ao da água. Após, esta foi lavada com metanol e seca em estufa a $105^{\circ} \mathrm{C}$ até massa constante. A porcentagem de holocelulose foi determinada através da Equação 5:

$$
\% \text { Holocelulose }=\frac{\mathrm{m}_{1}}{\mathrm{~m}_{2}} \times 100
$$

Sendo:

$\mathrm{m}_{1}=$ massa $(\mathrm{g})$ de holocelulose seca

$\mathrm{m}_{2}=$ massa $(\mathrm{g})$ de amostra

Neste processo, a lignina é totalmente eliminada e a amostra final é composta por holocelulose, ou seja, celulose e hemicelulose (ou polioses). 


\subsubsection{Determinação do teor de $\alpha$-celulose}

A determinação do teor de celulose foi realizada com as amostras resultantes da determinação do teor de holocelulose, em triplicata. Colocou-se 1,0 g de amostra de holocelulose em um almofariz e foi adicionado $10 \mathrm{~mL}$ de solução de $\mathrm{NaOH}$ 17,5\%. Deixou-se em repouso por 2 min e triturou-se por $8 \mathrm{~min}$. Adicionou-se então mais $10,0 \mathrm{~mL}$ de solução de $\mathrm{NaOH}$ 17,5\% e deixou-se em repouso por mais $20 \mathrm{~min}$. Em seguida, adicionou-se $40 \mathrm{~mL}$ de água destilada e filtrou-se a vácuo em funil de vidro sinterizado (previamente tarado). 0 material retido (celulose) foi lavado com água destilada até pH neutro. Lavou-se então com 200,0 mL de ácido acético diluído (20\%) e com mais 200,0 mL de água destilada. Secou-se em estufa de circulação de ar a $105{ }^{\circ} \mathrm{C}$. Após, resfriou-se em dessecador contendo sílica e pesou-se. A determinação do teor de celulose presente na holocelulose foi feita de acordo com a Equação 6:

$$
\% \text { Celulose }=\frac{\mathrm{m}_{1}}{\mathrm{~m}_{2}} \times 100
$$

Sendo:

$\mathrm{m}_{1}=$ massa $(\mathrm{g})$ de celulose seca

$\mathrm{m}_{2}=$ massa $(\mathrm{g})$ de holocelulose seca

Assim, o percentual de hemicelulose (polioses) foi determinado pela diferença entre a porcentagem de holocelulose e $\alpha$-celulose da fibra.

\subsubsection{Difração de raios $X$}

Para a determinação do Índice de Cristalinidade $\left(I_{c}\right)$ da celulose presente nas fibras lignocelulósicas utilizou-se a técnica de difração de raios X. $\mathrm{O}$ Índice de Cristalinidade é um dado importante, pois informa a proporção de regiões cristalinas em relação às regiões não cristalinas presentes no material. A cristalinidade pode ser relacionada diretamente com o acesso aos grupos hidroxila da celulose presente nos materiais lignocelulósicos da seguinte forma: nas regiões cristalinas o acesso dos reagentes aos grupos hidroxila é dificultado, oposto do que ocorre nas regiões não cristalinas (TITA, 2002). Através do difratograma de raios X das fibras é possível observar a presença dos picos característicos da celulose, referente aos planos 


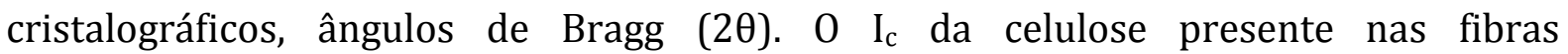
lignocelulósicas é obtido a partir dos picos característicos da celulose.

Por meio da Equação 7, descrita por Buschle-Diller e Zeronian (1992) o I pode ser calculado da seguinte forma:

$$
\mathrm{I}_{c}=1-\frac{\mathrm{I}_{1}}{\mathrm{I}_{2}}
$$

Sendo:

$\mathrm{I}_{1}=$ intensidade de difração mínima, referente à região não cristalina

$\mathrm{I}_{2}=$ intensidade de difração máxima, referente à região cristalina

As análises de raios $\mathrm{X}$ para as fibras de sisal foram feitas em um difratômetro RIGAKU com tubo de cobre selado, radiação $(\mathrm{k} \alpha)$ e comprimento de onda de $1542 \AA$ $(\mathrm{k} \alpha)$. As medidas foram realizadas a velocidade de $2^{\circ} \mathrm{min}^{-1}$, no intervalo angular de 5 a $50^{\circ}$ (ângulo de Bragg 20), potencia de $40 \mathrm{~mA}$ e $40 \mathrm{kV}$. As amostras foram previamente moídas e secas em estufa de circulação de ar a $105^{\circ} \mathrm{C}$.

\subsubsection{Microscopia Eletrônica de Varredura (MEV)}

A microscopia eletrônica de varredura foi utilizada na avaliação da morfologia da superfície das fibras de sisal. 0 equipamento utilizado foi da marca ZEISS-LEICA modelo 440 com aceleração de elétrons de $20 \mathrm{kV}$. As amostras foram colocadas em um portaamostra de alumínio e em seguida recobertas com uma fina camada de ouro.

\subsubsection{Calorimetria Exploratória Diferencial (DSC)}

A análise DSC foi realizada com o equipamento Shimadzu modelo DSC-50. Foram utilizadas amostras com massa de aproximadamente 5,0 mg, colocadas em portaamostra de alumínio selado. As corridas foram realizadas no intervalo de $25-400{ }^{\circ} \mathrm{C}$, com razão de aquecimento de $10{ }^{\circ} \mathrm{C} \mathrm{min}^{-1}$, em atmosfera de nitrogênio, com fluxo de $50,0 \mathrm{~mL} \mathrm{~min}^{-1}$. 


\subsubsection{Termogravimetria (TG)}

A análise termogravimétrica foi realizada com o equipamento da Shimadzu TG modelo 50 WSI. Foram utilizadas amostras com massa de aproximadamente 5,0 mg, colocadas em porta-amostra de platina. As corridas foram realizadas no intervalo de 25$800{ }^{\circ} \mathrm{C}$, com razão de aquecimento de $10{ }^{\circ} \mathrm{C} \mathrm{min}^{-1}$, em atmosfera de nitrogênio com fluxo de $50 \mathrm{~mL} \mathrm{~min}^{-1}$.

\subsubsection{Espectroscopia na região do infravermelho (IV)}

Os espectros de infravermelho das amostras foram obtidos utilizando-se um espectrômetro BOMEM, modelo MB-102, na região de 400 a $4000 \mathrm{~cm}^{-1}$. As análises foram realizadas em pastilhas preparadas a partir de 1,0 mg de amostra e 100,0 mg de brometo de potássio $(\mathrm{KBr})$, prensadas na forma de disco. Todas as amostras foram previamente moídas e secas a 105 ํ em estufa de circulação de ar.

\subsection{Caracterização do poli (tereftalato de etileno) reciclado}

\subsubsection{Calorimetria Exploratória Diferencial (DSC)}

Para a análise de DSC, a amostra de PET reciclado foi analisada de duas diferentes maneiras: (1) sem nenhum tratamento térmico e (2) após ser submetida a um aquecimento de $180^{\circ} \mathrm{C}$ e mantida a esta temperatura por quatro horas. Utilizou-se este tratamento térmico para a eliminação de água residual da amostra, pois a água presente no PET pode atuar como agente de degradação hidrolítica, e, em teores de umidade acima de 0,5\%, intensificar a degradação deste polímero. Assim, evita-se uma possível degradação hidrolítica da amostra de PET reciclado e a consequente formação de acetaldeído e ácido tereftálico (RUVOLO-FILHO; CURTI, 2007).

\subsubsection{Termogravimetria (TG)}

Análise descrita conforme item 5.1.9. 


\subsubsection{Espectroscopia na região do Infravermelho (IV)}

Análise descrita conforme item 5.1.10. Diferentemente da pré-secagem das fibras de sisal, a amostra de PET reciclado, sob a forma de pó, foi previamente seca a $180{ }^{\circ} \mathrm{C}$, por um período de no mínimo 4 h, em estufa de circulação de ar.

\subsubsection{Determinação do Índice de Fluidez (MFI)}

No presente trabalho, mediu-se o MFI para o PET reciclado em um plastômero da marca Davenport MFI 150, de acordo com a norma ASTM D 1238. A análise foi realizada em triplicata à temperatura de $160{ }^{\circ} \mathrm{C}$ e carga nominal de $2,16 \mathrm{Kg}$.

\subsection{Caracterização dos plasticizantes}

\subsubsection{Calorimetria Exploratória Diferencial (DSC)}

Análise descrita conforme item 5.1.8.

\subsubsection{Termogravimetria (TG)}

Análise descrita conforme item 5.1.9.

\subsubsection{Espectroscopia na região do infravermelho (IV)}

Análise descrita conforme item 5.1.10, mas com algumas modificações. Devido ao estado líquido dos plasticizantes, não foi possível, por prensagem, o preparo de pastilhas destes com $\mathrm{KBr}$. As amostras de plasticizantes foram analisadas mediante o uso de pastilhas de silício (Si), nas quais com o uso de uma pipeta de Pasteur uma gota dos plasticizantes foi vertida nestas para posterior análise. 


\subsection{Caracterização dos Compósitos}

\subsubsection{Microscopia Eletrônica de Varredura (MEV)}

Foram analisadas por MEV as superfícies fraturadas dos corpos de prova, pósensaio de impacto, conforme descrito no item 5.1.7.

\subsubsection{Calorimetria Exploratória Diferencial (DSC)}

Análise descrita conforme item 5.1.8.

\subsubsection{Termogravimetria (TG)}

Análise descrita conforme item 5.1.9.

\subsubsection{Absorção de água}

Os ensaios de absorção de água foram realizados de acordo com a norma ASTM D570. Para estes ensaios, foram cortados e usinados corpos de prova nas dimensões de (76,2 x 25,4 x 3,2 mm) (c x l x e). As análises foram feitas por imersão dos corpos de prova, até saturação, em béqueres contendo água destilada a temperatura ambiente. Após cada intervalo de tempo, as amostras foram retiradas da água, uma de cada vez, colocadas em um pedaço de tecido seco (para retirar o excesso de água) e imediatamente pesadas em uma balança analítica. A porcentagem de aumento de massa (teor de água absorvida) foi calculada pela diferença de massa, de acordo com a Equação 8.

$$
\% \text { Água }=\frac{m_{1}-m_{2}}{m_{1}} \times 100
$$

Sendo:

$\mathrm{m}_{1}=$ massa $(\mathrm{g})$ inicial da amostra

$\mathrm{m}_{2}=\operatorname{massa}(\mathrm{g})$ da amostra seca (final) 


\subsubsection{Ensaio de resistência ao impacto Izod}

No presente estudo foram realizados ensaios de resistência mecânica ao impacto do tipo Izod com corpos de prova não entalhados nas dimensões de $(63,5 \times 12,7$ x 4,5 $\mathrm{mm}$ ) (c x l x e), de acordo com a norma ASTM D256. 0 equipamento utilizado foi o da marca CEAST Resil 25 do Departamento de Engenharia de Materiais (DEMA) da Universidade Federal de São Carlos - UFSCar (São Carlos, SP).

\subsubsection{Ensaio de resistência à flexão}

Foram realizados ensaios de resistência à flexão com corpos de prova nas dimensões de $(127,0$ x 12,7 x 4,5 mm) (c x l x e), de acordo com a norma ASTM 790-96a. Utilizou-se uma máquina de ensaios universal INSTRON, modelo 5569 do Departamento de Engenharia de Materiais (DEMA) da Universidade Federal de São Carlos - UFSCar (São Carlos, SP).

\subsubsection{Análise Térmica Dinâmico-Mecânica (DMTA)}

Foram analisados por DMTA corpos de prova nas dimensões de $(63,5$ x 12,7 x 3,2 $\mathrm{mm}$ ) (c x l x e). Utilizou-se o equipamento da TA Instruments, modelo Q800 DMA, pertencente ao Departamento de Engenharia de Materiais (DEMA) da Universidade Federal de São Carlos - UFSCar (São Carlos, SP). O equipamento foi utilizado no modo de flexão, com amplitude de oscilação de $20 \mu \mathrm{m}$, freqüência de $1 \mathrm{~Hz}$, taxa de aquecimento de $2{ }^{\circ} \mathrm{C} \mathrm{min}^{-1}$, no intervalo de temperatura de $30-200^{\circ} \mathrm{C}$. 


\section{Resultados e Discussão}

\subsection{Caracterização das fibras de sisal}

\subsubsection{Composição química}

As fibras lignocelulósicas, como o sisal, são compostas principalmente por celulose, lignina e hemicelulose (MARTIN et al., 2010). Por se tratar de um material de origem natural, as fibras de sisal apresentam falta de uniformidade quanto às suas propriedades, pois fatores como a origem da planta, idade, condições climáticas a que a planta foi submetida, processos de extração e purificação influenciam não só a estrutura da fibra, mas também a sua composição química (AKRAM KHAN et al., 2011). A Tabela 1 apresenta os valores médios dos resultados da caracterização das fibras de sisal utilizadas no presente trabalho.

Tabela 1. Teor de componentes químicos majoritários das fibras de sisal.

\begin{tabular}{|c|c|}
\hline Componente & Teor (\%) \\
\hline Umidade & $7,10 \pm 0,10$ \\
\hline Cinzas & $0,38 \pm 0,08$ \\
\hline Lignina Klason insolúvel & $9,60 \pm 0,69$ \\
\hline Lignina Klason solúvel & $2,06 \pm 0,24$ \\
\hline Lignina Klason total & $11,66 \pm 0,93$ \\
\hline Holocelulose & $90,29 \pm 1,61$ \\
\hline $\boldsymbol{\alpha}$-Celulose & $64,92 \pm 2,73$ \\
\hline Hemicelulose & $25,37 \pm 4,34$ \\
\hline
\end{tabular}

Estes resultados são compatíveis com os valores encontrados em estudos anteriores, desenvolvidos no mesmo grupo de pesquisa no qual este trabalho se insere. Nestes trabalhos, a caracterização das fibras de sisal forneceu proporções de lignina total de 9-11\%, 51-64\% de celulose e 21-35\% de hemicelulose (DE OLIVEIRA, 2010; DA SILVA, 2011). A hemicelulose, presente nas regiões não cristalinas da fibra de sisal, assim como em outras fibras lignocelulósicas, é responsável em grande parte pela absorção de água na fibra. Assim, a variação no teor de hemicelulose pode implicar na 
variação de umidade na fibra, com consequências nas propriedades finais dos materiais obtidos, no caso deste trabalho, os compósitos.

Os teores de umidade e cinzas (compostos inorgânicos de cálcio, sódio, potássio e sílica aderidos às fibras sob a forma de sais) obtidos no presente trabalho também estão próximos aos valores encontrados na literatura (6-11\% de umidade e 0,6-1,1\% de cinzas) (MEGIATTO, 2006; FAVAR0, 2010; AKRAM KHAN et al., 2011).

\subsubsection{Determinação do Índice de Cristalinidade por Difração de raios $X$}

A Figura 33 apresenta o difratograma obtido para as fibras de sisal. Pode-se observar que o difratograma consiste de três regiões com diferentes larguras e intensidades, o que caracteriza as diferentes estruturas cristalográficas da celulose, responsável pela cristalinidade da fibra (SAIKIA, 2008). As setas de cor vermelha indicam as regiões de intensidade de difração máxima e mínima utilizadas para o cálculo do Índice de Cristalinidade.

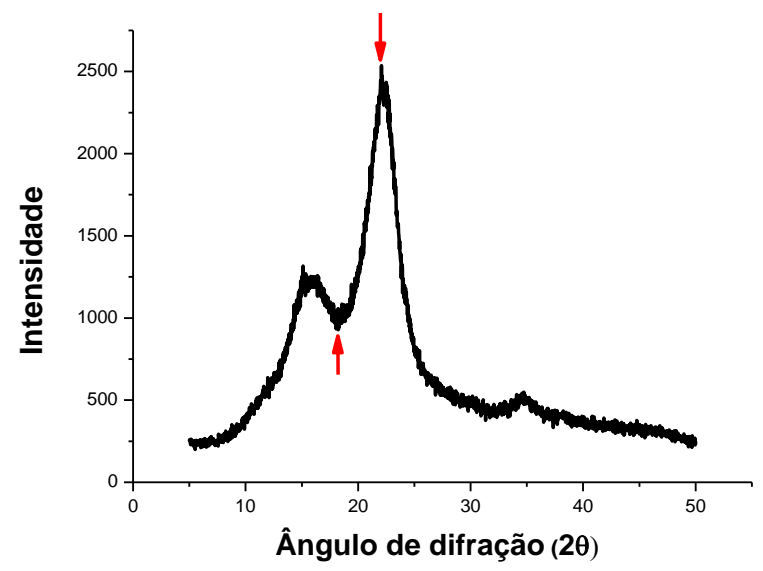

Figura 33. Difratograma de raios $\mathrm{X}$ das fibras de sisal.

O Índice de Cristalinidade foi determinado de acordo com a Equação 7 (item 5.1.6), obtendo-se o valor de 58\%. Valores próximos a este foram obtidos em trabalhos anteriores, em que as fibras de sisal também foram utilizadas. Ramires (2010) obteve para fibras de sisal com 64\% de celulose, Índice de Cristalinidade de 61\%. Oliveira (2010) e da Silva (2011) obtiveram para fibras de sisal com respectivamente $52 \%$ e $64 \%$ de celulose, $55 \%$ e $60 \%$ de cristalinidade, respectivamente. 


\subsubsection{Microscopia Eletrônica de Varredura (MEV)}

A morfologia das fibras de sisal foi analisada a partir das imagens de MEV. As Figuras 34-a e 34-b mostram micrografias da superfície das fibras de sisal. Através destas, pode-se observar a presença de alguns fragmentos na superfície das fibras, provavelmente provenientes de resíduos de células parênquimas, nas quais as fibras estavam anteriormente ligadas (MEGIATTO, 2006).

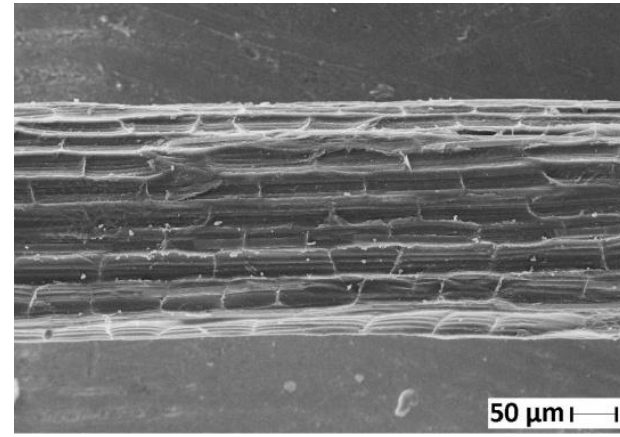

(a)

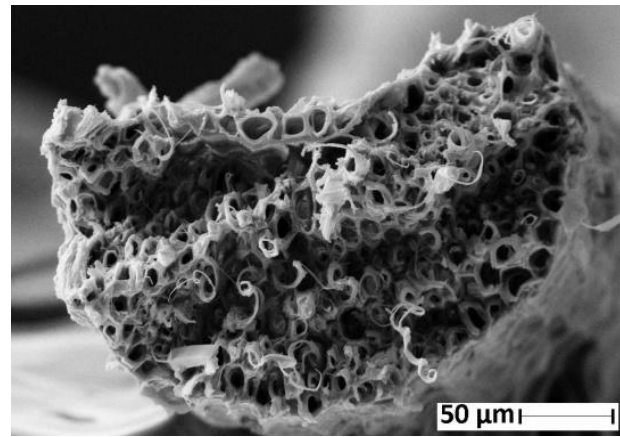

(c)

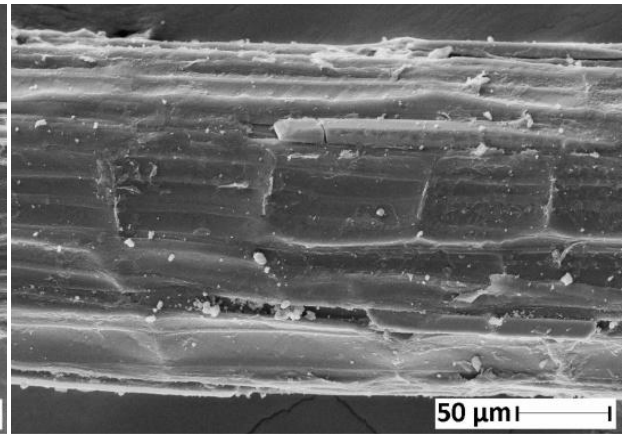

(b)

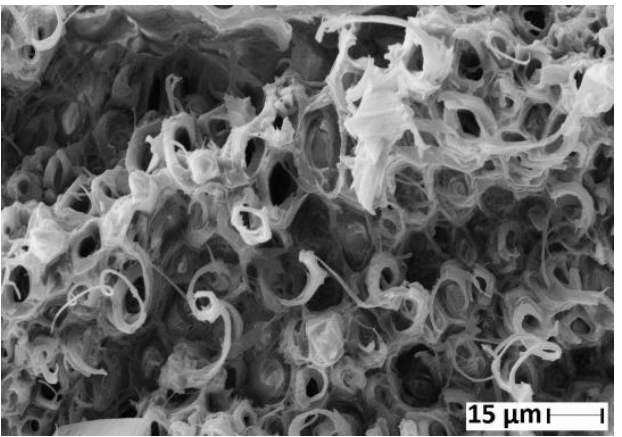

(d)

Figura 34. Micrografias das fibras de sisal: (a) e (b) superfície ampliada; (c) e (d) corte transversal ampliado.

Nas micrografias das Figuras 34-c e 34-d pode-se observar o interior das fibras de sisal, as quais são compostas por uma estrutura fibrilar formada pela união de feixes de fibrilas, os quais, por sua vez, são constituídos por um grande número de células, justapostas e intimamente ligadas por substâncias de origem péctica (SALAZAR; LEÃO, 2006). As fibrilas são ocas, constituídas por macromoléculas de celulose, recobertas e aderidas umas as outras por uma matriz de lignina e hemicelulose. Cada fibrila possui uma complexa estrutura em camadas em que uma fina casca envolve uma segunda camada mais interna e espessa, sendo que o conjunto de fibrilas forma espirais ao longo do eixo das fibras (DOS SANTOS, 2006). Os canais formados por esta estrutura fibrosa, que podem ser observados nestas micrografias, são de grande importância na utilização 
das fibras como agente de reforço em compósitos, pois podem facilitar a difusão da resina polimérica para o interior da fibra, com consequente melhor adesão/interação fibra-matriz (TRINDADE et al., 2005; MEGIATTO, 2006). 0 diâmetro médio das fibras lignocelulósicas de sisal utilizadas no presente trabalho, avaliado a partir das imagens de MEV (utilizando o programa ImageJ), foi de $208 \pm 43 \mu \mathrm{m}$.

\subsubsection{Análise Térmica}

As curvas DSC, TG e dTG para a fibra de sisal (Figura 35) mostram um comportamento típico de fibras lignocelulósicas.

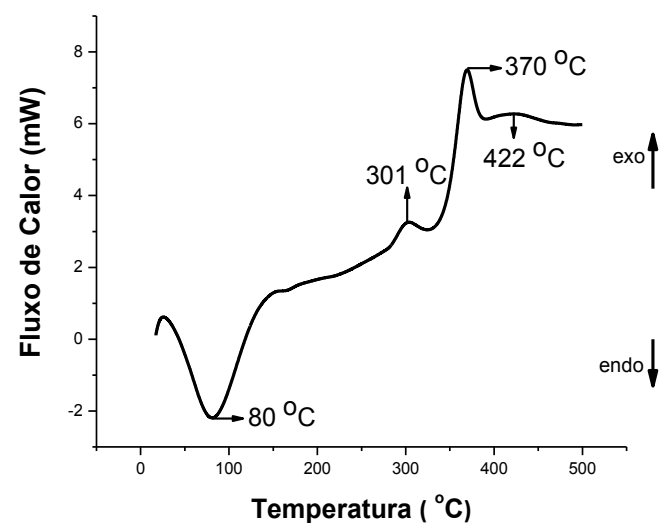

(a)

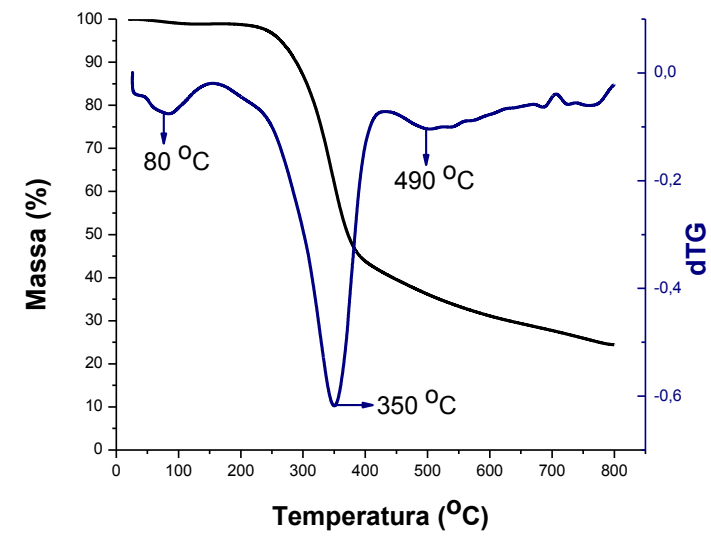

(b)

Figura 35. Curvas (a) DSC e (b) TG e dTG para a fibra de sisal (fluxo de $\mathrm{N}_{2}$ de $50 \mathrm{~mL} \mathrm{~min}^{-1}$, razão de

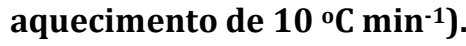

Pode-se observar, na Figura 35-a, um deslocamento da linha base na região de $80{ }^{\circ} \mathrm{C}$, referente ao evento endotérmico de vaporização de água presente na superfície e sítios intersticiais da fibra (SAIKIA, 2008; RAMIRES, 2010). Observa-se também um pico pouco intenso na região de $301{ }^{\circ} \mathrm{C}$, devido ao evento exotérmico de decomposição da hemicelulose. $\mathrm{O}$ pico observado na região de $370{ }^{\circ} \mathrm{C}$ pode ser atribuído ao evento exotérmico de decomposição da celulose. Nesta temperatura ocorre a decomposição térmica da celulose, através de sua desidratação e despolimerização, levando à formação de produtos voláteis, como dióxido e monóxido de carbono (MEGIATTO, 2006; RAMIRES, 2010).

A lignina se decompõe acima de $400{ }^{\circ} \mathrm{C}$, estando provavelmente este evento ligado ao pico alargado e de baixa intensidade nesta região (Figura 35-a). A baixa intensidade é decorrente do baixo teor de lignina desta fibra (em torno de 11\%, Tabela 
1). As reações de decomposição são exotérmicas, mas como paralelamente ocorre a liberação de voláteis (evento endotérmico), os picos observados podem ser exotérmicos ou endotérmicos, dependendo do balanceamento entre a reação de decomposição/liberação de voláteis (RAMIRES, 2010). Na Figura 35-a todos os picos observados foram exotérmicos.

A curva TG para a amostra de fibra de sisal (Figura 35-b) mostra que, até $105^{\circ} \mathrm{C}$, há perda de aproximadamente $1 \%$ de massa, relacionada à perda de água relativa à umidade absorvida (ou adsorvida) pela fibra. A prévia secagem em estufa da amostra, previamente a análise, não eliminou totalmente a água, devido ao elevado caráter hidrofílico do material, o qual apresenta moléculas de água ligadas às suas respectivas estruturas. A maior parte das moléculas de água se liga às hemiceluloses que ficam nas regiões não cristalinas da fibra (RAMIRES, 2010).

No intervalo de temperatura de $160-245^{\circ} \mathrm{C}$, a fibra de sisal apresenta perda de massa de aproximadamente $2 \%$, a qual pode estar relacionada com a perda de água estrutural da fibra, ou seja, fortemente adsorvida. A partir de $245{ }^{\circ} \mathrm{C}$, até aproximadamente $420{ }^{\circ} \mathrm{C}$, há elevada perda de massa (55\%) decorrente da decomposição térmica da fibra de sisal, inicialmente atribuída à decomposição da hemicelulose, seguida da degradação da celulose (AKRAM KHAN et al., 2011; DA SILVA, 2011). De acordo com a curva dTG, o pico intenso que caracteriza a decomposição destes componentes da fibra possui um máximo em $350{ }^{\circ} \mathrm{C}$, o qual corresponde à temperatura máxima de decomposição $\left(\mathrm{T}_{\mathrm{p}}\right)$ da fibra. Pode-se considerar que, até $245^{\circ} \mathrm{C}$, a amostra de fibra de sisal apresenta estabilidade térmica, devido a baixa perda de massa da amostra, que não é decorrente da decomposição térmica. Assim, a temperatura de $245^{\circ} \mathrm{C}$ pode ser considerada a temperatura máxima para a aplicação das fibras de sisal, pois a partir desta temperatura há elevada perda de massa com a decomposição térmica das fibras.

Acima de $450{ }^{\circ} \mathrm{C}$ pode-se observar um pico largo e pouco intenso, referente a um novo estágio de perda de massa, atribuído à quebra de ligações da protolignina (lignina nativa), caracterizando a decomposição térmica do componente minoritário da fibra de sisal, no caso, a lignina (AKRAM KHAN et al., 2011; DA SILVA, 2011). A lignina possui elevada estabilidade térmica quando comparada a outros componentes da fibra, como a celulose, por exemplo, como consequência de sua estrutura aromática (DA SILVA, 2011). 
Os eventos de decomposição térmica dos componentes da fibra foram observados nas mesmas faixas de temperatura nas curvas correspondentes a TG e DSC (Figura 35).

\subsubsection{Espectroscopia na região do infravermelho (IV)}

A Figura 36 mostra o espectro na região do infravermelho para a fibra de sisal, e a Tabela 2 mostra as possíveis atribuições para as bandas presentes.

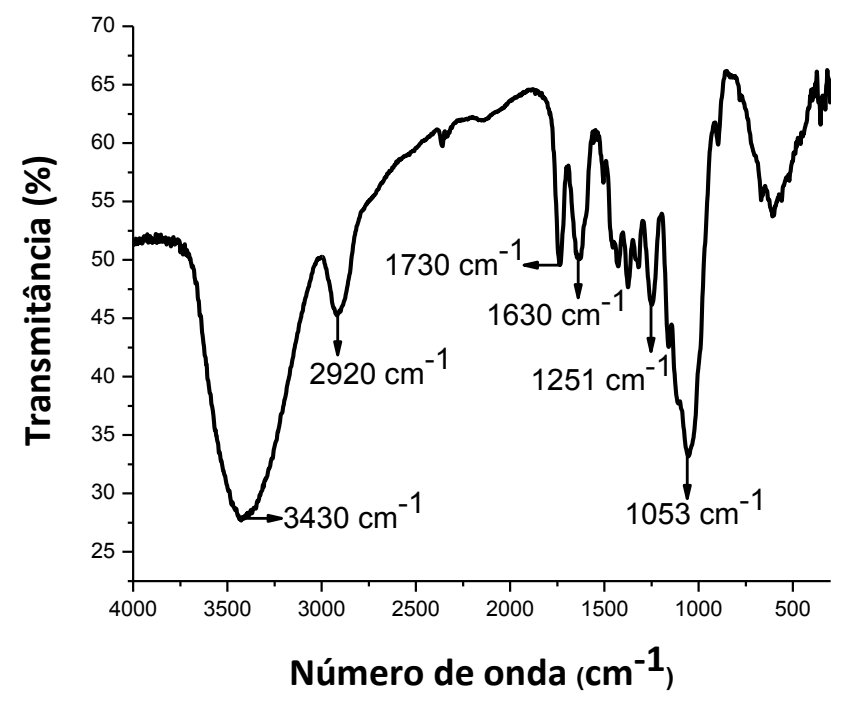

Figura 36. Espectro na região do infravermelho para a fibra de sisal.

Tabela 2. Principais absorções observadas no espectro na região do infravermelho da fibra de sisal e seus respectivos modos vibracionais (SILVERSTEIN; BASSLER; MORRIL, 1994; DE OLIVEIRA, 2010).

\begin{tabular}{|c|c|}
\hline $\begin{array}{l}\text { Número de } \\
\text { onda }\left(\mathrm{cm}^{-1}\right)\end{array}$ & Possíveis atribuições \\
\hline 3430 & $\begin{array}{c}\text { Estiramento ou deformação axial da ligação O-H (em ligações } \\
\text { hidrogênio intra e intermolecular) }\end{array}$ \\
\hline 2920 & Estiramento da ligação C-H de hidrocarbonetos saturados \\
\hline 1730 & Deformação axial da ligação C=0 (lignina) \\
\hline 1630 & Deformação axial das ligações C-C do anel aromático (lignina) \\
\hline 1251 & Deformação angular no plano da ligação $0-\mathrm{H}$ \\
\hline 1163 & Deformação axial da ligação C-0-C de grupos metoxila \\
\hline 1053 & $\begin{array}{c}\text { Deformação axial simétrica da ligação C-O-C dos grupos } \\
\text { metoxilas (lignina) }\end{array}$ \\
\hline
\end{tabular}

Foram observadas bandas referentes à absorção de grupos presentes na celulose (Figura 11-c), como os grupos hidroxila (banda intensa e larga). Também se observou 
bandas características referentes à absorção de grupos presentes na lignina, de estrutura aromática (Figura 11-b), e na hemicelulose, caracterizando um espectro típico de fibras lignocelulósicas (RAMIRES, 2010).

\subsection{Caracterização do poli (tereftalato de etileno) reciclado}

\subsubsection{Análise Térmica}

Analisando-se as curvas DSC obtidas para a amostra de PET reciclado (Figura 37-a), observa-se que o PET reciclado pós-tratamento térmico (após ser submetido a um aquecimento de $180{ }^{\circ} \mathrm{C}$ e mantido a esta temperatura por $4 \mathrm{~h}$ ) apresenta um pico pouco intenso na região de $190{ }^{\circ} \mathrm{C}$ e um pico intenso na região de $250{ }^{\circ} \mathrm{C}$, ambos referentes ao evento endotérmico de fusão. 0 pico a $187{ }^{\circ} \mathrm{C}$ corresponde à fusão de fração de cristais formados a partir de cadeias com menor massa molar média (MARCONCINI; RUVOLO FILHO, 2006).

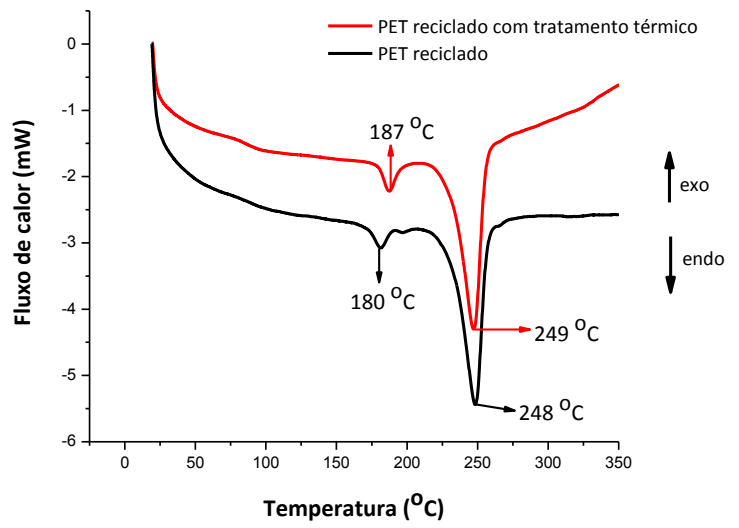

(a)

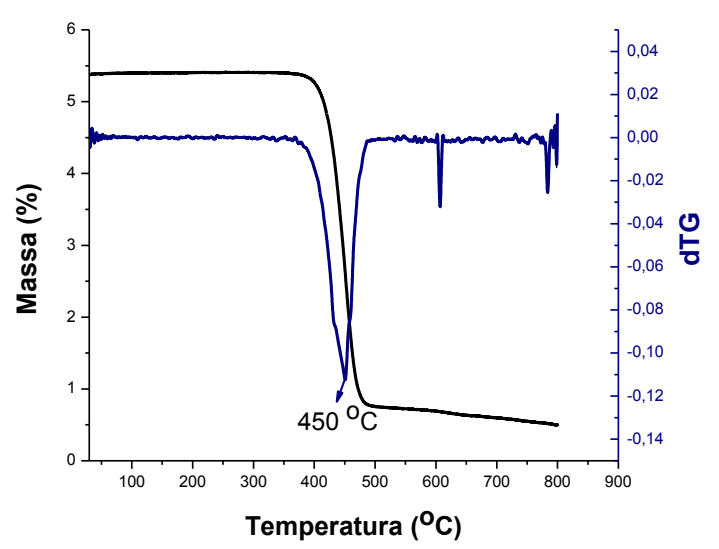

(b)

Figura 37. Curvas (a) DSC para as amostras de PET reciclado sem tratamento térmico e póstratamento térmico e (b) TG e dTG para a amostra de PET reciclado sem tratamento térmico (fluxo

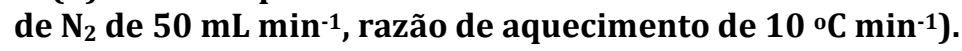

Com relação à curva DSC do PET reciclado sem tratamento térmico (Figura 37a), esta apresenta um pico pouco intenso na região de $180{ }^{\circ} \mathrm{C}$ e um pico intenso na região de $250{ }^{\circ} \mathrm{C}$, ambos, também referentes ao evento endotérmico de fusão. A menor temperatura de fusão, $180^{\circ} \mathrm{C}$, quando comparada à temperatura de fusão da amostra de PET reciclado pós-tratamento térmico, $187^{\circ} \mathrm{C}$, deve-se à presença de água residual na amostra, que pode elevar a proporção de cristais formados a partir de cadeias com menor massa molar média (RUVOLO-FILHO; CURTI, 2007). Este fenômeno ocorre 
devido à atuação da água como um plasticizante, aumentando a distância entre as cadeias poliméricas e reduzindo as interações intermoleculares entre estas. Consequentemente, há um aumento da mobilidade das cadeias e segmentos de regiões cristalinas, diminuindo a temperatura de fusão do polímero.

Não foi possível, via análise DSC, detectar o evento térmico referente à transição vítrea do PET reciclado, a qual ocorre em uma temperatura de aproximadamente $80{ }^{\circ} \mathrm{C}$ (MARCONCINI; RUVOLO FILHO, 2006). Esta transição é detectada por uma mudança na linha base da curva DSC, o que normalmente não é identificado com facilidade.

Pode-se observar, através das curvas TG e dTG (Figura 37-b), que há um único estágio de perda de massa significante, contido no intervalo entre 367-500 ${ }^{\circ} \mathrm{C}$, o qual é associado à decomposição do PET reciclado sem tratamento térmico (com perda de cerca de $80 \%$ de massa). A temperatura máxima de decomposição ( $\mathrm{T}_{\mathrm{p}}$ ) observada é de $450^{\circ} \mathrm{C}$.

Assim, a temperatura de decomposição máxima $\left(\mathrm{T}_{\mathrm{p}}\right)$ para a fibra de sisal $\left(350^{\circ} \mathrm{C}\right.$, Figura 35-b) é menor do que a $\mathrm{T}_{\mathrm{p}}$ do PET reciclado $\left(450^{\circ} \mathrm{C}\right)$. O PET reciclado apresenta boa estabilidade térmica até $367^{\circ} \mathrm{C}$, ou seja, mais de $120^{\circ} \mathrm{C}$ acima de sua temperatura de fusão.

\subsubsection{Espectroscopia na região do infravermelho (IV)}

A Figura 38 mostra o espectro na região do infravermelho para a amostra de PET reciclado.

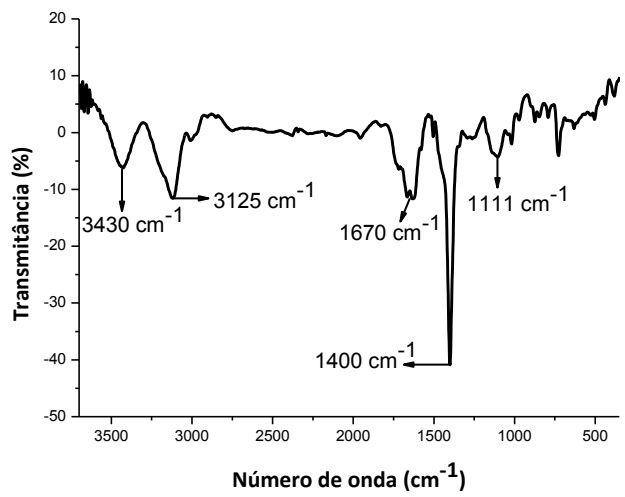

(a)

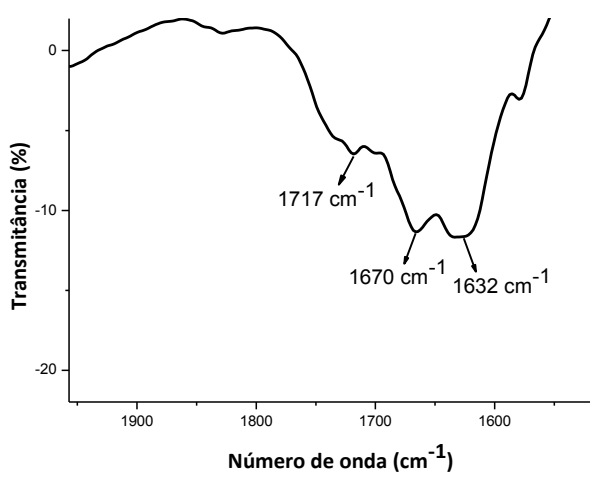

(b)

Figura 38. Espectro na região do infravermelho a) para o PET reciclado e b) ampliado na região de $1500-1900 \mathrm{~cm}^{-1}$. 
Analisando-se o espectro ampliado na região do infravermelho, Figura 38-b, pode-se observar a presença de uma banda desdobrada em três picos, na região de $1600-1720 \mathrm{~cm}^{-1}$. O pico na região de $1717 \mathrm{~cm}^{-1}$ pode ser atribuído ao estiramento da ligação de $-\mathrm{C}=0$ de um éster conjugado, característico do PET. As bandas nas regiões de menor número de onda podem ser atribuídas a outros compostos presentes no PET, tais como os advindos da degradação hidrolítica do PET durante o processo de reciclagem, como o ácido tereftálico. 0 ácido tereftálico possui uma banda característica na região de 1670-1700 $\mathrm{cm}^{-1}$, correspondente ao estiramento da ligação de $-\mathrm{C}=0$. Assim, a presença do ácido tereftálico é sustentada pela presença de bandas em menores números de onda, em torno de $1670 \mathrm{~cm}^{-1}$, características de ácidos carboxílicos aromáticos, juntamente com uma banda larga na região de $3400 \mathrm{~cm}^{-1}$, característica do grupo hidroxila (Figura 38-a). Entretanto, esta última banda pode também ser atribuída à absorção dos grupos hidroxilas terminais das cadeias do PET, assim como à presença de umidade, apesar da secagem em estufa por no mínimo 4 horas, a $160{ }^{\circ} \mathrm{C}$ da amostra de PET reciclado, antes da análise espectroscópica (MANCINI; ZANIN, 2002).

Analisando-se o espectro, pode-se observar também a presença de um pico intenso e bem definido na região de $1400 \mathrm{~cm}^{-1}$. Esse pico é característico da deformação angular da ligação C-O-H presente em ácidos carboxílicos, o que vem a sustentar a hipótese do ácido tereftálico estar presente na amostra analisada.

Observa-se a presença de banda característica na região de $3125 \mathrm{~cm}^{-1}$ correspondente à deformação axial de $\mathrm{C}$-H de aromáticos, presente na estrutura do PET (SILVERSTEIN; BASSLER; MORRIL, 1994).

Portanto, pode-se concluir, pelo espectro apresentado pela amostra de PET reciclado, que a amostra pode conter resíduos de ácido tereftálico advindos da degradação hidrolítica do PET durante o processo de reciclagem.

\subsubsection{Determinação do Índice de Fluidez (MFI)}

Para a verificação de possíveis efeitos do processo de reciclagem sobre a massa molar média do PET reciclado utilizado no presente trabalho, este polímero foi caracterizado com relação ao Índice de Fluidez (MFI). Para a mostra de PET reciclado obteve-se um MFI de 36,4 g (10 min)-1, sendo o resultado compatível com valores 
encontrados em trabalhos anteriores, nos quais amostras de PET reciclado também foram analisadas (MANCINI; BEZERRA; ZANIN, 1998; TAJAN et al., 2006).

Em seu estudo, Mancini, Bezerra e Zanin (1998) verificaram a influência do tipo e número de ciclos de reciclagem no MFI do PET. Por meio deste estudo foi possível concluir que o MFI do PET aumenta em função do número de reciclagens, do tipo mecânica, a que o polímero é submetido. Assim, o MFI obtido para o PET virgem foi de aproximadamente $16 \mathrm{~g} \mathrm{(10} \mathrm{min})^{-1}$ e, conforme o aumento do número de reciclagens (cinco no total), chegou a valores na faixa de $400 \mathrm{~g}(10 \mathrm{~min})^{-1}$, cerca de 20 vezes maior. O aumento do MFI é consequência de uma diminuição da viscosidade do polímero, o que indica normalmente queda de sua massa molar média, conforme o aumento do número de reciclagens. Este comportamento foi confirmado pelo aumento da concentração de grupos terminais carboxílicos do PET, pois quanto maior o número de grupos terminais - $\mathrm{COOH}$, maior também é o número de cadeias menores, que apresentam facilidade para deslizar entre as cadeias maiores, quando no estado fundido, fazendo escoar mais material.

O PET reciclado utilizado no presente trabalho foi obtido através da reciclagem mecânica de garrafas incolores de PET, e, devido a valor obtido de MFI, pode-se concluir que este material sofreu degradação parcial de suas cadeias poliméricas e/ou quebra de ligações, diminuindo assim sua viscosidade e consequentemente aumentando o MFI, em comparação ao PET virgem.

\subsection{Caracterização dos plasticizantes}

\subsubsection{Análise Térmica}

A Figura 39 mostra as curvas DSC para os plasticizantes polibutadieno hidroxilado (PBHL), tributil citrato (TBC), óleo de soja epoxidado (OSE), óleo de mamona (OM), glicerol e acetil tributil citrato (ATBC). 


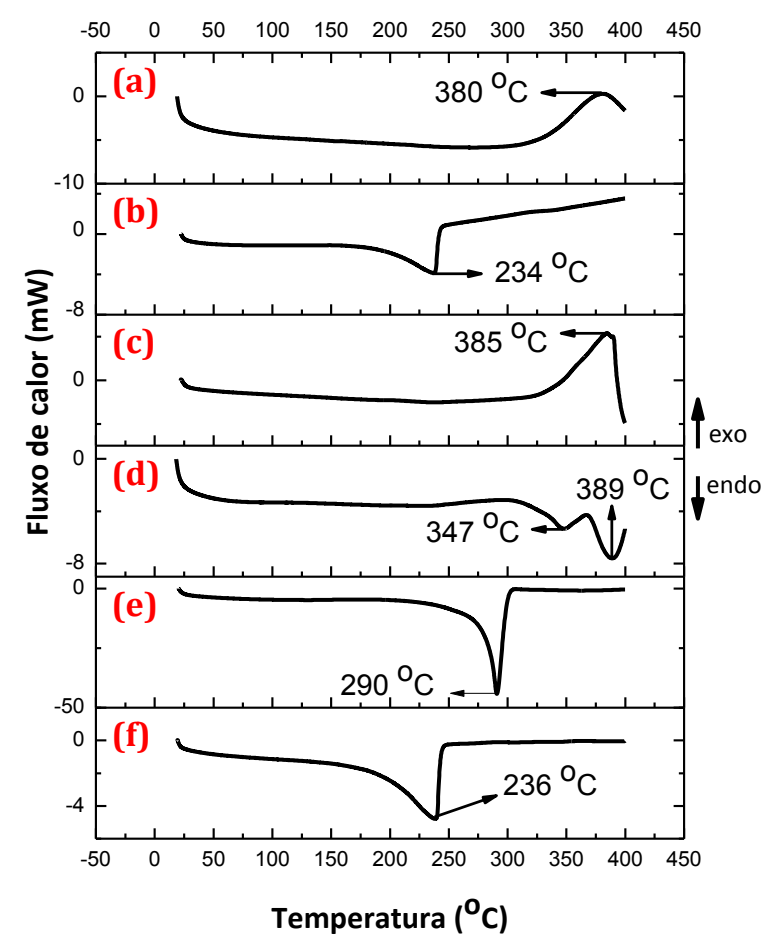

Figura 39. Curvas DSC para os plasticizantes (a) PBHL, (b) TBC, (c) OSE, (d) OM, (e) Glicerol e (f) ATBC (fluxo de $\mathrm{N}_{2}$ de $50 \mathrm{~mL} \mathrm{~min}^{-1}$, razão de aquecimento de $10{ }^{\circ} \mathrm{C} \mathrm{min}-1$ ).

Pode-se observar que a curva DSC para a amostra de PBHL (Figura 39-a) apresenta um pico exotérmico largo e intenso em aproximadamente $380{ }^{\circ} \mathrm{C}$, que pode ser atribuído à decomposição térmica da borracha.

Analisando a curva DSC da amostra de TBC (Figura 39-b), pode-se observar um pico intenso na região de $230{ }^{\circ} \mathrm{C}$, provavelmente referente ao evento endotérmico de volatilização do plasticizante, já que este apresenta um ponto de ebulição de $234{ }^{\circ} \mathrm{C}$. Destaca-se que, não necessariamente, o evento endotérmico relacionado à volatilização do plasticizante será detectado em temperatura igual ou próxima da temperatura de ebulição que se encontra em tabelas, tendo em vista que as condições experimentais em que normalmente os pontos de ebulição são determinados diferem das condições em que as varreduras TG/DSC são feitas.

A curva DSC do plasticizante OSE (Figura 39-c) apresenta um pico intenso na região de $385{ }^{\circ} \mathrm{C}$, provavelmente referente ao evento exotérmico de decomposição do material.

Podem-se observar dois picos endotérmicos presentes na curva DSC para a amostra de OM (Figura 39-d), um pico pouco intenso na região de $347^{\circ} \mathrm{C}$ e um pico intenso na região de $389{ }^{\circ} \mathrm{C}$. Estes picos podem ser atribuídos à 
volatilização/decomposição dos ésteres de ácidos graxos que compõem o óleo de mamona, sendo o principal deles o éster do ácido ricinoléico, o qual provavelmente é responsável pelo pico intenso na região de $389^{\circ} \mathrm{C}$ (CONCEIÇÃO et al., 2007).

A amostra de glicerol analisada apresenta em sua curva DSC (Figura 39-e) um pico intenso na região de $290^{\circ} \mathrm{C}$, referente ao evento endotérmico de volatilização do material, que apresenta ponto de ebulição de aproximadamente $290^{\circ} \mathrm{C}$.

O ATBC, em sua curva DSC (Figura 39-f), apresenta um pico intenso e largo na região de $230{ }^{\circ} \mathrm{C}$, provavelmente referente ao evento endotérmico de volatilização do material, já que este apresenta ponto de ebulição de aproximadamente $174{ }^{\circ} \mathrm{C}$.

A Figura 40 apresenta as curvas TG e dTG para as amostras de plasticizantes.

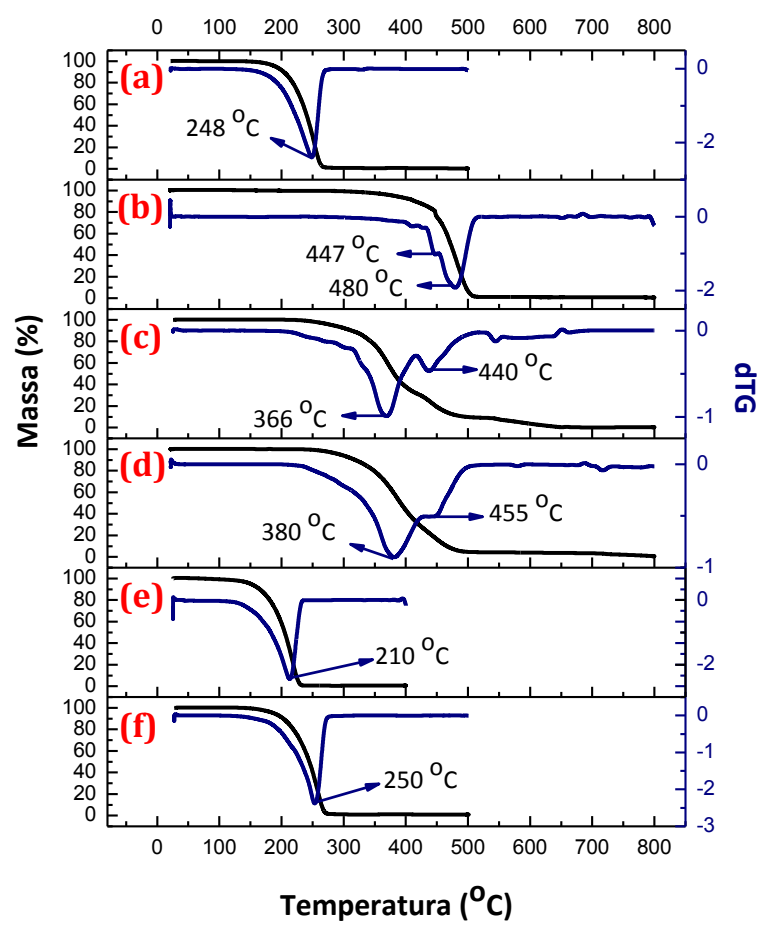

Figura 40. Curvas TG e dTG para os plasticizantes (a) TBC, (b) PBHL, (c) OSE, (d) OM, (e) Glicerol e (f) ATBC (fluxo de $\mathrm{N}_{2}$ de $50 \mathrm{~mL} \mathrm{~min}^{-1}$, razão de aquecimento de $10{ }^{\circ} \mathrm{C} \mathrm{min}^{-1}$ ).

Pode-se observar através das curvas TG e dTG para o TBC (Figura 40-a) que há um único estágio de perda de massa significante, contido no intervalo entre $126-280{ }^{\circ} \mathrm{C}$, associado à volatilização do TBC (com perda de cerca de 99\% de massa). A temperatura máxima de volatilização (Tp) observada é de $248^{\circ} \mathrm{C}$.

As curvas TG e dTG para o PBHL (Figura 40-b) mostram boa estabilidade térmica até $300{ }^{\circ} \mathrm{C}$, quando então inicia a decomposição da borracha. Este evento pode ser observado pela presença de dois picos na curva dTG, no intervalo de $300-452{ }^{\circ} \mathrm{C}$, 
com máximo em $447^{\circ} \mathrm{C}$ e com aproximadamente $25 \%$ de perda de massa, e no intervalo de $452-519{ }^{\circ} \mathrm{C}$, com máximo em $480{ }^{\circ} \mathrm{C}$ e com aproximadamente $73 \%$ de perda de massa.

Analisando as curvas TG e dTG do OSE (Figura 40-c), pode-se observar dois picos com intensidades diferentes, referentes à decomposição da amostra. 0 primeiro pico contido no intervalo de $192-416^{\circ} \mathrm{C}$ é intenso, com máximo em $366^{\circ} \mathrm{C}$ e perda de massa de aproximadamente 68\%. 0 segundo pico observado na curva dTG da amostra está contido no intervalo de 416-516 ${ }^{\circ} \mathrm{C}$, sendo menos intenso e apresentando um máximo em $440{ }^{\circ} \mathrm{C}$, com aproximadamente $23 \%$ de perda de massa

O OM apresenta em sua curva dTG (Figura 40-d) dois estágios de perda de massa, referentes à decomposição dos ésteres de ácidos graxos constituintes do material, no qual há a predominância de ácido ricinoléico. 0 primeiro estágio pode ser observado pelo pico intenso no intervalo de 200-428 ${ }^{\circ} \mathrm{C}$, com máximo em $380{ }^{\circ} \mathrm{C}$ e aproximadamente $74 \%$ de perda de massa, de acordo com sua curva TG. 0 segundo estágio de perda de massa pode ser observado pela presença de um pico pouco intenso no intervalo de $428-530{ }^{\circ} \mathrm{C}$, com máximo em $455^{\circ} \mathrm{C}$ e aproximadamente $22 \%$ de perda de massa.

A curva dTG do glicerol (Figura 40-e) apresenta um único pico, de intensidade elevada, no intervalo de $98-237^{\circ} \mathrm{C}$, com máximo em $210^{\circ} \mathrm{C}$, referente à volatilização do material, a qual ocorre em temperatura mais baixa do que a apresentada pela curva DSC (290 ${ }^{\circ} \mathrm{C}$, Figura 39-e). Observa-se, pela curva TG do material, que a perda de massa neste intervalo de temperatura é de aproximadamente 98,6\%.

Para o ATBC, a curva dTG (Figura 40-f) mostra apenas um intervalo significativo de perda de massa, que pode ser observado pela presença de um pico intenso no intervalo de $101-280^{\circ} \mathrm{C}$, com máximo em $250^{\circ} \mathrm{C}$, referente à volatilização do material. Pode-se observar, analisando-se a curva TG do material, que a perda de massa contida neste intervalo de temperatura é de aproximadamente 99\%.

\subsubsection{Espectroscopia na região do infravermelho (IV)}

A Figura 41 mostra os espectros na região do infravermelho para as amostras de plasticizantes. 


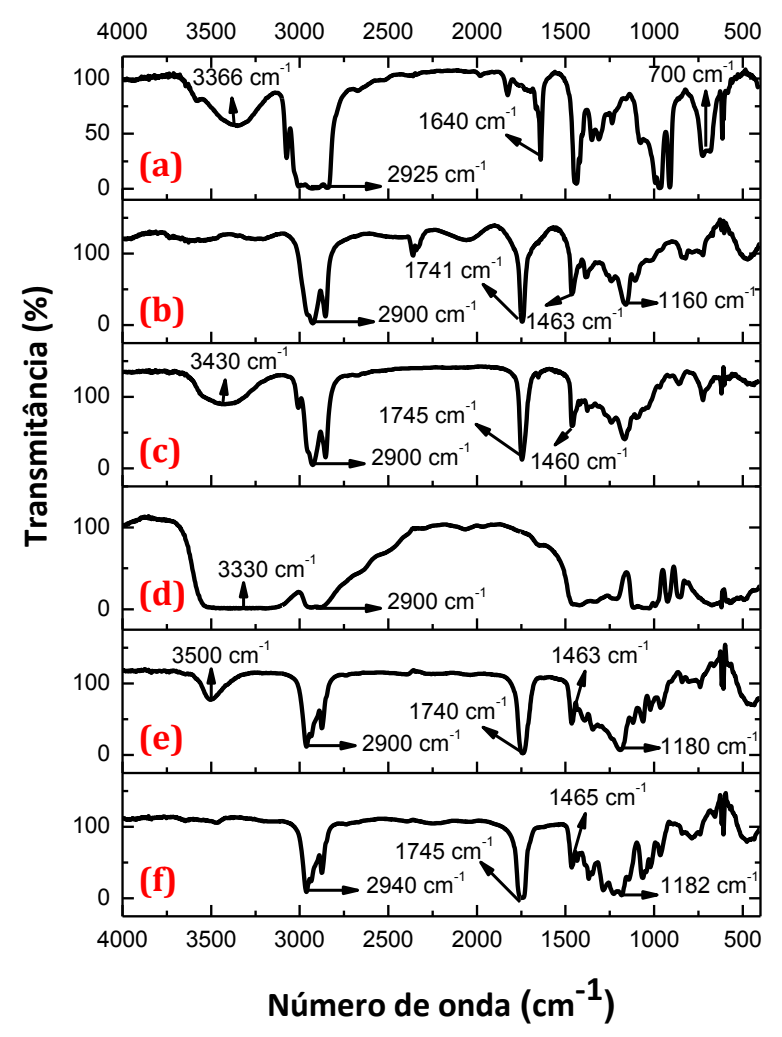

Figura 41. Espectro na região do infravermelho dos plasticizantes (a) PBHL, (b) OSE, (c) OM, (d) Glicerol, (e) TBC e (f) ATBC.

Analisando-se o espectro na região do infravermelho do PBHL (Figura 41-a), pode-se observar a presença de uma banda na região de $3360 \mathrm{~cm}^{-1}$, que pode ser atribuída à deformação axial da ligação -0-H. A banda larga em torno de $2920 \mathrm{~cm}^{-1}$ pode ser atribuída ao estiramento da ligação -C-H. Observa-se também um pico na região de $1640 \mathrm{~cm}^{-1}$, o qual pode ser atribuído à deformação axial da ligação -C=C. 0 pico na região de $700 \mathrm{~cm}^{-1}$ pode ser atribuído à deformação angular da ligação $-\mathrm{C}-\mathrm{H}$ de alquenos (SILVERSTEIN; BASSLER; MORRIL, 1994).

No espectro na região do infravermelho do OSE (Figura 41-b), pode-se observar uma banda na região de $2900 \mathrm{~cm}^{-1}$, que pode ser atribuída à deformação axial da ligação -C-H. O pico intenso observado na região de $1740 \mathrm{~cm}^{-1}$ pode ser atribuído à deformação axial da ligação $-\mathrm{C}=0$ de éster. Na região de $1460 \mathrm{~cm}^{-1}$, observa-se um pico pouco intenso, o qual pode ser atribuído à deformação angular da ligação -C-H. O pico pouco intenso, observado na região de $1160 \mathrm{~cm}^{-1}$, pode ser atribuído à deformação axial da ligação -C-C(=0)-O (SILVERSTEIN; BASSLER; MORRIL, 1994).

Pode-se observar, no espectro na região do infravermelho para o OM (Figura 41c), a presença de uma banda larga na região de $3430 \mathrm{~cm}^{-1}$, que pode ser atribuída à 
deformação axial da ligação -0-H. A banda observada na região de $2900 \mathrm{~cm}^{-1}$ pode ser atribuída à deformação axial da ligação -C-H. Observa-se também a presença de um pico intenso na região de $1740 \mathrm{~cm}^{-1}$, provavelmente devido à deformação axial da ligação $-\mathrm{C}=0$. 0 pico pouco intenso na região de $1460 \mathrm{~cm}^{-1}$ pode ser atribuído à deformação angular da ligação -C-H (SILVERSTEIN; BASSLER; MORRIL, 1994).

No espectro na região do infravermelho para o glicerol (Figura 41-d), pode-se observar uma banda intensa e larga na região de $3330 \mathrm{~cm}^{-1}$, que pode ser atribuída à deformação axial da ligação -0-H, característica de álcoois. Observa-se também uma banda na região de $2900 \mathrm{~cm}^{-1}$, que pode ser atribuída à deformação axial da ligação -C-H (SILVERSTEIN; BASSLER; MORRIL, 1994).

Analisando-se o espectro na região do infravermelho para o TBC (Figura 41-e), pode-se observar uma banda pouco intensa na região de $3500 \mathrm{~cm}^{-1}$, que pode ser atribuída à deformação axial da ligação -0-H. A presença da banda na região de 2900 $\mathrm{cm}^{-1}$ pode ser atribuída à deformação axial da ligação -C-H. Observa-se um pico intenso na região de $1740 \mathrm{~cm}^{-1}$, que pode ser atribuído à deformação axial da ligação $-\mathrm{C}=0$ presente no plasticizante. 0 pico pouco intenso observado na região de $1460 \mathrm{~cm}^{-1}$ pode ser atribuído à deformação angular da ligação -C-H. Observa-se também a presença de uma banda pouco intensa na região de $1180 \mathrm{~cm}^{-1}$, a qual pode ser atribuída à deformação axial da ligação -C-O (SILVERSTEIN; BASSLER; MORRIL, 1994).

O espectro na região do infravermelho para o ATBC (Figura 41-f) apresenta uma banda na região de $2940 \mathrm{~cm}^{-1}$, que pode ser atribuída à deformação axial da ligação -C-H. Analisando o espectro deste plasticizante, pode-se observar um pico intenso na região de $1740 \mathrm{~cm}^{-1}$, que pode ser atribuído à deformação axial da ligação $-\mathrm{C}=0$. 0 espectro também apresenta um pico pouco intenso na região de $1460 \mathrm{~cm}^{-1}$, que pode ser atribuído à deformação angular da ligação -C-H. Pode-se observar também um pico pouco definido na região de $1180 \mathrm{~cm}^{-1}$, provavelmente referente à deformação axial da ligação -C-O (SILVERSTEIN; BASSLER; MORRIL, 1994). 


\subsection{Preparação dos compósitos de PET reciclado reforçados com fibras de sisal por moldagem por compressão}

\subsubsection{Desenvolvimento do ciclo de temperaturas para a moldagem por compressão dos compósitos}

Como já mencionado anteriormente, as condições para a preparação dos compósitos que levassem a materiais com o menor número de falhas possível, foram determinadas via testes experimentais, nos quais parâmetros como o ciclo de temperaturas para a moldagem por compressão dos compósitos, dentre outros parâmetros, foram considerados.

Inicialmente, considerou-se para o preparo dos compósitos uma proporção de $15 \%$ (em massa) de fibras de sisal (3 cm de comprimento) misturadas manualmente com 85\% de PET reciclado em flakes. A moldagem por compressão foi

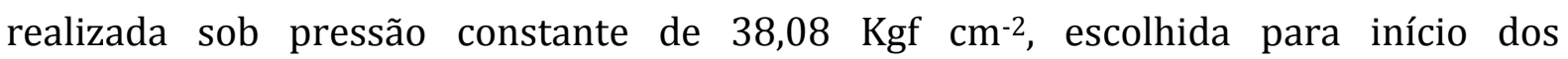
experimentos (RAMIRES, 2010; DA SILVA, 2011). Para o preparo dos compósitos, adotou-se o ciclo de temperaturas no 1 (Experimental). O compósito obtido ao final do processamento apresentou trincas e poros (Figura 42), provavelmente relacionados à decomposição térmica das fibras de sisal e consequente saída de voláteis, devido à temperatura máxima considerada neste ciclo $\left(260{ }^{\circ} \mathrm{C}\right)$, na qual já se inicia a decomposição térmica da fibra, de acordo com as curvas DSC e TG da mesma (Figura 35).

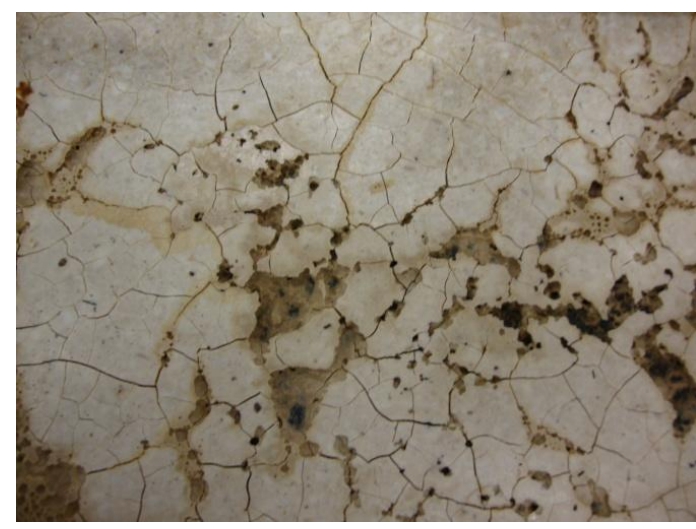

Figura 42. Fotografia da placa de compósito obtida utilizando-se o ciclo de temperaturas no 1 (Experimental).

A Figura 42 mostra pequenos pontos de cor preta, que correspondem às fibras de sisal pós-decomposição térmica. 0 ciclo de temperaturas no 1 (mesmo ciclo 
utilizado para o preparo da placa controle de PET reciclado (CTRPET)) foi elaborado com o objetivo de se chegar a temperaturas próximas à de fusão do PET, em torno de $265{ }^{\circ} \mathrm{C}$. Considerou-se como possibilidade a proteção térmica das fibras pela matriz, o que retardaria a decomposição das mesmas, o que não ocorreu.

Com base no teste anterior, visando à diminuição da temperatura de fusão do PET reciclado, realizou-se a moldagem por compressão da mistura de $80 \%$ de PET reciclado em flakes com 20\% de PBHL, sob pressão constante de $38,08 \mathrm{Kgf} \mathrm{cm}^{-2}$, adotando-se o ciclo de temperaturas no 2 (Experimental). O PBHL foi adicionado com o objetivo de o mesmo atuar como um plasticizante, diminuindo a temperatura de fusão do PET. A temperatura máxima utilizada foi $200{ }^{\circ} \mathrm{C}$, mas não houve a fusão do PET reciclado ao final do processamento.

Com o objetivo de diminuir a temperatura de fusão do PET reciclado, novamente utilizou-se PBHL como plasticizante, misturado manualmente com flakes do polímero. 0 processamento baseou-se nas mesmas condições anteriormente utilizadas, porém com a utilização do ciclo de temperaturas no 3 (Experimental). Este ciclo possuiu aproximadamente o dobro de duração comparativamente ao ciclo de temperaturas $n^{\circ} 2$, com temperatura máxima de $220^{\circ} \mathrm{C}$, por $2 \mathrm{~h}$, dobro da duração na máxima temperatura utilizada no ciclo de temperaturas $\mathrm{n}^{\circ} 2$. Ao final do processamento, observou-se novamente que não houve a fusão do PET reciclado.

Um novo processamento foi realizado utilizando a mistura de $80 \%$ de PET reciclado em flakes e $20 \%$ de PBHL, visando à diminuição da temperatura de fusão do polímero. Foram utilizadas as mesmas condições do processamento anterior (ciclo de temperaturas $n^{\circ} 3$ ), mas com a utilização do ciclo de temperaturas no $^{\mathbf{4}}$ (Experimental). Com 30 min a mais de duração em comparação com o ciclo de temperaturas $\mathrm{n}^{\circ} 3$, e utilizando temperatura máxima de $240{ }^{\circ} \mathrm{C}$, ao final do processamento, observou-se a incompleta fusão do polímero (Figura 43). 


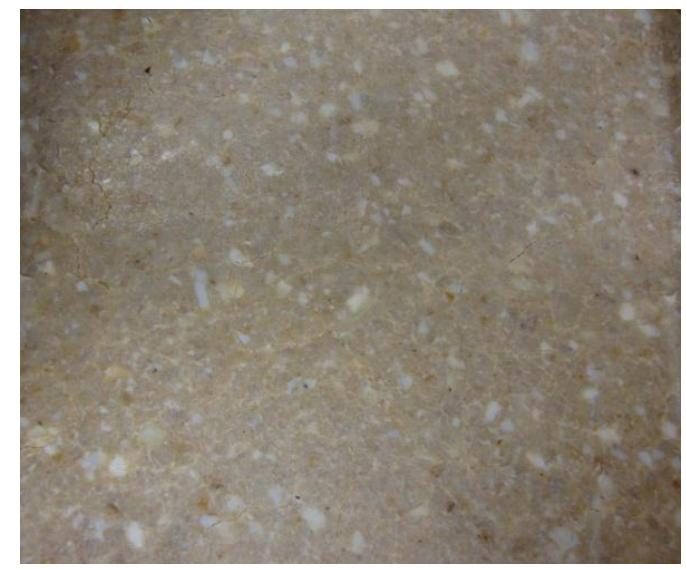

Figura 43. Fotografia da placa de PET reciclado/PBHL obtida utilizando-se o ciclo de temperaturas no 4 (Experimental).

Na Figura 43 são observados pontos de cor branca, os quais correspondem aos flakes de PET reciclado, presentes devido à incompleta fusão do material.

Somente com um novo processamento da mistura PET reciclado/PBHL, nas mesmas condições dos processamentos anteriores, porém adotando-se o ciclo de temperaturas no 5 (Experimental), houve, ao final do processamento, a fusão total do polímero. O ciclo de temperaturas adotado possuiu duração total de $7 \mathrm{~h}$, com temperatura máxima utilizada de 250 º . Embora tenha ocorrido a fusão do polímero, no processamento de compósitos utilizando fibras de sisal como agentes de reforço, com este ciclo de temperaturas, provavelmente haveria decomposição térmica das fibras, quando presentes. Assim, a utilização deste ciclo de temperaturas se mostrou inviável para o processamento de compósitos. Outros plasticizantes, como o glicerol, foram então testados.

Com a utilização de glicerol como plasticizante, visando à diminuição da temperatura de fusão do PET, a mistura de $\mathbf{8 0 \%}$ PET reciclado (pó)/20\% glicerol foi processada por moldagem por compressão nas mesmas condições dos testes anteriores, porém adotando-se o ciclo de temperaturas no 6 (Experimental). Destaca-se que, a partir do ciclo aqui referenciado, o PET reciclado passou a ser utilizado sob a forma de pó, não mais em flakes, objetivando que, com uma maior área de superfície, a fusão fosse facilitada. Com o uso deste ciclo, com menor duração (2 h $50 \mathrm{~min}$ ) que todos os ciclos adotados anteriormente, e máxima temperatura utilizada de $205{ }^{\circ} \mathrm{C}$, ao final do processamento não houve a fusão do polímero. Observou-se também o desprendimento de vapor do molde metálico durante o processamento, provavelmente devido à volatilização de parte do plasticizante. 
Utilizando a mistura PET reciclado (pó)/glicerol um novo processamento foi realizado nas mesmas condições dos processamentos anteriores, mas com o uso do ciclo de temperaturas no 7 (Experimental). Com este ciclo, de duração de 1 h 40 min, menor duração que o ciclo de temperaturas $n^{\circ} 6$, e máxima temperatura utilizada de $235{ }^{\circ} \mathrm{C}$, ao final do processamento, houve a fusão do PET reciclado. Foi observado o desprendimento de vapor do molde metálico durante o processamento, devido à possível volatilização de parte do plasticizante, o que foi observado também nos outros processamentos.

Destaca-se que as perdas de plasticizante durante o processamento de materiais poliméricos, por volatilização, são praticamente inerentes a processos que fazem uso de elevadas temperaturas (GRISA et al., 2011). A volatilização é um processo ativado termicamente e as variações de temperatura durante o processamento podem afetar não só a evaporação dos plasticizantes da superfície do polímero, como também a difusão dos mesmos do interior para a camada superficial (LODI, 2003).

Adotando-se o ciclo de temperaturas no 7 (Experimental), com o qual foi possível a fusão do PET reciclado, um novo processamento foi realizado. Utilizando-se a placa de PET/glicerol preparada no teste anterior e triturada criogenicamente, adicionou-se $15 \%$ de fibras de sisal (3 cm de comprimento) com relação à massa do polímero utilizada. A mistura foi processada, nas mesmas condições dos processamentos anteriores, e o ciclo utilizado foi denominado ciclo de temperaturas no 8. Ao final do processamento, obteve-se uma placa de compósito que mostrava uma possível decomposição parcial das fibras, e distribuição heterogênea da fibra pela matriz, de acordo com a Figura 44.

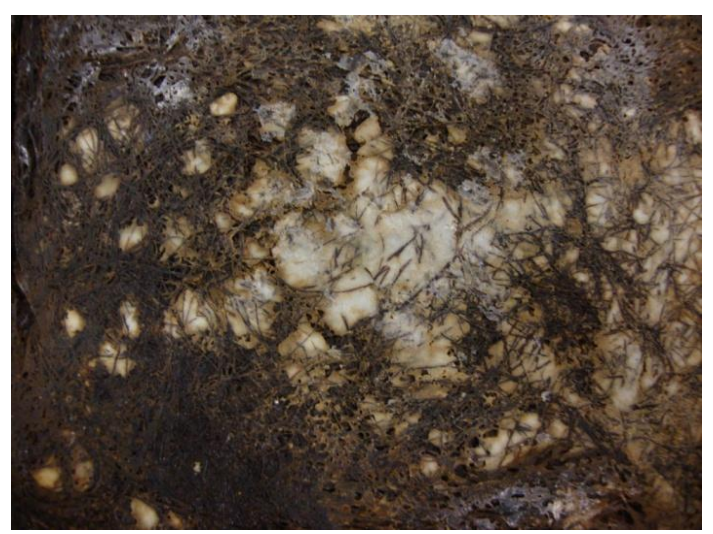

Figura 44. Fotografia da placa de PET reciclado/glicerol/fibra de sisal obtida utilizando-se o ciclo de temperaturas no 8 (Experimental). 
Assim, objetivando-se uma temperatura inferior à máxima temperatura utilizada no ciclo de temperaturas $n^{\circ} 8$, para evitar uma possível decomposição térmica das fibras, um novo ciclo de temperaturas foi adotado. A mistura 60\% PET reciclado/40\% glicerol foi processada, nas mesmas condições dos processamentos anteriores, porém fazendo-se uso do ciclo de temperaturas no 9 (Experimental). Neste ciclo, com o dobro da quantidade de glicerol utilizada anteriormente, foi possível o uso de máxima temperatura de 225 oC, e duração total do ciclo de 4 h $15 \mathrm{~min}$. Ao final do processamento, observou-se que houve fusão parcial do PET reciclado.

Considerando os ciclos de temperatura anteriores, um novo ciclo foi considerado com o objetivo de não somente diminuir a temperatura de fusão do PET reciclado, evitando assim a decomposição térmica das fibras, como também diminuir sua viscosidade, visando à obtenção de compósitos com uma distribuição homogênea das fibras pela matriz. Neste contexto, adotou-se o ciclo de temperaturas no 10 (Experimental), com máxima temperatura utilizada de $225^{\circ} \mathrm{C}$ (mesma temperatura utilizada no ciclo de temperaturas $\mathrm{n}^{\circ}$ 9) e possuindo uma duração de 5 h 55 min (mais longo em comparação com o ciclo anterior). Assim, à mistura de 60\% PET reciclado (pó)/40\% glicerol foi adicionado $15 \%$ de fibras de sisal, sendo a mistura resultante processada de acordo com as mesmas condições dos processamentos anteriores e utilização do ciclo de temperaturas anteriormente descrito. Ao final do processamento, observou-se que houve a fusão do polímero, sem a ocorrência de decomposição térmica das fibras, com a obtenção de uma placa de compósito (CG) com visível distribuição mais homogênea das fibras na matriz, comparativamente ao compósito que antecedeu a este (Figura 45).

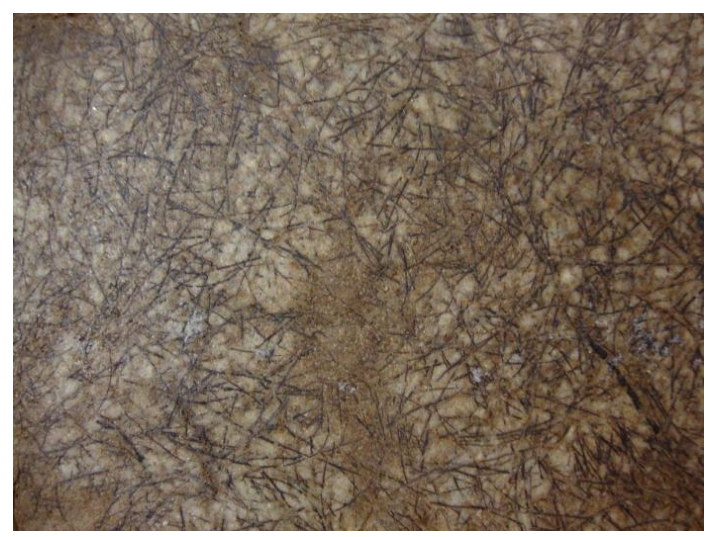

Figura 45. Fotografia da placa de PET reciclado/glicerol/fibra de sisal (CG) obtida utilizando-se o ciclo de temperaturas no 10 (Experimental). 
Portanto, adotando-se para o processamento dos compósitos o ciclo de temperaturas no 10 (Experimental), novas misturas de 85\% PET reciclado/15\% fibras de sisal com a adição de 40\%, em relação à massa de polímero utilizada, de diferentes tipos e misturas de plasticizantes foram processadas por moldagem por compressão.

A Tabela 3 descreve os compósitos preparados utilizando-se o ciclo de temperaturas no 10 , mostrando os diferentes tipos e misturas de plasticizantes usados.

Tabela 3. Compósitos preparados por moldagem por compressão, com o uso de plasticizantes e $15 \%$ de fibras de sisal $-3 \mathrm{~cm}$ (\% em massa)

\begin{tabular}{|c|c|}
\hline Compósitos & Composição \\
\hline CT & PET reciclado/fibras de sisal/TBC \\
\hline CGT & PET reciclado/fibras de sisal/glicerol/TBC \\
\hline CGTM & PET reciclado/fibras de sisal/glicerol/TBC/OM \\
\hline CGTS & PET reciclado/fibras de sisal/glicerol/TBC/OSE \\
\hline CAT & PET reciclado/fibras de sisal/ATBC \\
\hline CGTP & PET reciclado/fibras de sisal/glicerol/TBC/PBHL \\
\hline CGMP & PET reciclado/fibras de sisal/glicerol/OM/PBHL \\
\hline CG & PET reciclado/fibras de sisal/glicerol \\
\hline CGM & PET reciclado/fibras de sisal/glicerol/OM \\
\hline
\end{tabular}

Em todos os compósitos, até o final dos processos, houve uma significativa perda dos diferentes tipos e misturas de plasticizantes adicionados. Este fato pode ser atribuído à volatilização dos plasticizantes e exsudação destes durante o processamento, para a superfície do material e, ao final, consequente retenção no molde metálico. Contudo, como os processos iniciaram com relativamente alta quantidade de plasticizante (40\%), o produto final reteve parte do plasticizante adicionado.

No entanto, destaca-se que durante o processamento o plasticizante cumpriu com a função de diminuir a temperatura de fusão do PET, preservando desta forma a fibra, assim como reduziu a viscosidade do material fundido, favorecendo a molhabilidade da fibra pelo polímero. A parte dos plasticizantes que permaneceu no produto final garante, devido às características estruturais dos mesmos, que estes atuem também como compatibilizantes, conforme já mencionado.

Anteriormente aos testes de processamento de compósitos de PET reciclado/fibras de sisal por moldagem por compressão, e mesmo do uso de diferentes 
tipos e misturas de plasticizantes com o objetivo de diminuir a temperatura de fusão do polímero, outro tipo de processamento foi testado. Utilizou-se a reometria de torque e posterior termoprensagem para o processamento inicial de compósitos de PET reciclado/fibras de sisal, fazendo-se uso da temperatura constante de $260{ }^{\circ} \mathrm{C}$, próxima a temperatura de fusão do polímero.

Devido à decomposição térmica das fibras no processamento por reometria de torque e posterior termoprensagem dos compósitos a $260{ }^{\circ} \mathrm{C}$, iniciou-se os testes de moldagem por compressão, aliados ao uso de plasticizantes. Após o estabelecimento das condições para a preparação dos compósitos, e fazendo-se uso dos plasticizantes, novamente testou-se a reometria de torque e posterior termoprensagem no preparo destes materiais, utilizando a máxima temperatura de $225^{\circ} \mathrm{C}$ (item 6.5).

A seguir, são descritos os resultados obtidos usando-se reometria de torque.

\subsection{Preparação dos compósitos de PET reciclado reforçados com fibras de sisal por reometria de torque e posterior termoprensagem}

Inicialmente, processou-se em um reômetro de torque Haake a mistura de $\mathbf{8 5 \%}$ PET reciclado (flakes)/15\% fibras de sisal a $260{ }^{\circ} \mathrm{C}$ por um período de aproximadamente $6 \mathrm{~min}$, obtendo-se uma curva de variação do torque em função do tempo de processamento, representada na Figura 46. Conforme já mencionado, este teste foi realizado antes da exploração de parâmetros de moldagem descritos no item anterior. 


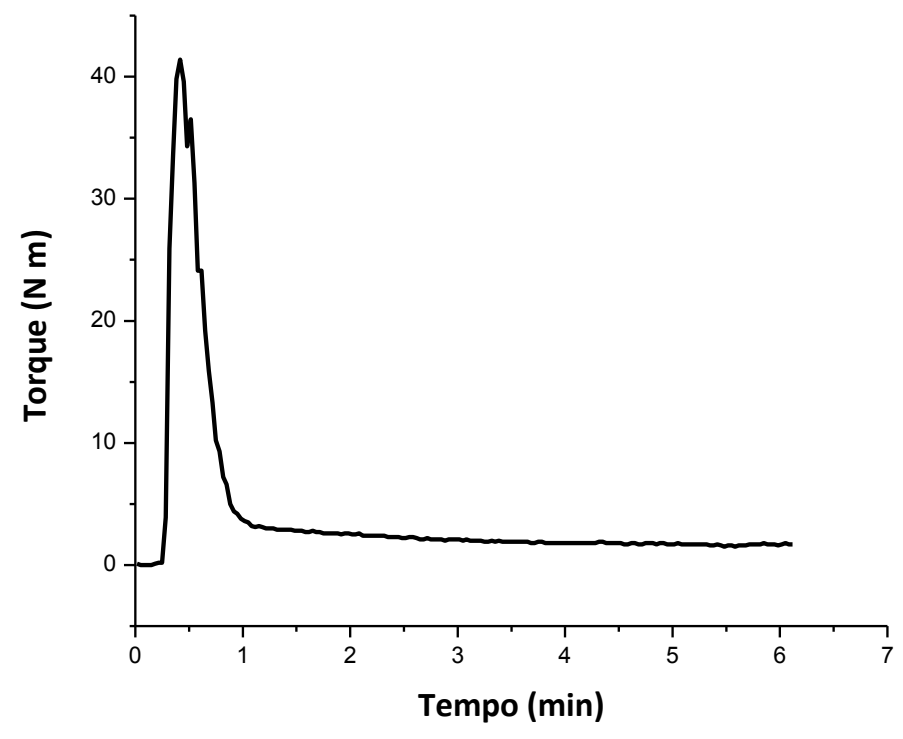

Figura 46. Curva de processamento da mistura PET reciclado/fibras de sisal a $260^{\circ} \mathrm{C}$.

Na Figura 46, pode-se observar um pico intenso referente ao torque necessário para a compactação do material, que se encontra no estado sólido, e alimentação deste na câmara de mistura. Seguiu-se a este evento a compressão e mistura do material com consequente fusão do polímero, que geralmente pode aparecer como outro pico da curva, mas que neste caso, não foi observado. Após a fusão do material, pode-se observar a queda do torque e estabilização do mesmo, pois a mistura tende a se tornar mais homogênea (BRETAS; D'AVILLA, 2000). Após a estabilização, o torque torna-se dependente da viscosidade do fluido na temperatura de processamento. Quanto maior a viscosidade, maior o torque. Pode ocorrer uma ligeira diminuição do torque, após a estabilização, como se pode observar pela Figura 46, devido ao aumento da temperatura do sistema com a diminuição da viscosidade e o início de degradação (diminuição de massa molar média) do polímero (VALADARES, 2005). Ao final do processamento, o material obtido mostrou visível decomposição térmica parcial das fibras.

Após o processamento, o material obtido anteriormente foi termoprensado a $260{ }^{\circ} \mathrm{C}$ por um tempo total de 4 min. Mesmo já tendo sido observada decomposição térmica das fibras, quando a mistura foi submetida ao reômetro de torque, a termoprensagem foi feita a fim de se obter informações que poderiam ser úteis para a sequência dos experimentos. Ao final da termoprensagem, obteve-se o compósito sob a forma de placa $(\mathbf{C H})$. A placa do compósito apresentou poros, devido à possível saída de 
voláteis em decorrência da decomposição térmica das fibras (Figura 47). Esta placa de compósito foi fraturada criogenicamente e analisada somente por MEV (item 6.6.5).

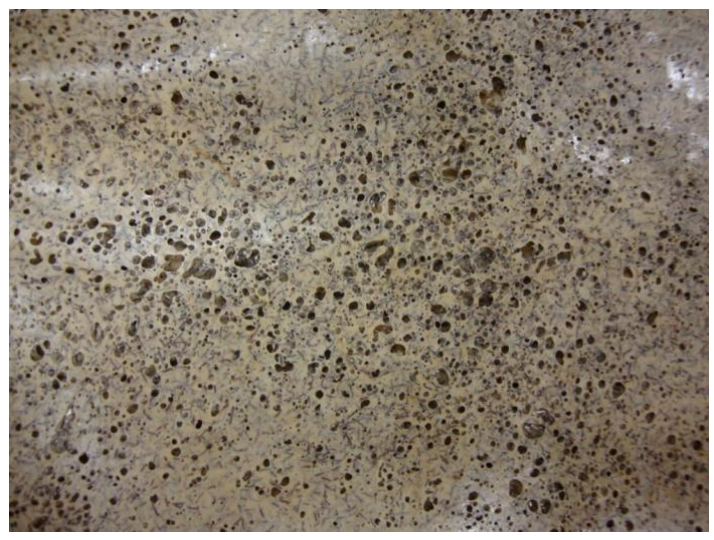

Figura 47. Fotografia da placa do compósito PET reciclado/fibras de sisal obtida por termoprensagem a $260^{\circ} \mathrm{C}(\mathrm{CH})$.

Devido à ocorrência de decomposição térmica das fibras de sisal no processamento descrito anteriormente, uma nova tentativa de processamento por reometria de torque foi realizada com a mistura de PET reciclado (pó)/fibras de sisal/glicerol/OM, à temperatura de $225{ }^{\circ} \mathrm{C}$ (estabelecida após os testes de processamento por moldagem por compressão), por aproximadamente 5 min. 0 óleo de mamona (OM) foi adicionado com o objetivo de atuar como agente compatibilizante fibra-matriz nos compósitos, por possuir cadeias hidrocarbônicas com afinidade com o PET reciclado, e grupos hidroxila com afinidade com os grupos polares presentes nas fibras de sisal (Figura 24). Durante o processamento, pôde-se observar a exsudação de parte do plasticizante para a superfície do material e, ao final, sua retenção na câmara de mistura.

A mistura resultante não apresentou decomposição térmica das fibras, e foi reservada para posterior termoprensagem. Um novo processamento por reometria de torque foi realizado com a mistura de PET reciclado (pó)/glicerol/OM, nas mesmas condições utilizadas anteriormente. Durante o processamento, observou-se também a exsudação de parte do plasticizante e sua retenção na câmara de mistura, sendo o material resultante reservado para posterior termoprensagem. A Figura 48 apresenta as curvas de variação do torque em função do tempo de processamento para os materiais resultantes. 


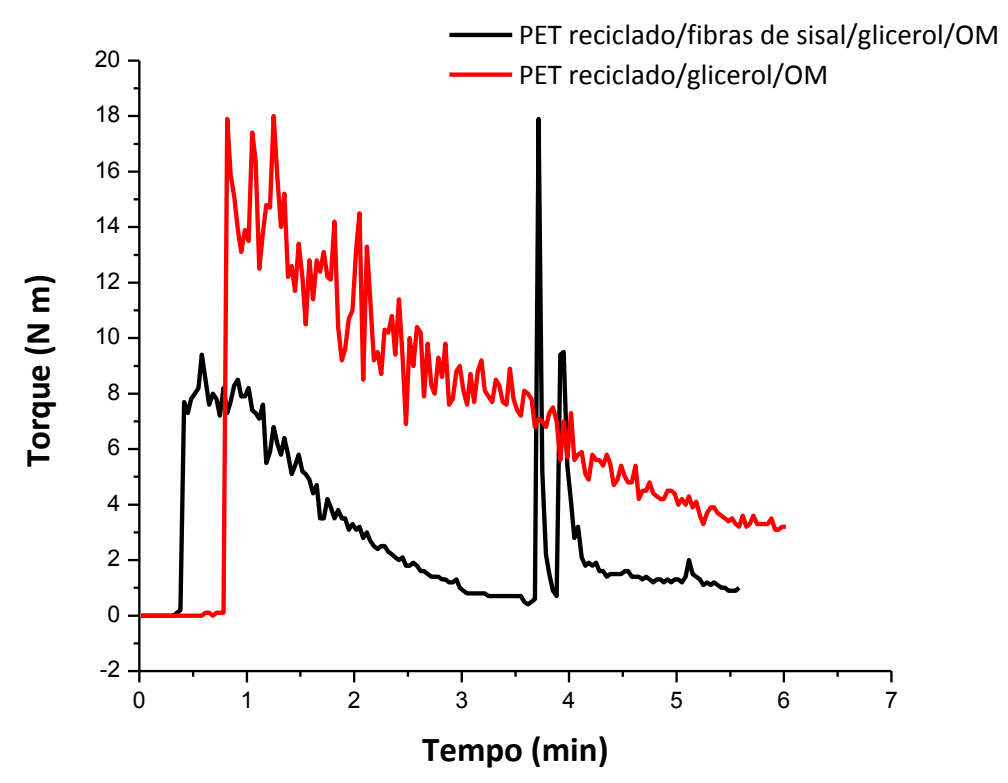

Figura 48. Curvas de processamento das misturas PET reciclado/fibras de sisal/glicerol/OM e PET reciclado/glicerol/0M.

$\mathrm{Na}$ Figura 48, pode-se observar que a curva da mistura de PET reciclado/glicerol/OM apresenta, inicialmente, valores de torque maiores, provavelmente devido à compactação do material, que se encontra no estado sólido, e alimentação deste na câmara de mistura. Segue-se a este evento a compressão, mistura do material e consequente fusão do polímero, não sendo observado outro pico da curva neste caso. Com a fusão do polímero, há um decréscimo progressivo do torque, indicando redução da viscosidade do polímero.

Na curva da mistura de PET reciclado/fibras de sisal/glicerol/OM (Figura 48) pode-se observar inicialmente um aumento do torque devido ao carregamento inicial da mistura de PET e glicerol, compactação do material, que se encontra no estado sólido, e fusão do polímero. Após a fusão do polímero, pode-se observar a queda progressiva do torque, devido à diminuição da viscosidade do sistema. Após aproximadamente $3 \mathrm{~min}$ de processamento, com a adição da mistura fibras de sisal/OM ao sistema, podem-se observar dois picos intensos da curva. 0 primeiro pico pode ser atribuído ao torque necessário para o carregamento da mistura e compactação do material e, após esse pico, segue-se o aparecimento de um "vale", que representa o torque necessário para a compressão e mistura do material. 0 segundo pico deve-se, provavelmente, ao aumento da viscosidade do sistema pela adição das fibras de sisal. Após, há uma diminuição da viscosidade e estabilização do torque, devido à homogeneização da mistura (BRETAS; 
D'AVILLA, 2000). Durante este processamento, pode ocorrer um desfibrilamento dos aglomerados de fibra (DE CASTR0, 2010).

Os materiais obtidos anteriormente foram termoprensados a $225{ }^{\circ} \mathrm{C}$ por um tempo total de $4 \mathrm{~min}$. Durante a termoprensagem, para ambos os materiais, observou-se visualmente o desprendimento de vapor do sistema, devido a possível volatilização de parte dos plasticizantes. Ao final da termoprensagem, obteve-se uma placa da mistura de PET reciclado/glicerol/OM (CTRH), a qual se fragmentou após sua retirada da termoprensa, provavelmente devido à fragilidade do material, por conter a mistura dos plasticizantes glicerol/OM sem o reforço das fibras de sisal. Desta placa, não foi possível a obtenção de corpos de prova para posteriores ensaios mecânicos, sendo realizada somente a análise térmica destes. Ao final de nova termoprensagem (mesmas condições utilizadas para a obtenção de CTRH), foi possível a obtenção do compósito de PET reciclado/fibras de sisal/glicerol/OM sob a forma de uma placa (CHGM), na qual não foi observada a decomposição térmica das fibras. Devido à fragilidade apresentada por CHGM, não foi possível a confecção de corpos de prova, considerando as medidas de corte exigidas pela norma, para o ensaio de absorção de água.

Importante ressaltar que, além da mistura PET reciclado/fibras de sisal/glicerol/OM ser processada por reometria de torque, outras misturas do polímero e fibras contendo 40\% (em massa), com relação à massa do polímero, de diferentes tipos e misturas de plasticizantes foram também processadas utilizando-se o reômetro de torque. No entanto, dentre os materiais obtidos pós-processamento, a mistura PET reciclado/fibras de sisal/glicerol/OM apresentou-se mais homogênea, sendo, portanto, escolhida para posterior termoprensagem e caracterização.

\subsection{Caracterização dos compósitos}

Destaca-se que os compósitos de PET reciclado/fibras de sisal, contendo diferentes tipos e misturas de plasticizantes (sintetizados pela Tabela 3), conforme mencionado anteriormente, foram preparados por moldagem por compressão, utilizando o ciclo de temperaturas no 10 , com máxima temperatura de processamento de $225{ }^{\circ}$ C. Após, os compósitos CT, CGT, CGTM, CGTS, CAT, CGTP, CGMP, CG e CGM, assim como a placa controle de PET reciclado (CTRPET), foram caracterizados por 
análise térmica, resistência ao impacto Izod, resistência à flexão, DMTA, MEV e absorção de água.

O compósito de PET reciclado/fibras de sisal, preparado por reometria de torque e posterior termoprensagem à temperatura de $260{ }^{\circ} \mathrm{C}(\mathbf{C H})$, foi somente analisado por MEV. Os compósitos de PET reciclado/fibras de sisal/glicerol/OM (CHGM), também preparados por reometria de torque e posterior termoprensagem à temperatura de $225{ }^{\circ} \mathrm{C}$, foram analisados fazendo-se uso das mesmas técnicas de caracterização empregadas para os compósitos preparados por moldagem por compressão, com exceção da análise de absorção de água, que não foi realizada. A mistura de PET reciclado/glicerol/OM, preparada por reometria de torque e posterior termoprensagem também à temperatura de $225{ }^{\circ} \mathrm{C}$ (CTRH), foi somente caracterizada por análise térmica.

A seguir, os resultados de análise térmica (DSC/TG) são descritos.

\subsubsection{Análise Térmica}

A Figura 49 apresenta as curvas DSC de CTRPET, CT, CGT, CGTM, CGTS, CAT, CGTP, CGMP, CG e CGM, obtidos por moldagem por compressão. 

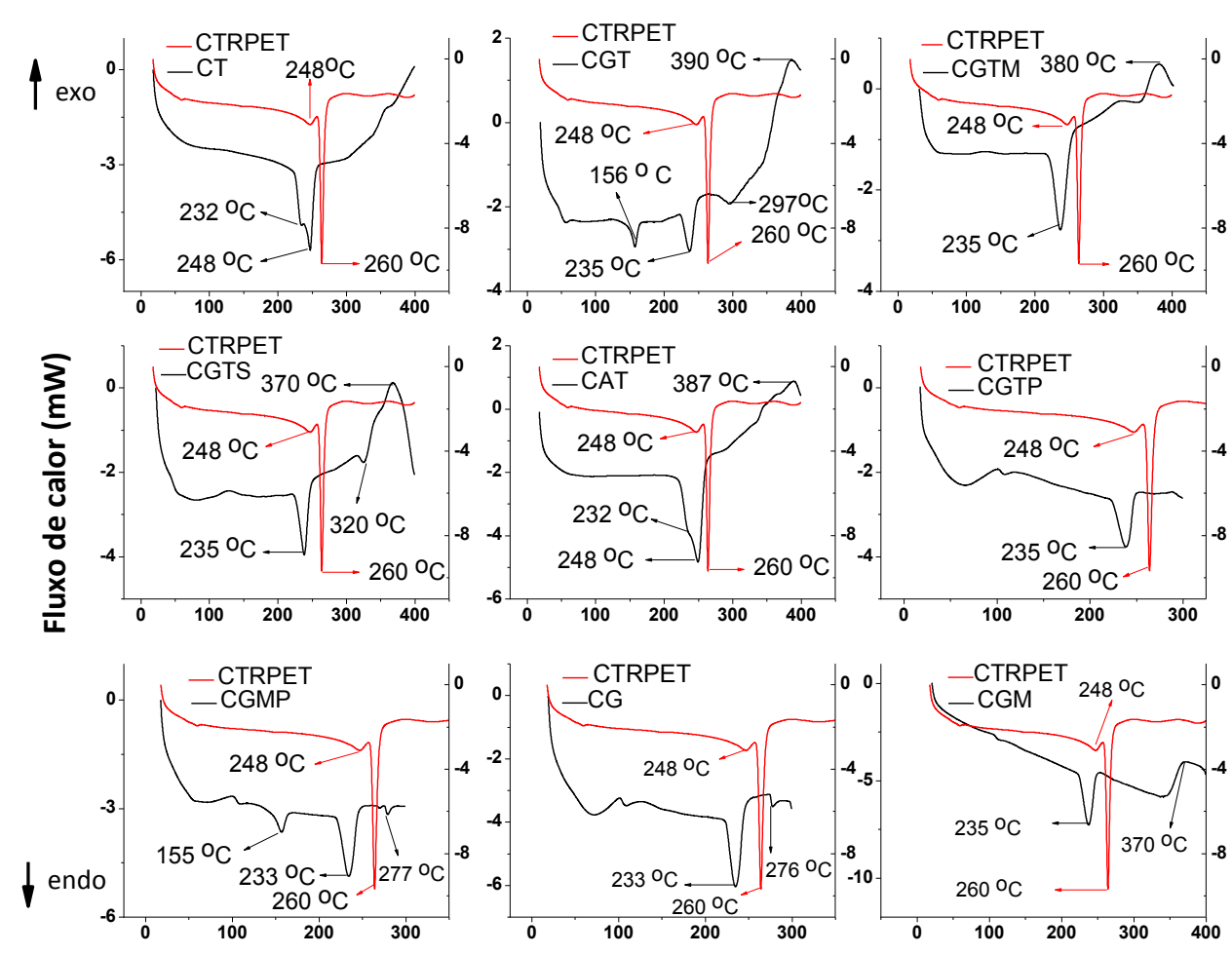

CTRPET: Placa controle de PET reciclado

CT: PET reciclado /fibra /TBC

CGT: PET reciclado / fibra / glicerol / TBC CGTM: PET reciclado /fibra /glicerol /TBC /OM

CGTS: PET reciclado /fibra /glicerol /TBC /OSE

CAT: PET reciclado /fibra /ATBC CGTP: PET reciclado /fibra /glicerol /TBC /PBHL

CGMP: PET reciclado /fibra /glicerol /OM /PBHL

CGM: PET reciclado /fibra /glicerol /OM CG: PET reciclado /fibra /glicerol

Temperatura $\left({ }^{\circ} \mathrm{C}\right)$

Figura 49. Curvas DSC da placa controle de PET reciclado (CTRPET) e dos compósitos CT, CGT, CGTM, CGTS, CAT, CGTP, CGMP, CG e CGM obtidos por moldagem por compressão (fluxo de $\mathrm{N}_{2}$ de $50 \mathrm{~mL} \mathrm{~min}{ }^{-1}$, razão de aquecimento de $10{ }^{\circ} \mathrm{C} \mathrm{min}^{-1}$ ).

Analisando-se a curva DSC de CTRPET, observa-se que esta apresenta um pico pouco intenso na região de $250{ }^{\circ} \mathrm{C}$ e um pico intenso na região de $260{ }^{\circ} \mathrm{C}$, ambos referentes ao evento endotérmico de fusão do material. A menor temperatura de fusão, $250{ }^{\circ} \mathrm{C}$, corresponde à fração de cristais formados a partir de cadeias com menor massa molar média. Comparando-se com a curva DSC obtida para a mostra de PET reciclado, não moldado, na forma de pó (Figura 37-a), observa-se que nesta os picos referentes à fusão do polímero ocorrem em regiões de temperatura inferiores às apresentadas por CTRPET, respectivamente nas regiões de $180{ }^{\circ} \mathrm{C}$ (pico pouco intenso) e $250{ }^{\circ} \mathrm{C}$ (pico intenso). Pode-se atribuir a este deslocamento dos picos para regiões de temperaturas mais elevadas em CTRPET a perda de voláteis como água residual, devido ao processamento por moldagem por compressão do PET reciclado, em um ciclo de temperaturas com duração de 3 h 20 min, chegando à temperatura máxima de $260{ }^{\circ} \mathrm{C}$, assim como devido a rearranjos que podem ter levado ao aumento da proporção de domínios cristalinos formados a partir de cadeias com maior massa molar média. 
Ainda, pode-se atribuir também a esse deslocamento de temperaturas o fato de que a amostra de PET reciclado analisada estava sob a forma de pó, e a de CTRPET, obtida a partir do processo de trituração criogênica da placa de PET reciclado, encontrava-se sob a forma de pequenos fragmentos. Assim, o PET reciclado sob a forma de pó apresentava maior área de superfície, facilitando sua fusão em comparação aos fragmentos de CTRPET, de menor área de superfície.

Com relação às curvas DSC dos compósitos obtidos por moldagem por compressão (Figura 49), observa-se que os compósitos CGT, CGMP também apresentaram dois picos, nas regiões de $155^{\circ} \mathrm{C}$ e $235{ }^{\circ} \mathrm{C}$, referentes ao evento endotérmico de fusão da matriz, no caso o PET reciclado. Estes picos apresentados pelas curvas DSC dos compósitos foram observados em regiões de temperatura inferiores as apresentadas por CTRPET (260 ${ }^{\circ} \mathrm{C}$ ). Para os compósitos CGT e CGMP foram observados picos endotérmicos nas regiões de $150{ }^{\circ} \mathrm{C}$ (picos pouco intensos) e em $230{ }^{\circ} \mathrm{C}$ (picos intensos). Estes picos ocorreram em temperaturas inferiores às apresentadas pela amostra de PET reciclado não moldado. Os picos referentes ao evento endotérmico de fusão de CT e CAT (232-248 $\left.{ }^{\circ} \mathrm{C}\right)$ foram observados em regiões de temperatura inferiores as de CTRPET $\left(260^{\circ} \mathrm{C}\right.$ ), porém na mesma região de temperatura para as frações de PET reciclado de maior massa molar média $\left(248{ }^{\circ} \mathrm{C}\right.$ ). Assim, pode-se concluir que os plasticizantes TBC e ATBC, presentes nos compósitos CT e CAT, respectivamente, atuaram de forma menos significativa na diminuição da temperatura de fusão dos compósitos, em comparação às misturas de plasticizantes glicerol/TBC e glicerol/OM/PBHL, presentes, respectivamente, nas composições de CGT e CGMP.

Observou-se que as curvas DSC dos demais compósitos, obtidos por moldagem por compressão, apresentaram um único pico (intenso) referente ao evento endotérmico de fusão. Estes picos foram observados em região de temperatura inferior $\left(235^{\circ} \mathrm{C}\right)$ as de CTRPET $\left(260^{\circ} \mathrm{C}\right)$ e PET reciclado $\left(248^{\circ} \mathrm{C}\right)$.

Pode-se observar também, analisando-se as curvas DSC de CGT, CGTS, CGMP e CG, a presença de picos pouco intensos na região de $300{ }^{\circ} \mathrm{C}$, os quais podem ser atribuídos ao evento endotérmico de volatilização do glicerol (ponto de ebulição de aproximadamente $290^{\circ} \mathrm{C}$ ).

Observam-se nas curvas DSC de CGT, CGTM, CGTS, CAT e CGM picos na região de 370-390 ${ }^{\circ} \mathrm{C}$ referentes, provavelmente, ao evento exotérmico de decomposição da 
fibra de sisal, possivelmente de seu componente majoritário, a celulose, cujo pico de decomposição na fibra ocorre na região de $370{ }^{\circ} \mathrm{C}$ (Figura 35-a).

Na Figura 50 são mostradas as curvas DSC para o PET reciclado não processado, CTRH e CHGM, obtidos por reometria de torque e posterior termoprensagem.

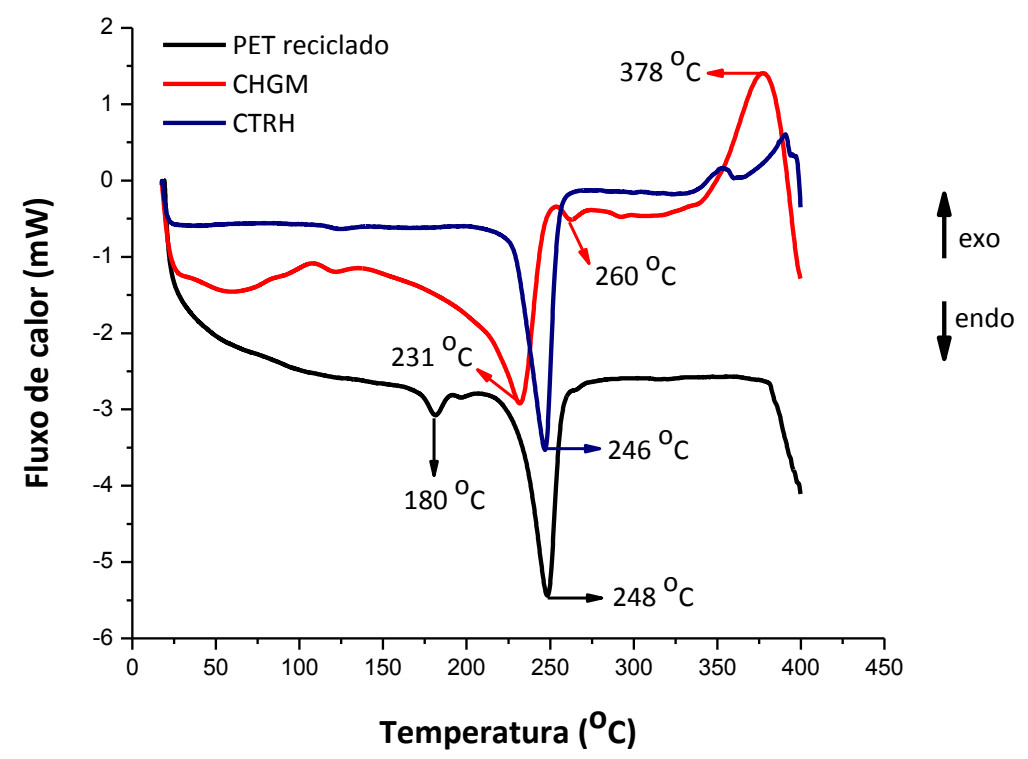

Figura 50. Curvas DSC do PET reciclado, da placa controle de PET/glicerol/OM (CTRH) e do compósito PET reciclado/fibras de sisal/glicerol/OM (CHGM) obtidos por reometria de torque e posterior termoprensagem (fluxo de $\mathrm{N}_{2}$ de $50 \mathrm{~mL} \mathrm{~min}^{-1}$, razão de aquecimento de $10{ }^{\circ} \mathrm{C} \mathrm{min}{ }^{-1}$ ).

Analisando-se as curvas DSC do PET reciclado, CTRH e CHGM, observam-se picos nas regiões de $180{ }^{\circ} \mathrm{C}, 230{ }^{\circ} \mathrm{C}$ e $250{ }^{\circ} \mathrm{C}$, referentes ao evento endotérmico de fusão dos materiais. CHGM apresenta o pico endotérmico de fusão deslocado para uma região de menor temperatura $\left(230^{\circ} \mathrm{C}\right)$ em comparação aos demais materiais. Visto que, tanto CTRH quanto CHGM contem a mistura de plasticizantes glicerol/OM em suas composições, em CHGM pode ter ocorrido maior retenção destes plasticizantes em decorrência da interação destes com as fibras (não presentes em CTRH e no PET reciclado), com estes atuando de forma mais significativa na diminuição da temperatura de fusão do material.

Observa-se também na curva DSC de CHGM, na região de $380{ }^{\circ} \mathrm{C}$, um pico exotérmico que pode estar ligado ao evento exotérmico de decomposição da fibra de sisal, possivelmente da celulose (componente majoritário), cujo pico de decomposição na fibra ocorre na região de $370{ }^{\circ} \mathrm{C}$ (Figura 36-a).

A Figura 51 apresenta as curvas dTG de CTRPET, CT, CGT, CGTM, CGTS, CAT, CGTP, CGMP, CG e CGM. 


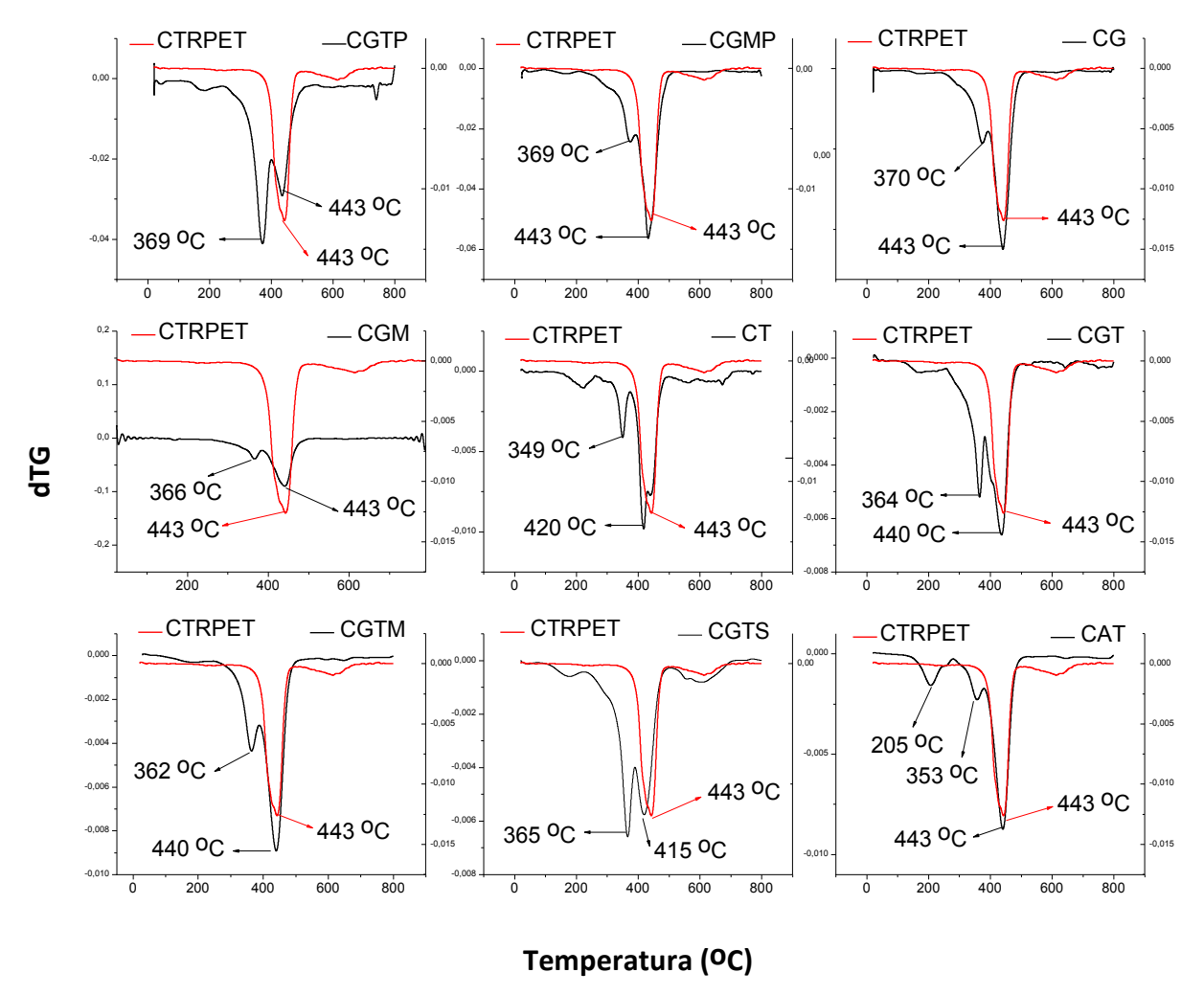

\begin{tabular}{l}
\hline CTRPET: Placa \\
controle de PET \\
reciclado \\
CT: PET reciclado \\
/fibra /TBC \\
CGT: PET reciclado / \\
fibra / glicerol / TBC \\
CGTM: PET reciclado \\
/fibra /glicerol /TBC \\
/OM \\
CGTS: PET reciclado \\
/fibra /glicerol /TBC \\
/OSE \\
CAT: PET reciclado \\
/fibra /ATBC \\
CGTP: PET reciclado \\
/fibra /glicerol /TBC \\
/PBHL \\
CGMP: PET reciclado \\
/fibra /glicerol /OM \\
/PBHL \\
CGM: PET reciclado \\
/fibra /glicerol /OM \\
CG: PET reciclado \\
/fibra /glicerol \\
\hline
\end{tabular}

Temperatura $\left({ }^{\circ} \mathrm{C}\right)$

Figura 51. Curvas dTG da placa controle de PET reciclado (CTRPET) e dos compósitos CGTP, CGMP, CG, CGM, CT, CGT, CGTM, CGTS e CAT obtidos por moldagem por compressão

(fluxo de $\mathrm{N}_{2}$ de $50 \mathrm{~mL} \mathrm{~min}^{-1}$, razão de aquecimento de $10{ }^{\circ} \mathrm{C} \mathrm{min}^{-1}$ ).

Analisando-se as curvas dTG de CTRPET e demais compósitos obtidos por moldagem por compressão, pode-se observar que CTRPET apresenta um único estágio de perda de massa, com um pico intenso de decomposição na região de $440{ }^{\circ} \mathrm{C}$, e os compósitos apresentam dois estágios de perda de massa, com exceção de CAT, que apresenta três estágios de perda de massa. Um dos picos de decomposição apresentados pelos compósitos CGT, CGTM, CGTP, CGMP, CG e CGM ocorre na região de $350-370{ }^{\circ} \mathrm{C}$, enquanto o outro em torno de $340{ }^{\circ} \mathrm{C}$, os quais apresentam intensidades diferentes. Com relação às curvas dTG dos compósitos CT e CGTS, são observados picos de decomposição, com intensidades diferentes, deslocados para regiões de menor temperatura, $350-360{ }^{\circ} \mathrm{C}$ e $420{ }^{\circ} \mathrm{C}$. CAT, como mencionado anteriormente, possui em sua curva dTG três estágios de perda de massa, com picos de intensidades diferentes, nas regiões de $200{ }^{\circ} \mathrm{C}, 350^{\circ} \mathrm{C}$ e $440{ }^{\circ} \mathrm{C}$. 0 pico de menor intensidade, na região de $200{ }^{\circ} \mathrm{C}$, pode ser provavelmente atribuído a volatilização do plasticizante ATBC, que ocorre em temperaturas próximas de $200{ }^{\circ} \mathrm{C}$, enquanto o pico, na região de $440{ }^{\circ} \mathrm{C}$, corresponde 
provavelmente à decomposição do PET reciclado. Os picos de decomposição, apresentados por CTRPET e compósitos nas regiões de aproximadamente 420-440 ${ }^{\circ} \mathrm{C}$, correspondem também à decomposição do PET reciclado. Os picos apresentados pelos compósitos, na região de aproximadamente $350-370{ }^{\circ} \mathrm{C}$, podem ser atribuídos à decomposição da fibra de sisal, principalmente devido à degradação da celulose (componente majoritário) (Figura 35-b), assim como o pico apresentando por CAT (em aproximadamente $350{ }^{\circ} \mathrm{C}$ ), o qual também pode ser atribuído à decomposição da fibra de sisal.

Observa-se também que os compósitos apresentam menor estabilidade térmica em comparação a CTRPET, com início de decomposição nas regiões de $240-250{ }^{\circ} \mathrm{C}$ e $340{ }^{\circ} \mathrm{C}$, respectivamente, devido à presença das fibras de sisal nos compósitos.

A Figura 52 apresenta as curvas dTG do PET reciclado, CTRH e CHGM (obtidos por reometria de torque e posterior termoprensagem).

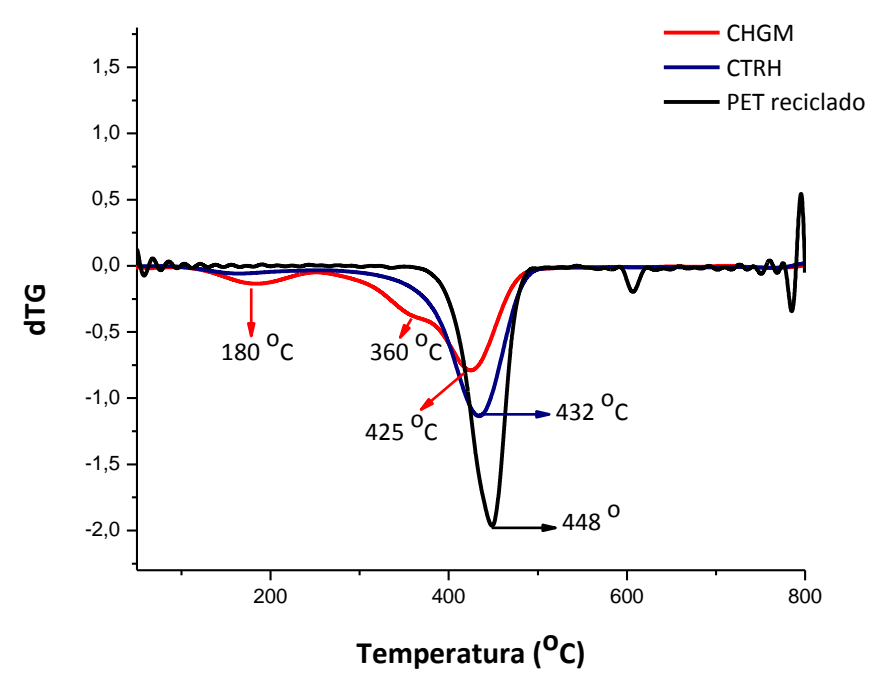

Figura 52. Curvas dTG do PET reciclado, da placa controle de PET/glicerol/OM (CTRH) e do compósito PET reciclado/fibras de sisal/glicerol/OM (CHGM) obtidos por reometria de torque e posterior termoprensagem (fluxo de $\mathrm{N}_{2}$ de $50 \mathrm{~mL} \mathrm{~min}^{-1}$, razão de aquecimento de $10{ }^{\circ} \mathrm{C} \mathrm{min} \mathrm{m}^{-1}$ ).

Analisando-se as curvas dTG (Figura 52), um único estágio de perda de massa é observado para os materiais, com exceção de CHGM, o qual apresenta dois estágios. 0 primeiro estágio de perda de massa para CHGM, na região de $180{ }^{\circ} \mathrm{C}$, está provavelmente associado à saída de voláteis, oriundos da presença dos plasticizantes. 0 outro estágio de perda de massa para CHGM, também presente em CTRH e PET reciclado, mostra picos de diferentes intensidades de decomposição do polímero. Estes picos apresentam-se deslocados, com relação ao apresentado pelo PET reciclado (450 
${ }^{\circ} \mathrm{C}$ ), para regiões de menor temperatura, aproximadamente $430{ }^{\circ} \mathrm{C}$ e $420^{\circ} \mathrm{C}$, respectivamente para CTRH e CHGM. Em CHGM, também se pode observar um "ombro" na região de $360^{\circ} \mathrm{C}$, provavelmente ligado ao evento de decomposição térmica das fibras de sisal (Figura 35-b).

Observa-se que CHGM apresenta menor estabilidade térmica em comparação a CTRH e o PET reciclado. Em CHGM a decomposição inicia-se em aproximadamente $270{ }^{\circ} \mathrm{C}$, para CTRH e o PET reciclado este evento inicia, respectivamente, em aproximadamente $310^{\circ} \mathrm{C}$ e $360^{\circ} \mathrm{C}$. Quando as fibras lignocelulósicas e os plasticizantes fazem parte do material, as temperaturas de início de decomposição podem variar, devido a fatores como a presença da fibra e também dependendo dos plasticizantes utilizados, o que pode diversificar a temperatura máxima de aplicação destes materiais.

\subsubsection{Resistência ao impacto Izod}

$\mathrm{Na}$ Figura 53, são apresentados os resultados do ensaio de resistência ao impacto Izod. Foram considerados a placa controle de PET reciclado (CTRPET) e os compósitos obtidos por moldagem por compressão, assim como o compósito obtido por reometria de torque.

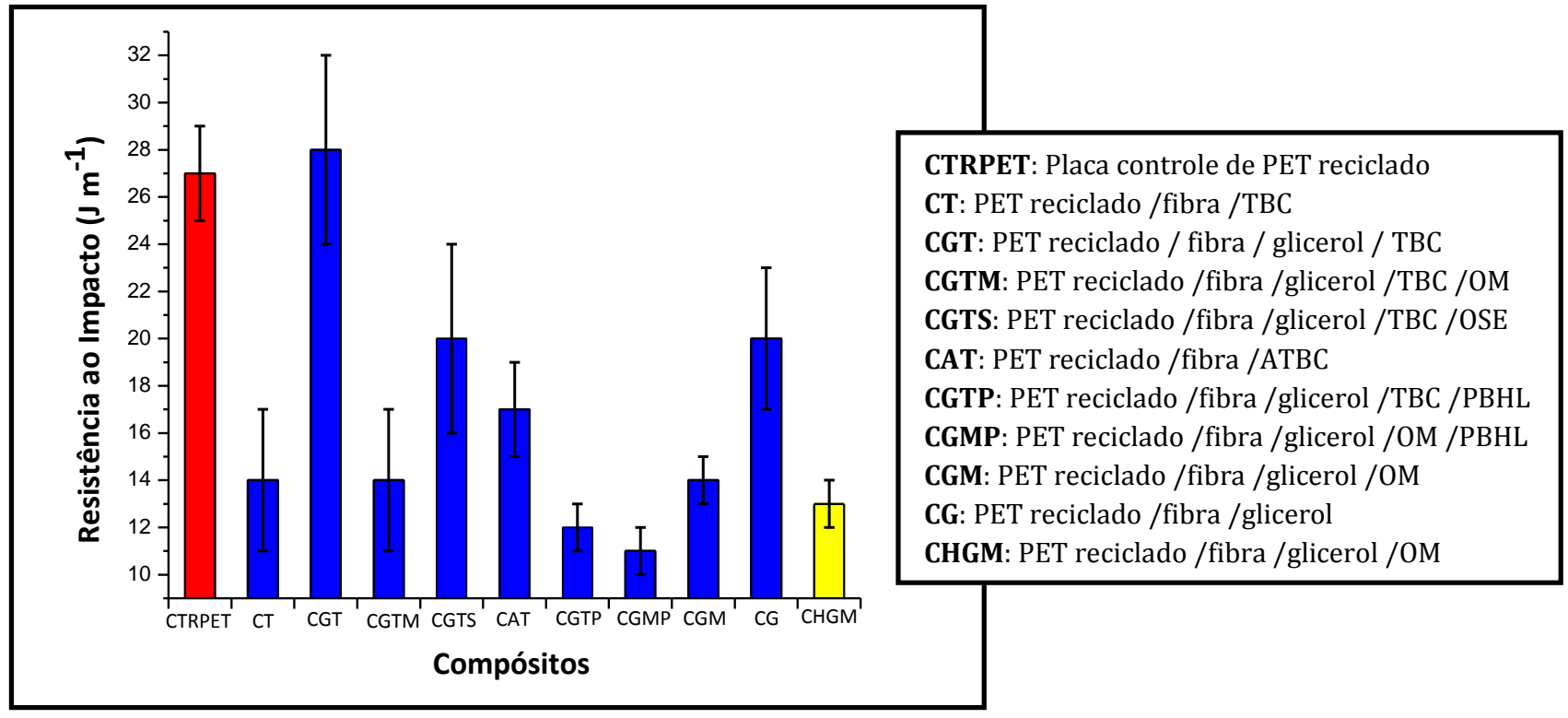

Figura 53. Resistência ao impacto Izod da placa controle de PET reciclado (CTRPET), dos compósitos CT, CGT, CGTM, CGTS, CAT, CGTP, CGMP, CGM e CG obtidos por moldagem por compressão e do compósito CHGM obtido por reometria de torque e posterior termoprensagem. 
Os resultados obtidos demonstraram que, com exceção do compósito CGT, cuja resistência ao impacto é de $28 \mathrm{~J} \mathrm{~m}^{-1}$, valor semelhante à resistência ao impacto de CTRPET, todos os demais compósitos apresentaram resistência ao impacto inferior a CTRPET. Portanto, a mistura dos plasticizantes glicerol e TBC, com relação à resistência ao impacto, foi a melhor combinação de plasticizantes utilizada, no que diz respeito a esta propriedade, levando a compósitos com maior adesão fibra-matriz. Pode-se considerar que a mistura de plasticizantes atua como um agente de acoplamento, modificando a interface fibra-matriz, interagindo com ambos os componentes e formando uma espécie de "ponte" entre ambos, com consequente intensa adesão fibramatriz (ROWELL et al., 1997). Devido a esta intensa adesão fibra-matriz, provavelmente há maior transferência da energia mecânica da matriz para a fibra durante os ensaios, com consequente maior resistência ao impacto de CGT.

Em geral, compósitos de matriz termoplástica reforçados com fibras vegetais podem apresentar uma queda na resistência ao impacto com relação ao polímero não reforçado, devido à adição das fibras, o que pode ser constatado no presente trabalho. A presença das fibras vegetais pode diminuir a energia absorvida pelos compósitos e criar regiões de concentração de stress, com consequente menor energia para a propagação de trincas durante os ensaios de impacto. Rowell et al. (1997), em seu estudo, verificaram que a adição de 50\% (em massa) de fibras de milho levou a compósitos de PP com resistência ao impacto 6,5 vezes menor, em relação ao PP puro.

O teor de fibras (15\%) utilizado no presente trabalho também pode ser o responsável pelo comportamento frágil apresentado pelos compósitos. Castro (2010), em seu estudo, verificou que um aumento do teor de fibras de curauá de 5\% para 15\% em compósitos de biopolietileno, foi responsável pela redução de aproximadamente $34 \%$ na resistência ao impacto destes materiais, corroborando o observado no presente trabalho. Além disso, com uma porcentagem maior de fibras nos compósitos, torna-se maior a probabilidade de regiões em que haja aglomeração das fibras, sendo essas regiões concentradoras de tensões, necessitando de menor energia para iniciar ou propagar uma trinca, conforme mencionado anteriormente.

Pode-se observar também que os compósitos contendo em sua formulação PBHL, CGTP e CGMP apresentaram um dos menores valores de resistência ao impacto, respectivamente, $12 \mathrm{~J} \mathrm{~m}^{-1}$ e $11 \mathrm{~J} \mathrm{~m}^{-1}$ (Figura 53). Assim, pode-se concluir que o PBHL diminuiu a resistência ao impacto dos compósitos, tornando-os mais frágeis em 
comparação aos demais. Os resultados obtidos por Castro (2010) para compósitos de biopolietileno/curauá/PBHL são contrários aos apresentados no presente trabalho. Neste estudo, foi observado que a adição de PBHL aos compósitos aumentou a resistência ao impacto dos mesmos, devido ao efeito de tenacificação provocado pela adição da borracha.

Observou-se também que, assim como ocorreu com a adição de PBHL à formulação dos compósitos, a adição de OM e OSE diminuiu a resistência ao impacto dos compósitos CGTM, CGTS, CGMP, CGM e CHGM (Figura 53).

Os diferentes processamentos dos compósitos, moldagem por compressão, reometria de torque e termoprensagem, não influenciaram significativamente a resistência ao impacto dos compósitos de mesma composição, CGM e CHGM, que possuem resistências ao impacto semelhantes $\left(14 \mathrm{~J} \mathrm{~m}^{-1}\right.$ e $13 \mathrm{~J} \mathrm{~m}^{-1}$ respectivamente). Pode-se concluir também que o comprimento das fibras nos compósitos CGM e CHGM, respectivamente de $3 \mathrm{~cm}$ e $5 \mathrm{~mm}$, também não teve influência nos resultados obtidos. Santos et al. (2006), em seu estudo, verificaram que houve uma diminuição de $50 \%$ da resistência ao impacto em compósitos de matriz termoplástica de poliamida-6 reforçados por fibras de curauá, em comparação ao valor apresentado pelo polímero, independentemente do tamanho das fibras utilizadas (0,01-100 $\mathrm{mm}$ de comprimento).

Pode-se observar também que os valores de resistência ao impacto obtidos no presente trabalho para CTRPET e demais compósitos são menores que o valor de resistência ao impacto encontrado na literatura para o PET virgem $\left(90 \mathrm{~J} \mathrm{~m}^{-1}\right)$ (OLIVEIRA, 2006). Mancini, Bezerra e Zanin (1998), em seu estudo, verificaram que com o aumento do número de reciclagens do PET, há acentuada tendência de queda nos valores de resistência ao impacto deste polímero, podendo chegar a valores de aproximadamente $5 \mathrm{~J} \mathrm{~m}^{-1}$.

Zou, Reddy e Yang (2011) prepararam compósitos a partir de tecidos preparados previamente via tecelagem de fios de PET/fibras de algodão (65/35\%) com a adição de glicerol (10\% em massa). Neste estudo, os autores obtiveram 99,0 $\pm 15,3 \mathrm{~J} \mathrm{~m}^{-1} \mathrm{de}$ resistência ao impacto para os compósitos preparados por moldagem por compressão, à temperatura de $260^{\circ} \mathrm{C}$ por $1 \mathrm{~h} 50 \mathrm{~min}$ e entalhados. Destaca-se, no entanto, que neste estudo as fibras lignocelulósicas foram incorporadas via tecelagem à matriz de PET, o que possibilita uma distribuição controlada da fibra de algodão, dentre outros fatores que distinguem este estudo deste presente. 


\subsubsection{Resistência à flexão}

O CTRPET apresentou baixa deformação na ruptura (em torno de 0,5\%) (Figura 54), com a fratura ocorrendo durante a deformação elástica do polímero, sem que este tenha experimentado qualquer deformação plástica. 0 módulo de flexão apresentado por CTRPET, 4,2 GPa, é consequência de sua rigidez elevada, apresentando o material comportamento frágil quando submetido a aplicação da tensão de flexão.

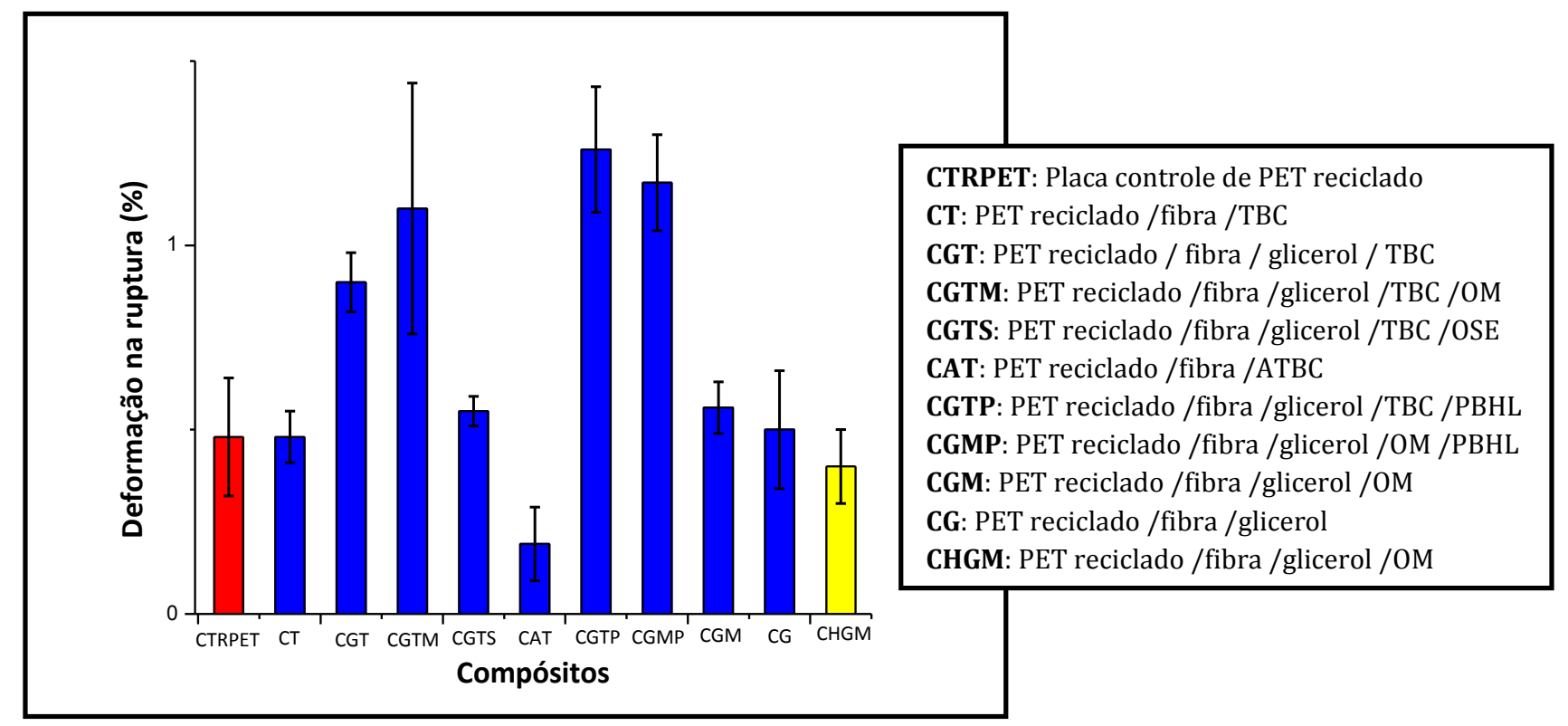

Figura 54. Deformação na ruptura da placa controle de PET reciclado (CTRPET), dos compósitos CT, CGT, CGTM, CGTS, CAT, CGTP, CGMP, CG e CGM obtidos por moldagem por compressão e do compósito CHGM obtido por reometria de torque e posterior termoprensagem.

Para CGTM e demais compósitos, a resposta à aplicação da tensão de flexão ocorreu inicialmente mediante deformação elástica, seguida do escoamento e de deformação plástica (CALLISTER JR., 2002; CANEVAROLO JR., 2007). Os compósitos apresentam, devido à adição de plasticizantes, um comportamento dúctil, caracterizado por deformação razoável na ruptura (Figura 54), com exceção de CT, CAT e CHGM (respectivamente 0,5\%,0,2\% e 0,4\% de deformação na ruptura) e baixos valores dos módulos de flexão apresentados (Figura 55), em comparação a CTRPET. 


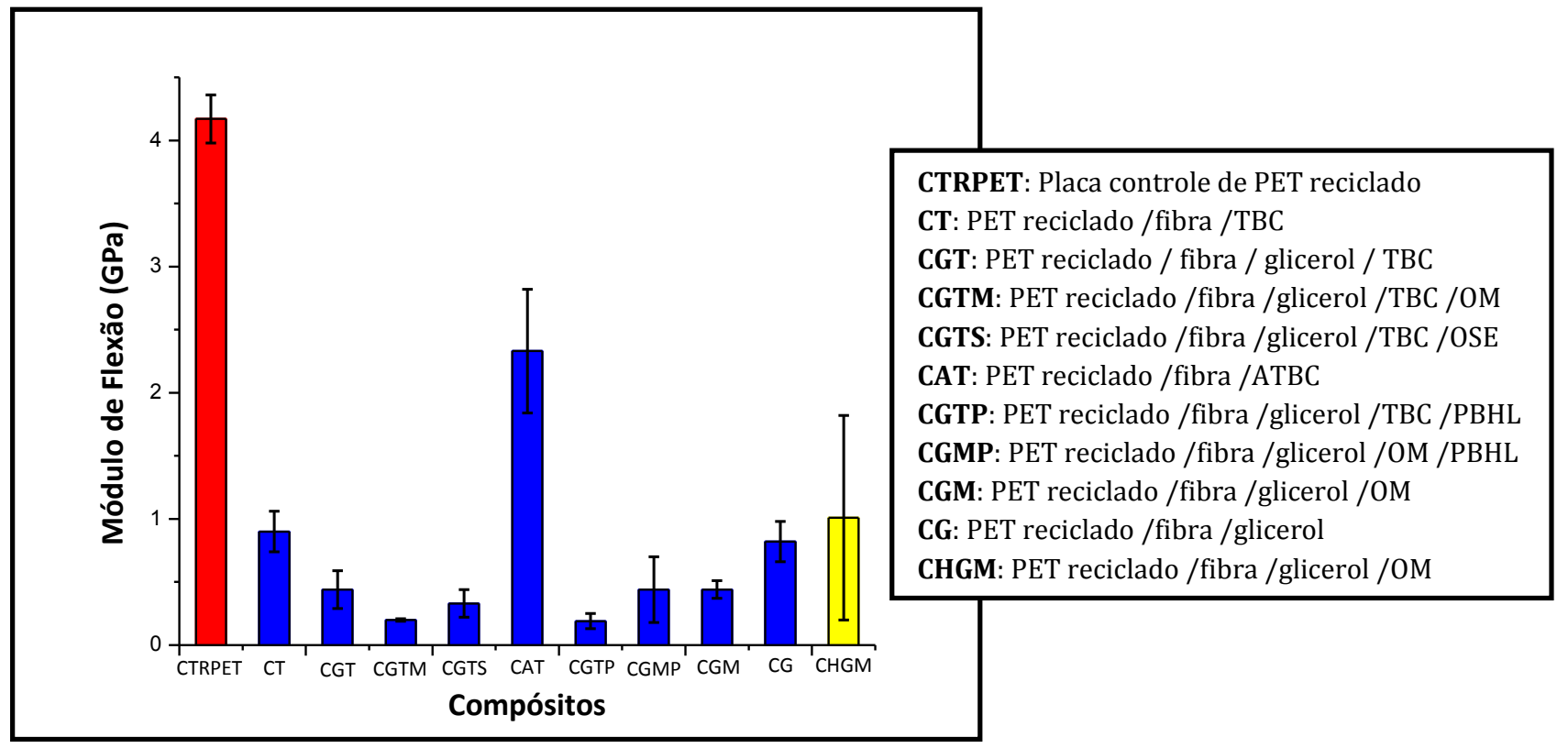

Figura 55. Módulos de flexão da placa controle de PET reciclado (CTRPET), dos compósitos CT, CGT, CGTM, CGTS, CAT, CGTP, CGMP, CG e CGM obtidos por moldagem por compressão e do compósito CHGM obtido por reometria de torque e posterior termoprensagem.

A Figura 56 apresenta os valores obtidos de resistência à flexão de CTRPET e dos compósitos. 


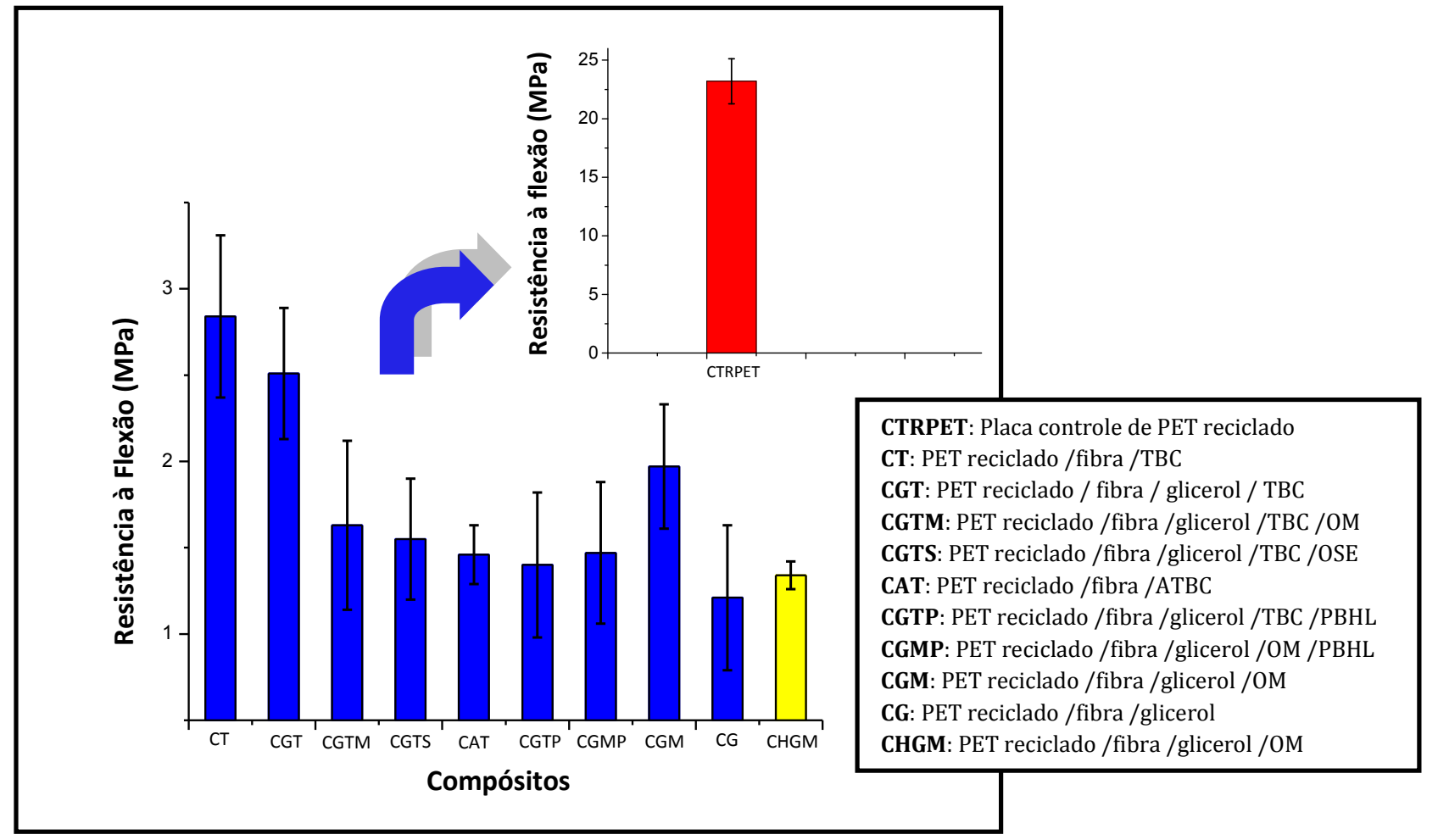

Figura 56. Resistência à flexão da placa controle de PET reciclado (CTRPET), dos compósitos CT, CGT, CGTM, CGTS, CAT, CGTP, CGMP, CG, CGM obtidos por moldagem por compressão e do compósito CHGM obtido por reometria de torque e posterior termoprensagem.

Pode-se observar, na Figura 56, que devido à adição de plasticizantes, os compósitos apresentam resistências à flexão muito inferiores a de CTRPET (aproximadamente dez vezes menor). Isto se deve ao fato de que, as moléculas de plasticizantes presentes nos compósitos, podem ocupar posições intersticiais entre as grandes cadeias poliméricas, o que resulta no aumento da distância entre estas. Consequentemente, há uma redução das interações intermoleculares, facilitando o movimento de alongamento e alinhamento das cadeias mediante a aplicação de uma tensão, e, portanto, reduzindo a resistência à flexão destes materiais (CALLISTER JR., 2002).

Observa-se também que os compósitos apresentam tendências opostas com relação ao módulo de flexão e resistência à flexão. CAT apresenta o maior módulo de flexão entre os compósitos, porém um dos menores valores de resistência à flexão. CT apresenta o maior valor de resistência à flexão entre os compósitos, porém um dos menores valores do módulo de flexão.

Pode-se observar que a adição de PBHL aos compósitos CGTP e CGMP, assim como ocorreu no ensaio de resistência ao impacto, levou a compósitos com menores resistências à flexão em comparação com os compósitos CGT e CGM, que diferem apenas por não possuírem PBHL em suas composições. Esta tendência não foi observada com relação ao módulo de flexão. 
Analisando-se os resultados, observou-se também que, os compósitos de mesma composição, CGM e CHGM, porém processados por técnicas distintas, respectivamente moldagem por compressão e reometria de torque com posterior termoprensagem, apresentaram valores distintos do módulo de flexão e resistência à flexão. Este resultado é contrário ao que foi observado nos ensaios de resistência ao impacto, em que CGM e CHGM apresentaram valores semelhantes de resistência. CGM apresentou maior resistência à flexão do que CHGM, porém o oposto foi observado com relação ao módulo de flexão. Provavelmente, a maior resistência à flexão apresentada por CGM, deve-se ao reforço mais efetivo pelo uso de fibras mais longas, com $3 \mathrm{~cm}$ de comprimento, em comparação a CHGM, no qual fez-se uso de fibras com $5 \mathrm{~mm}$ de comprimento.

Pode-se concluir também que CGT apresentou o melhor desempenho com relação à resistência à flexão e ao impacto, por apresentar o maior valor de resistência ao impacto $\left(28 \mathrm{~J} \mathrm{~m}^{-1}\right)$ e o segundo maior valor de resistência à flexão $(2,51 \mathrm{MPa})$.

Observa-se que os valores de resistência à flexão obtidos no presente trabalho para CTRPET e demais compósitos são menores que o valor encontrado na literatura para o PET virgem, respectivamente $65 \mathrm{MPa}$ (YUAN et al., 2007). Mancini, Bezerra e Zanin (1998), em seu estudo, observaram que com o aumento do número de reciclagens do PET há acentuada tendência de queda em suas propriedades mecânicas, devido à diminuição da massa molar média do polímero e aumento de sua cristalinidade, como consequências do processo de reciclagem. Pode-se observar também que os valores obtidos no presente trabalho para o módulo de flexão de CTRPET e CAT, respectivamente 4,17 $\mathrm{GPa}$ e 2,33 $\mathrm{GPa}$, são maiores que o valor encontrado na literatura para o PET virgem (1,8 GPa) (YUAN, 2006), o que não é válido para os demais compósitos.

Zou, Reddy e Yang (2011), para os compósitos preparados a partir de tecidos de fios de PET/fibras de algodão (65/35\%) com a adição de glicerol (10\% em massa), processados por moldagem por compressão à temperatura de $260{ }^{\circ} \mathrm{C}$ por $1 \mathrm{~h} 50 \mathrm{~min}$, obtiveram para o módulo de flexão o valor de 2,7 GPa. Com relação à resistência à flexão, os autores obtiveram o valor de 18,7 MPa. No entanto, conforme já mencionado, o processamento destes compósitos seguiu parâmetros consideravelmente diferentes daqueles do presente estudo. 


\subsubsection{Análise Térmica Dinâmico-Mecânica (DMTA)}

As propriedades dinâmico-mecânicas dos compósitos reforçados com fibras lignocelulósicas são dependentes de vários fatores, tais como a natureza da matriz e fibra utilizadas, distribuição e orientação das fibras nos compósitos, plasticizantes utilizados, dentre outros fatores (DE OLIVEIRA, 2010). A camada de matriz que recobre as fibras, imediatamente posterior à interface fibra-matriz, pode ter propriedades distintas do restante do material, pois as interações fibra-matriz podem alterar a mobilidade das cadeias poliméricas (PAIVA; FROLLINI, 2002; TRINDADE et al., 2005).

$\mathrm{Na}$ Figura 57, observa-se que os módulos de armazenamento (E') dos compósitos, a $30{ }^{\circ} \mathrm{C}$, foram menores que o apresentado por CTRPET. Deste resultado, pode-se inferir que a incorporação das fibras na matriz polimérica, assim como dos diferentes tipos e misturas de plasticizantes, resultou em uma diminuição da rigidez dos compósitos, quando comparados a CTRPET. Os plasticizantes, como mencionado anteriormente, podem diminuir a rigidez dos materiais devido a uma redução das interações intermoleculares entre as cadeias poliméricas, facilitando o movimento destas e tornando os materiais menos rígidos (CALLISTER JR., 2002). Além disso, o uso de 15\% (em massa) de fibras de sisal no preparo dos compósitos também pode ter contribuído para a diminuição do módulo de armazenamento em relação ao de CTRPET.

O compósito CT foi o que apresentou o maior módulo de armazenamento e, consequentemente, maior rigidez. Este fato pode ser explicado pela maior transferência de energia mecânica na interface fibra-matriz deste compósito, devido, possivelmente, a boa interação do PET com as fibras e do plasticizante TBC com o polímero e as fibras. 


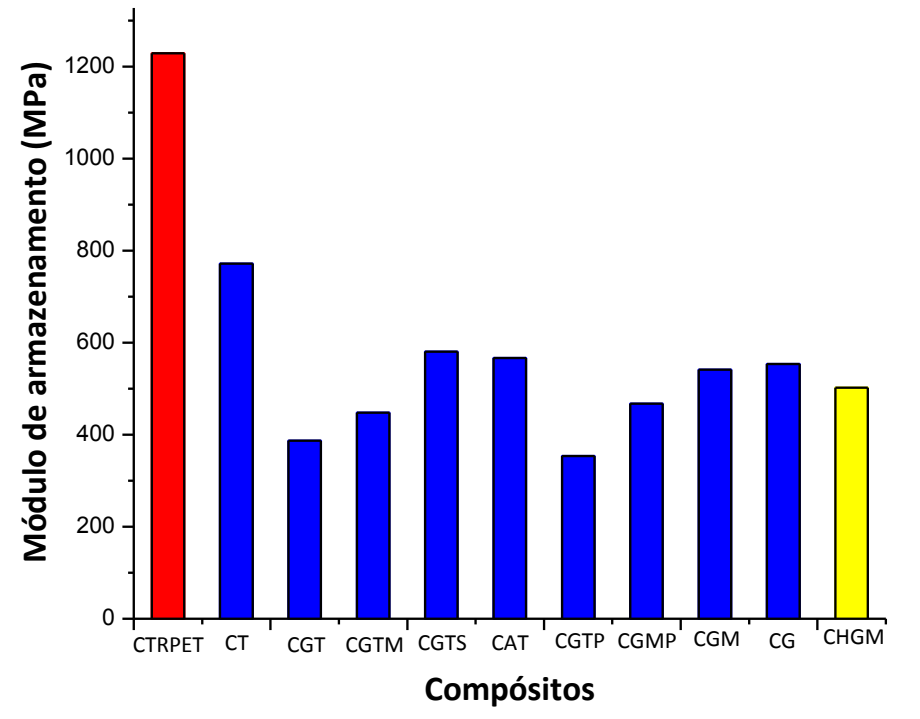

CTRPET: Placa controle de PET reciclado CT: PET reciclado /fibra /TBC CGT: PET reciclado / fibra / glicerol / TBC CGTM: PET reciclado /fibra /glicerol /TBC /OM CGTS: PET reciclado /fibra /glicerol /TBC /OSE CAT: PET reciclado /fibra /ATBC

CGTP: PET reciclado / fibra /glicerol /TBC /PBHL CGMP: PET reciclado /fibra /glicerol /OM /PBHL CGM: PET reciclado /fibra /glicerol /OM CG: PET reciclado /fibra /glicerol CHGM: PET reciclado / fibra /glicerol /OM

Figura 57. Módulo de armazenamento $\left(30^{\circ} \mathrm{C}\right)$ da placa controle de PET reciclado (CTRPET), dos compósitos CT, CGT, CGTM, CGTS, CAT, CGTP, CGMP, CG, CGM obtidos por moldagem por compressão, e do compósito CHGM obtido por reometria de torque e posterior termoprensagem.

Analisando-se a Figura 57, pode-se observar também que CGTP e CGMP possuem um dos menores valores do módulo de armazenamento, dentre os demais compósitos. Este fato pode ser explicado pela adição do componente elastomérico PBHL na concentração de 15\% (em massa) com relação à massa total de PET reciclado e dos demais plasticizantes adicionados. Os resultados do módulo de armazenamento obtidos por Castro (2010) para blendas de biopolietileno/ PBHL, com o uso de 5-30\% do elastômero na composição dos compósitos, corroboram os dados apresentados no presente trabalho. Em seu estudo, o autor observou que a rigidez das blendas decresceu com o aumento da concentração do componente elastomérico (CASTRO, 2010).

A análise dinâmico-mecânica (DMTA) permite a obtenção de vários parâmetros, sendo um deles a relação entre o módulo de perda e o de armazenamento, denominado $\tan$ delta $(\tan \delta) .0 \tan \delta$, também conhecido por fator de perda ou "damping", expressa a capacidade de um material em converter energia mecânica e tem seu valor máximo associado à temperatura de transição vítrea, $\mathrm{T}_{\mathrm{g}}$. A Figura 58 apresenta os valores da temperatura de transição vítrea ( $\mathrm{T}_{\mathrm{g}}$ ) de CTRPET e dos compósitos CT, CGT, CGTM, CGTS, CAT, CGTP, CGMP, CG, CGM e CHGM, obtidos a partir do máximo das curvas de $\tan \delta$ em função da temperatura. 


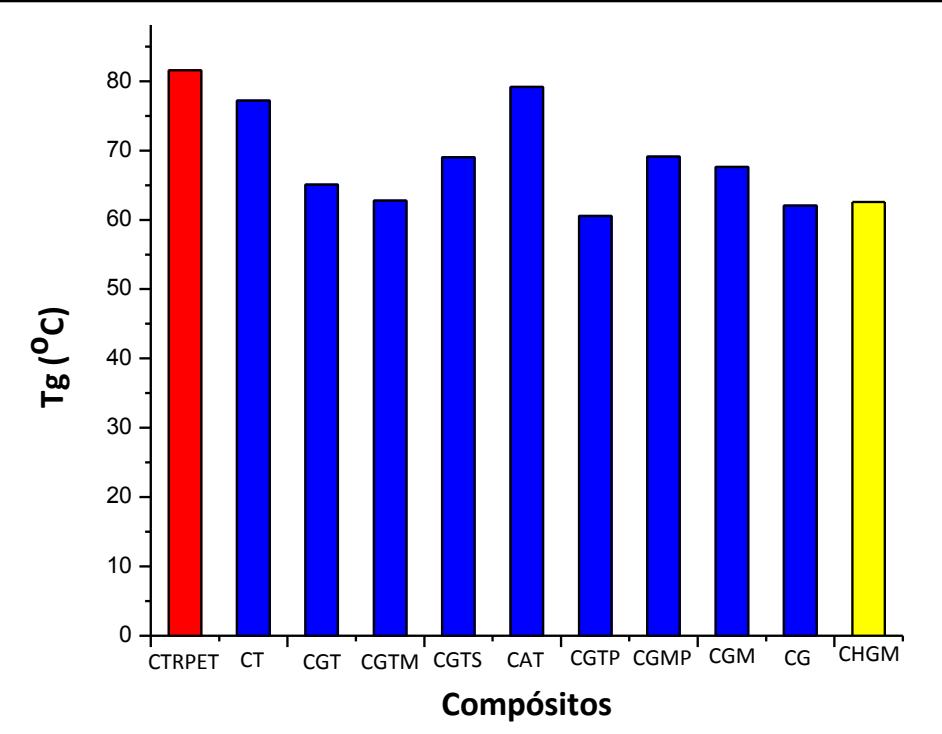

CTRPET: Placa controle de PET reciclado CT: PET reciclado /fibra /TBC CGT: PET reciclado / fibra / glicerol / TBC CGTM: PET reciclado /fibra /glicerol /TBC /OM CGTS: PET reciclado /fibra /glicerol /TBC /OSE CAT: PET reciclado /fibra /ATBC

CGTP: PET reciclado /fibra /glicerol /TBC /PBHL CGMP: PET reciclado /fibra /glicerol /OM /PBHL CGM: PET reciclado / fibra /glicerol /OM CG: PET reciclado /fibra /glicerol

CHGM: PET reciclado /fibra /glicerol /OM

Figura 58. Temperatura de transição vítrea $\left(\mathrm{T}_{\mathrm{g}}\right)$ da placa controle de PET reciclado (CTRPET), dos compósitos CT, CGT, CGTM, CGTS, CAT, CGTP, CGMP, CG, CGM obtidos por moldagem por compressão e do compósito CHGM obtido por reometria de torque e posterior termoprensagem.

Observa-se na Figura 58, que há uma diminuição dos valores da $\mathrm{T}_{\mathrm{g}}$ dos compósitos em relação à CTRPET. 0 valor de $\mathrm{T}_{\mathrm{g}}$ observado para CTRPET, aproximadamente $82{ }^{\circ} \mathrm{C}$, encontra-se na faixa de temperatura observada na literatura para o PET virgem e PET reciclado, a qual é relatada no intervalo de $70-80{ }^{\circ} \mathrm{C}$ (BILLMEYER JR., 1995; CORRADINI et al., 2009). A diminuição da T $\mathrm{g}_{\mathrm{g}}$ observada para os compósitos em relação à CTRPET deve-se ao uso dos diferentes plasticizantes, e misturas destes, na preparação dos compósitos. Os plasticizantes, como mencionado anteriormente, alojam-se entre as cadeias poliméricas afastando-as umas das outras, reduzindo as interações intermoleculares entre estas. Assim, ocorre uma redução da energia associada às transições relacionadas ao movimento de rotação entre as ligações de segmentos destas cadeias, levando ao abaixamento da temperatura de transição vítrea da matriz polimérica.

Analisando-se os valores de $\mathrm{T}_{\mathrm{g}}$ obtidos para os compósitos, em relação à ação dos diferentes tipos e misturas de plasticizantes utilizados, observa-se que CGTP apresentou o menor valor de $\mathrm{T}_{\mathrm{g}}$ (aproximadamente $60{ }^{\circ} \mathrm{C}$ ) em comparação aos demais compósitos e a CTRPET. Este fato deve-se, possivelmente, a melhor interação do polímero com a mistura de plasticizantes glicerol, TBC e PBHL. Estes plasticizantes, os quais possuem muitos grupos polares (hidroxilas e carbonilas) (Figura 18, 23 e 25), 
possivelmente interagem mais intensamente com os grupos polares presentes nos componentes das fibras e com a matriz polimérica, o que pode levar a maior retenção destes plasticizantes (com menor volatilização durante o processamento), garantindo uma ação efetiva maior na redução da $\mathrm{T}_{\mathrm{g}}$. No entanto, a ação dos plasticizantes TBC no compósito CT e ATBC no compósito CAT não foi tão efetiva com relação ao abaixamento da $\mathrm{T}_{\mathrm{g}}$ do polímero, sendo que valores no intervalo de $77-79{ }^{\circ} \mathrm{C}$ foram observados. Portanto, pode-se concluir que houve menor interação dos plasticizantes TBC e ATBC com a matriz polimérica, mesmo observando que a ação destes plasticizantes levou ao abaixamento da temperatura de fusão dos compósitos (CT e CAT, 232-248 ${ }^{\circ} \mathrm{C}$ ) em relação a CTRPET $\left(260^{\circ} \mathrm{C}\right)$. Este fato é suportado ao se analisar o efeito da adição de TBC e glicerol ao compósito (CGT), o que levou a um valor de $\mathrm{T}_{\mathrm{g}}$ ligeiramente superior em relação à adição apenas de glicerol (CG), o qual demonstrou, pela discussão até o momento, uma atividade como plasticizante mais efetiva.

\subsubsection{Microscopia Eletrônica de varredura (MEV)}

A Figura 59 apresenta a micrografia da superfície fraturada pós-ensaio de impacto de CTRPET, onde se pode observar uma superfície de fratura relativamente sem rugosidades, com a ocorrência de regiões espelhadas, indicadas pelas setas amarelas. Este tipo de fratura (frágil) é característico de um material rígido e quebradiço, com baixa ductilidade, como o PET reciclado (KIM; MAI, 1991).

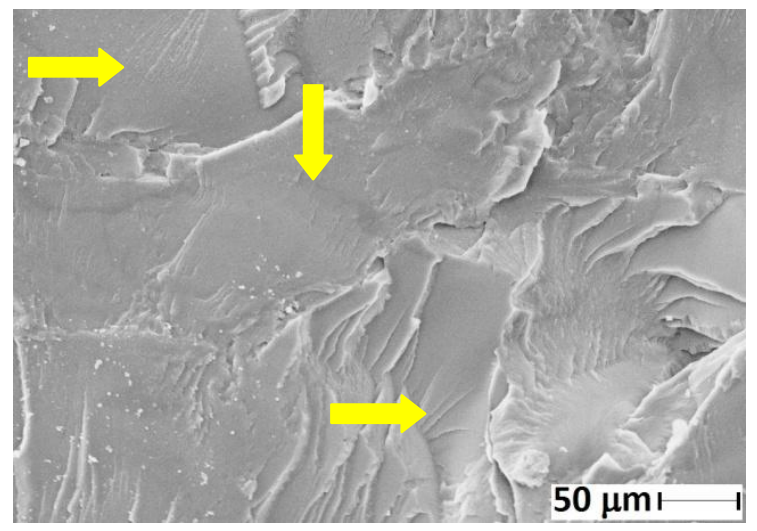

Figura 59. Micrografia da superfície fraturada da placa controle de PET reciclado (CTRPET) obtida por moldagem por compressão.

A Figura 60 apresenta as micrografias das superfícies de fratura dos compósitos CT, CGT, CGTM, CGTS e CAT. 


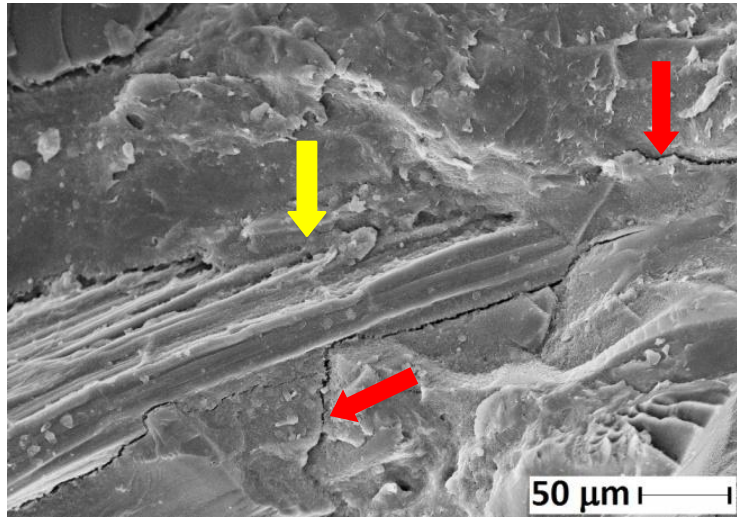

(a)

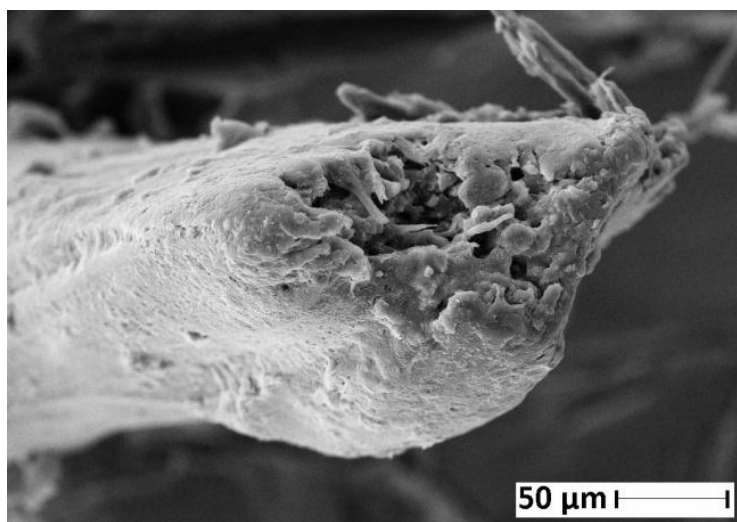

(c)

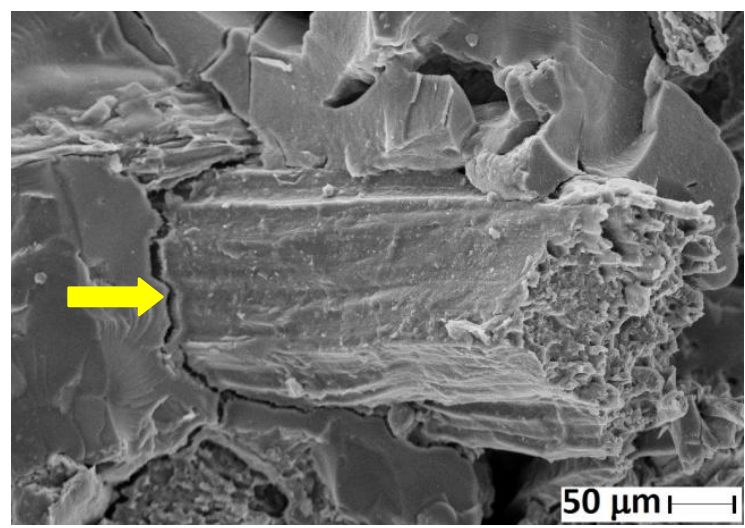

(e)

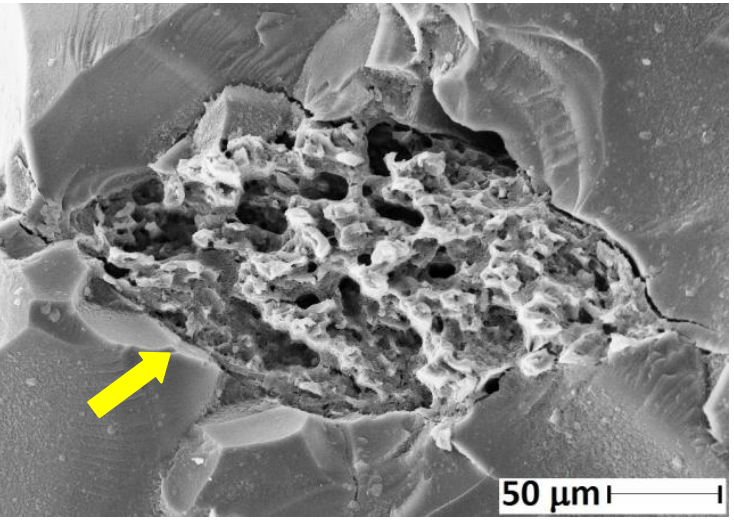

(b)

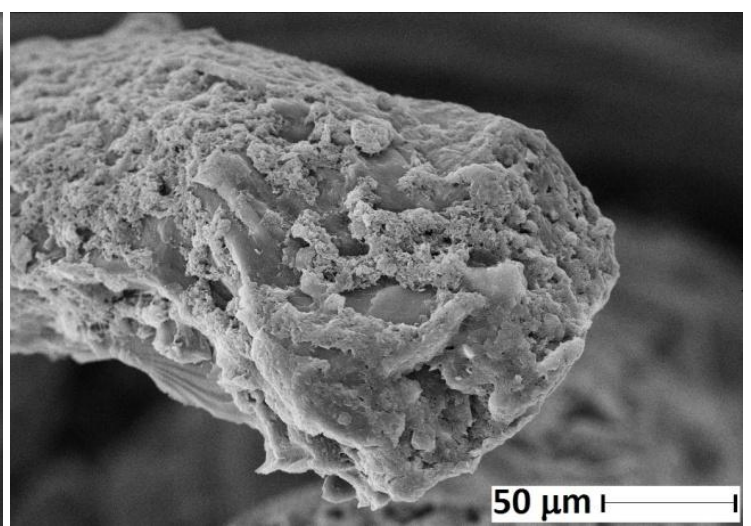

(d)

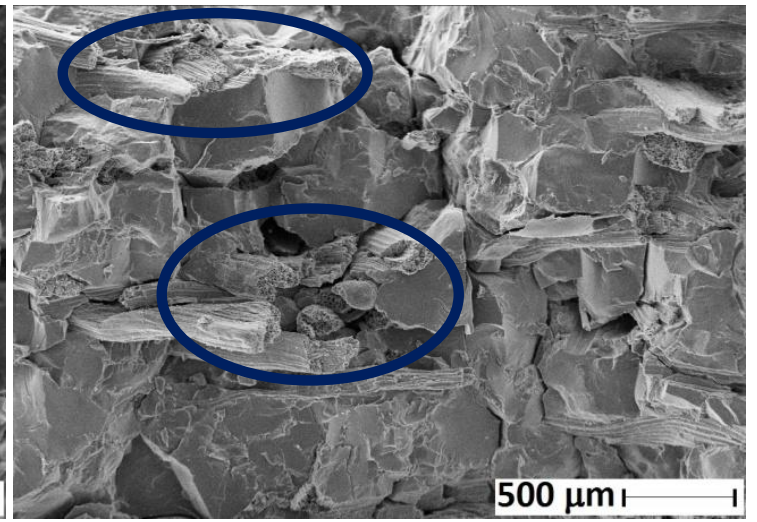

(f)

Figura 60. Micrografias das superfícies de fratura dos compósitos obtidos por moldagem por compressão: (a) PET reciclado/fibras de sisal/TBC (CT); (b) e (c) PET reciclado/fibras de sisal/glicerol/TBC (CGT); (d) PET reciclado/fibras de sisal/glicerol/TBC/OM (CGTM); (e) PET reciclado/fibras de sisal/glicerol/TBC/OSE (CGTS); (f) PET reciclado/fibras de sisal/ATBC (CAT).

Pode-se observar que a micrografia de CT (Figura 60-a) apresenta região de boa adesão entre a fibra e a matriz na interface, indicada pela seta amarela. Nem sempre uma forte adesão fibra-matriz leva a melhores resultados de resistência ao impacto, como foi o caso deste compósito, que apresentou baixa resistência ao impacto (Figura 53). Quando há forte adesão, o "golpe" na interface possivelmente não libera a fibra da 
matriz, facilitando a propagação de trincas pelo compósito. Observa-se nesta micrografia a propagação de trincas, indicadas por setas vermelhas, ao redor da fibra, evidenciando a transferência de carga, aplicada durante os ensaios de impacto, da matriz para a fibra (MEGIATTO, 2006). Em uma situação contrária à apresentada, em casos em que a adesão fibra-matriz em compósitos não é tão intensa, há um descolamento da fibra mediante o "golpe", e a energia de impacto é absorvida, podendo levar a melhores resultados de resistência ao impacto (BRAHMAKUMAR; PAVITHRAN; PILLAI, 2005). A Figura 60-b apresenta uma micrografia de CGT, em que novamente observa-se boa adesão fibra-matriz, com o rompimento da fibra no mesmo plano de fratura da matriz, indicativo de certa resistência do compósito.

Nas micrografias de CGT e CGTM, respectivamente Figuras 60-c e 60-d, observa-se considerável recobrimento das fibras pela matriz, assim como preenchimento das cavidades das mesmas (recobrimento das estruturas fibrilares, ocas, pela matriz). Este fato é consequência da boa impregnação fibra-matriz, que ocorreu durante o processamento destes compósitos, devido provavelmente a grande interação que pode ocorrer entre os plasticizantes (glicerol, TBC e óleo de mamona) com as fibras de sisal e a matriz polimérica, levando a um aumento das interações na interface fibra/matriz, mostrando que estes plasticizantes agiram como bons compatibilizantes.

A Figura 60-e mostra a micrografia de CGTS, em que se observa o descolamento parcial da fibra (debonding), indicado pela seta amarela, possivelmente um dos principais responsáveis pela absorção da energia de impacto, conforme anteriormente mencionado. Consequentemente, devido à melhor absorção da energia de impacto, CGTS apresentou tendência de maior resistência ao impacto $\left(20 \mathrm{~J} \mathrm{~m}^{-1}\right)$ em comparação a CT $\left(14 \mathrm{~J} \mathrm{~m}^{-1}\right)$.

CAT e CG apresentaram em suas micrografias, respectivamente Figuras 60-f e 62-a, aglomerados e emaranhados de fibras, indicados por elipses de cor azul, evidenciando que não houve uma distribuição muito homogênea das fibras pela matriz, fato que também refletiu nos baixos valores de resistência ao impacto apresentados por estes compósitos.

Na Figura 61 são apresentadas as micrografias dos compósitos CGTP e CGMP, ambos contendo PBHL em suas composições. 


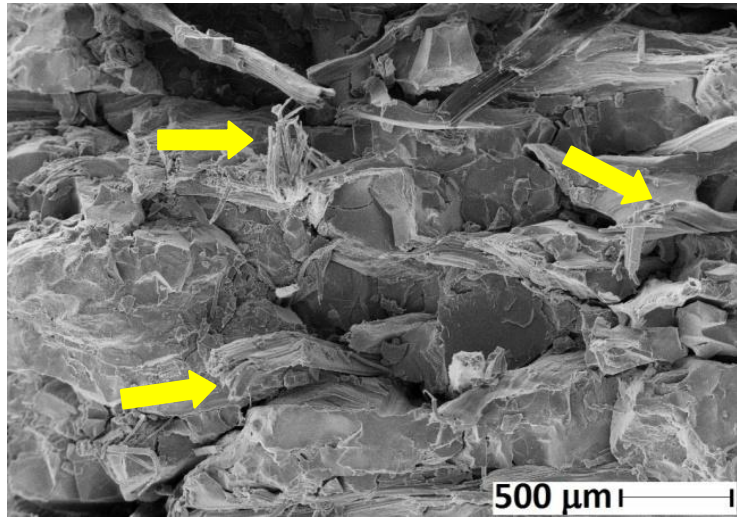

(a)

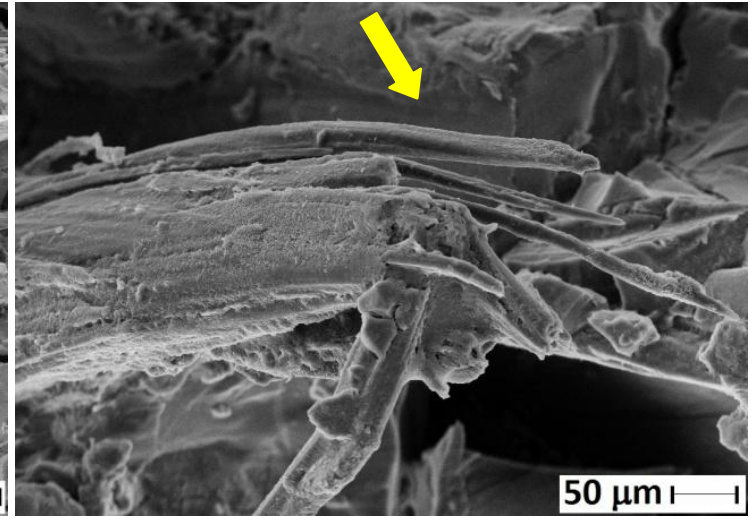

(b)

Figura 61. Micrografias das superfícies de fratura dos compósitos obtidos por moldagem por compressão: (a) PET reciclado/fibras de sisal/glicerol/TBC/PBHL (CGTP); (b) PET reciclado/fibras de sisal/glicerol/OM/PBHL (CGMP).

Nas micrografias da Figura 61, observa-se a fragmentação da estrutura fibrilar das fibras, o que pode justificar os menores valores de resistência ao impacto de CGTP e CGMP, em comparação aos demais compósitos que apresentam fibras com estruturas fibrilares íntegras. Em compósitos em que a estrutura fibrilar das fibras permanece íntegra, há melhor distribuição da tensão aplicada sobre os materiais, apresentando melhores resistências ao impacto (RAMIRES, 2010).

A Figura 62 apresenta as micrografias dos compósitos CG e CGM.

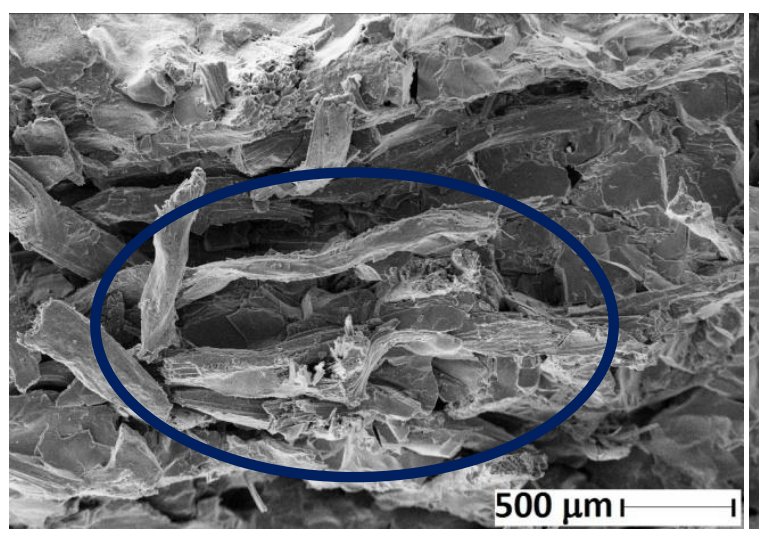

(a)

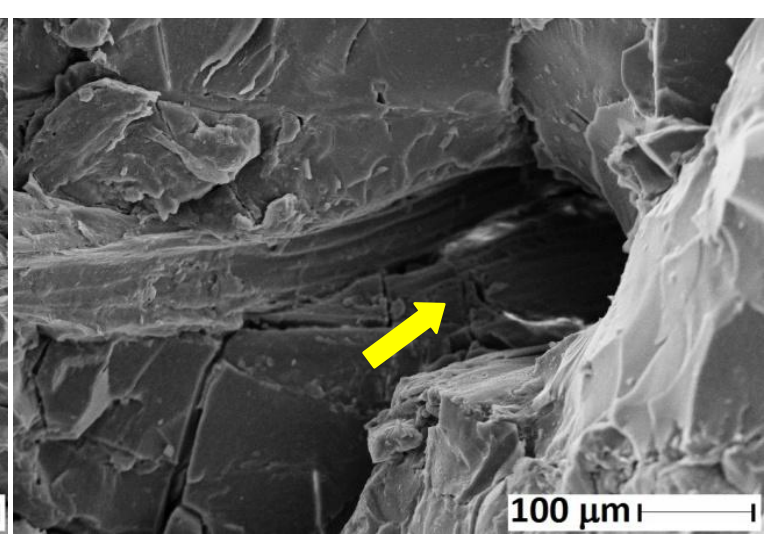

(b)

Figura 62. Micrografias das superfícies de fratura dos compósitos obtidos por moldagem por compressão: (a) PET reciclado/fibras de sisal/glicerol (CG); (b) PET reciclado/fibras de sisal/glicerol/OM (CGM).

Observa-se, na micrografia de CGM (Figura 62-b), o mecanismo de pull-out, em que há o arrancamento da fibra do interior da matriz, geralmente após a propagação de uma trinca. A presença deste mecanismo é um indicativo que nestas regiões a adesão fibra-matriz na interface foi fraca. 
Na Figura 63 são apresentadas as micrografias dos compósitos processados por reometria de torque e posterior termoprensagem.

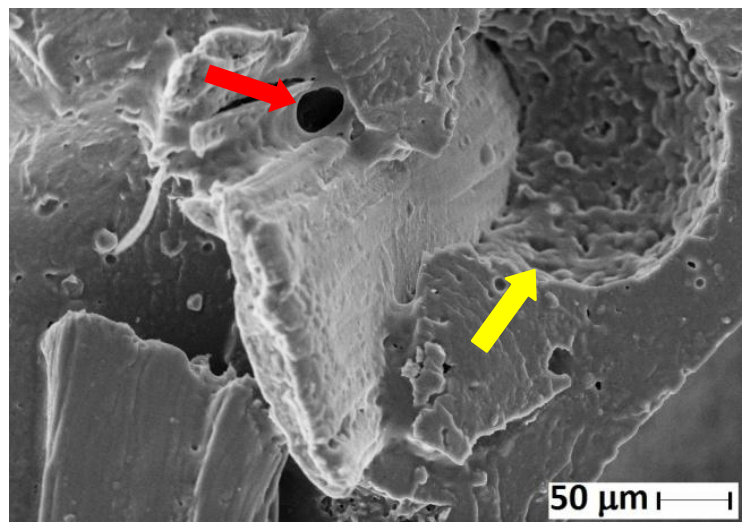

(a)

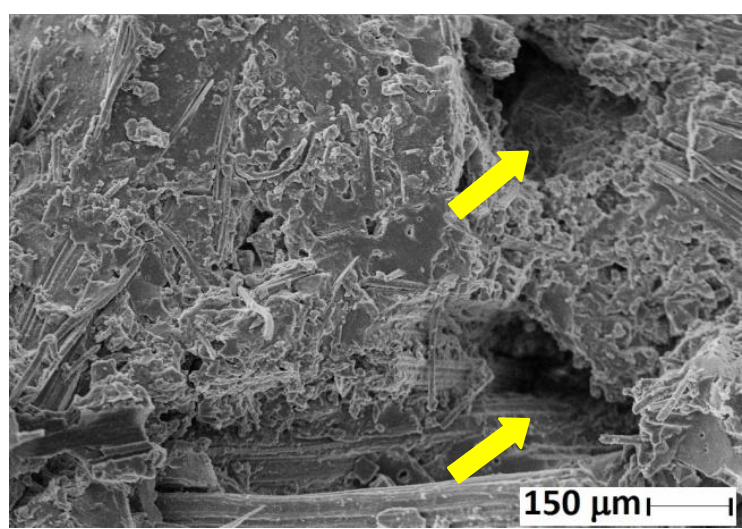

(c)

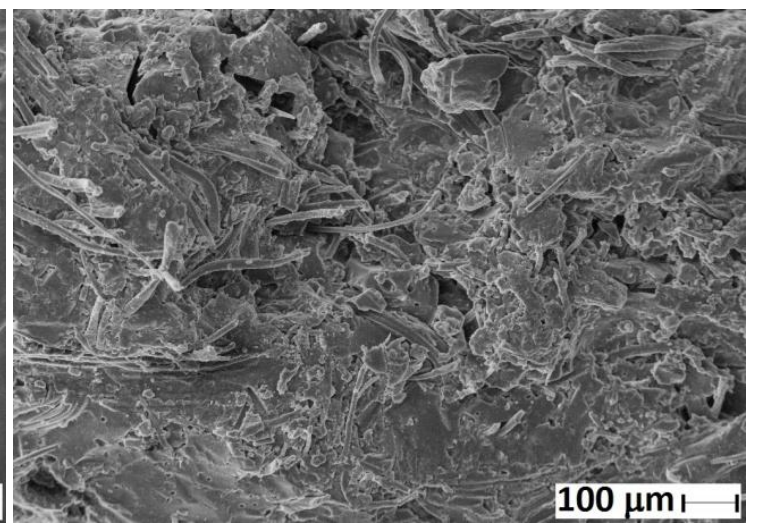

(b)

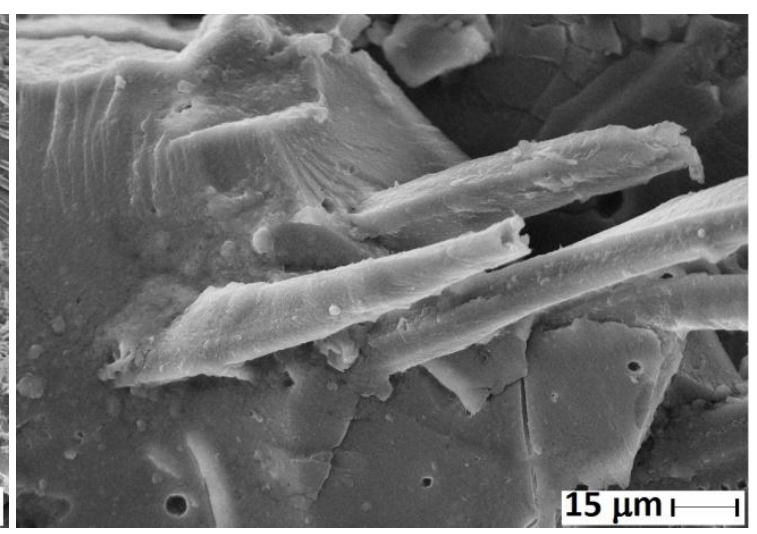

(d)

Figura 63. Micrografias das superfícies de fratura dos compósitos obtidos por reometria de torque e posterior termoprensagem: (a) PET reciclado/fibras de sisal (CH); (b), (c) e (d) PET reciclado/fibras de sisal/glicerol/OM (CHGM).

Na micrografia de CH, Figura 63-a, se observa a presença de poro (indicado por seta amarela), devido à saída de voláteis durante o processamento. Observa-se também a presença de "vazio" (indicado por seta vermelha), possivelmente também devido à saída de voláteis. Na micrografia da Figura 63-b, pode-se observar que CHGM apresentou uma distribuição homogênea das fibras pela matriz, sem a presença de aglomerados e emaranhados de fibras. Observa-se também em CHGM, com destaque para a Figura 63-d, que as fibras de sisal apresentaram-se como fibrilas, devido à fragmentação e consequente desfibrilamento das fibras. Este fenômeno, que ocorre com as fibras em CHGM, pode ser atribuído ao processamento por reometria de torque, com elevada taxa cisalhante, e devido à pulverização da mistura pré-termoprensagem, com o auxílio de um moinho de facas. 0 valor de resistência ao impacto, apresentado por este compósito $\left(13 \mathrm{~J} \mathrm{~m}^{-1}\right)$, pode ser devido a uma distribuição de tensão aplicada ao material 
menos efetiva, como consequência da fragmentação das fibras em fibrilas. Na micrografia de CHGM da Figura 63-c, pode-se observar também o mecanismo de pullout (indicado por setas amarelas), revelando uma mais fraca adesão fibra-matriz em algumas regiões.

\subsubsection{Absorção de água}

Os compósitos preparados por moldagem por compressão, assim como a placa controle de PET reciclado (CTRPET), foram avaliados em relação à afinidade destes materiais com a água. Neste ensaio de absorção de água, os corpos de prova foram imersos em água, até que estes atingissem um estado de saturação. As condições adotadas no presente trabalho foram mais drásticas em relação às normalmente utilizadas para este tipo de ensaio. No presente trabalho, corpos de prova dos compósitos foram imersos em água sem nenhuma proteção lateral. Usualmente, testes de absorção de água são aplicados a compósitos protegidos lateralmente por revestimentos, assim as fibras naturais não são expostas lateralmente. Ainda, estes materiais são, no geral, sujeitos somente à umidade do ar, sem a devida imersão em água (DA SILVA, 2011).

Na Figura 64, encontra-se o gráfico que mostra os resultados obtidos referentes aos testes de absorção de água dos compósitos após $1 \mathrm{~h}$ de imersão. Destaca-se que os testes de absorção de água foram realizados até que se completassem aproximadamente 750 h de imersão. No entanto, analisando-se os resultados obtidos, observou-se que, após $1 \mathrm{~h}$ de imersão, os corpos de prova já haviam atingido seu ponto de saturação. Pode-se concluir, portanto, que a máxima absorção de água pelos compósitos ocorreu até aproximadamente $1 \mathrm{~h}$ de imersão, sendo que após este período, não foi mais observado variação significativa no teor de água absorvida. Este fato devese, provavelmente, dentre outros fatores, à presença de vazios nos materiais devido à volatilização dos plasticizantes durante o processamento, os quais foram responsáveis pela penetração e permanência de um maior número de moléculas de água, gerando, também, consequente maior absorção destas pelas fibras (PAIVA; FROLLINI, 2002). 


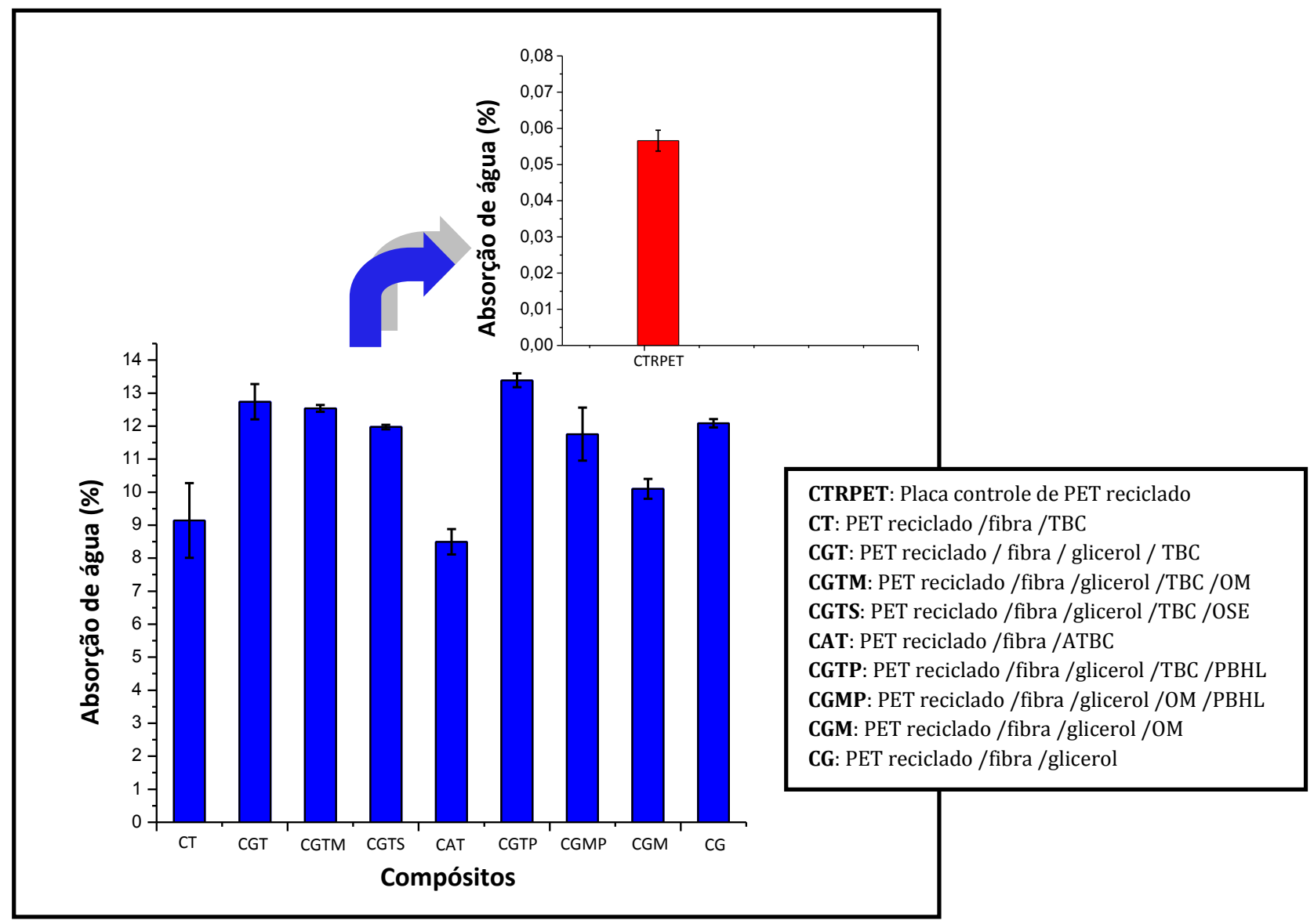

Figura 64. Absorção de água, após 1 h de imersão (temperatura ambiente), da placa controle de PET reciclado (CTRPET) e dos compósitos CT, CGT, CGTM, CGTS, CAT, CGTP, CGMP, CG, CGM obtidos por moldagem por compressão.

Analisando-se o gráfico da Figura 64, pode-se observar que CTRPET apresentou máxima absorção de água de 0,057\%. Assim, o teor de água absorvida por CTRPET é baixo em comparação aos compósitos, e pode inclusive ser considerado insignificante frente ao conteúdo de água absorvido pelos compósitos, os quais contêm fibras e plasticizantes em sua composição. As fibras e os plasticizantes, por apresentarem grupos polares que favorecem uma maior interação com as moléculas de água, podem ser considerados os grandes responsáveis pela maior absorção de água apresentada pelos compósitos em relação à CTRPET.

Pode-se observar que CT e CAT, contendo respectivamente os plasticizantes TBC e ATBC, apresentaram, no geral, a menor absorção de água dentre os demais compósitos. Destaca-se que, em relação aos outros compósitos, estes foram os únicos a não apresentar glicerol em suas composições, o qual possui um grande caráter hidrofílico (Figura 23), o que lhe confere responsabilidade na superior absorção de água pelos demais compósitos CGT, CGTM, CGTS, CGTP, CGMP, CGM e CG. A ligeira 
diferença encontrada na absorção de água entre CT e CAT, com um valor superior para o primeiro compósito, deve-se, provavelmente, ao fato de CT possuir um grupo hidroxila, o qual está acetilado em CAT, tornando o primeiro compósito mais hidrofílico. Esta diferença vem em direção a tornar o compósito com TBC (Figura 18) mais hidrofílico que o compósito com ATBC (Figura 17), gerando maior absorção de água na primeira hora de teste, o que pode ser observado na Figura 64.

Pode-se observar, na Figura 64, que o compósito CGTP contendo glicerol, TBC e PBHL (Figura 25), foi o que mais absorveu água, no período considerado. Os componentes utilizados como plasticizantes neste compósito (glicerol, TBC e PBHL) podem ser considerados de grande caráter hidrofílico, visto que estes apresentam grupos hidroxilas disponíveis, aumentando a higroscopicidade do material em questão. Neste sentido, observa-se que sem a adição de PBHL, o compósito CGT (com apenas glicerol e TBC) apresentou a segunda maior absorção de água. Na sequência, para os compósitos CGTM, CGTS, os quais apresentaram semelhantes valores de absorção de água, observa-se que, a adição do óleo de mamona (Figura 24) e OSE (Figura 23), resultou em menor absorção de água em relação aos compósitos anteriores. Estes óleos, aqui considerados, possuem um alto caráter hidrofóbico, devido as suas extensas cadeias hidrocarbônicas apolares, o que justifica esta diminuição no caráter higroscópico dos compósitos. Em contrapartida, o óleo de mamona, o qual é constituído em quase sua totalidade por ésteres de ácido ricinoléico (Figura 24), apresenta hidroxilas em sua estrutura, garantindo maior absorção de água para CGTM em relação à CGTS.

Observa-se que para os demais compósitos, os quais não possuem TBC em suas composições, CG foi o que apresentou maior absorção de água, seguido de CGMP e CGM. Nota-se que, novamente, a adição de óleo de mamona na composição dos compósitos, levou à diminuição do caráter hidrofílico do material. Entretanto, a adição de PBHL ao compósito, garantiu por sua vez maior caráter higroscópico a CGMP, o que pode ser claramente conferido na Figura 64. 


\section{Conclusões}

Pode-se concluir que, como pretendido, viabilizou-se o preparo de compósitos de PET reciclado/fibras de sisal, com a adição de diferentes tipos e misturas de plasticizantes, possibilitando o processamento dos materiais a temperaturas inferiores à $\mathrm{T}_{\mathrm{m}}$ do polímero, com consequente redução dos efeitos de decomposição térmica das fibras.

O uso da técnica de processamento por moldagem por compressão levou a compósitos com melhores propriedades mecânicas do que as apresentadas pelos materiais preparados por reometria de torque e posterior termoprensagem. Também foi possível, através do processamento por moldagem por compressão, a utilização de fibras longas (3 cm de comprimento) em comparação às fibras utilizadas no processamento por reometria de torque (5 $\mathrm{mm}$ de comprimento), visando uma diminuição da concentração de pontas, as quais podem atuar como concentradores de tensão, prejudiciais às propriedades mecânicas dos compósitos.

Dentre os compósitos, pode-se considerar que CGT, contendo em sua composição a mistura de plasticizantes glicerol e TBC, apresentou o melhor desempenho mecânico, que levou, no geral, a bons resultados de resistência ao impacto (28 $\left.\mathrm{J} \mathrm{m}^{-1}\right)$, resistência à flexão $(2,5 \mathrm{MPa})$ e boa deformação na ruptura $(0,90 \%)$ comparativamente aos outros compósitos. O compósito CT, contendo em sua composição o plasticizante TBC, apresentou um desempenho diferenciado frente aos demais compósitos, principalmente em relação à resistência à flexão $(2,8 \mathrm{MPa})$, ao baixo teor de água absorvida e por apresentar elevado módulo de armazenamento (771,5 $\mathrm{MPa})$.

Destaca-se que, em comparação aos compósitos, o polímero reciclado não reforçado (CTRPET) apresentou os melhores resultados no que diz respeito à resistência à flexão, módulo de flexão, absorção de água e maior módulo de armazenamento. Em relação à resistência ao impacto, CTRPET apresentou valor semelhante ao compósito CGT, e em relação também aos demais compósitos, apresentou um dos menores valores de deformação na ruptura, devido à sua elevada rigidez e ausência de plasticizantes em sua composição. 0 polímero não reforçado, assim como os compósitos preparados a partir dele, não apresentaram boa resistência ao impacto, ou seja, as características da matriz foram predominantes. No entanto, o uso 
de plasticizantes, além de viabilizar o processamento dos compósitos, possibilitou a obtenção de materiais, no geral, com elevada ductilidade e flexibilidade em comparação a CTRPET, analisando-se os resultados de resistência à flexão e DMTA. O uso de plasticizantes também aumentou a molhabilidade das fibras de sisal pelo PET reciclado, devido à diminuição da viscosidade do polímero.

As imagens de MEV das superfícies de fratura dos compósitos corroboram o que foi concluído anteriormente, demonstrando, no geral, uma boa adesão na interface fibra-matriz, indício da atuação também dos plasticizantes como compatibilizantes entre a fibra e a matriz, como foi pretendido no presente estudo.

Ainda, em relação aos diferentes tipos e misturas de plasticizantes utilizados na composição dos compósitos, pode-se concluir que a absorção de água pelos materiais deveu-se à natureza hidrofílica das fibras e de alguns destes aditivos. Destaca-se que em determinadas aplicações, peças preparadas a partir de compósitos que contenham componente hidrofílico recebem camadas de revestimentos hidrofóbicos na superfície, viabilizando a aplicação, por exemplo, em ambientes úmidos.

Assim, em linhas gerais, pode-se concluir que os objetivos traçados para o presente trabalho foram atingidos, visando à valorização das fibras lignocelulósicas de sisal e a reciclagem do PET. Foi desenvolvida metodologia para o preparo de compósitos de PET reciclado reforçados com fibras de sisal (15\%), em temperaturas inferiores à de decomposição térmica das fibras, por meio do uso de plasticizantes de origem natural. Portanto, os resultados obtidos mostraram que compósitos de PET reciclado/fibras de sisal podem ser preparados, gerando produtos finais com elevado valor agregado e alto teor de matéria-prima obtida de fonte renovável. Os materiais preparados neste estudo se adequam às aplicações em que a resistência ao impacto não corresponda a critério para seleção de material. 0 aumento da resistência ao impacto em compósitos baseados em PET reciclado exige futuras explorações no assunto. 


\section{Sugestões para trabalhos futuros}

- A partir dos resultados do presente estudo, os parâmetros de processamento dos compósitos poderão ser otimizados, visando reduzir de forma significativa o tempo total de processamento dos mesmos.

- Investigação para que sejam minimizadas as perdas de plasticizantes durante o processamento dos compósitos, assim como a determinação de uma concentração mínima de plasticizantes que possibilite a obtenção de compósitos com boas propriedades mecânicas.

- Estudo no sentido de comparar a influência do processo de reciclagem do PET sobre as propriedades dos compósitos, através da preparação e caracterização de compósitos preparados a partir de PET virgem, fibras de sisal e plasticizantes.

- Preparação de compósitos de PET reciclado/fibras de sisal com a utilização de outros plasticizantes/compatibilizantes oriundos de fontes renováveis, assim como uso de outros comprimentos e proporções de fibras, visando melhorar as propriedades mecânicas dos compósitos. 


\section{Referências Bibliográficas}

ADVANI, S. G.; SOZER, E. M. Process Modeling in Composites Manufacturing. New York: Marcel Dekker, Inc, 2003. p. 250.

AHMED, A.; ALEXANDROU, A. N. Compression molding using a generalized eulerianlagrangian formulation with automatic remeshing. Advances in Polymer Technology, v. 11, n. 3, p. 203-211, 1992.

AKRAM KHAN, M.; GURU, S.; PADMAKARAN, P.; MISHRA, D.; MUDGAL, M.; DHAKAD, S. Characterisation Studies and Impact of Chemical Treatment on Mechanical Properties of Sisal Fiber. Composite Interfaces, v. 18, n. 6, p. 527-541, 2011.

ALAM, A. K. M. M.; SHUBHRA, Q. T. H.; AL-IMRAN, G.; BARAI, S.; ISLAM, M. R.; RAHMAN, M. M. Preparation and characterization of natural silk fiber-reinforced polypropylene and synthetic $E$ glass fiber-reinforced polypropylene composites: a comparative study. Journal of Composite Materials, v. 45, n. 22, p. 2301-2308, 2011.

ALVES, R. M. V.; OLIVEIRA, L. M.; COLTRO, L.; GARCIA, E. E. C.; SARANTOPOULOS, C. I. G. L.; PADULA, M. Ensaios para avaliação de embalagens plásticas rígidas. Campinas, 1998. 340 p.

ANUAR, H.; AHMAD, S. H.; RASID, R.; SURIP, S. N.; CZIGANY, T.; ROMHANY, G. Essential Work of Fracture and Acoustic Emission Study on TPNR Composites Reinforced by Kenaf Fiber. Journal of Composite Materials, v. 41, n. 25, p. 3035-3049, 2007.

BARBOZA, A. P. Influência de compatibilizantes interfaciais nas propriedades mecanicas de compositos de PET reciclado/fibra de vidro. 2003. 161 f. Dissertação (Mestrado em Engenharia de Materiais) - Departamento de Engenharia de Materiais, Universidade de São Paulo, São Carlos, 2003.

BARKOULA, N. M.; ALCOCK, B.; CABRERA, N. O.; PEIJS, T. Fatigue properties of highly oriented polypropylene tapes and all-polypropylene composites. Polymers and Polymer Composites, v. 16, n. 2, p. 101-113, 2008.

BARRY, R. P.; PELLEREAU, B. Bioriented film. US n. 5,241,030, 31 aug. 1993.

BILLMEYER JR., F. W. Ciencia de los polimeros. Barcelona: Editorial Reverte, 1995. 591 p. 300.

BRAHMAKUMAR, M.; PAVITHRAN, C.; PILLAI, R. M. Coconut fibre reinforced polyethylene composites: effect of natural waxy surface layer of the fibre on fibre/matrix interfacial bonding and strength of composites. Composites Science and Technology, v. 65, n. 3-4, p. 563-569, 2005. 
BRETAS, R. E. S.; D'AVILLA, M. A. Reologia de polímeros fundidos. São Carlos: EdUFSCAR, 2000. p. 123.

BUSCHLE-DILLER, G.; ZERONIAN, S. H. Enhancing the reactivity and strength of cotton fibers. Journal of Applied Polymer Science, v. 45, n. 6, p. 967-979, 1992.

CÁCERES, C. A.; CANEVAROLO JR., S. V. Correlação entre o Índice de Fluxo à Fusão e a Função da Distribuição de Cisão de Cadeia durante a degradação termo-mecânica do polipropileno.

Polímeros, v. 16, p. 294-298, 2006.

CALLISTER JR., W. D. Ciência e Engenharia de Materiais: Uma Introdução. Rio de Janeiro: LTC, 2002. p. 310.

CAMPOS, A. D.; TEODORO, K. B. R.; MARCONCINI, J. M.; MATTOSO, L. H. C.; MARTINS-FRANCHETTI, S. $M$. Efeito do tratamento das fibras nas propriedades do biocompósito de amido termoplástico/policaprolactona/sisal. Polímeros, v. 21, p. 217-222, 2011.

CANEVAROLO JR., S.V. Ciência dos Polímeros: um texto básico para tecnólogos e engenheiros. São Paulo: Artliber, 2006. p. 110.

CANEVAROLO JR., S. V. Técnicas de Caracterização de Polímeros. São Paulo: Ed. Artliber, 2007. p. 213.

CAÑIGUERAL, N.; VILASECA, F.; MÉNDEZ, J. A.; LÓPEZ, J. P.; BARBERÀ, L.; PUIG, J.; PÈLACH, M. A.; MUTJÉ, $P$. Behavior of biocomposite materials from flax strands and starch-based biopolymer. Chemical Engineering Science, v. 64, n. 11, p. 2651-2658, 2009.

CHAWLA, K. K. Composites Materials. New York: Springer, 1998. p. 304.

CHEGOLYA, A. S.; SHEVCHENKO, V. V.; MIKHAILOV, G. D. FORMATION OF POLYETHYLENE TEREPHTHALATE IN THE PRESENCE OF DICARBOXYLIC ACIDS. J Polym Sci Polym Chem Ed, v. 17, n. 3, p. 889-904, 1979.

CHEN, S. C.; CHEN, Y. C.; CHENG, N. T. Simulation of injection-compression moldfilling process. International Communications in Heat and Mass Transfer, v. 25, n. 7, p. 907-917, 1998.

CHIELLINI, E.; CINELLI, P.; IMAM, S. H.; MAO, L. Composite Films Based on Biorelated Agro-Industrial Waste and Poly(vinyl alcohol). Preparation and Mechanical Properties Characterization. Biomacromolecules, v. 2, p. 1029-1037, 2001.

CHILDS, W. I. Molding, compression. In: International Encyclopedia of Composites. New York: VCH Publishers, 1990. v. 3, p. 458-465. 
CONCEIÇÃO, M. M.; CANDEIA, R. A.; SILVA, F. C.; BEZERRA, A. F.; FERNANDES, V. J.; SOUZA, A. G. Thermoanalytical characterization of castor oil biodiesel. Renewable and Sustainable Energy Reviews, v. 11, n. 5, p. 964-975, 2007.

CORRADINI, E.; ITO, E. N.; MARCONCINI, J. M.; RIOS, C. T.; AGNELLI, J. A. M.; MATTOSO, L. H. C. Interfacial behavior of composites of recycled poly(ethyelene terephthalate) and sugarcane bagasse fiber. Polymer Testing, v. 28, n. 2, p. 183-187, 2009.

COSTA, H. M.; RAMOS, V. D.; ABRANTES, T. A. S.; CASTRO, D. F.; VISCONTE, L. Y.; NUNES, R. C. R.; FURTADO, C. R. G. Efeito do Óleo de Mamona em Composições de Borracha Natural Contendo Sílica. Polímeros: Ciência e Tecnologia, v. 14, n. 1, p. 46-50, 2004.

COUTINHO, F. M. B.; COSTA, M. P. M.; GUIMARÃES, M. J. O. C.; SOARES, B. G. Estudo comparativo de diferentes tipos de polibutadieno na tenacificação de poliestireno. Polímeros, v. 17, p. 318-324, 2007.

CRESPO, J. E.; SANCHEZ, L.; GARCIA, D.; LOPEZ, J. Study of the Mechanical and Morphological Properties of Plasticized PVC Composites Containing Rice Husk Fillers. Journal of Reinforced Plastics and Composites, v. 27, n. 3, p. 229-243, 2007.

DA SILVA, C. G. Bagaço de cana de açúcar como reforço de matrizes termorrígidas baseadas em macromoléculas de ligninas. 2011. 220 f. Tese (Doutorado em Ciências) - Instituto de Química de São Carlos, Universidade de São Paulo, São Carlos, 2011.

DE CARVALHO, L. H.; CAVALCANTI, W. S. Propriedades Mecânicas de Tração de Compósitos Poliéster/Tecidos Híbridos Sisal/Vidro. Polímeros: Ciência e Tecnologia, v. 16, n. 1, p. 33-37, 2006.

DE CASTRO, D. O. Biocompósitos a partir de biopolietileno de alta densidade reforçados por fibras de curauá. 2010. 125 f. Dissertação (Mestrado em Ciências) - Instituto de Química de São Carlos, Universidade de São Paulo, São Carlos, 2010.

DE CASTRO, D. O.; RUVOLO-FILHO, A.; FROLLINI, E. Compósitos de biopolietileno de alta densidade reforçados por fibra de curauá usando como agente de acomplamento polibutadieno hidroxilado líquido e óleo de mamona. In: $11^{\circ}$ Congresso Brasileiro de Polímeros, 26, 2011, Campos do Jordão. Livro de Resumos.: São Carlos: Associação Brasileira de Polímeros, 2011.

DE OLIVEIRA, F. Lignosulfonato de sódio como agente de modificação de superfícies de fibras lignocelulósicas e da formulação de termorrígo fenólico. 2010. 137 f. Dissertação (Mestrado em Ciências) - Instituto de Química de São Carlos, Universidade de São Paulo, São Carlos, 2010.

DE PAOLI, M. A. Degradação e estabilização de polímeros. São Paulo: Artliber, 2008. p. 200. 
DE SOUSA, M. V.; MONTEIRO, S. N.; D'ALMEIDA, J. R. M. Evaluation of pre-treatment, size and molding pressure on flexural mechanical behavior of chopped bagasse-polyester composites. Polymer Testing, v. 23, n. 3, p. 253-258, 2004.

DEDAVID, B. A.; GOMES, C. I.; MACHADO, G. Microscopia eletrônica de varredura : aplicações e preparação de amostras : materiais poliméricos, metálicos e semicondutores. Porto Alegre: EDIPUCRS, 2007, 2007. p. 112.

DEVI, L. U.; BHAGAWAN, S. S.; THOMAS, S. Dynamic mechanical properties of pineapple leaf fiber polyester composites. Polymer Composites, v. 32, n. 11, p. 1741-1750, 2011.

DONMEZ ÇAVDAR, A.; KALAYCIOGLU, H.; MENGELOGLU, F. Tea mill waste fibers filled thermoplastic composites: the effects of plastic type and fiber loading. Journal of Reinforced Plastics and Composites, v. 30, n. 10, p. 833-844, 2011.

DOS SANTOS, A. C. Estudo da reciclagem do poli (tereftalato) de etileno- PET pós-consumo e de suas propriedades quando submetido à radiação ionizante. 2008. Dissertação (Mestrado em Ciências na Área de Tecnologia Nuclear) - Instituto de Pesquisa e Energia Nuclear, Universidade de São Paulo, São Paulo, 2008.

DOS SANTOS, P. A. Uso de fibras de curauá como agente de reforço para poliamida 6. 2006. $82 \mathrm{f}$. Dissertação (Mestrado em Físico-Química) - Instituto de Química, Universidade Estadual de Campinas, Campinas, 2006.

DUH, B. Reaction kinetics for solid-state polymerization of poly(ethylene terephthalate). Journal of Applied Polymer Science, v. 81, n. 7, p. 1748-1761, 2001.

DUH, B. Effect of antimony catalyst on solid-state polycondensation of poly(ethylene terephthalate). Polymer, v. 43, n. 11, p. 3147-3154, 2002.

EHRIG, R. J. Plastics recycling: products and processes. New York: Hanser Publishers, 1992. 452 p. 220.

FAULSTICH DE PAIVA, J. M.; FROLLINI, E. Unmodified and Modified Surface Sisal Fibers as Reinforcement of Phenolic and Lignophenolic Matrices Composites: Thermal Analyses of Fibers and Composites. Macromolecular Materials and Engineering, v. 291, n. 4, p. 405-417, 2006.

FAVARO, S. L. Chemical, morphological and mechanical analysis of sisal fiber-reinforced recycled high-density polyethylene composites. eXPRESS Polymer Letters, v. 4, n. 8, p. 465-473, 2010.

FENGEL, D.; WEGENER, G. Wood: chemistry, ultrastructure, reactions. New York: Walter de Gruyter, 1989. p. 340. 
FERNANDEZ, M. P.; IKONOMOU, M. G.; BUCHANAN, I. An assessment of estrogenic organic contaminants in Canadian wastewaters. Science of The Total Environment, v. 373, n. 1, p. 250-269, 2007.

FOLLMANN, E. D. M. Utilização de derivados da glicerina na produção de plastificantes. 2009. 140 f. Dissertação (Mestrado em Ciências) - Departamento de Química, Universidade Federal do Paraná, Curitiba, 2009.

FONSECA, V. M.; FERNANDES, V. J.; DE CARVALHO, L. H.; D'ALMEIDA, J. R. M. Evaluation of the mechanical properties of sisal-polyester composites as a function of the polyester matrix formulation. Journal of Applied Polymer Science, v. 94, n. 3, p. 1209-1217, 2004.

FOWLER, P. A.; HUGHES, J. M.; ELIAS, R. M. Biocomposites: Technology, environmental credentials and market forces. Journal of the Science of Food and Agriculture, v. 86, n. 12, p. 1781-1789, 2006.

FROLLINI, E. Lignina como substituta parcial do fenol em espumas e compósitos reforçados com fibras lignocelulósicas. 2002. 325 f. Tese (Livre-Docência) - Instituto de Química de São Carlos, Universidade de São Paulo, São Carlos, 2002.

FROMME, H.; KÜCHLER, T.; OTTO, T.; PILZ, K.; MÜLLER, J.; WENZEL, A. Occurrence of phthalates and bisphenol $A$ and $F$ in the environment. Water Research, v. 36, n. 6, p. 1429-1438, 2002.

GEORGOPOULOS, S. T.; TARANTILI, P. A.; AVGERINOS, E.; ANDREOPOULOS, A. G.; KOUKIOS, E. E. Thermoplastic polymers reinforced with fibrous agricultural residues. Polymer Degradation and Stability, v. 90, p. 303-312, 2005.

GIACOMINI, N. P. Compósitos com fibras naturais para a indústria automobilística. 2003. $168 \mathrm{f}$. Dissertação (Mestrado em Ciência e Engenharia de Materais) - Instituto de Química de São Carlos, Universidade de São Paulo, São Carlos, 2003.

GRISA, A. M. C.; SIMIONI, T.; CARDOSO, V.; ZENI, M.; BRANDALISE, R. N.; ZOPPAS, B. C. D. A. Degradação biológica do PVC em aterro sanitário e avaliação microbiológica. Polímeros, v. 21, p. 210-216, 2011.

GUIMARÃES, J. L.; WYPYCH, F.; SAUL, C. K.; RAMOS, L. P.; SATYANARAYANA, K. G. Studies of the processing and characterization of corn starch and its composites with banana and sugarcane fibers from Brazil. Carbohydrate Polymers, v. 80, n. 1, p. 130-138, 2010.

HABIBI, Y.; EL-ZAWAWY, W. K.; IBRAHIM, M. M.; DUFRESNE, A. Processing and characterization of reinforced polyethylene composites made with lignocellulosic fibers from Egyptian agro-industrial residues. Composites Science and Technology, v. 68, n. 7-8, p. 1877-1885, 2008. 
HAINES, P. J. Thermal Methods of Analysis - Principles, Aplications and Problems. London: Champman and Hall, 1995. 235 p. 214.

HARPER, R. C.; PUGH, J. H. Thermoforming of thermoplastics matrix composites. In: International Encyclopedia of Composites. New York: VCH: Publishers, 1990. v. 5, p. 496-530.

HEMMINGER, W.; SARGE, S. M. Calibration as an aspect of quality assurance in differential scanning calorimetry (DSC) measurements. Thermochimica Acta, v. 245, n. C, p. 181-187, 1994.

HERAKOVICH, C. T. Mechanics of Fibrous Composites. New York: John Wiley, 1998. p. 350.

HERRMANN, M.; ENGEL, W.; EISENREICH, N. Thermal expansion, transitions, sensitivities and burning rates of HMX. Propellants, Explosives, Pyrotechnics, v. 17, n. 4, p. 190-195, 1992.

HEUDORF, U.; MERSCH-SUNDERMANN, V.; ANGERER, J. Phthalates: Toxicology and exposure. International Journal of Hygiene and Environmental Health, v. 210, n. 5, p. 623-634, 2007.

HUQ, T.; KHAN, A.; AKTER, T.; NOOR, N.; DEY, K.; SARKER, B.; SAHA, M.; KHAN, R. A. Thermomechanical, Degradation, and Interfacial Properties of Jute Fiber-reinforced PET-based Composite. Journal of Thermoplastic Composite Materials, v. 24, n. 6, p. 889-898, 2011.

HUQ, T.; KHAN, A.; NOOR, N.; SAHA, M.; KHAN, R. A.; KHAN, M. A.; GAFUR, M. A. Comparative Studies on the Mechanical, Degradation and Interfacial Properties between Jute and E-Glass FiberReinforced PET Composites. Polymer-Plastics Technology and Engineering, v. 49, n. 11, p. 11281135, 2010.

HUTCHINSON, J. M. The Physics of Glassy Polymers. London: Chapman and Hall, 1997. p. 300.

IANNACE, S.; ALI, R.; NICOLAIS, L. Effect of processing conditions on dimensions of sisal fibers in thermoplastic biodegradable composites. Journal of Applied Polymer Science, v. 79, n. 6, p. 10841091, 2001.

ISMAIL, H.; JAFFRI, R. M.; ROZMAN, H. D. Oil palm wood flour filled natural rubber composites: The effects of various bonding agents. International Journal of Polymeric Materials, v. 49, n. 3, p. 311322, 2001.

ISOLDI, A. B. G. Estudo do efeito da dose de rádioesterilização sobre as propriedades do poli(tereftalato) de etileno - PET reciclado. 2003. 72 f. Dissertação (Mestrado em Ciências na Área de Tecnologia Nuclear - Aplicações) - Instituto de Pesquisas Energéticas e Nucleares, Universidade de São Paulo, São Paulo, 2003. 
JACOB, M.; THOMAS, S.; VARUGHESE, K. T. Mechanical properties of sisal/oil palm hybrid fiber reinforced natural rubber composites. Composites Science and Technology, v. 64, n. 7-8, p. 955-965, 2004.

JOHN, M. J.; THOMAS, S. Biofibres and biocomposites. Carbohydrate Polymers, v. 71, p. 343-364, 2008.

JOSHI, S. V.; DRZAL, L. T.; MOHANTY, A. K.; ARORA, S. Are natural fiber composites environmentally superior to glass fiber reinforced composites? Composites Part A: Applied Science and Manufacturing, v. 35, n. 3, p. 371-376, 2004.

KIM, J.-K.; MAI, Y.-W. High strength, high fracture toughness fibre composites with interface control-A review. Composites Science and Technology, v. 41, n. 4, p. 333-378, 1991.

KOTSIKOS, G.; GIBSON, A. G. Investigation of the squeeze flow behaviour of Sheet Moulding Compounds (SMC). Composites Part A: Applied Science and Manufacturing, v. 29, n. 12, p. 15691577, 1998.

KRAUSKOPF, L. G.; GODWIN, A. D. Plasticizer factors influencing take-up by PVC resins. Journal of Vinyl and Additive Technology, v. 5, n. 2, p. 107-112, 1999.

KUSHWAHA, P. K.; KUMAR, R. Studies on Water Absorption of Bamboo-Polyester Composites: Effect of Silane Treatment of Mercerized Bamboo. Polymer-Plastics Technology and Engineering, $\mathrm{v}$. 49, n. 1, p. 45-52, 2009.

LAI, S. M.; YEH, F. C.; WANG, Y.; CHAN, H. C.; SHEN, H. F. Comparative study of maleated polyolefins as compatibilizers for polyethylene/wood flour composites. Journal of Applied Polymer Science, v. 87, n. 3, p. 487-496, 2002.

LAUNAY, A.; THOMINETTE, F.; VERDU, J. Hydrolysis of poly(ethylene terephthalate): a kinetic study. Polymer Degradation and Stability, v. 46, n. 3, p. 319-324, 1994.

LEE, C.-C.; FOLGAR, F.; TUCKER, C. L. Simulation of Compression Molding for Fiber-Reinforced Thermosetting Polymers. Journal of Engineering for Industry, v. 106, n. 2, p. 114-125, 1984.

LI, Y.; MAI, Y.-W.; YE, L. Sisal fibre and its composites: a review of recent developments. Composites Science and Technology, v. 60, n. 11, p. 2037-2055, 2000.

LIMA, A. C.; MONTEIRO, S. N.; SATYANARAYANA, K. G. Recycled Polyethylene Composites Reinforced with Jute Fabric from Sackcloth: Part II-Impact Strength Evaluation. Journal of Polymers and the Environment, v. 19, n. 4, p. 957-965, 2011. 
LODI, P. C. Aspectos de degradação de geomembranas poliméricas de polietileno de alta densidade (PEAD) e poli (cloreto de vinila) (PVC). 2003. $354 \mathrm{f}$. Tese (Doutorado em Geotecnia) Departamento de Geotecnia, Universidade de São Paulo, São Carlos, 2003.

LUCAS, E. F.; SOARES, B. G.; MONTEIRO, E. E. C. Caracterização de Polímeros, Determinação de Peso Molecular e Análise térmica. Rio de Janeiro: E-papers Serviços Editoriais Ltda., 2001. p. 220.

LUSINCHI, J. M.; BOUTEVIN, B.; TORRES, N.; ROBIN, J. J. In situ compatibilization of HDPE/PET blends. Journal of Applied Polymer Science, v. 79, n. 5, p. 874-880, 2001.

MADALENO, E.; ROSA, D. S.; ZAWADZKI, S. F.; PEDROZO, T. H.; RAMOS, L. P. Composições de PVC. Polímeros: Ciência e Tecnologia, v. 19, n. 4, p. 7, 2009a.

MADALENO, E.; ROSA, D. S.; ZAWADZKI, S. F.; PEDROZO, T. H.; RAMOS, L. P. Estudo do uso de plastificantes de fontes renovável em composições de PVC. Polímeros, v. 19, p. 263-270, 2009b.

MANCINI, S. D.; BEZERRA, M. N.; ZANIN, M. Reciclagem de PET adivindo de garrafas de refrigerante pós-consumo. Polímeros: Ciência e Tecnologia, p. 68-75, 1998.

MANCINI, S. D.; ZANIN, M. Influência de Meios Reacionais na Hidrólise de PET Pós-Consumo. Polímeros, v. 12, p. 34-40, 2002.

MANO, H. Polímeros como materiais de engenharia. São Paulo: Edgar Blücher Ltda, 1991. 140 p. 110.

MARCONCINI, J. M.; RUVOLO FILHO, A. Análise termodinâmica do comportamento mecânico na região elástica de blendas de poli (tereftalato de etileno) reciclado e poliolefinas recicladas. Polímeros, v. 16, p. 323-331, 2006.

MARTIN, A. R.; MARTINS, M. A.; DA SILVA, O. R. R. F.; MATTOSO, L. H. C. Studies on the thermal properties of sisal fiber and its constituents. Thermochimica Acta, v. 506, n. 1-2, p. 14-19, 2010.

MATTHEWS, F. L.; RAWLINGS, R. D. Composites Materials: engineering and science. New York: Chapman\&Hall, 1994. p. 320.

MEGIATTO, J. D. Fibras de Sisal: Estudo de propriedades e modificações químicas visando aplicação em compósitos de matriz fenólica. 2006. 272 f. Tese (Doutorado em Ciências) - Instituto de Química de São Carlos, Universidade de São Paulo, São Carlos, 2006.

MEGIATTO, J. D.; RAMIRES, E. C.; FROLLINI, E. Phenolic matrices and sisal fibers modified with hydroxy terminated polybutadiene rubber: Impact strength, water absorption, and morphological aspects of thermosets and composites. Industrial Crops and Products, v. 31, n. 1, p. 178-184, 2010. 
MOHANTY, A. K.; MISRA, M.; DRZAL, L. T. Natural fibers, biopolymers, and biocomposites. Boca Raton: CRC Press, 2005. p. 330.

MOHSIN, M.; HOSSIN, A.; HAIK, Y. Thermal and mechanical properties of poly(vinyl alcohol) plasticized with glycerol. Journal of Applied Polymer Science, v. 122, n. 5, p. 3102-3109, 2011.

MONTEIRO, S.; LOPES, F.; FERREIRA, A.; NASCIMENTO, D. Natural-fiber polymer-matrix composites: Cheaper, tougher, and environmentally friendly. JOM Journal of the Minerals, Metals and Materials Society, v. 61, n. 1, p. 17-22, 2009.

MURAYAMA, T. Encyclopedia of Polymer Science and Engineering. New York: John Wiley \& Sons, 1988. p. 230.

NABI SAHEB, D.; JOG, J. P. Natural fiber polymer composites: A review. Advances in Polymer Technology, v. 18, n. 4, p. 351-363, 1999.

NAKATANI, J.; HIRAO, M. Multicriteria Design of Plastic Recycling Based on Quality Information and Environmental Impacts. Journal of Industrial Ecology, v. 15, n. 2, p. 228-244, 2011.

NHLAPO, L. P.; LUYT, A. S. Thermal and mechanical properties of LDPE/sisal fiber composites compatibilized with functionalized paraffin waxes. Journal of Applied Polymer Science, v. 123, n. 6, p. 3627-3634, 2012.

NIU, H.; JIAO, X.; WANG, R.; ZHOU, H. Direct manufacturing of flax fibers reinforced low melting point PET composites from nonwoven mats. Fibers and Polymers, v. 11, n. 2, p. 218-222, 2010.

OLIVEIRA, J. A. Oligomerização e Policondensação em Estado Fundido do Poli(Tereftalato de Etileno) - Estudo Experimental e de Modelagem da Curva de Distribuição de Pesos Moleculares. 2006. 208 f. Tese (Doutorado em Engenharia Química) - Departamento de Engenharia Química, Universidade Federal do Rio de Janeiro, Rio de Janeiro, 2006.

OUAJAI, S.; SHANKS, R. A. Biocomposites of Cellulose Acetate Butyrate with Modified Hemp Cellulose Fibres. Macromolecular Materials and Engineering, v. 294, n. 3, p. 213-221, 2009.

PAIVA, J. M. F.; FROLLINI, E. Sugarcane bagasse reinforced phenolic and lignophenolic composites. Journal of Applied Polymer Science, v. 83, n. 4, p. 880-888, 2002.

FAULSTICH PAIVA, J. M.Compósitos de Matrizes Termorrígidas Fenólicas e Lignofenólicas Reforçadas com Fibras Vegetais. 2001. $266 \mathrm{f}$. Tese (Doutorado) - Programa Interunidades em Ciência e Engenharia de Materiais - IQSC/EESC/IFSC, Universidade de São Paulo, São Carlos, 2001 
PAUL, D.; GOODMAN, I.; KROSCHWITZ, J. I. Polyesters to Polypeptide Synthesis - Encyclopedia of Polymer Science and Engineering. New York: J. I. Kroschwitz, 1985. 740 p. 220.

PERNICONE, N.; CERBONI, M.; PRELAZZI, G.; PINNA, F.; FAGHERAZZI, G. An investigation on Pd/C industrial catalysts for the purification of terephthalic acid. Catalysis Today, v. 44, n. 1-4, p. 129135, 1998.

PO, R.; OCCHIELLO, E.; GIANNOTTA, G.; PELOSINI, L.; ABIS, L. New polymeric materials for containers manufacture based on PET/PEN copolyesters and blends. Polymers for Advanced Technologies, $\mathrm{v}$. 7, n. 5-6, p. 365-373, 1996.

RAHMAN, M. R.; HUQUE, M. M.; ISLAM, M. N.; HASAN, M. Improvement of physico-mechanical properties of jute fiber reinforced polypropylene composites by post-treatment. Composites Part A: Applied Science and Manufacturing, v. 39, n. 11, p. 1739-1747, 2008.

RAMIRES, E. C. Biocompósitos a partir de matrizes poliméricas baseadas em lignina, tanino e glioxal reforçadas com fibras naturais. 2010. 277 f. Tese (Doutorado em Ciências) - Instituto de Química de São Carlos, Universidade de São Paulo, São Carlos, 2010.

RATNA PRASAD, A. V.; MOHANA RAO, K. Mechanical properties of natural fibre reinforced polyester composites: Jowar, sisal and bamboo. Materials \& Design, v. 32, n. 8-9, p. 4658-4663, 2011.

RAVINDRANATH, K.; MASHELKAR, R. A. Polyethylene terephthalate-II. Engineering analysis. Chemical Engineering Science, v. 41, n. 12, p. 2969-2987, 1986.

RAZERA, I. A. T. Fibras lignocelulosicas como agente de reforco de compositos de matriz fenolica e lignofenolica. 2006. 167 f. Tese (Doutorado em Fisico-Quimica) - Instituto de Quimica de Sao Carlos, Universidade de Sao Paulo, Sao Carlos, 2006.

ROMÃO, W.; SPINACÉ, M. A. S.; DE PAOLI, M. A. Poli(Tereftalato de Etileno), PET: Uma Revisão Sobre os Processos de Síntese, Mecanismos de Degradação e sua Reciclagem. Polímeros: Ciência e Tecnologia, v. 19, n. 2, p. 121-132, 2009.

ROSÁRIO, F.; PACHEKOSKI, W. M.; SILVEIRA, A. P. J.; SANTOS, S. F. D.; JÚNIOR, H. S.; CASARIN, S. A. Resíduos de sisal como reforço em compósitos de polipropileno virgem e reciclado. Polímeros, $v$. 21, p. 90-97, 2011.

ROWELL, R.; SANADI, A.; CAULFIELD, D.; JACOBSON, R. Utilization of Natural Fibers in Plastic Composites: Problems and Opportunities. In: Lignocellulosic-Plastics Composites: Alcides L. Leão; Francisco X. Carvalho; Elisabete Frollini, 1997. v., p. 23-51. 
RUVOLO-FILHO, A.; CURTI, P. S. PET recycled and processed from flakes with different amount of water uptake: characterization by DSC, TG, and FTIR-ATR. Journal of Materials Science, v. 43, n. 4, p. 1406-1420, 2007.

SAIKIA, D. Investigations on Structural Characteristics, Thermal Stability, and Hygroscopicity of Sisal Fibers at Elevated Temperatures. International Journal of Thermophysics, v. 29, n. 6, p. 2215-2225, 2008.

SALAZAR, V. L. P.; LEÃO, A. L. Biodegradação das fibras de coco e de sisal aplicadas na indústria automotiva. Energia na Agricultura, v. 21, n. 2, p. 99-133, 2006.

SCHLEMMER, D.; SALES, M. J. A.; RESCK, I. S. Preparação, caracterização e degradação de blendas PS/TPS usando glicerol e óleo de buriti como plastificantes. Polímeros, v. 20, p. 6-13, 2010.

SCUDAMORE, R. J.; CANTWELL, W. J. The effect of moisture and loading rate on the interfacial fracture properties of sandwich structures. Polymer Composites, v. 23, n. 3, p. 406-417, 2002.

SEARS, J. K.; DARBY, J. R. The technology of Plasticizers. New York: John Wiley \& Sons, 1982. p. 310.

SEKI, Y.; SEVER, K.; ERDEN, S.; SARIKANAT, M.; NESER, G.; OZES, C. Characterization of Luffa cylindrica fibers and the effect of water aging on the mechanical properties of its composite with polyester. Journal of Applied Polymer Science, v. 123, n. 4, p. 2330-2337, 2012.

SILVERSTEIN, R. M.; BASSLER, G. C.; MORRIL, T. C. Identificacao espectrometrica decompostos organicos. Rio de Janeiro: Guanabara Koogan, 1994. p. 235.

SIMMCHEN, J.; VENTURA, R.; SEGURA, J. Progress in the removal of di-[2-ethylhexyl]-phthalate as plasticizer in blood bags. Transfus Med Rev, v. 26, n. 1, p. 27-37, 2012.

SPINACÉ, M. A. S. Poli(tereftalato de etileno): reprocessamento por extrusao e metodologias de caracterizacao. 2000. $122 \mathrm{f}$. Tese (Doutorado) - Instituto de Química, Universidade Estadual de Campinas, Campinas, 2000.

SURESH, S.; SENTHIL KUMAR, V. S. An Overview of Recent Research Works on the Forming of Thermoplastic Composite Sheets. Applied Mechanics and Materials, v. 117-119, p. 764-768, 2011.

TAJAN, M.; CHANUNPANICH, N.; TECHAWINYUTHAM, W.; LEEJARKPAI, T. Characterisation and Rheological Behavior of Recycled PET Modified by Chain Extending. In: 4th Thailand Materials Science and Technology Conference, Thailand Science Park Convention Center. Livro de Resumos., 2006.

TAKANO, E. H.; BUSSO, C.; GONÇALVES, E. A. L.; CHIERICE, G. O.; CATANZARO-GUIMARÃES, S. A.; CASTRO-PADRO, M. A. A. Inibição do desenvolvimento de fungos fitopatogênicos por detergente 
derivado de óleo da mamona (Ricinus communis). Ciência Rural, Santa Maria, v. 37, n. 5, p. 1235 1240, 2007.

TITA, S. P. S. Efeito dos tratamentos de superficie das fibras de bagaco de cana-de açúcar e sisal nas propriedades de compositos de matriz fenolica e lignofenolica. 2002. $202 \mathrm{f}$. Dissertacao (Mestrado em Fisico-Quimica) - Instituto de Quimica de Sao Carlos, Universidade de São Paulo, São Carlos, 2002.

TRINDADE, W. G.; HOAREAU, W.; MEGIATTO, J. D.; RAZERA, I. A. T.; CASTELLAN, A.; FROLLINI, E. Thermoset Phenolic Matrices Reinforced with Unmodified and Surface-Grafted Furfuryl Alcohol Sugar Cane Bagasse and Curaua Fibers: Properties of Fibers and Composites. Biomacromolecules, v. 6, n. 5, p. 2485-2496, 2005.

VALADARES, L. F. Nanocompósitos de borracha natural e argila: preparação a partir de látex. 2005. 81 f. Dissertação (Mestrado em Ciências) - Instituto de Química, Universidade Estadual de Campinas, Campinas, 2005.

WELLE, F. Twenty years of PET bottle to bottle recycling-An overview. Resources, Conservation and Recycling, v. 55, n. 11, p. 865-875, 2011.

WENDLANDT, W. W. Thermal Analysis. New York: Wiley, 1985. p. 242.

WONG, S.; SHANKS, R. A.; HODZIC, A. Poly( Lactic acid) Composites With Flax Fibers Modified by Plasticizer Absorption. Polymer Engineering \& Science, v. 3, n. 9, p. 1566-1576, 2003.

WOOL, R. P.; SUN, X. S. Bio-based polymers and composites. New York: Elsevier Science \& Technology Books, 2005. p. 345.

WUNDERLICH, B. Thermal Characterization of Polymer Materials. New York: Academic Press, 1997. p. 324.

WYPYCH, G. Handbook of Plasticizers. Ontario: ChemTech, 2003. p. 356.

XUE, Y.; VEAZIE, D. R.; GLINSEY, C.; HORSTEMEYER, M. F.; ROWELL, R. M. Environmental effects on the mechanical and thermomechanical properties of aspen fiber-polypropylene composites. Composites Part B: Engineering, v. 38, n. 2, p. 152-158, 2007.

YANG, K. S.; AN, K. H.; CHOI, C. N.; JIN, S. R.; KIM, C. Y. Solubility and esterification kinetics of terephthalic acid in ethylene glycol III. The effects of functional groups. Journal of Applied Polymer Science, v. 60, n. 7, p. 1033-1039, 1996. 
YUAN, X.; LI, C.; GUAN, G.; LIU, X.; XIAO, Y.; ZHANG, D. Synthesis and characterization of poly(ethylene terephthalate)/attapulgite nanocomposites. Journal of Applied Polymer Science, v. 103, n. 2, p. 1279-1286, 2007.

ZDRAZILOVA, N.; HAUSNEROVA, B.; KITANO, T.; SAHA, P. Rheological Behaviour of PP/PET and Modified PP/PET Blends. I. Steady State Flow Properties. Polymers and Polymer Composites, v. 11, n. 6, p. 487-503, 2003.

ZENG, F.; WEN, J.; CUI, K.; WU, L.; LIU, M.; LI, Y.; LIN, Y.; ZHU, F.; MA, Z.; ZENG, Z. Seasonal distribution of phthalate esters in surface water of the urban lakes in the subtropical city, Guangzhou, China. J Hazard Mater, v. 169, n. 1-3, p. 719-725, 2009.

ZOU, Y.; REDDY, N.; YANG, Y. Reusing polyester/cotton blend fabrics for composites. Composites Part B: Engineering, v. 42, n. 4, p. 763-770, 2011. 